UNIVERSIDADE DE SÃO PAULO

DANIEL JULIEN BARROS DA SILVA SAMPAIO

AUTOMAÇÃO DO MONITORAMENTO DA QUALIDADE DO PROCESSO

DE SOLDA A PONTO RESISTIVA

São Paulo

2010 
DANIEL JULIEN BARROS DA SILVA SAMPAIO

\section{AUTOMAÇÃO DO MONITORAMENTO DA QUALIDADE DO PROCESSO DE SOLDA A PONTO RESISTIVA}

Tese apresentada à Escola Politécnica da Universidade de São Paulo para obtenção do título de Doutor em Engenharia.

Área de Concentração:

Engenharia de Controle e Automação Mecânica

Orientador:

Prof. Dr. Lucas A. Moscato

São Paulo 
Este exemplar foi revisado e alterado em relação à versão original, sob responsabilidade única do autor e com a anuência de seu orientador.

São Paulo, 21 de maio de 2010.

Assinatura do autor

Assinatura do orientador

FICHA CATALOGRÁFICA

Sampaio, Daniel Julien Barros da Silva

Automação do monitoramento da qualidade do processo de solda a ponto resistiva / D.J.B.S. Sampaio. -- ed.rev. -- São Paulo, 2010.

$173 \mathrm{p}$.

Tese (Doutorado) - Escola Politécnica da Universidade de São Paulo. Departamento de Engenharia Mecatrônica e de Sistemas Mecânicos.

1. Qualidade do processo (Monitoramento) 2. Soldagem por ponto 3. Inteligência artificial I. Universidade de São Paulo. Escola Politécnica. Departamento de Engenharia Mecatrônica e de Sistemas Mecânicos II. t. 


\section{DEDICATÓRIA}

Ao bem mais valioso que me há dado a vida, a "MINHA FAMÍLIA", por todo amor, compreensão, carinho e apoio dado durante todos esses anos, em especial a minha esposa Nice, meu filho Ian, minha mãe Roseli, meu irmão Henrique e ao meu pai Dimas. 


\section{AGRADECIMENTOS}

Ao Prof. Dr. Lucas A. Moscato, pela valiosa orientação, paciência, compreensão e apoio cruciais à feitura e conclusão deste trabalho.

Ao estimado amigo Samuel pelo apoio e ajuda perene.

Ao estimado amigo Prof. Dr. Norbert Link pelo apoio técnico e ajuda na viabilização da obtenção dos dados práticos.

A Michael Peschl e Dietmar Zettel da empresa HWH GmbH pelas discussões e apoio técnico e a própria empresa HWH GmbH por autorizar o uso dos dados que validaram este trabalho.

A todos do Programa de Pós-Graduação em Engenharia Mecânica da Poli pela oportunidade de realizar este trabalho.

Aos colegas e amigos da Unesp - Guaratinguetá pelo apoio e compreensão.

Ao CNPQ pela bolsa cedida em parte do período de realização deste trabalho.

Ao Tio Hélio pelo apoio logístico e paciência.

A todos meus amigos que apoiaram e acreditaram que conseguiria terminar este trabalho.

A Nossa Senhora Aparecida por iluminar meu caminho e pela proteção. 
"A maior vitória é estar feliz consigo mesmo" (Daniel Sampaio)

"Dificuldades e obstáculos são fontes valiosas de saúde e força para qualquer sociedade."

(Albert Einstein) 


\section{RESUMO}

SAMPAIO, D. J. B. S. Automação do monitoramento da qualidade do processo de solda a ponto resistiva. 2010. 173 f. Tese (Doutorado) - Escola Politécnica da Universidade de São Paulo, São Paulo, 2010.

Neste trabalho é proposto e avaliado um sistema capaz de monitorar de forma nãodestrutiva, não-invasiva, individualizada, em tempo real e em ambiente industrial, a qualidade de soldas produzidas através do processo de solda a ponto resistiva (PSPR), diminuindo ou mesmo eliminando a necessidade dos testes destrutivos, reduzindo custos e aumentando a produtividade. Este sistema de monitoramento é baseado em reconhecimento de padrões, através de redes neurais artificiais do tipo Perceptron multicamadas. As características do processo usadas na entrada da rede neural são os parâmetros ajustados de um modelo matemático parametrizável, criado com o intuito de refletir as propriedades fundamentais da grandeza do processo passível de ser medida e monitorada em tempo real, neste caso a curva de resistência dinâmica. Estes valores ajustados dos parâmetros do modelo são ainda relacionados com os estados ou condições do processo, de forma a permitir a identificação de possíveis causas para falhas detectadas. Para avaliar e validar este sistema, usaram-se dados reais obtidos na produção de lotes de contatos elétricos através do PSPR. Os resultados obtidos mostram que o sistema proposto é capaz de monitorar satisfatoriamente a qualidade do processo investigado, com erro médio quadrático de $16,5 \mathrm{~N}$, na estimação da força de cisalhamento suportada pela solda, no pior caso. O sistema também mostrou-se capaz de identificar a causa para soldas cuja qualidade estimada foi considerada baixa, com taxa de acerto acima de 97\%. Esse sistema proposto não contém especificidades de nenhum processo produtivo e, portanto, tem potencial para ser aplicado em outros processos, além do PSPR.

Palavras-chave: Qualidade do processo (Monitoramento). Soldagem por ponto. Inteligência artificial. 


\begin{abstract}
SAMPAIO, D. J. B. S. Automatic quality monitoring of resistance spot welding process. 2010. 173 p. Thesis (Doctorate) - Escola Politécnica da Universidade de São Paulo, São Paulo, 2010.

In this work a non-destructive, non-invasive, individualized, real-time system has been proposed and evaluated to monitor the quality of welds produced by resistance spot welding process (RSWP) in industrial environment. This system is able to reduce or eliminate the need for destructive tests, leading to cost reduction and increase in productivity. This monitoring system is based on pattern recognition with multilayer Perceptron artificial neural networks (ANN). The process features used as input of the ANN are adjusted parameters of a parametric mathematic model created to reflect the fundamental properties of the process variable that is measurable in real time, in this work, the dynamic resistance curve. The adjustable model parameters values are related with the process states and conditions, so that it is possible to identify the causes for detected bad quality. In order to evaluate and validate the proposed system, real data obtained in the production of electric contacts by RSWP were used. The results show that the proposed system is capable of properly monitoring the investigated process quality, with a mean square error of $16.5 \mathrm{~N}$, in the estimation of the shear force supported by the weld, in the worst case. The system proved to be able to identify the causes for detected bad quality, with a reliability of more than $97 \%$. The proposed system contains no productive process specificities, and, therefore, can be applied to other processes.
\end{abstract}

Keywords: Process quality (Monitoring). Spot welding. Artificial intelligence. 


\section{LISTA DE FIGURAS}

Figura 2.1 - Representação do Processo de Solda a Ponto Resistiva

Figura 2.2 - Valores aproximados das resistências para chapas de aço de $1 \mathrm{~mm}$ e eletrodos de cobre de $5 \mathrm{~mm}$ de diâmetro .26

Figura 2.3 - Desenho esquemático do PSPR 32

Figura 2.4 - Caminho idealizado da onda através das partes (esquerda) e a forma de onda correspondente obtida (direita) (DENISOV et al., 2004) .34

Figura 2.5 - Imagem da impressão no material após o PSPR (RUISZ et al., 2007) .39

Figura 2.6 - Curva da resistência dinâmica clássica para soldagem de aço 40

Figura 3.1 - Fluxograma do Sistema de Monitoramento da Qualidade Proposto.....

Figura 3.2 - Diagrama Esquemático do Sistema de Monitoramento da Qualidade Proposto. .53

Figura 3.3 - Tela de créditos da ferramenta de software TOMAHAWK 55

Figura 3.4 - Exemplo de encadeamento de plug-ins na ferramenta TOMAHAWK .56

Figura 3.5 - Desenho esquemático de uma máquina de solda a ponto resistiva .57

Figura 3.6 - Desenho esquemático das medições de tensão e corrente no PSPR .58

Figura 3.7 - Uma bobina Rogowski usada na medição de corrente .59

Figura 3.8 - Fixação dos cabos para medição da tensão de soldagem 61

Figura 3.9 - Curva dos dados brutos da variação de tensão durante o PSPR .61

Figura 3.10 - Curva dos dados brutos da variação de corrente durante o PSPR .62

Figura 3.11- Work list para pré-processamento dos dados de tensão e corrente .63

Figura 3.12 - Curva da variação de tensão durante o PSPR após correções 64

Figura 3.13 - Curva da variação de corrente durante o PSPR após correções 64

Figura 3.14 - Defasagem entre as curvas de tensão (V) (vermelho) e corrente (kA) (preto) 
Figura 3.15 - Curva da variação da resistência elétrica durante a produção de um contato elétrico

Figura 3.16 - Desenho esquemático do arranjo do PSPR ..................................................68

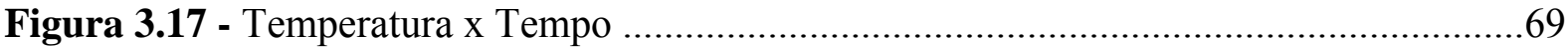

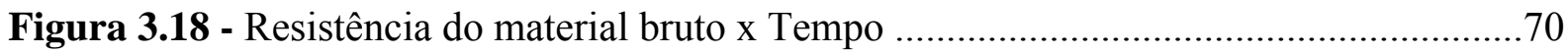

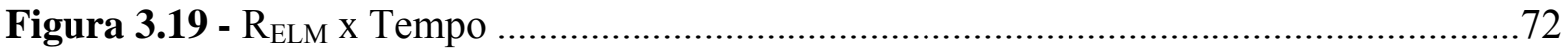

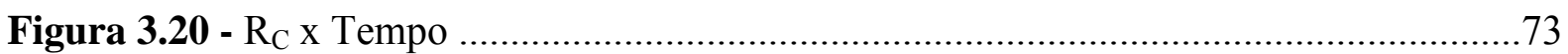

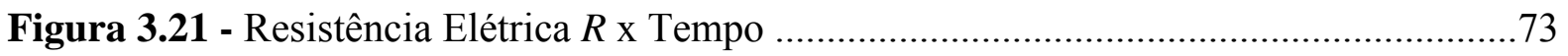

Figura 3.22 - Tela de Configuração do Plug-in "Model_CalcVariables" ..............................81

Figura 3.23 - Processo de treinamento da rede neural artificial ..........................................83

Figura 3.24 - Processo de aplicação da rede neural artificial ................................................84

Figura 4.1 - Esquemático das partes a serem soldadas (superior) e contato elétrico após soldagem (inferior)

Figura 4.2 - Esquemático do ajuste da pressão dos eletrodos através de uma mola ..............90

Figura 4.3 - Detalhes da curva da resistência dinâmica de um dos testes .............................96

Figura 4.4 - Curva da resistência dinâmica considerando somente o segundo estágio ..........97

Figura 4.5 - Tela de configuração do plug-in "Model_CalcVariables" preenchida ...............98

Figura 4.6 - Curva com pior ajuste entre os dados do conjunto analisado ...........................100

Figura 4.7 - Curva com bom ajuste entre os dados do conjunto analisado ..........................100

Figura 4.8 - Resultado da topologia 5-5-1 para os dados de validação .................................104

Figura 4.9 - Resultado da melhor combinação de parâmetros (5 parâmetros) e da melhor topologia entre as testadas (5-8-1) para o primeiro conjunto de dados 114

Figura 4.10 - Resultado da melhor combinação de parâmetros (5 parâmetros) e da melhor topologia entre as testadas (5-8-1) para o segundo conjunto de dados 115 
Figura 4.11 - Relação entre QC e o parâmetro $\mathrm{K}_{\mathrm{C}-\mathrm{SOFT}}$ para o primeiro conjunto de dados 123

Figura 4.12 - Relação entre QC e o parâmetro $R_{0 C}$ para o primeiro conjunto de dados 124

Figura 4.13 - Relação entre QC e o parâmetro $K_{E L M}$ para o primeiro conjunto de dados

Figura 4.14 - Relação entre QC e o parâmetro $R_{O E L M}$ para o primeiro conjunto de dados

Figura 4.15 - Relação entre QC e o parâmetro $K_{C}$ para o primeiro conjunto de dados.

Figura 4.16 - Fluxograma do procedimento usado para identificar a causa no caso de perda de qualidade por parte da solda para o primeiro conjunto de dados 128

Figura 4.17 - Relação entre QC e o parâmetro $K_{C-S O F T}$ para o segundo conjunto de dados

Figura 4.18 - Relação entre QC e o parâmetro $R_{0 C}$ para o segundo conjunto de dados 129

Figura 4.19 - Relação entre QC e o parâmetro $K_{E L M}$ para o segundo conjunto de dados 130

Figura 4.20 - Relação entre QC e o parâmetro $R_{0 E L M}$ para o segundo conjunto de dados 130

Figura 4.21 - Relação entre QC e o parâmetro $K_{C}$ para o segundo conjunto de dados. 130

Figura 4.22 - Fluxograma do procedimento usado para identificar a causa no caso de perda de qualidade por parte da solda para o segundo conjunto de dados 131

Figura A.1. Conexões de um Neurônio (a) Neurônio Biológico; (b) Neurônico Artificial. 144

Figura A.2 - Arquitetura de uma RNA típica 146 
Figura A.3 - Diagrama de um neurônio. 146

Figura A.4 - Funções de Ativação de um Neurônio.

Figura A.5 - Separação Linear no Perceptron: (a) Perceptron com duas entradas; (b) Perceptron com três entradas.

Figura A.6 - Gráficos bi-dimensionais de operações lógicas básicas: (a) E (x1คx2); (b) OU $(\mathrm{x} 1 \cup \mathrm{x} 2) ;(\mathrm{c})$ OU-exclusivo $(\mathrm{x} 1 \oplus \mathrm{x} 2)$ 152

Figura A.7 - Perceptron com duas camadas 153

Figura A.8 - Rede Neural que utiliza back-propagation com três camadas 156

Figura A.9 - Rede Neural de três camadas para solucionar a operação OU exclusivo 160

Figura A.10 - Curva de treinamento para a operação OU exclusivo. 163

Figura A.11 - Limites de decisão construída pela rede neural: (a) E (x1คx2); (b) OU $(\mathrm{x} 1 \cup \mathrm{x} 2)$; (c) OU-exclusivo $(\mathrm{x} 1 \oplus \mathrm{x} 2)$ 164 


\section{LISTA DE TABELAS}

Tabela 4.1 - Resultados iniciais obtidos com a topologia 5-5-1

Tabela 4.2 - Resultados de diferentes topologias com 1 parâmetro na entrada da rede....... 106

Tabela 4.3 - Resultados de diferentes topologias com 2 parâmetros na entrada da rede......107

Tabela 4.4 - Resultados de diferentes topologias com 3 parâmetros na entrada da rede......108

Tabela 4.5 - Resultados de diferentes topologias com 4 parâmetros na entrada da rede......109

Tabela 4.6 - Resultados de diferentes topologias com 5 parâmetros na entrada da rede......109

Tabela 4.7 - Resultados de diferentes topologias com 1 parâmetro na entrada da rede........110

Tabela 4.8 - Resultados de diferentes topologias com 2 parâmetros na entrada da rede......111

Tabela 4.9 - Resultados de diferentes topologias com 3 parâmetros na entrada da rede......112

Tabela 4.10 - Resultados de diferentes topologias com 4 parâmetros na entrada da rede....113

Tabela 4.11 - Resultados de diferentes topologias com 5 parâmetros na entrada da rede....113

Tabela 4.12 - Resultados do sistema proposto por Dilthey e Dichersbach (1999) aplicado no primeiro conjunto de dados com diferentes topologias de rede.

Tabela 4.13 - Resultados do sistema proposto por Dilthey e Dichersbach (1999) aplicado no segundo conjunto de dados com diferentes topologias de rede.

Tabela 4.14 - Resultados do sistema proposto por Aravinthan et al. (2001) aplicado no primeiro conjunto de dados com diferentes topologias de rede.

Tabela 4.15 - Resultados do sistema proposto por Aravinthan et al. (2001) aplicado no segundo conjunto de dados com diferentes topologias de rede.......

Tabela 4.16 - Resultados do sistema proposto por Wen et al. (2009) aplicado no primeiro conjunto de dados com diferentes topologias de rede.

Tabela 4.17 - Resultados do sistema proposto por Wen et al. (2009) aplicado no segundo conjunto de dados com diferentes topologias de rede. 
Tabela A.1 - Analogia entre Rede Neural Biológica e Artificial.........................................144

Tabela A.2. Tabela Verdade para as operações lógicas básicas.........................................151

Tabela A.3. Exemplo de treinamento do Perceptron: operação lógica E..............................152

Tabela A.4. Resultados finais do aprendizado da rede de três camadas: a operação lógica OU

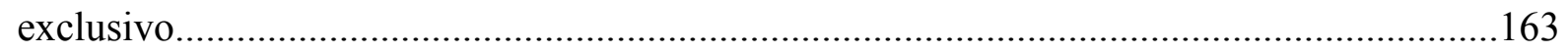

Tabela B.1 - Detalhamento dos Testes do Primeiro Conjunto de Dados.............................165

Tabela B.2 - Detalhamento dos Testes do Segundo Conjunto de Dados............................169 


\section{LISTA DE ABREVIATURAS}

MAD Desvio Absoluto Máximo

MSE Erro Médio Quadrático

PSPR Processo de Solda a Ponto Resistiva

QC Qualidade do Contato Produzido

$\mathrm{R}^{2}$ ou $\mathrm{R}^{\wedge} 2 \quad$ Coeficiente de Determinação

Recog\% $\quad$ Taxa de Reconhecimento

RNA Rede Neural Artificial 


\section{LISTA DE SÍMBOLOS}

\begin{tabular}{|c|c|}
\hline$\alpha$ & Coeficiente térmico de resistência \\
\hline$\chi^{2}$ & Função de mérito ("chi-square") \\
\hline$i$ & Corrente de soldagem \\
\hline$K_{C}$ & Fator de variação da resistência de contato \\
\hline$K_{C-S o f t}$ & Fator de amolecimento dos materiais \\
\hline$K_{E L M}$ & Fator de variação eletrodo-material \\
\hline$K_{T}$ & Fator de variação da temperatura \\
\hline$L$ & Indutância equivalente total \\
\hline$Q_{\text {solda }}$ & Quantidade de calor gerado \\
\hline$R$ & Resistência total dos elementos do circuito \\
\hline$R_{0 B}$ & Resistência elétrica inicial do material bruto \\
\hline$R_{0 C}$ & Resistência elétrica inicial de $R_{C}$ \\
\hline$R_{0 E L M}$ & Resistência elétrica inicial de $R_{E L M}$ \\
\hline$R_{B}$ & Resistência elétrica do material bruto \\
\hline$R_{C}$ & Resistência elétrica da interface entre os materiais \\
\hline$R_{E L M}$ & Resistência elétrica do eletrodo e da interface entre eletrodos e materiais \\
\hline$t$ & tempo \\
\hline$T$ & Temperatura do processo estimada \\
\hline$T_{\text {fusao }}$ & Temperatura de fusão \\
\hline$T_{0}$ & Temperatura inicial \\
\hline$V_{L}$ & Tensão da componente indutiva \\
\hline
\end{tabular}




\section{SUMÁRIO}

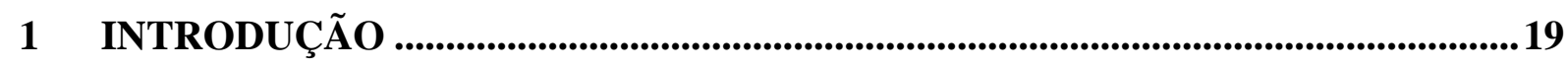

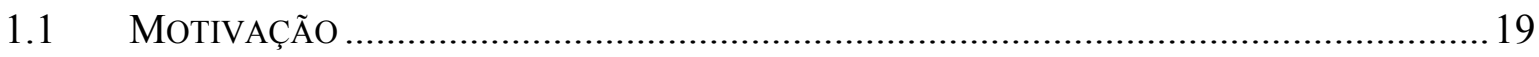

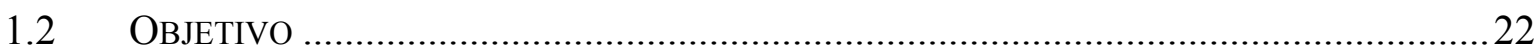

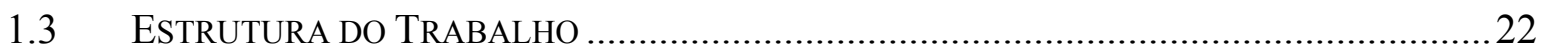

2 MONITORAMENTO E CONTROLE DA QUALIDADE DA SOLDA...................24

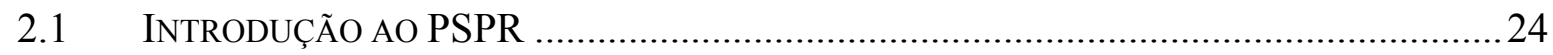

2.2 EvoluÇÃo do Monitoramento E CONTROLE DE QuALIDADE No PSPR ...............27

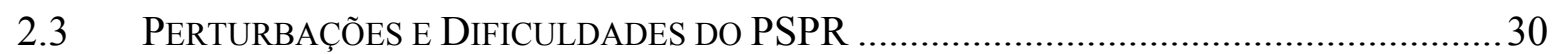

2.4 Sistemas BaSEAdos EM GRANDEZAS MENSURÁVEIS Do PSPR ............................... 31

3 O SISTEMA PROPOSTO E SEUS COMPONENTES .........................................48

3.1 Descrição do Sistema de Monitoramento Proposto ......................................48

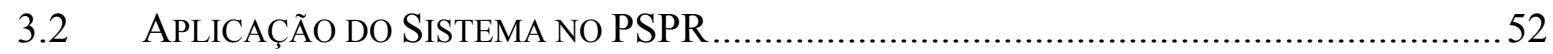

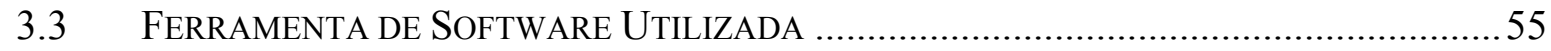

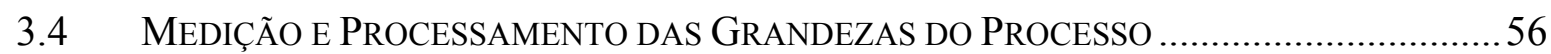

3.4.1 Medição da Corrente e Tensão de Soldagem...................................................... 58

3.4.2 Obtenção da Curva da Resistência Elétrica Dinâmica........................................65

3.5 Modelo Matemático PARAMETRIZÁvel do Processo .........................................67

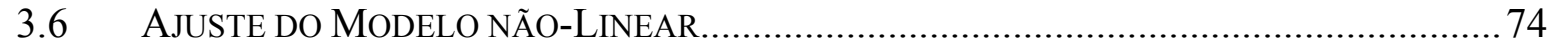

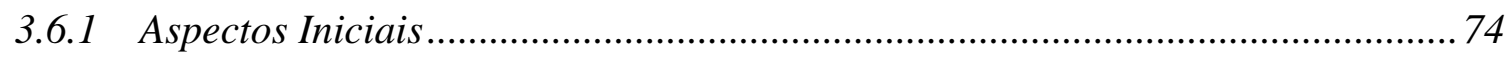

3.6.2 Gradiente e a Matriz Hessiana ........................................................................ 75

3.6.3 Algoritmo de Levenberg-Marquardt ............................................................ 77

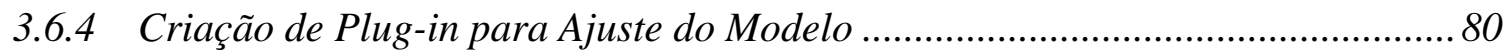

3.7 ESTIMAÇÃo da QUaLidade UTILIZANDo REDES NEURAis...................................... 82 
3.7.1 Software para Simulação de Redes Neurais.

3.8 IDENTIFICAÇÃO DE CAUSAS DE PERDA DE QUALIDADE NO PSPR .............................8

3.9 BANCO DE DAdos Com HistóRICO DE ProduÇÃo ................................................... 86

4 AVALIAÇÃO E VALIDAÇÃO DO SISTEMA PROPOSTO ................................87

4.1 Dados Utilizados na AvaliaÇÃo E VALIDAÇÃo do Sistema ................................. 87

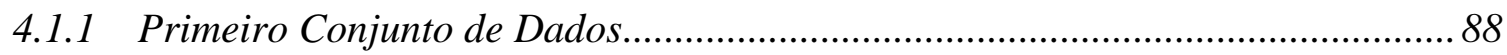

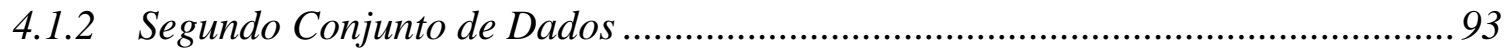

4.2 Avaliação do AJUSte entre o Modelo E O Processo ........................................96

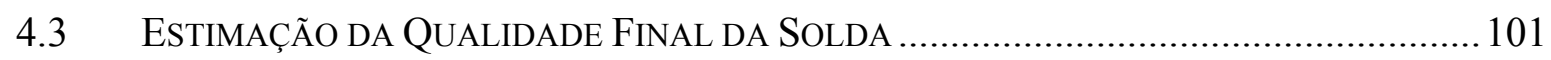

4.4 COMPARAÇÃo COM Sistemas Propostos NA Literatura ................................... 116

4.5 IdENTIFICAÇÃo DE CAUSAS DE Problemas no Processo...................................... 122

5 CONCLUSÃO

REFERÊNCIAS BIBLIOGRÁFICAS ..................................................................134

ANEXO A - REDES NEURAIS ARTIFICIAIS .......................................................143

A.1 FUNDAMENTOS DE REDES NEURAIS ARTIFICIAIS …................................... 143

A.2 O NEURÔNIO COMO UM SIMPLES ELEMENTO COMPUTACIONAL …................................. 146

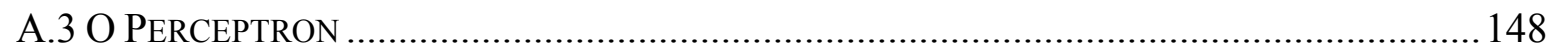

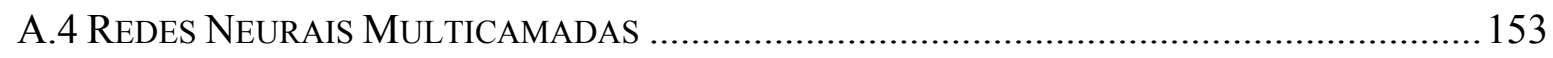

A.5 Algoritmo de Aprendizado BACK-Propagation............................................... 154

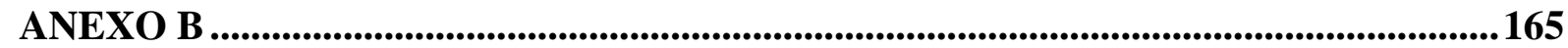




\section{Introdução}

\subsection{Motivação}

O monitoramento da qualidade de um processo produtivo assume cada vez mais um papel de destaque no mundo globalizado já que a interligação entre Qualidade, Produtividade e Competitividade são fatores da maior importância no mercado atual e podem determinar o sucesso ou fracasso de determinada empresa, processo ou produto.

Este monitoramento da qualidade pode ser feito de forma individualizada ou por amostragem (HALMSHAW, 1988). Na individualizada, todo o produto, fruto de um determinado processo produtivo, é verificado, em termos de especificações pré-estabelecidas, sendo descartado ou re-trabalhado, caso não esteja dentro dessas especificações. No caso do monitoramento por amostragem, onde uma ou algumas unidades de um lote do produto é verificada, também em termos de especificações pré-estabelecidas, uma amostra fora das especificações pode fazer com que todo o lote seja descartado ou re-trabalhado.

Infelizmente, em muitos produtos e processos, a verificação das especificações não pode ser realizada de forma simples, direta ou individualizada, devido às suas características e complexidades. Por exemplo, para conferir a capacidade de absorção de uma fralda descartável produzida, deve-se molhar a fralda até que ela não consiga mais absorver determinado líquido, verificando assim sua capacidade de absorção. É fácil perceber que esta fralda testada está inutilizada para consumo, já que um monitoramento da qualidade foi realizado utilizando-se um método destrutivo, o que impossibilita um monitoramento individualizado da qualidade. 
Outro exemplo, e que será focalizado neste trabalho, é o processo de solda a ponto resistivo amplamente usado na indústria em virtude de sua aparente simplicidade e baixo custo de instalação e execução (BROOMHEAD, 1990). Produzir soldas com qualidade assegurada é um desafio em vários tipos de manufatura e áreas, devido à forte conexão entre a qualidade da solda e os aspectos de segurança e confiabilidade. Por exemplo, um ponto de mau contato de um componente eletro-eletrônico, como o contato de um relê, pode danificar a funcionalidade de um grande sistema elétrico e conduzir o seu controle a paralisar uma planta industrial de produção. Outro exemplo é a possibilidade de causar-se um incêndio devido a um curto-circuito em um componente eletro-eletrônico em um avião. Além da importância de assegurar a qualidade da solda de contatos elétricos em componentes eletro-eletrônicos, outro exemplo é a qualidade da solda na produção de veículos automotivos, já que cada automóvel atualmente possui entre 2000 e 6000 pontos de solda (BROWN; SCHWABER, 2000). Basta multiplicar este número pela quantidade de automóveis produzidos por ano no mundo, para se ter uma idéia de que bilhões de soldas são produzidas anualmente somente na indústria automotiva.

Ensaio destrutivo é a forma mais utilizada para se obter informação confiável a respeito da qualidade da solda. Normalmente, a característica da solda escolhida para definir sua qualidade está diretamente relacionada com sua aplicação. Por exemplo, no caso da fabricação de contatos elétricos, a qualidade da solda é definida pela força de cisalhamento que este contato suporta, ou seja, a característica escolhida é a força de cisalhamento. Já no caso da produção de veículos, a qualidade da solda é definida pelo tamanho do diâmetro do ponto de solda produzido, ou seja, a característica escolhida é o diâmetro final do ponto de solda.

Em partes utilizadas em certas áreas de risco, um a cada dez pontos de solda tem que ser verificado, através de teste destrutivo, para garantir a qualidade e a segurança. Isso conduz 
a gastos consideráveis de dinheiro e tempo, além de um problema ambiental. Ensaios nãodestrutivos como ultrassom e raios-X têm sido testados e aplicados (ROYE, 2002), mas ainda não são uma solução de baixo custo, pois requerem treinamento e habilidade dos operadores para atingir uma alta precisão, além de não poderem ser facilmente instalados na linha de produção e não possibilitarem um monitoramento individualizado durante a produção, devido ao tempo de operação e preparo ser normalmente maior que o tempo de produção das soldas.

Estas necessidades serviram de motivação para este trabalho. A principal motivação é propor e avaliar um sistema de monitoramento não-destrutivo da qualidade do processo de solda a ponto resistiva (PSPR) que realize a detecção e o diagnóstico de possíveis falhas no processo de soldagem. Este sistema deve monitorar de forma não-destrutiva, individualizada, em tempo real e em ambiente industrial, a qualidade do processo, além de identificar e fornecer possíveis causas para problemas que possam surgir durante a produção. O processo de solda a ponto resistiva que será analisado e usado para avaliar e validar este trabalho foi escolhido devido à sua abrangência, importância e inexistência de modelos que consigam descrevê-lo com exatidão. Serão utilizados dados reais obtidos na produção de lotes de contatos elétricos através do PSPR, para avaliar e validar este trabalho. O processo de produção de contatos elétricos tem algumas características críticas que são a alta taxa de produção e o pequeno tempo de soldagem de cada parte. É possível encontrar máquinas que produzam mais de 200 partes por minuto e o tempo de soldagem de cada parte é normalmente inferior a 40 milissegundos. Se o controle de qualidade for feito posteriormente à produção, um lote inteiro, que pode chegar a ter mais de 80.000 partes, poderá ser rejeitado. O sistema de monitoramento proposto neste trabalho pode ser adaptado e aplicado também em outros processos produtivos, pois seus componentes não são exclusivamente aplicados no processo de solda a ponto resistiva. 


\subsection{Objetivo}

Com base nas motivações apresentadas anteriormente, o objetivo deste trabalho é propor e avaliar um sistema de monitoramento não-destrutivo da qualidade do PSPR, que opere de forma individualizada, em tempo real e que, ao detectar perda de qualidade no processo, seja capaz de diagnosticar as possíveis causas. Este sistema de monitoramento deve ainda ser exequível em ambiente industrial e apresentar um aspecto generalista, de forma a poder ser aplicado em outros processos, nos quais o monitoramento não possa ser feito de forma direta.

O sistema proposto será aplicado no monitoramento da qualidade de contatos elétricos produzidos pelo PSPR, que é um processo estocástico independente (dinâmico), o que permitirá avaliar seu desempenho e validar sua aplicabilidade.

Em suma, este trabalho deve resultar em um sistema capaz de monitorar de forma nãodestrutiva, individualizada, em tempo real e em ambiente industrial, a qualidade dos pontos de solda produzidos, diminuindo ou mesmo eliminando a frequência da necessidade de testes destrutivos, reduzindo custos e aumentando a produtividade. Esse sistema deve ainda facilitar a manutenção do processo produtivo.

\subsection{Estrutura do Trabalho}

Este trabalho está organizado em cinco capítulos descritos a seguir.

O capítulo 1 mostra a motivação do trabalho e descreve os objetivos e sua organização. 
O capítulo 2, intitulado "Monitoramento e Controle da Qualidade da Solda", apresenta uma revisão bibliográfica sobre o tema e situa o sistema proposto neste trabalho dentro do tema, reforçando os objetivos e mostrando o caráter inovador e original do mesmo.

O capítulo 3, intitulado "O Sistema Proposto e seus Componentes", apresenta em detalhes o sistema de monitoramento não destrutivo proposto neste trabalho. Inicialmente este será apresentado de forma geral, ou seja, sem conter especificidades de nenhum processo, apresentando assim potencial para ser aplicado em outros processos. Em seguida, este sistema será aplicado no PSPR, e cada um dos componentes do sistema será detalhado de acordo com essa aplicação. São mostradas ainda as ferramentas de software utilizadas neste trabalho.

No capítulo 4, intitulado "Avaliação e Validação do Sistema Proposto", são apresentados os dados que foram usados para avaliar e validar o sistema proposto neste trabalho, os testes realizados com esses dados e os resultados obtidos.

As conclusões do trabalho são apresentadas no capítulo 5, juntamente com as propostas de futuros trabalhos.

No anexo A são apresentadas as teorias básicas de redes neurais artificiais e do algoritmo de back-propagation e, no anexo B, uma apresentação detalhada dos testes de soldagem realizados para obtenção dos dados usados para analisar e validar este trabalho. 


\section{Monitoramento e Controle da Qualidade da Solda}

\subsection{Introdução ao PSPR}

A solda resistiva foi inventada no final do século XIX, sendo a primeira patente registrada por Elihu Thomson in 1885, o qual obteve grandes avanços nessa técnica nas duas décadas seguintes. Entretanto, sua aplicação industrial em larga escala ocorreu somente no século XX, inicialmente para fins militares, impulsionada principalmente pelas duas guerras mundiais, que demandavam um método barato e confiável para unir materiais (HARDT, 200?).

As principais vantagens da solda resistiva incluem o uso eficiente de energia, deformação limitada das partes soldadas, altas taxas de produção, automação relativamente fácil e não requerer material para preenchimento. Este método de soldagem produz soldas que normalmente possuem menor resistência mecânica quando comparado a outros métodos de soldagem. Por esta razão, não é apropriado para todos os tipos de aplicação (SAPP, 200-?). É usado em grande escala na indústria automobilística, para fabricação da carroceria de veículos, e na indústria eletro-eletrônica, para fabricação de contatos elétricos.

No início do PSPR, o eletrodo superior se move na direção do eletrodo inferior de forma que as partes a serem soldadas fiquem mantidas pressionadas. A amplitude da força de soldagem pode ser controlada pela pressão de ar em um cilindro pneumático. Após as partes serem pressionadas por algum tempo, o circuito formado pelo secundário do transformador da máquina de solda, pelos braços de soldagem, pelos eletrodos e pelas partes a serem soldadas é energizado (figura 2.1). Dessa maneira uma corrente elétrica irá circular por este circuito. Esta corrente elétrica é chamada de corrente de soldagem e depende das resistências elétricas dos elementos que formam este circuito elétrico. 


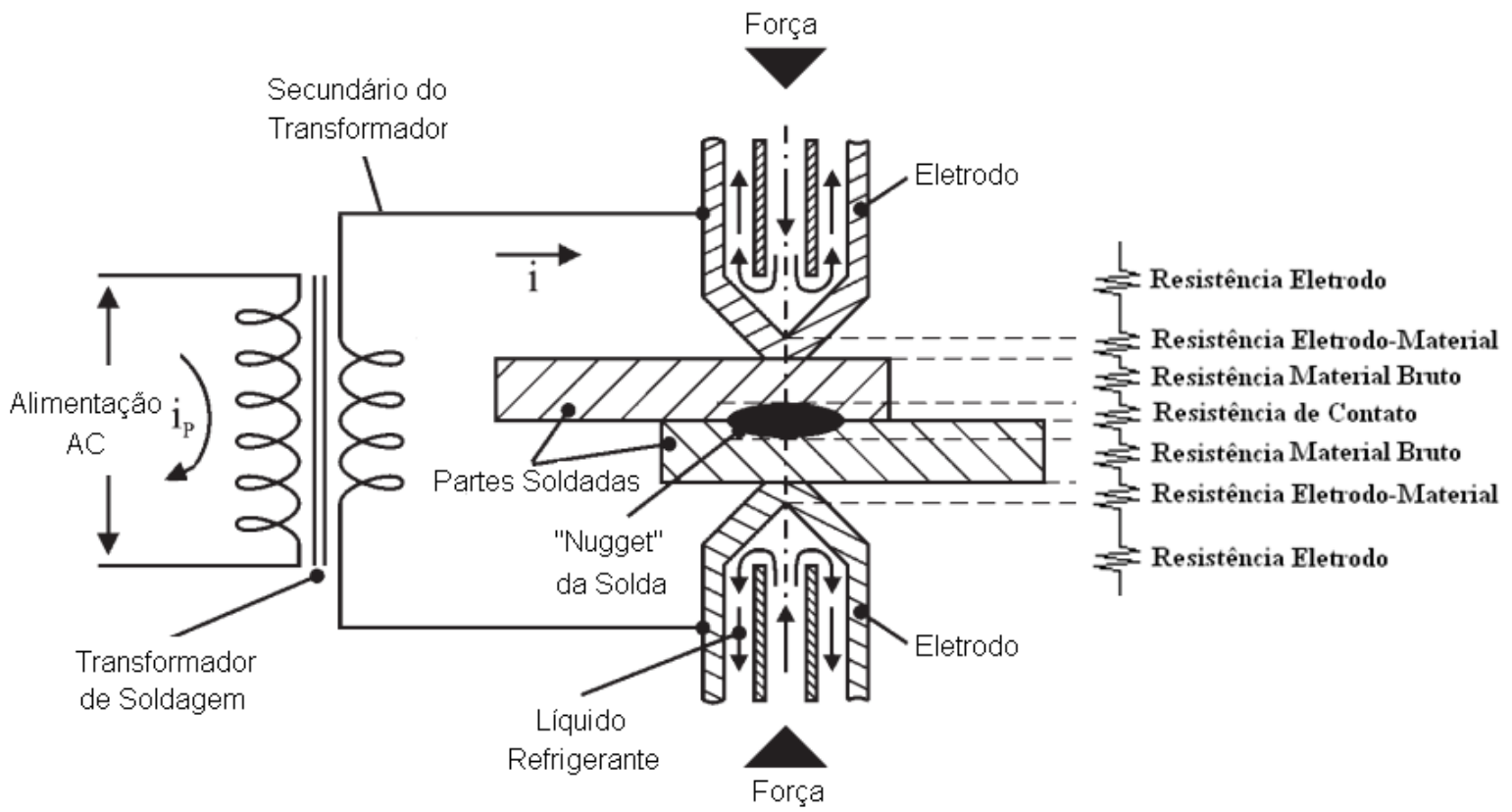

Figura 2.1 - Representação do Processo de Solda a Ponto Resistiva

Valores aproximados dessas resistências, para chapas de aço de $1 \mathrm{~mm}$ de espessura soldadas por eletrodos de cobre de $5 \mathrm{~mm}$ de diâmetro, são mostrados na figura 2.2 (PODRZAJ et al., 2008). Estas resistências variam bastante de acordo com a espessura e o tipo de material utilizado. As resistências dos braços de soldagem, eletrodos e secundário do transformador são normalmente consideradas desprezíveis.

A consequência da corrente de soldagem circulando por essas resistências é a geração de calor (efeito Joule), o qual depende do valor nominal dessa corrente, do tempo de soldagem e das resistências dos elementos do circuito, de acordo com a equação:

$$
Q_{\text {solda }}=\int_{0}^{t} i^{2}(t) \cdot R(t) d t
$$

onde: $Q_{\text {solda }}=$ quantidade de calor gerado;

$i(t)=$ corrente de soldagem;

$R(t)=$ resistência dos elementos do circuito 


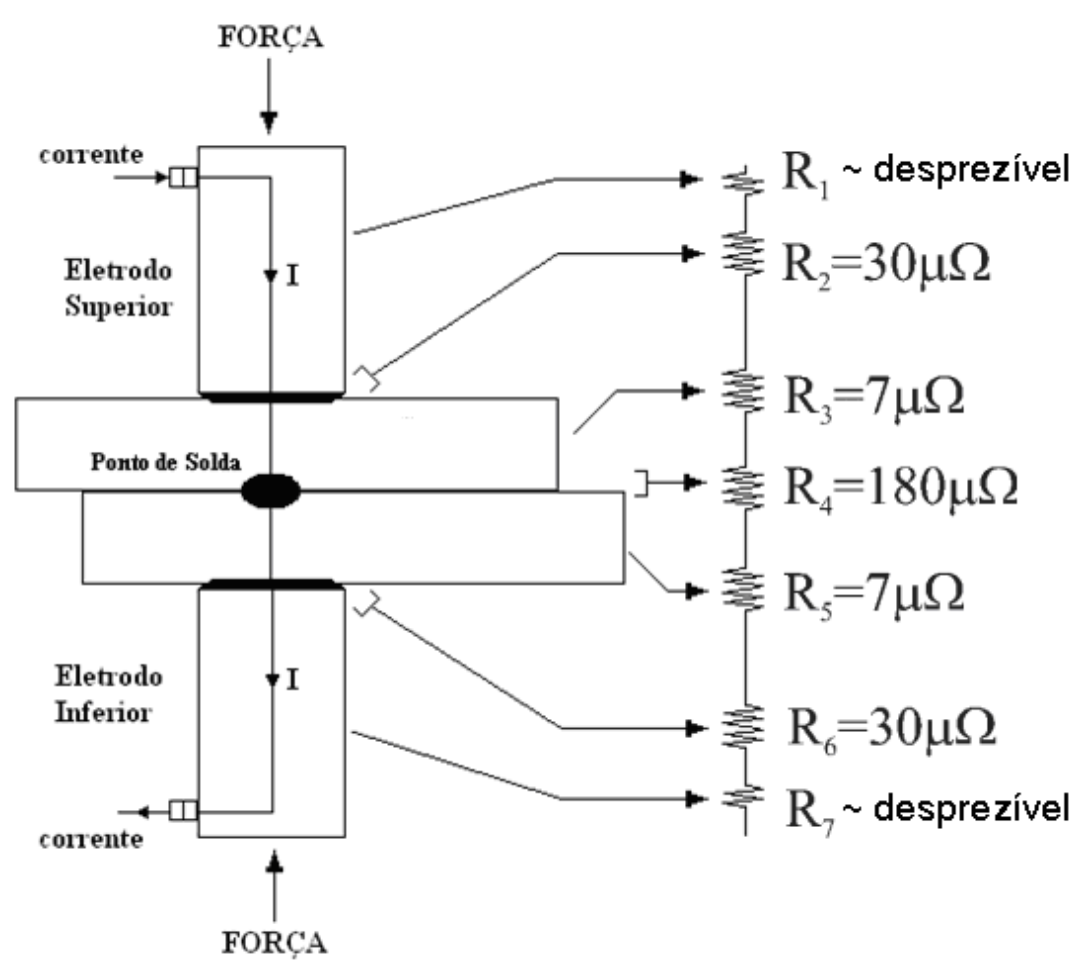

Figura 2.2 - Valores aproximados das resistências para chapas de aço de $1 \mathrm{~mm}$ e eletrodos de cobre de $5 \mathrm{~mm}$ de diâmetro

O resultado do calor gerado na interface material/material é a formação do botão de solda. O tamanho do botão é importante já que se relaciona com a força suportada pela solda.

Existem dois extremos em termos da quantidade de calor gerado durante o processo de soldagem. Se a quantidade de calor gerado for muito alta, resultará em expulsão de material e se for baixa demais, o botão de solda não se formará, sendo este efeito conhecido como solda fria. Portanto, a quantidade de calor gerado deve estar entre o requerido para uma solda fria e o que provoca expulsão de material. Soldas próximas do ponto de expulsão são preferidas, pois possuem um botão de solda maior e, portanto, uma maior resistência mecânica. A quantidade de calor gerada e, consequentemente, o ponto de expulsão depende da corrente de soldagem, do tempo de soldagem e da pressão dos eletrodos sobre os materiais a serem soldados. Se uma combinação apropriada desses parâmetros é escolhida, e não há perturbações no processo, uma solda aceitável é produzida. Embora a expulsão não necessariamente implique em uma diminuição da força suportada pela solda, ela é geralmente 
indesejada, pois causa um desgaste maior nos eletrodos, um maior consumo de energia, uma aparência visual insatisfatória da solda e uma reduzida resistência à corrosão, no caso de materiais revestidos (PODRZAJ et al., 2008).

Com as exigências cada vez maiores com relação à qualidade, nas linhas de produção com alto grau de automatização, ter um monitoramento em tempo real da qualidade final do produto e/ou poder controlá-la, é importante para tomar decisões adequadas e minimizar eventuais prejuízos causados pela produção de produtos que não atendam a requisitos mínimos de qualidade.

Tradicionalmente, ensaios destrutivos eram usados para inspecionar a qualidade dos pontos de solda. A força de cisalhamento suportada pelos pontos de solda e o diâmetro do ponto de solda resultante são normalmente usados como parâmetros para se definir se a solda é de boa qualidade ou não. Estes parâmetros são diretamente inspecionados após o processo de fabricação e estão diretamente relacionados, já que o diâmetro do ponto de solda resultante, após o resfriamento da solda, define a resistência mecânica da solda (SAPP, 200-?) (MEOLA et al., 2004).

Nas últimas décadas, métodos não destrutivos surgiram para inspecionar, monitorar e controlar a qualidade das soldas (ROYE, 2002) (WILLIAMS; PARKER, 2004a). Estes métodos serão apresentados no decorrer desse capítulo com as respectivas referências.

\subsection{Evolução do Monitoramento e Controle de Qualidade no PSPR}

As primeiras máquinas de solda a ponto resistiva eram bem simples. $\mathrm{O}$ operador era responsável por aplicar a força de soldagem nos eletrodos, estabelecer a alimentação do circuito, acionando um contator, e controlar a quantidade de calor gerada através do tempo de soldagem. Ele observava a região de soldagem e decidia quando parar o PSPR, baseado 
principalmente em sua experiência quanto à cor da solda. Como normalmente o PSPR dura apenas uma fração de segundo, era difícil de se obter repetitividade e soldas de boa qualidade (SAPP, 200-?).

Nasceu então a idéia de que se os parâmetros de soldagem pudessem ser fielmente repetidos em todas as soldagens, o que não era possível com soldadores humanos, isso asseguraria soldas de boa qualidade (SAPP, 200-?). Surgiram então sistemas de controle para se obter precisão e repetitividade do conjunto de parâmetros principais do PSPR, a tensão ou corrente de soldagem, a força aplicada nos eletrodos e o tempo de soldagem. A força de soldagem começou a ser controlada com alto grau de precisão através de sistemas pneumáticos. O tempo de soldagem foi inicialmente controlado com diodos, depois por contadores síncronos que o terminavam após contar um determinado número de ciclos da frequência da rede de alimentação (conhecidos como controladores de corrente alternada de 50/60Hz) (STANWAY, 1992) (HOLDREN, 1993). Com a invenção dos controles de alimentação utilizando fontes chaveadas operando em média frequência (alguns $\mathrm{kHz}$ ), conhecidos como controles de alimentação CC, surgiram também diferentes estratégias de controle baseadas no conceito de que se manter determinado parâmetro da fonte de alimentação da máquina de solda constante, ao longo do processo de soldagem, seria suficiente para se obter soldas de boa qualidade.

Surgiram os controles de alimentação de corrente constante, nos quais o valor da corrente é monitorado e ajustado durante o processo de soldagem de forma a permanecer o mais constante possível (EL-BANNA et al., 2006). Encontramos também os controles de alimentação de tensão constante, que ao invés da corrente, tentam manter a tensão constante (SHVIRER et al., 1999) (WILLIAMS; PARKER, 2004a). Outro subgrupo é dos controladores de calor constante, que é baseado na ideia de se fornecer uma quantidade específica de calor por solda, isto é, uma quantidade fixa de calor induzido por unidade de 
volume (WILLIAMS; PARKER, 2004a) (PODRZAJ et al., 2008). Estes tipos de controle de alimentação possibilitaram a produção de procedimentos de soldagem.

Há várias pesquisas para aperfeiçoar os procedimentos de soldagem embora este tipo de abordagem sempre encontre alguns problemas (IRVING, 1996) (MEWBORNE, 1999) (MARTÍN et al., 2006). Dado o número crescente de materiais utilizados nos PSPR, devido à variedade de geometrias de eletrodos, aos diferentes tipos de máquinas de soldagem, um grande número de procedimentos de soldagem torna-se necessário para cobrir todas as possíveis combinações. Além disso, esta abordagem desconsidera que existem perturbações durante o processo de soldagem (WILLIAMS; PARKER, 2004a). Portanto é imprescindível monitorar e limitar as possíveis perturbações, o que, dependendo do processo, tem sido inviável, em virtude do custo e do tempo necessário.

Atualmente, procedimentos de soldagem estão sendo criados com a ajuda do método de elementos finitos (EISAZADEH et al., 2010). Este tipo de abordagem tem sido utilizado para se ajustar os parâmetros principais de soldagem como intensidade da corrente, tempo de soldagem, força nos eletrodos e geometria dos eletrodos, através de simulações com um modelo de elementos finitos acoplando características térmicas, elétricas e mecânicas. Essas simulações auxiliam bastante na redução de custos já que reduzem ou eliminam a necessidade de onerosos testes experimentais reais normalmente utilizados para se ajustar esses parâmetros (EISAZADEH et al., 2010).

A consideração das perturbações gerou, na última década, outro tipo de abordagem para sistemas de monitoramento e controle da qualidade do PSPR, baseada no monitoramento de variáveis, sinais ou parâmetros do processo possíveis de serem medidos e que pudessem ser relacionados com a qualidade final da solda. Esses sistemas serão abordados no item 2.4. Em termos de controle de alimentação, surgiram recentemente os chamados controles de alimentação inteligentes, que monitoram algumas grandezas e, caso certas características 
esperadas dessas grandezas não sejam atingidas, aumentam ou diminuem a corrente de soldagem, a pressão nos eletrodos e/ou o tempo de soldagem durante o PSPR (PODRZAJ et al., 2008).

\subsection{Perturbações e Dificuldades do PSPR}

Como visto anteriormente, os procedimentos de soldagem podem falhar principalmente devido às perturbações que ocorrem durante o PSPR. As principais perturbações que incidem no PSPR são:

- Perturbações na fonte de alimentação elétrica. Podem ocorrer variações na tensão e/ou corrente de alimentação;

- Condições variáveis da superfície do material a ser soldado. Esta pode estar, por exemplo, contaminada com óleo, empoeirada, empenada afetando assim a resistência de contato;

- Perturbações no sistema pneumático que controla a força de soldagem;

- Área e resistência de contato variável entre os eletrodos e as partes a serem soldadas. Devido ao desgaste dos eletrodos ao longo de sua vida útil, a área de contato tende a aumentar, assim como a possível impregnação de material das partes sendo soldadas, nos casos de expulsão de material, fazem com que a resistência eletrodo-material aumente (WILLIAMS; PARKER, 2004b);

- Variações na espessura e no revestimento das lâminas de material utilizado;

- Posicionamento ou ajuste ruim entre as partes a serem soldadas;

- Existência, próximo ao local da nova solda, de outro ponto de solda, acarretando desvio da corrente de soldagem devido à baixa resistência neste ponto (efeito shunting); 
- Soldas próximas da borda dos materiais, conhecidas como "edge welding".

As dificuldades associadas à implementação de um sistema de monitoramento e/ou controle de soldagem são:

- A variável de controle de qualidade, ou seja, a força suportada pela solda teria que ser medida em tempo real, o que é impossível já que somente é conhecida após o resfriamento da solda e necessita-se de um ensaio destrutivo para determinar seu valor;

- Inexistência de um modelo preciso do sistema, ou seja, uma relação entre a força suportada pela solda e todas as variáveis atuantes durante a soldagem;

- Existência de diferentes combinações de parâmetros de soldagem que resultam em uma solda com uma resistência mecânica aceitável, por exemplo, uma corrente de soldagem menor pode ser compensada, dentro de certos limites, por um período maior de soldagem e vice-versa.

Portanto, não se pode projetar um sistema capaz de monitorar e/ou controlar diretamente a força suportada pela solda já que esta não pode ser diretamente medida, o que torna necessário o uso de outras variáveis que possam ser medidas e que sejam correlacionadas com a qualidade da solda.

\subsection{Sistemas Baseados em Grandezas Mensuráveis do PSPR}

Os sistemas não destrutivos de monitoramento e/ou controle da qualidade do PSPR, baseados em grandezas mensuráveis do processo relacionadas com a qualidade final da solda, tornaram-se o foco principal das pesquisas e desenvolvimento, nesta área, na última década.

As principais variáveis e procedimentos encontrados na literatura são: 
- Raio-x;

- Ultrassonografia;

- Medições baseadas na expansão do material durante a soldagem;

- Emissão acústica e sônica durante a soldagem;

- Medição da temperatura através de emissão infravermelha ou termopar;

- Imagem captada por câmera;

- Força de soldagem;

- Variáveis elétricas: a tensão de soldagem, a corrente de soldagem e a resistência dinâmica.

A figura 2.3 mostra um desenho esquemático do PSPR com exemplos de posicionamento dos principais sensores e das principais medições necessárias para se obter as variáveis relacionadas com a qualidade da solda encontradas na literatura, e usadas para monitorar e/ou controlar o PSPR.

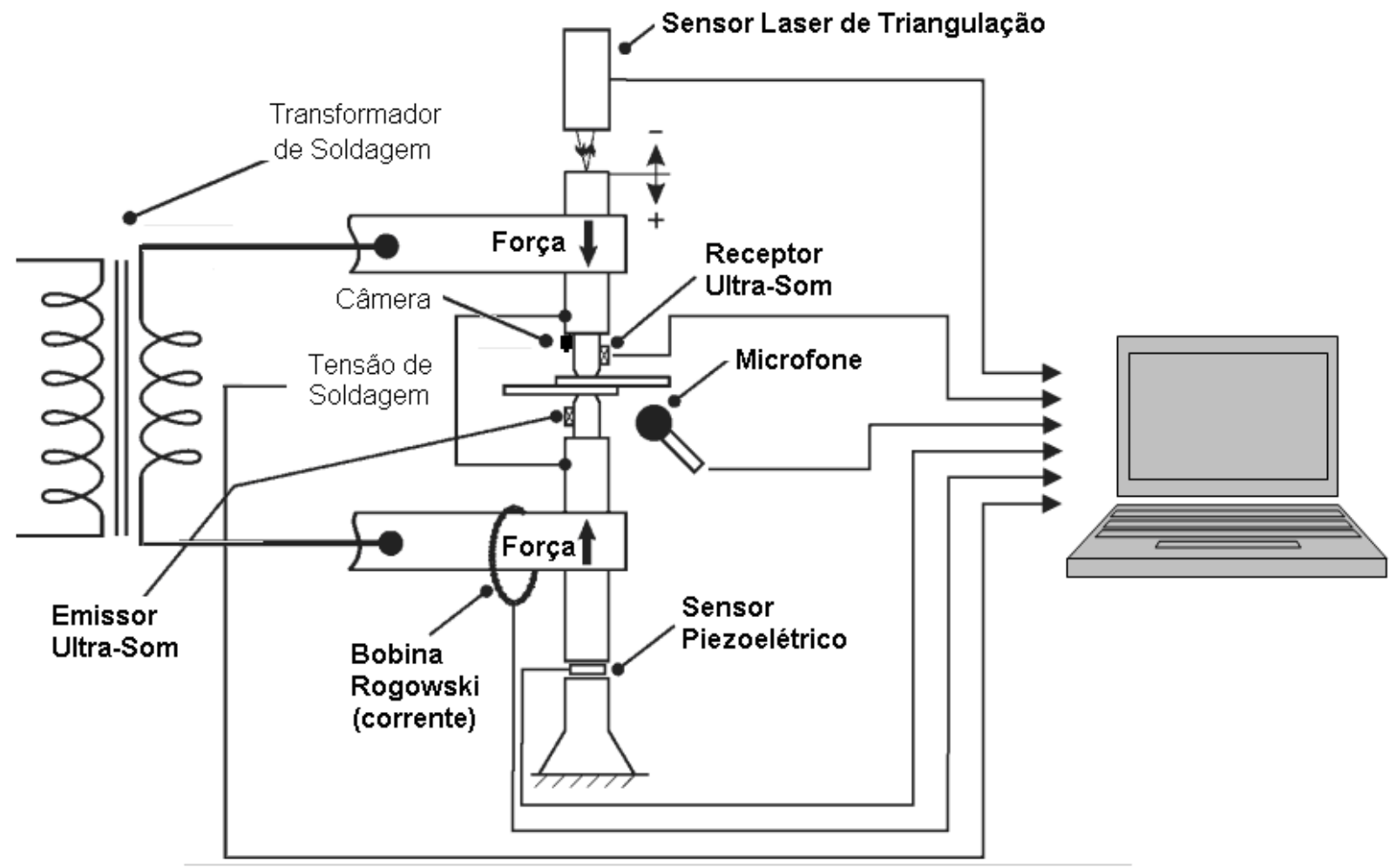

Figura 2.3 - Desenho esquemático do PSPR 
O equipamento de raio-x não aparece na figura 2.3, pois é um procedimento difícil de ser incorporado ao equipamento de soldagem e necessita de ambiente especial devido à radiação envolvida. Não é, portanto, realizado no local de produção. Após o término do processo de soldagem, a peça é levada a um local com ambiente adequado à realização do ensaio com raio-x (HALMSHAW, 1988) (ROYE, 2002). Consequentemente, esse tipo de equipamento, apesar de possibilitar uma leitura do diâmetro final da solda, não é viável para se ter um monitoramento ou controle individualizado e em tempo real da qualidade final da solda.

A ultrassonografia pode ser aplicada como na figura 2.3, ou seja, com um transmissor de ultrassom e um receptor de ultrassom em módulos separados, sendo a razão da amplitude entre o sinal transmitido e o sinal recebido usada para estimar o tamanho da solda (VOGT et al., 2006).

Outra técnica de ultrassonografia é aquela que aproveita o eco produzido pelo som para ver em tempo real as reflexões produzidas pelas estruturas (MANSOUR, 1988). Neste caso, transmissor e receptor são montados no mesmo módulo. A onda se propaga através do ponto de solda em uma direção perpendicular às faces das partes unidas. O som vai sendo parcialmente refletido conforme mudanças na densidade e composição das estruturas. Um scanner sonográfico determina o tempo desde a transmissão até a recepção do eco e, a partir do intervalo de tempo, calcula a distância (profundidade) onde o foco se formou e também mede a intensidade do eco. De posse dessas informações, é possível gerar uma imagem, alocando para cada pixel da imagem uma intensidade.

A figura 2.4 mostra o caminho de propagação da onda ao longo da amostra e o formato das ondas idealmente recebidas (DENISOV et al., 2004). A presença de reflexão na área entre as partes soldadas indica que estas estão separadas, o que corresponde a uma área não soldada (Fig. 2.4A). Se as partes foram soldadas, não há uma onda de reflexão interna, e 
há a reflexão da face oposta da outra parte (Fig. 2.4C). Se a onda se propaga em uma área parcialmente soldada, o sinal resultante é uma combinação das formas de onda de A e C (Fig. 2.4B).

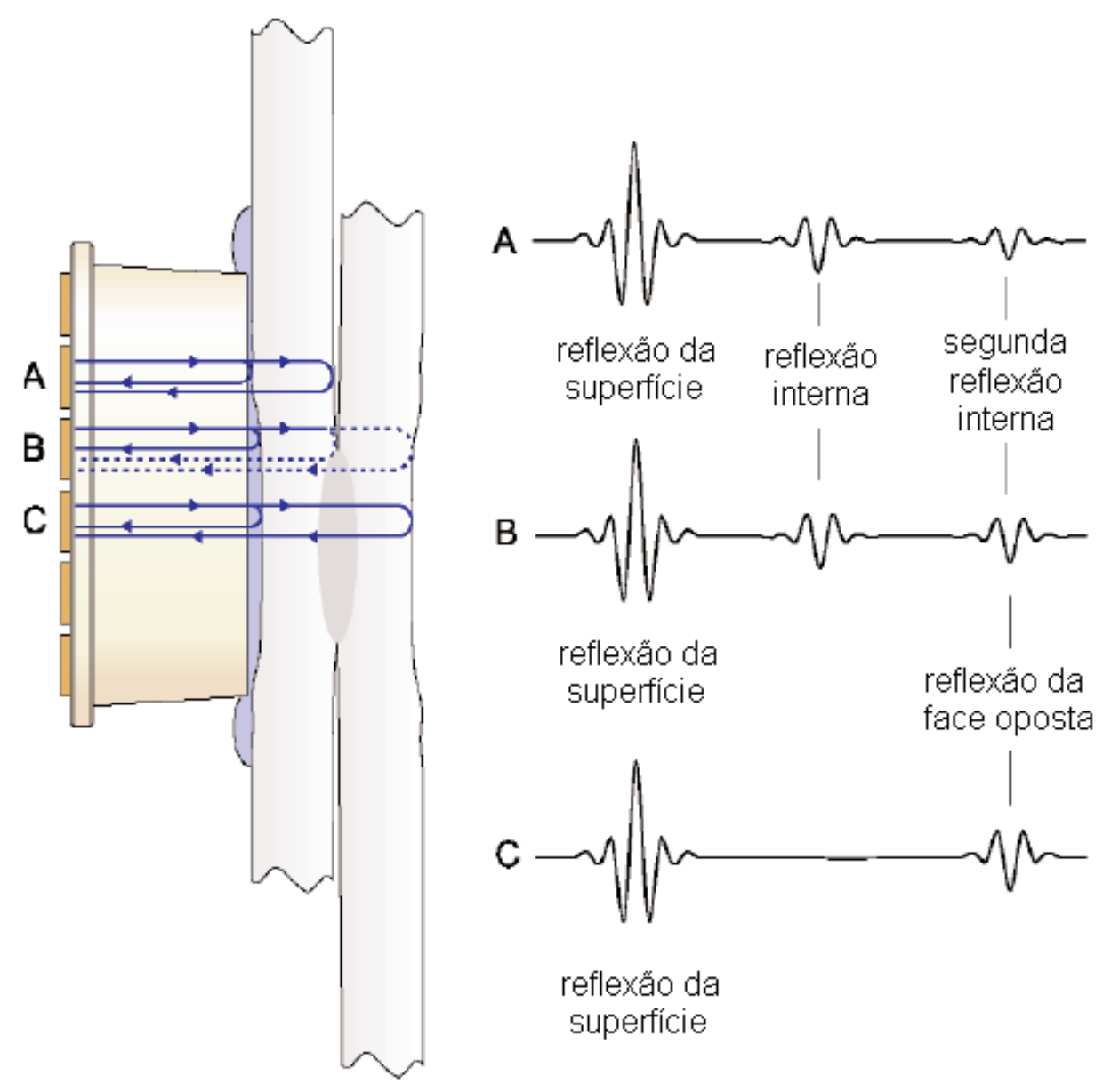

Figura 2.4 - Caminho idealizado da onda através das partes (esquerda) e a forma de onda correspondente obtida (direita) (DENISOV et al., 2004)

No trabalho publicado por VOGT et al. (2006), é apresentado um sistema proprietário aplicado em campo, baseado em técnicas de ultrassonografia, usado para inspecionar e controlar o processo de solda a ponto resistiva. Este sistema pode ser instalado diretamente nos braços de soldagem, integrando a este um sensor ultrassônico. Os sinais de eco são coletados, armazenados e analisados, utilizando lógica fuzzy e redes neurais. É obtida então uma relação entre a área do ponto de solda e a qualidade do mesmo. Infelizmente este sistema 
apresenta a necessidade de se calibrar o sensor regularmente, não suporta processos com alta taxa de produção, é relativamente caro e os sinais são susceptíveis a flutuações do campo magnético durante a soldagem e não determinam a força de cisalhamento em processos nos quais este é o parâmetro de qualidade.

A técnica de ultrassonografia tem sido explorada também por outros pesquisadores, para medir a qualidade do ponto de solda, principalmente na indústria automobilística, na produção de carrocerias, já que o parâmetro de qualidade para este tipo de solda é o diâmetro da solda e este pode ser facilmente obtido na imagem gerada (DOYUM; SONAT, 2003) (MARTÍN et al., 2007). Mas as soluções propostas baseadas nessa técnica possuem limitações para aplicações em tempo real e parecem funcionar satisfatoriamente somente em laboratório onde não existem tantas perturbações quantas em um ambiente industrial real. Podem ser utilizadas na análise de soldas em uma parte específica da carroceria após a fabricação, mas são de difícil adaptação a uma linha de produção real, e não suportam processos com alta taxa de produção.

Outra técnica amplamente encontrada na literatura é baseada na expansão do material durante a soldagem. Esse tipo de abordagem pode ainda ser dividido em duas classes. A primeira é baseada na medição da pressão exercida por essa expansão na superfície dos eletrodos. A segunda é baseada na medição direta do deslocamento entre os eletrodos durante a expansão.

Existe uma distinta diferença entre a força de soldagem aplicada nos eletrodos e a força térmica na superfície dos eletrodos. A primeira é um importante parâmetro do processo de soldagem a ponto resistivo, já que ela garante o contato entre as partes a serem soldadas, criando então um caminho elétrico para circulação da corrente de soldagem e também ajuda a manter a energia concentrada entre os eletrodos durante a soldagem, evitando que haja expulsão de material. A segunda é aquela que surge devido à expansão do material durante o 
processo de soldagem. Essa força térmica é então sentida pelos braços nos quais os eletrodos estão fixados. O seu monitoramento indica se o ponto de soldagem já teve um crescimento suficiente e é usada como retroalimentação para o controle da soldagem, já que reflete o estado do metal durante o processo de soldagem (MESSLER, 1995). Este tipo de abordagem foi explorado por alguns pesquisadores, mas tem como grande desvantagem o fato do sistema necessitar ser extremamente rígido, de forma que a estrutura tenha o mínimo de vibração possível, para ser capaz de medir com precisão a sutil variação de pressão nos eletrodos devido ao crescimento do ponto de solda, portanto reduzindo muito sua real aplicabilidade (HIRSCH, 1993).

A medição direta do deslocamento dos eletrodos durante a expansão tem sido explorada por vários pesquisadores. Um transformador diferencial linear é normalmente utilizado para medir o deslocamento do eletrodo (PENGXIAN et al., 2007). Para evitar a interferência de medição devido à influência do campo magnético, o deslocamento do eletrodo também pode ser medido com um codificador óptico digital, como o sensor laser de triangulação apresentado na figura 2.3 (LEE et al., 2001). Esta técnica parte do princípio de que a quantidade de expansão térmica, fusão e expulsão dos materiais envolvidos pode ser correlacionada com a curvatura e magnitude da curva de deslocamento do eletrodo durante a soldagem (CHO; RHEE, 2003 e 2004). Esta curva de deslocamento dos eletrodos medida pode ser dividida em uma curva de variação e uma curva de tendência, as quais refletem diferentes aspectos da qualidade da solda a ponto resistiva (EL-BANNA et al., 2008). Para analisar as medições de deslocamento do eletrodo, alguns métodos analíticos são utilizados, como análise por Wavelets e análise de Fourier e os dados obtidos são normalmente aplicados em uma rede neural artificial ou em um sistema neuro-fuzzy (ZHANG et al., 2005) (JOU, 2001 e 2003) (ZHANG et al., 2007) (XINMIN et al., 2007). A principal limitação dessa técnica é a falta de robustez. De um ponto de vista prático, os problemas com a fiação, 
vibrações do equipamento e o campo magnético sempre serão um ponto negativo. Além disso, essa técnica não é adequada para materiais de pequena espessura $(<0,5 \mathrm{~mm})$ e em processos com alta taxa de produção.

A técnica baseada na emissão acústica e sônica detecta os sons emitidos durante o processo de soldagem. O termo emissão acústica é utilizado se o sensor é montado na parte a ser soldada ou no eletrodo. Se um microfone comum é usado, utiliza-se o termo emissão sônica. Existem diversas fontes de emissão de som durante o PSPR. A magnitude da emissão acústica e sônica durante a condução da corrente de soldagem depende da quantidade de calor sendo gerado e, portanto, pode ser correlacionada com a força suportada pela solda (PODRZAJ et al., 2005). A maior desvantagem de se medir a emissão acústica é a necessidade de se fixar o sensor ou na parte a ser soldada, o que deve ser feito em todas as partes, consumindo muito tempo, ou nos eletrodos, o que resulta em um sinal com alto grau de ruído devido à circulação interna de líquido para refrigerá-lo. A medição da emissão sônica é bem mais simples e pode alcançar resultados satisfatórios na estimação da força suportada pela solda em laboratório. O principal problema para sua aplicação industrial é o ruído ambiente, normalmente significativo em um ambiente de produção industrial (PODRZAJ et al., 2005).

Ainda outra técnica empregada é aquela baseada na medição da temperatura da solda durante o PSPR. A luz infravermelha emitida e a tensão produzida por um termopar são usadas para medir a temperatura na superfície da solda. A luz infravermelha emitida pode ser relacionada com a força suportada pela solda e usada como entrada em um sistema de controle (PODRZAJ et al., 2008). Entretanto, este sinal não é adequado para uso em ambiente industrial de produção, pois necessita de cuidados especiais para assegurar uma emissividade constante da superfície, e mesmo quando isso é assegurado, a sujeira e a fumaça produzidas durante o PSPR podem contaminar o sinal. A tensão produzida por um termopar também não 
é adequada para uso em ambiente de produção devido às dificuldades de fixação do termopar. Seu uso é normalmente limitado ao período de resfriamento da região soldada. A taxa de resfriamento depende do tamanho da lentilha de solda (PODRZAJ et al., 2008).

A imagem captada por uma câmera é usada em um método de visão computacional para estimar a qualidade da solda produzida (RUISZ et al., 2007). A câmera é fixada na pinça de soldagem de forma que seja possível adquirir a imagem da impressão deixada no material pelo PSPR, como mostrado na figura 2.5. O formato e o tamanho das estruturas na impressão são correlacionados com a área da lentilha de solda e permitem estimar a qualidade do ponto de solda. $\mathrm{O}$ sistema segmenta a imagem e separa a parte da impressão relativa à marca do eletrodo da parte da impressão que representa a área que sofreu maior impacto do calor gerado pelo processo. Nesta área de maior impacto do calor gerado é então encontrado o diâmetro do ponto de solda. O autor diz obter uma boa precisão na estimação da qualidade com este sistema proposto e que ele apresenta várias limitações. O sistema necessita de iluminação especial para adquirir-se a imagem. Não pode ser adaptado em todo tipo de máquina de soldagem. O processo de segmentação da imagem depende da variação de contraste entre as áreas alvo, e essa variação nem sempre é suficiente para uma boa segmentação das áreas, conforme o próprio autor relata.

A força de soldagem é medida por um sensor piezoelétrico que necessita ser adaptado ao braço da máquina que segura o eletrodo. Não existem trabalhos que usem exclusivamente este sinal para monitorar ou controlar a qualidade final da solda. Embora esta força não seja usada diretamente para se estimar a qualidade da solda, em conjunto com outros sinais, como o deslocamento do eletrodo e a resistência dinâmica do PSPR, ela tem sido explorada por alguns pesquisadores (LI et al., 2000 e 2001). A força de soldagem é usada também como sinal auxiliar em sistemas de controle da alimentação de soldagem (SUBRAMANIAN et al., 2004) (WILLIAMS; PARKER, 2004a). 


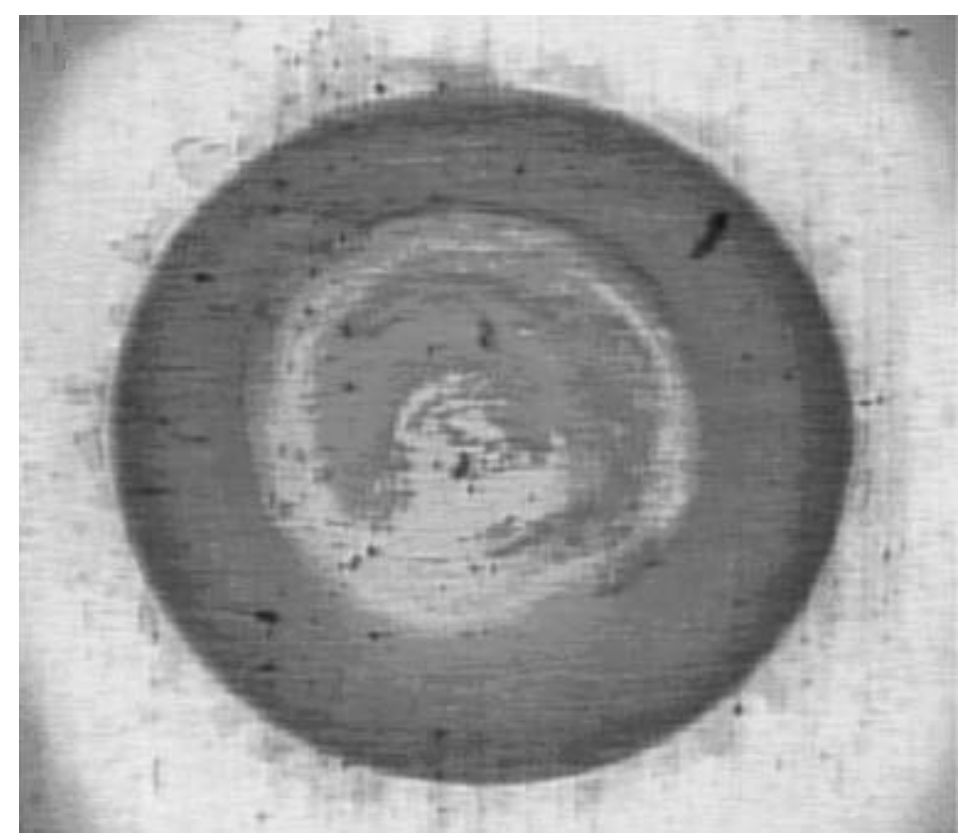

Figura 2.5 - Imagem da impressão no material após o PSPR (RUISZ et al., 2007)

As variáveis elétricas são comumente utilizadas já que para medi-las não é necessário o uso de sensores ou equipamentos caros. A tensão de soldagem pode ser medida diretamente nos eletrodos, enquanto a corrente de soldagem pode ser obtida através da tensão induzida medida com uma bobina Rogowski, conforme ilustrado na fig. 2.3. A razão entre a tensão de soldagem e a corrente de soldagem varia durante o processo de soldagem já que a resistividade elétrica dos materiais depende da temperatura e, portanto, varia durante a formação da solda. Por esta razão, é chamada de resistência dinâmica.

Diversas pesquisas mostraram que a resistência dinâmica é particularmente importante porque pode ser usada para monitorar mudanças nas partes soldadas (CHO; RHEE, 2003). Portanto, esta variável é estabelecida como base primária para desenvolvimento da maioria dos sistemas de monitoramento e controle do PSPR.

Para entender qualquer PSPR, é necessário entender a função das várias resistências presentes entre os eletrodos e como estas resistências influenciam a geração de calor nas 
várias interfaces. Uma curva teórica clássica da resistência dinâmica durante a soldagem de aço é mostrada na figura 2.6.

O trabalho mais aprofundado de alguns pesquisadores indicou que a curva da resistência dinâmica pode ser subdividida em cinco estágios (WILLIAMS; PARKER, 2004a). No primeiro estágio, a resistência dinâmica tende a diminuir com a melhora no contato entre as partes a serem soldadas devido ao colapso da rugosidade e também devido à melhora no contato entre os eletrodos e as partes.

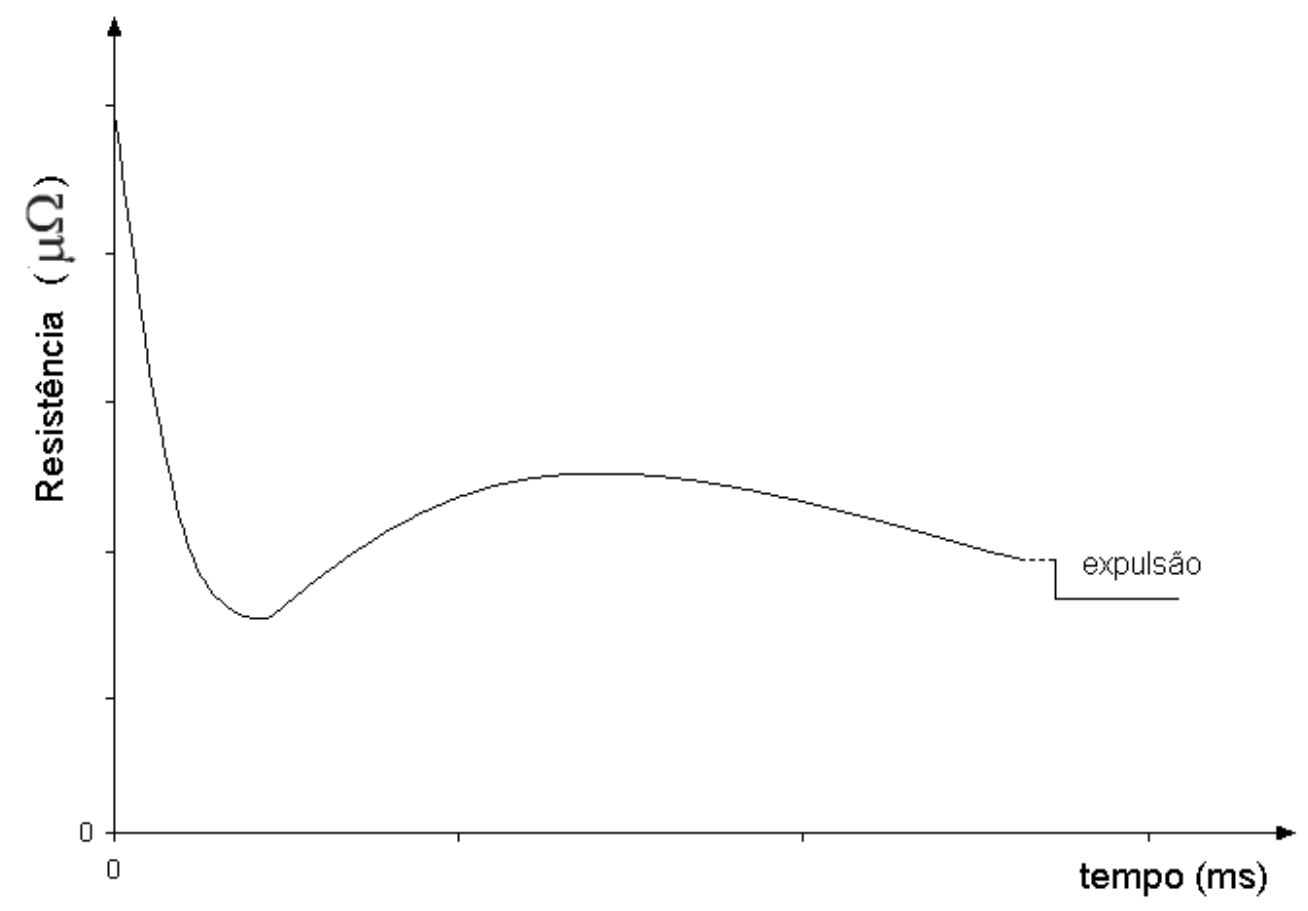

Figura 2.6 - Curva da resistência dinâmica clássica para soldagem de aço

Em um segundo estágio, a resistência dinâmica atinge um valor mínimo e começa a crescer quando o efeito do aumento da resistividade das partes, devido ao aumento da temperatura, supera o efeito citado no primeiro estágio. No terceiro estágio a resistência dinâmica cresce, devido à predominância do aquecimento das partes. Em um quarto estágio, as partes atingem o nível de aquecimento necessário para iniciar a fusão na interface de contato e esta zona de fusão vai crescendo rapidamente. A taxa de crescimento da resistência dinâmica passa a ser um compromisso entre o aumento da resistência devido ao aquecimento 
das partes e uma diminuição da resistência devido ao aumento do tamanho da zona de fusão. Neste estágio atinge-se o pico da resistência dinâmica, conhecido na literatura como pico $\beta$ ( $\beta$ peak). No quinto estágio ocorre uma diminuição da resistência dinâmica devido ao crescimento da zona de fusão e ao início de colapso da resistência mecânica das partes que faz com que os eletrodos comecem a penetrar, diminuindo o caminho da corrente. Neste estágio, a solda deve ser finalizada antes que ocorra expulsão de material. Caso haja expulsão de material, uma brusca queda instantânea ocorre na resistência dinâmica, fazendo com que este problema seja facilmente detectado através de análise da curva da resistência dinâmica.

O formato da curva de resistência dinâmica do PSPR pode variar bastante de um processo para outro, influenciado principalmente pelo tipo de material das partes soldadas, utilização de materiais revestidos, espessura dos materiais e tempo de soldagem.

A curva da resistência dinâmica foi escolhida para ser utilizada neste trabalho para desenvolver um sistema capaz de realizar em tempo real e em ambiente industrial o monitoramento da qualidade do PSPR, em que se destacam os seguintes motivos:

- A curva de resistência dinâmica reflete a variação da temperatura e outras alterações na região de soldagem;

- As medições de tensão e corrente necessárias para obtenção da resistência dinâmica não são invasivas, não estorvam a produção da solda, não alteram os parâmetros de soldagem, podem ser feitas em qualquer tipo de pinça de soldagem e são robustas ao ambiente industrial.

Os sistemas de monitoramento e controle da qualidade do PSPR baseados nas medições de variáveis elétricas encontrados na literatura podem ser divididos em três grupos principais (PODRZAJ et al., 2008): 
- Sistema de Controle da Qualidade Realimentado: neste sistema os parâmetros de soldagem podem ser ajustados durante o processo de solda, ou seja, dentro do tempo de soldagem, de acordo com os valores de medição intermediários realimentados;

- Sistema de Controle da Qualidade Solda a Solda: neste tipo de sistema os parâmetros de soldagem podem ser ajustados no período entre o final da produção de uma solda e o início da produção de outra. O ajuste para a próxima solda é determinado pelas medições executadas durante a(s) soldagem(s) anterior(es).

- Sistema de Monitoramento da Qualidade: este tipo de sistema não reajusta os parâmetros de soldagem, somente determina a qualidade final da solda. Esta determinação pode ser qualitativa ou quantitativa.

Os primeiros tipos de sistemas de controle da qualidade realimentados eram do tipo liga-desliga. A resistência dinâmica era monitorada e o controle interrompia o processo de soldagem quando um valor pré-determinado era atingido (PODRZAJ et al., 2008).

Depois vieram os sistemas de controle da qualidade realimentados do tipo tracking, onde o sistema ajusta a corrente de soldagem de forma a seguir um sinal de referência, como no trabalho de Chen e Araki (1997), que descreve um sistema de controle fuzzy adaptativo para o PSPR baseado na identificação da resistência dinâmica durante o PSPR, e no trabalho de Furlanetto, Motomura e Batalha (2008). Este tipo de sistema apresenta resultados melhores que o do tipo liga-desliga, mas ambos são afetados pelas perturbações do PSPR. Além disso, curvas de referência para diferentes materiais e espessuras de materiais ainda necessitam ser obtidas experimentalmente.

Pertencem ainda a este grupo de sistemas os controles de alimentação de corrente constante, de tensão constante e os de calor constante ou potência constante, já mencionados no item 2.2, que monitoram e buscam manter, respectivamente, corrente, tensão e potência 
constantes como condição para se obter soldas de boa qualidade. Estes três tipos, principalmente o de corrente constante, são muito utilizados ainda hoje, mas não levam em consideração as perturbações do PSPR, que prejudicam seu desempenho.

Em vista da dificuldade de prover modelos matemáticos eficientes do PSPR para servirem como base de um algoritmo de controle e devido ao curto tempo de soldagem de alguns processos, sistemas de monitoramento da qualidade ganharam ênfase e técnicas alternativas passaram a ser examinadas. A tendência nesses sistemas de monitoramento propostos é a aplicação de técnicas de inteligência artificial, em particular, o uso de redes neurais artificiais e de lógica fuzzy. Encontramos também o uso de Support Vector Machine (ZHANG; HOU, 2009), mas os resultados apresentados são inferiores aos obtidos com os outros métodos.

O uso de lógica fuzzy em sistemas de monitoramento é mais restrito e normalmente é utilizada em sistemas de controle do tipo tracking como citado anteriormente. Exemplos de sistemas de monitoramento que utilizam lógica fuzzy podem ser encontrados nos trabalhos de Brown et al. (1998), Lee et al. (2001) e Zhang et al. (2007). Já as redes neurais artificiais são amplamente utilizadas para estimar o diâmetro da lentilha de solda ou a força de cisalhamento suportada pela solda ou para classificar as soldas. O tipo mais comum de rede neural utilizada é do tipo Perceptron multicamadas, com uma camada escondida, em conjunto com o algoritmo de aprendizagem backpropagation. O que basicamente difere os sistemas de monitoramento utilizando essa técnica são as características extraídas das variáveis elétricas medidas que passam a representar as amostras do processo.

No trabalho de Dilthey e Dickersbach (1999), o valor da corrente máxima em cada meio ciclo senoidal e o respectivo valor de tensão neste mesmo tempo foram utilizados como dados de entrada da rede neural possibilitando a essa estimar a força de cisalhamento suportada pelas soldas. Como resultado, obteve-se um erro quadrático médio de $0,27 \mathrm{kN}$ em 
um processo ajustado para produzir soldas que suportassem 4,3kN. Aravinthan et al. (2001) utilizam esses pontos de máximo da corrente e tensão divididos um pelo outro, ou seja, a curva de resistência dinâmica como entrada da rede neural. Já Ivezic et al. (1999) utilizam na entrada da rede proposta 16 neurônios que recebem dados de oito picos de tensão e seus respectivos picos de corrente, alguns neurônios para os parâmetros estáticos de soldagem e três neurônios organizados como um tipo de registrador de deslocamento, sendo estes caracterizados por uma integração da curva de resistência dinâmica com tempos sucessivamente maiores. Os resultados mostram 95\% de precisão na classificação das soldas, como aprovadas ou reprovadas, com relação ao tamanho do ponto de solda resultante.

No trabalho de Garza e Das (2000) é proposto um novo método para cálculo da resistência dinâmica baseado em um modelo variante no tempo que tem como entrada a corrente e como saída, a tensão de soldagem. Em 2001, estes mesmos autores propõem o uso da curva da resistência dinâmica da solda calculada por esse novo método, reduzida para 120 pontos por método de decimação, em um sistema de monitoramento da qualidade baseado em redes neurais artificiais para identificar soldas ruins (GARZA; DAS, 2001). O resultado obtido de 5 erros de classificação em 40 amostras usadas para treinar e testar a rede neural não mostra grandes vantagens em utilizar esse método. Cho e Rhee (2000) propõem medir no circuito primário da máquina de soldagem as variáveis do processo e usá-las para obter a curva de variação da resistência dinâmica através dos eletrodos. Dessa curva, quatro características são extraídas, como desvio padrão, localização e valor do pico de resistência e o ângulo de inclinação durante o crescimento da resistência. Como resultado a resistência dinâmica apresentou um erro de $2 \mu \Omega$ quando comparada ao método tradicional de medição no secundário e a estimação da força de cisalhamento pela rede apresentou um erro percentual médio de 8,7228\%. Em 2002, estes mesmos autores, ainda usando medições no primário, utilizaram modelos de regressão linear e não-linear com 10 fatores de estimação como entrada 
da rede neural (CHO; RHEE, 2002). Como resultado obtiveram um erro médio quadrático de $84 \mathrm{~N}$ em amostras que suportavam uma força de cisalhamento entre $2,6 \mathrm{kN}$ e $3,5 \mathrm{kN}$.

No trabalho de Subramanian et al. (2004), as características extraídas da curva da resistência dinâmica e usadas na entrada da rede neural são a resistência máxima, tempo para atingir a resistência máxima, diferença entre a resistência máxima e a resistência mínima, integral da curva do início ao fim da soldagem, taxa de decaimento da curva após atingir a resistência máxima e a resistência inicial quando os eletrodos iniciam a pressão nas partes. Foi obtida neste trabalho uma precisão de $+/-0,4 \mathrm{~mm}$, mas somente 15 amostras foram usadas para validar a rede. Seguindo esta linha, Ling et al. (2009) usam a resistência mínima, resistência máxima, resistência final, tempo para atingir a resistência mínima e tempo para atingir a resistência máxima como entrada de uma rede neural usada para classificar as soldas em 3 classes, boas, ruins ou com expulsão. Na pesquisa de Martín et al. (2006), são usadas como características da rede o tempo de soldagem, a curva de corrente e o tipo de eletrodo. De forma similar, Wen et al. (2009) usam na entrada da rede neural o tempo de soldagem, a curva de corrente e o valor da resistência final da curva de resistência dinâmica. Já Gong et al. (2007) usam o fator de potência dinâmico, calculado através da defasagem entre as curvas de tensão e corrente, como entrada da rede. Essa característica não é muito viável, pois depende de uma altíssima freqüência de amostragem em sistema de controle de alimentação em média frequência para se obter um valor razoável da defasagem, caso contrário, a defasagem será basicamente a mesma em todos os pontos. Uma mistura de características de várias medições como tensão, corrente, resistência dinâmica, deslocamento do eletrodo, emissão infravermelha e emissão ultrassônica é usada no trabalho de Cullen et al. (2008). Após testar várias combinações, o melhor resultado foi uma precisão de $90 \%$.

Rede Neural do tipo Hopfield também é encontrada na literatura e usada para classificar as soldas (CHO; RHEE, 2004), mas os resultados apresentados não são melhores 
que os encontrados em artigos que utilizam as redes neurais do tipo Perceptron multicamadas. O treinamento das redes usando quantização linear de vetores ao invés do algoritmo de backpropagation também é encontrado na literatura e segundo os autores mostra resultados promissores (EL-BANNA et al., 2008).

Conforme mostrado, a maioria dos métodos encontrados na literatura baseados em variáveis elétricas, devido às características geométricas ou estatísticas extraídas da curva tais como valor médio, valor máximo, tempo para se atingir o valor máximo, derivada de crescimento, análise das componentes principais, não apresenta boa reprodutibilidade, ou seja, só funciona com um tipo específico de controlador e de processo. Outros requerem um conjunto muito grande de dados para treinamento e validação. Métodos baseados na medição de outras grandezas, que não as variáveis elétricas, são muito susceptíveis a ruídos diversos nas medições (eletromagnéticos, vibrações, fumaça, som ambiente) e alguns não são possíveis de se implementar em tempo real e em ambiente industrial. Nenhum dos sistemas para monitoramento da qualidade encontrado detecta possíveis causas que podem estar degradando a qualidade do processo caso uma solda de má qualidade seja identificada. Somente fazem uma estimativa não numérica da qualidade final da solda.

Neste trabalho será proposto um sistema que satisfaz as características do grupo dos sistemas de monitoramento da qualidade, mas que além de determinar a qualidade final das soldas, identifica possíveis causas para soldas de qualidade insatisfatória. O sistema proposto tem ainda potencial para ser usado também como sistema de controle solda a solda, como será justificado no capítulo 3 .

Este sistema de monitoramento não destrutivo proposto é baseado na curva da resistência elétrica dinâmica obtida durante o processo de soldagem e em um modelo parametrizável fundamentado em propriedades físicas do processo. Este sistema pode ser implementado em campo e em tempo real, não requer um conjunto muito grande de amostras 
para treinamento, pode ser aplicado em máquinas de soldagem com qualquer tipo de controlador, apresenta boa imunidade aos ruídos nos sinais medidos e não depende nem de uma amostra estatística específica nem de um comportamento específico da grandeza medida. O sistema proposto tem ainda potencial para ser usado também como sistema de controle solda a solda e também tem potencial de ser aplicado em outros processos. O capítulo 3 apresentará uma descrição detalhada desse sistema de monitoramento proposto e a argumentação para justificar suas características. 


\section{O Sistema Proposto e seus Componentes}

Neste capítulo será apresentado em detalhes o sistema de monitoramento não destrutivo proposto. Inicialmente este será apresentado de forma geral, ou seja, sem conter especificidades de nenhum processo, apresentando assim potencial para ser aplicado em diversos processos. Depois este sistema será aplicado no processo de solda a ponto resistiva, e cada um de seus componentes será detalhado de acordo com essa aplicação. São apresentadas ainda as ferramentas de software utilizadas neste trabalho.

\subsection{Descrição do Sistema de Monitoramento Proposto}

O sistema de monitoramento da qualidade não destrutivo proposto é baseado em reconhecimento de padrões através de redes neurais artificiais de forma a realizar em tempo real e em um ambiente industrial a estimação da qualidade de cada parte produzida.

Como dito, este sistema é idealizado para processos industriais nos quais o monitoramento da qualidade não possa ser feito de forma direta, ou seja, sem que se utilize um método de ensaio destrutivo.

Um fluxograma do sistema proposto pode ser visto na figura 3.1.

Inicialmente é necessário avaliar o processo e verificar quais grandezas (variáveis ou sinais) podem ser medidas direta ou indiretamente, e se pode haver uma relação entre essas grandezas e a qualidade final do produto produzido pelo processo. A existência dessa relação poderá ser avaliada pelo resultado obtido no treinamento do sistema.

Essas medições devem ser pré-processadas de forma a eliminar o máximo possível de ruído e deixar os dados representativos da grandeza medida. 


\section{Sistema de Monitoramento Individualizado e Não-Destrutivo da Qualidade}

Medição e Processamento das Grandezas do Processo:

- Medição da(s) Grandeza(s) Observável(is);

- Pré-Processamento dessas medições.

- Modelo Matemático Parametrizável.

- Estimação dos parâmetros do modelo proposto

(equações não-lineares) através de ajuste da curva deste com a curva real do processo.

- Estimação da qualidade final através de reconhecimento de padrões usando redes neurais treinadas, tendo como dados de entrada os parâmetros estimados do modelo e como saída, a grandeza que define a qualidade.

Caso a estimativa para a qualidade da parte produzida seja inferior a desejada:

- Correlação entre os parâmetros do modelo e as condições ou estados do processo.

- Fornecimento de possíveis causas.

- Armazenamento do histórico de produção em um banco de dados para certificação e possíveis futuras análises do produto.

Figura 3.1 - Fluxograma do Sistema de Monitoramento da Qualidade Proposto

É necessário então criar um modelo matemático parametrizável da grandeza observável. Este modelo parametrizável deve ser construído baseado em propriedades físicas dessa grandeza do processo, passível de ser medida e monitorada em tempo real, de forma 
direta ou indireta. Este modelo matemático parametrizável não é idealizado para fins de simulação do processo e sim para refletir as propriedades fundamentais da grandeza possível de se observar no processo que descreve.

De posse da curva medida no processo da variação no tempo da grandeza observável e de posse da curva produzida pelo modelo matemático parametrizável, é possível fazer o ajuste dessas curvas, utilizando um método de ajuste de curvas. Este método ajustará os valores dos parâmetros variáveis do modelo, até que se obtenha um ajuste aceitável (menor que um erro pré-determinado) entre a curva gerada pelo modelo e a curva real da grandeza observável do processo. Por tratar-se de um modelo baseado em propriedades físicas conhecidas, estes valores dos parâmetros do modelo obtidos na etapa de ajuste das curvas poderão ser interpretados e relacionados com os estados ou condições do processo de forma a auxiliar na identificação de possíveis problemas que afetem a qualidade.

Como dito, o importante é que o modelo matemático parametrizável reflita as propriedades fundamentais do processo em investigação. Assim, o melhor ajuste da curva gerada pelo modelo refletirá somente aquelas propriedades expressas pelo modelo e resultará em um grupo de valores correspondentes para os parâmetros do modelo. Desta forma, componentes do sinal adquirido que não são refletidas no modelo serão filtradas. Usando os parâmetros do modelo como características do processo em investigação no método de reconhecimento de padrões, somente componentes do sinal adquiridos em conformidade com o modelo determinarão os resultados. Estas características concentram as informações relevantes do sinal (compressão do sinal) e o sinal reconstruído utilizando os valores dos parâmetros do modelo pode ser considerado filtrado por conformidade com o modelo.

Com a utilização de redes neurais artificiais, é possível fazer a estimativa da qualidade final do produto, mas estas redes devem, inicialmente, ser treinadas e validadas com um conjunto de amostras reais do processo. 
Conforme citado anteriormente, como características das amostras do processo serão utilizados os parâmetros do modelo matemático parametrizável ajustados na fase anterior.

Cada amostra do processo será, portanto, representada por um conjunto de valores (os valores dos parâmetros ajustados do modelo) e é necessário conhecer o valor da grandeza que define a qualidade para cada amostra (possivelmente obtido através de ensaio destrutivo), ou seja, qual o valor da qualidade final de cada amostra, para que se possa treinar e validar a rede neural.

Uma parte do conjunto de amostras reais do processo é usada para treinar a rede neural e outra parte, para validá-la. Diferentes topologias de rede devem ser testadas de forma a encontrar a melhor topologia para o processo analisado. Dessa forma, a rede será capaz de estimar o valor da qualidade final de cada amostra submetida.

Após o treinamento e a validação da rede neural, analisando os resultados, é possível saber se a grandeza observável e os parâmetros do modelo apresentam uma correlação com a qualidade final do processo, ou seja, se o sistema realmente consegue estimar a qualidade final do processo. Para isso, deve-se verificar se o erro quadrático médio e/ou o erro relativo médio e o coeficiente de determinação $\left(\mathrm{R}^{2}\right)$ são aceitáveis. Caso os valores encontrados não sejam aceitáveis, antes de se descartar a grandeza observável, deve-se verificar falhas no modelo matemático criado e reajustá-lo. Caso os resultados ainda não sejam aceitáveis, o sistema proposto neste trabalho não pode ser aplicado ao processo em investigação.

Caso a estimativa para a qualidade final do produto pela rede seja aceitável, o sistema pode ainda ser usado para identificar possíveis problemas no processo em amostras que apresentem uma qualidade estimada inferior à mínima desejada, através da correlação entre os valores dos parâmetros do modelo matemático e as condições do processo. Isso é possível graças à possibilidade de interpretação dos parâmetros do modelo. 
Os dados de produção podem ainda ser armazenados em um banco de dados formando um histórico de produção que pode ser usado para certificação do processo e para possíveis análises futuras do produto.

Observando-se as características do sistema de monitoramento da qualidade individualizado e não destrutivo apresentado, algumas conclusões com relação ao sistema podem ser deduzidas:

- Ele é viável já que para sua aplicação só é necessário que alguma grandeza do processo possa ser medida e que um modelo matemático parametrizável baseado nas propriedades físicas dessa grandeza possa ser criado;

- Não contém especificidades de nenhum processo produtivo e, portanto, apresenta potencial para ser aplicado em diferentes processos;

- É realizável em ambiente industrial, desde que as características desse ambiente não inviabilizem a aquisição de sinais do processo;

- Automatiza o monitoramento da qualidade, já que após sua implementação não há mais necessidade de atuação humana na estimação da qualidade final do produto;

- Pode identificar possíveis problemas no processo, graças à possibilidade de interpretação dos parâmetros do modelo, o qual é baseado em propriedades físicas conhecidas.

\subsection{Aplicação do Sistema no PSPR}

A avaliação e a validação deste sistema de monitoramento serão realizadas por meio de dados reais obtidos diretamente da produção de lotes de contatos elétricos produzidos através do processo de solda a ponto resistiva. 
De forma a facilitar a análise e visualização, a figura 3.2 apresenta um diagrama esquemático ilustrativo do sistema de monitoramento individualizado não destrutivo da qualidade proposto aplicado ao PSPR.

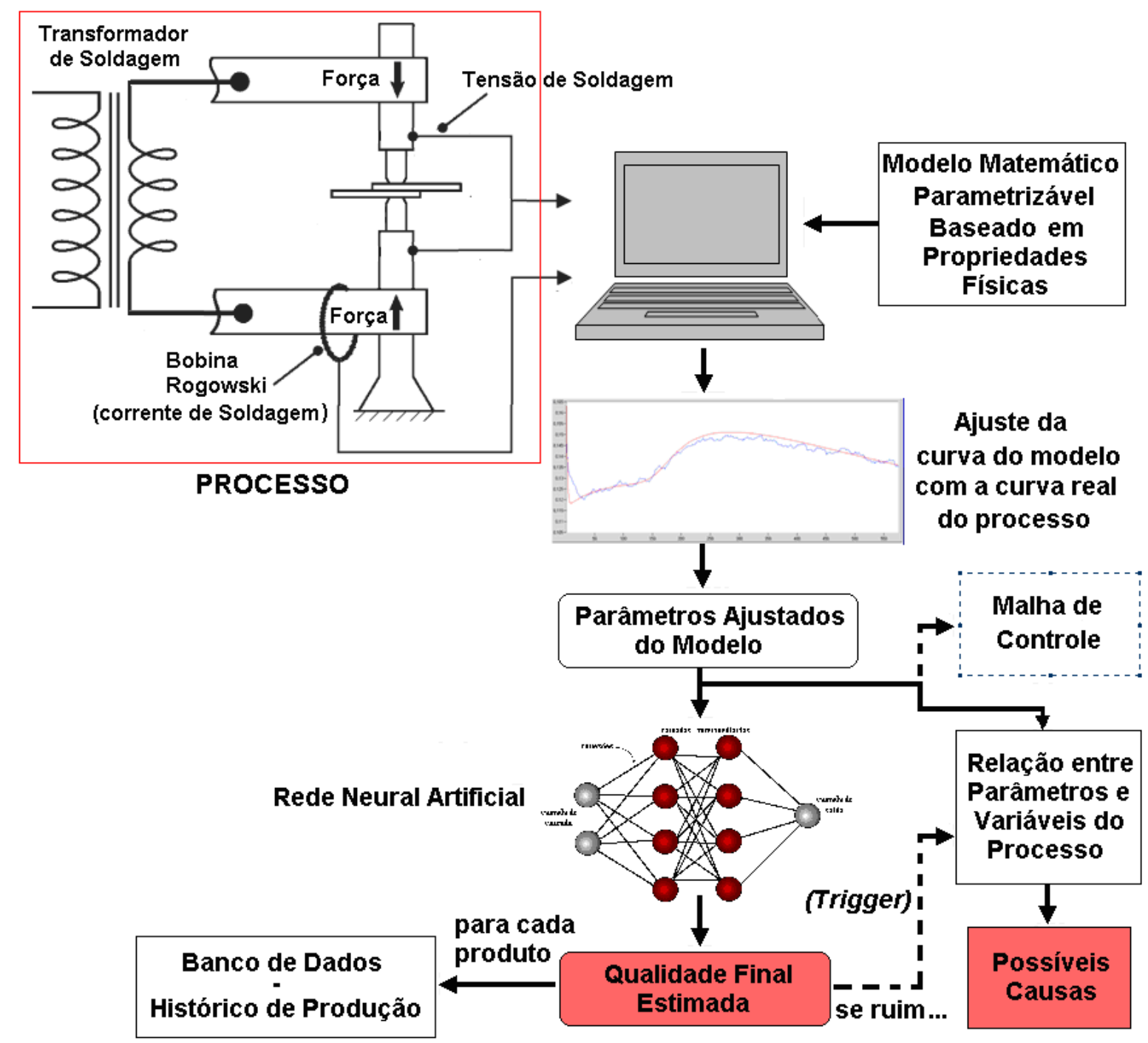

Figura 3.2 - Diagrama Esquemático do Sistema de Monitoramento da Qualidade Proposto

As grandezas medidas do processo e utilizadas como base para o monitoramento da qualidade são a tensão entre os eletrodos e a corrente nos eletrodos durante o processo de solda, por serem relacionadas com a qualidade final da solda conforme vários estudos já demonstraram (DILTHEY; DICKERSBACH, 1999) (CHO; RHEE, 2000) (GARZA; DAS, 2001) e pelas vantagens já citadas no capítulo 2 . 
Como abordado também no capítulo 2, com a medição dessas grandezas, é possível obter-se a curva da resistência dinâmica do PSPR.

O modelo matemático parametrizável será, portanto, criado baseado nas propriedades físicas da variação da resistência elétrica durante o processo de soldagem.

Por ser tratar de um processo não linear e altamente não determinístico, é necessário um método não linear para realizar o ajuste da curva do modelo com a curva real do processo.

Os parâmetros ajustados do modelo criado podem ser utilizados para caracterizar o processo. Após essa etapa, redes neurais artificiais de diferentes topologias podem ser treinadas e validadas através de um conjunto de amostras do processo, cada qual composta pelos parâmetros ajustados do modelo e pela qualidade final da solda, representada pela força de cisalhamento suportada, obtida através de ensaio destrutivo.

Após o treinamento e validação, a melhor topologia de rede pode ser usada para estimar a qualidade final da solda. Caso essa qualidade esteja comprometida, os parâmetros do modelo podem ser usados para determinar as possíveis causas, auxiliando assim na manutenção do processo. Esses parâmetros do modelo têm ainda o potencial de serem utilizados em uma malha de controle solda a solda, alterando o procedimento de soldagem de acordo com os valores assumidos. Esse potencial não foi analisado por este trabalho e ficará como sugestão para futuros trabalhos.

Os dados de produção podem ser armazenados em um banco de dados formando assim um histórico de produção que pode ser usado para certificação do processo e possíveis análises futuras do produto.

Nos próximos subitens desse capítulo, cada uma dessas etapas de implementação do sistema de monitoramento proposto e os componentes necessários para sua execução serão apresentados e discutidos mais detalhadamente. 


\subsection{Ferramenta de Software Utilizada}

Com o propósito de ler, processar e disponibilizar os dados obtidos do processo, uma ferramenta de software chamada "TOMAHAWK" foi utilizada. O núcleo e o programa principal dessa ferramenta foram desenvolvidos em Visual C++ IDE, em um Instituto da Universidade de Ciências Aplicadas de Karlsruhe, Hochschule Karlsruhe, da Alemanha, chamado IAF (Institut für Angewandte Forschung), por Dietmar Zettel, em seu trabalho de mestrado, com a ajuda do autor desse trabalho, Daniel Sampaio, entre 2002 e 2004. A figura 3.3 mostra a tela de créditos da ferramenta de software "TOMAHAWK".

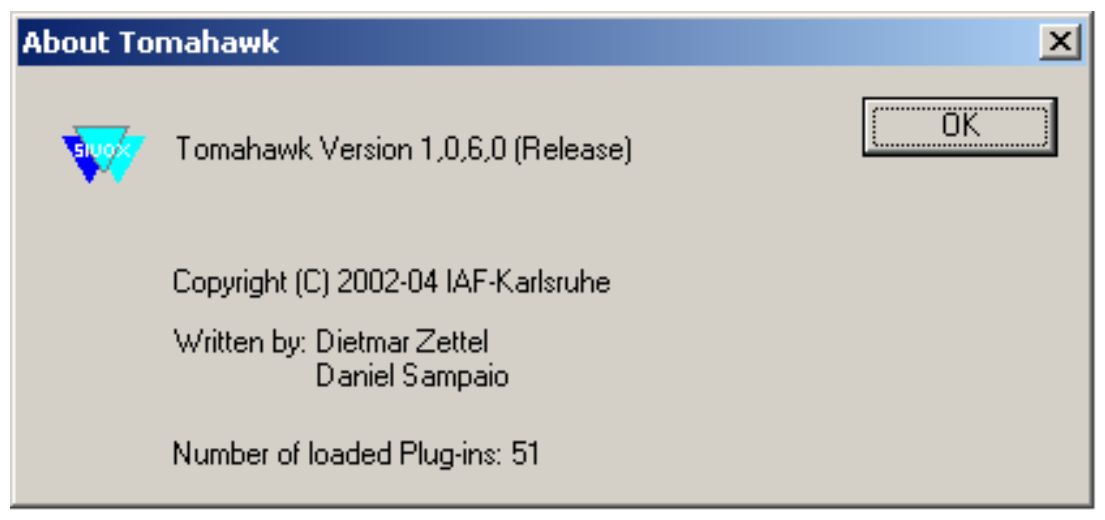

Figura 3.3 - Tela de créditos da ferramenta de software TOMAHAWK

A base dessa ferramenta é uma técnica baseada em plug-ins usando dynamic link library (DLL). Esses plug-ins são módulos fáceis de criar, que permitem o desenvolvimento de algoritmos e que podem ser conectados um ao outro, desde que apresentem compatibilidade de dados, na sequência desejada. Dessa forma, é possível ler um conjunto de dados específico, processar esses dados de acordo com as necessidades e gerar diferentes tipos de saídas. Todos os plug-ins utilizam a mesma interface definida pelo programa principal e novos plug-ins podem ser criados e facilmente adicionados através da interface padrão. A principal vantagem dessa técnica é que os plug-ins podem ser desenvolvidos de 
forma independente do programa principal. A figura 3.4 mostra um exemplo genérico de encadeamento de plug-ins usando a ferramenta de software "TOMAHAWK".

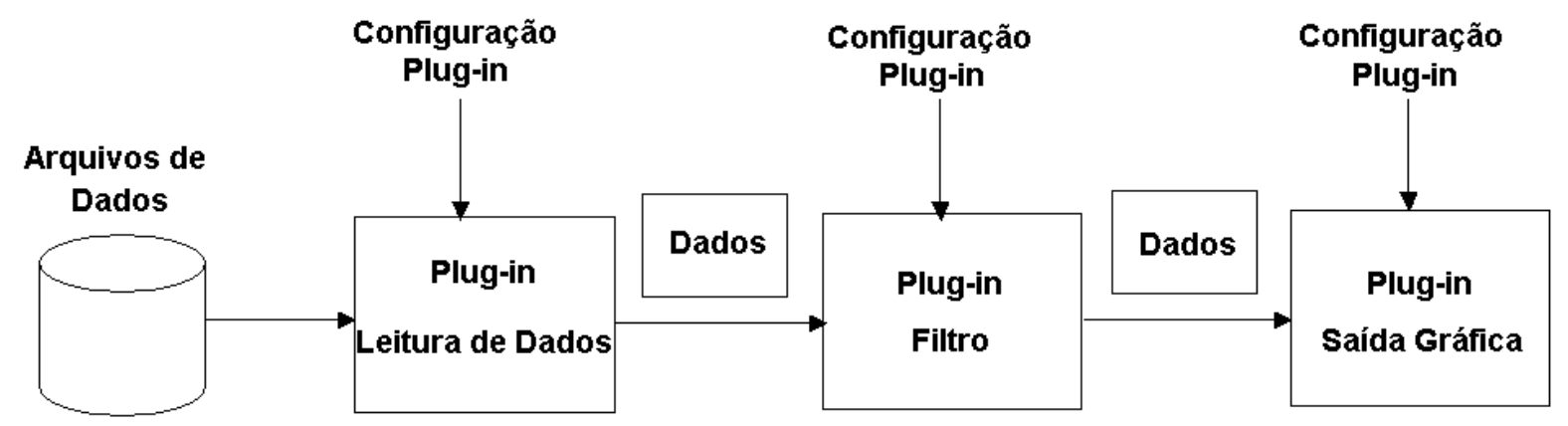

Figura 3.4 - Exemplo de encadeamento de plug-ins na ferramenta TOMAHAWK

Com esta ferramenta, os arquivos de dados armazenados são lidos pelo plug-in "Leitura de Dados", são enviados ao plug-in "Filtro" e são, então, enviados ao plug-in "Saída Gráfica", que mostra finalmente os dados na tela.

\subsection{Medição e Processamento das Grandezas do Processo}

O processo de solda a ponto resistiva consiste em unir em um ponto determinado duas ou mais partes metálicas utilizando como base o calor produzido. Um desenho de uma máquina de solda a ponto resistiva pode ser visto na figura 3.5. Uma alta corrente circula nas partes através dos eletrodos fixados na garra, pinça ou pistola de soldagem, produzindo assim uma grande quantidade de calor no ponto de contato entre as partes metálicas, devido à resistência elétrica. Um poço de material fundido é criado neste local devido a este crescente fluxo de energia térmica. Certa pressão deve ser aplicada aos eletrodos, para evitar a expulsão do material fundido devido à expansão térmica. Após a corrente ser desligada, este material 
fundido se resfria e um ponto sólido de união é produzido, chamado de ponto de solda, lentilha de solda ou botão de solda.

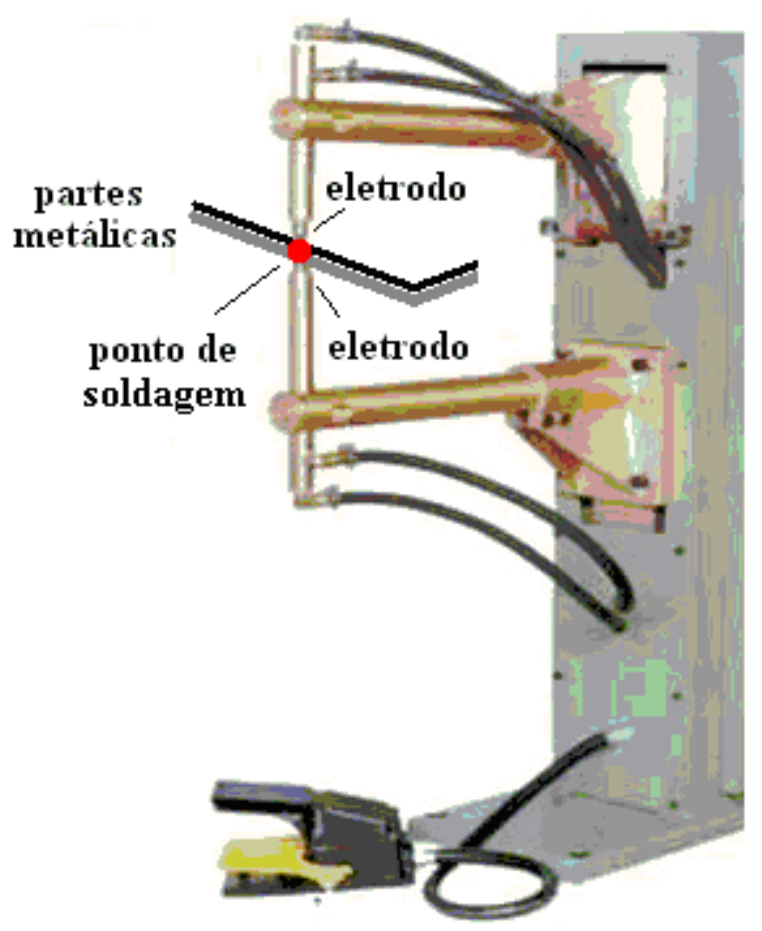

Figura 3.5 - Desenho esquemático de uma máquina de solda a ponto resistiva

Os eletrodos não devem sofrer fusão durante o fluxo de corrente, razão pela qual são usadas técnicas que não deixam que se atinjam suas temperaturas de fusão, sendo necessário, normalmente, fazer circular através deles um fluido refrigerante.

O PSPR é um processo não linear no qual nem as variáveis de estado nem as “condições relevantes do processo" são acessíveis através de medições diretas e para o qual, devido à inexistência de modelos dinâmicos de alta precisão, não se pode construir observadores confiáveis, já que não se consegue determinar e monitorar todas as variáveis que atuam no sistema.

Duas grandezas físicas que são acessíveis e podem ser medidas durante o PSPR são os sinais de tensão e corrente elétricas. De posse desses sinais, é possível extrair para cada ponto 
de solda a resistência elétrica e obter a variação dessa resistência elétrica durante o processo de solda. Assim, a variação da resistência elétrica associada a propriedades físicas do processo é a principal grandeza utilizada neste trabalho e servirá de base para derivar características e estimar outras variáveis do processo, principalmente a qualidade final do ponto de solda.

\subsubsection{Medição da Corrente e Tensão de Soldagem}

Um desenho esquemático para medições de tensão e corrente no PSPR é mostrado na figura 3.6.

O processo de soldagem utiliza normalmente correntes acima de $1 \mathrm{kA}$, as quais podem chegar a mais de 10kA, dependendo dos materiais envolvidos. As tecnologias mais comuns encontradas no mercado atualmente para se medir altas correntes são a resistência shunt, o transformador de corrente, o sensor de efeito Hall e a bobina Rogowski (KOON, 2002).

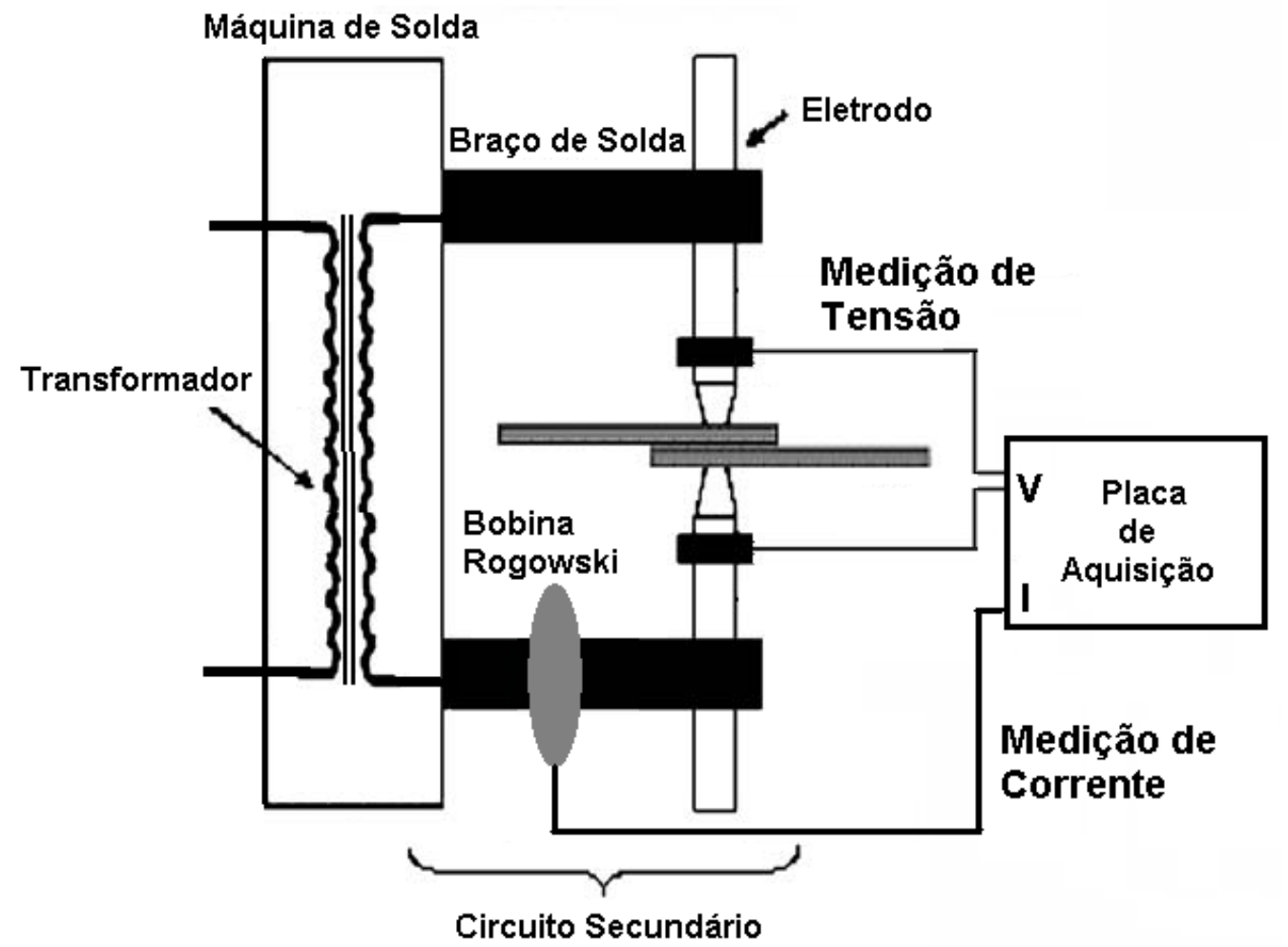

Figura 3.6 - Desenho esquemático das medições de tensão e corrente no PSPR 
A medição de corrente neste trabalho foi realizada utilizando-se uma bobina Rogowski devido às suas características superiores em relação às outras tecnologias (WARD; EXON, 1993). A bobina Rogowski pode ser feita flexível e em forma de cinta aberta, possibilitando sua fixação em torno de um condutor vivo sem causar distúrbios. Ela possui um núcleo de ar, ao invés de um núcleo de ferro, fazendo com que apresente uma baixa indutância e possa responder a altas taxas de variação da corrente a ser medida. Como não tem núcleo de ferro que pode saturar, ela é altamente linear mesmo em altas correntes. Uma bobina Rogowski construída corretamente, com espaçamento simétrico entre seus enrolamentos, é altamente imune à interferência eletromagnética. Além disso, ela tem baixo custo e baixo consumo de energia (RAMBOZ, 1996).

O princípio de funcionamento da bobina Rogowski é baseado na lei de indução de Faraday. De acordo com esta lei, o sinal na saída da bobina Rogowski é um sinal de tensão proporcional à derivada no tempo da corrente medida. Portanto, para se obter um sinal proporcional à corrente medida, o sinal na saída da bobina deve ser integrado. Devido a essa característica, este tipo de sensor não consegue medir correntes contínuas, somente correntes alternadas. A figura 3.7 mostra uma bobina Rogowski usada na medição de corrente.

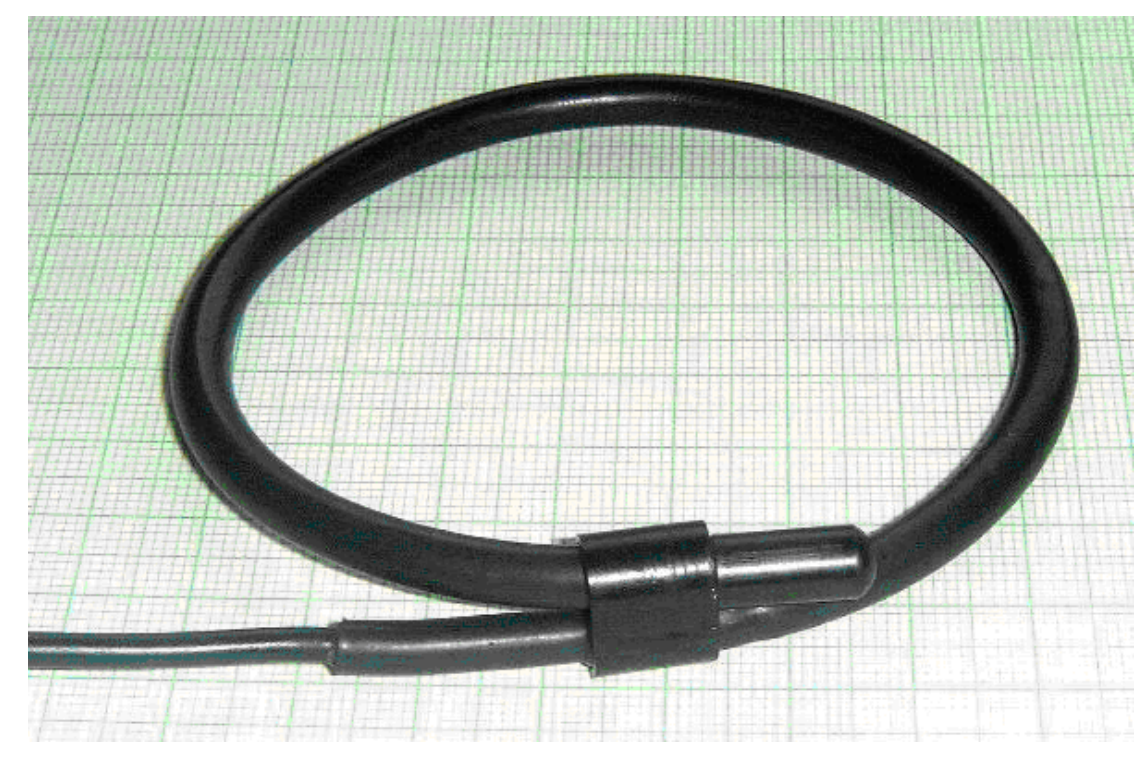

Figura 3.7 - Uma bobina Rogowski usada na medição de corrente 
Inicialmente essa integração necessária foi realizada por software. Mas, com o aumento da frequência básica dos controladores das máquinas de soldagem mais modernas (anteriormente trabalhavam na faixa de $50 / 60 \mathrm{~Hz}$, atualmente trabalham na faixa de alguns $\mathrm{kHz}$ ), as taxas de amostragem das placas de aquisição de dados (normalmente na faixa de $20 \mathrm{kHz}$ a $50 \mathrm{kHz}$ ) deixaram de ser suficientes para se obter uma resolução conveniente para se fazer uma integração digital. Para resolver este problema, atualmente, foram desenvolvidas e são utilizadas placas de aquisição de dados com um integrador analógico disponível em suas entradas, que pode ser ativado conforme a necessidade do usuário. Com isso, essa integração necessária no sinal recebido da bobina Rogowski passou a ser feita por hardware, diretamente pela placa de aquisição de dados, que possui o integrador analógico disponível em suas entradas, e, portanto, o sinal adquirido é automaticamente integrado pela placa de aquisição.

A medição da tensão de soldagem foi feita de forma direta nos eletrodos da máquina de soldagem. Uma das pontas dos dois cabos necessários para medir a tensão foi fixada em cada um dos dois eletrodos da máquina, através de um anel de fixação, e as outras duas pontas foram ligadas diretamente em uma das entradas da placa de aquisição de dados. A figura 3.8 mostra a fixação dos cabos para medição da tensão de soldagem.

A placa de aquisição de dados utilizada foi o modelo PCI M9720008 da empresa Sinus. Possui duas entradas, ambas com a opção de se usar um integrador analógico, e pode medir diretamente sinais de tensão. As duas entradas possuem uma resolução de conversão analógico/digital de 16 bits e dois amplificadores em série, de ganho ajustável, um antes do integrador e outro após o integrador. A frequência de amostragem é ajustável e foi fixada em $25,6 \mathrm{kHz}$ para todos os dados obtidos nesse trabalho. 


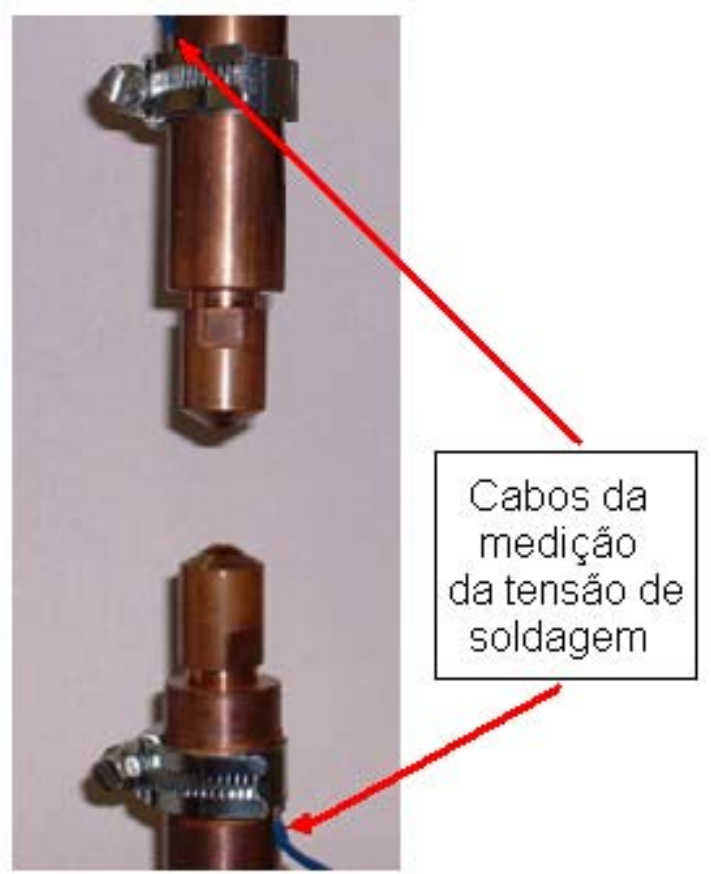

Figura 3.8 - Fixação dos cabos para medição da tensão de soldagem

Foi criado um plug-in para fazer a leitura do arquivo de dados de tensão e corrente obtido durante o processo de soldagem, que foi chamado de "Input BUI" e outro plug-in, para mostrar esses dados em forma de gráfico na tela, que foi chamado de "Curve View". As figuras 3.9 e 3.10 mostram os gráficos dos dados "brutos", isto é, sem nenhum tipo de préprocessamento, da variação de tensão e corrente, respectivamente, obtidas durante o processo de soldagem de um contato elétrico após a execução desses plug-ins.

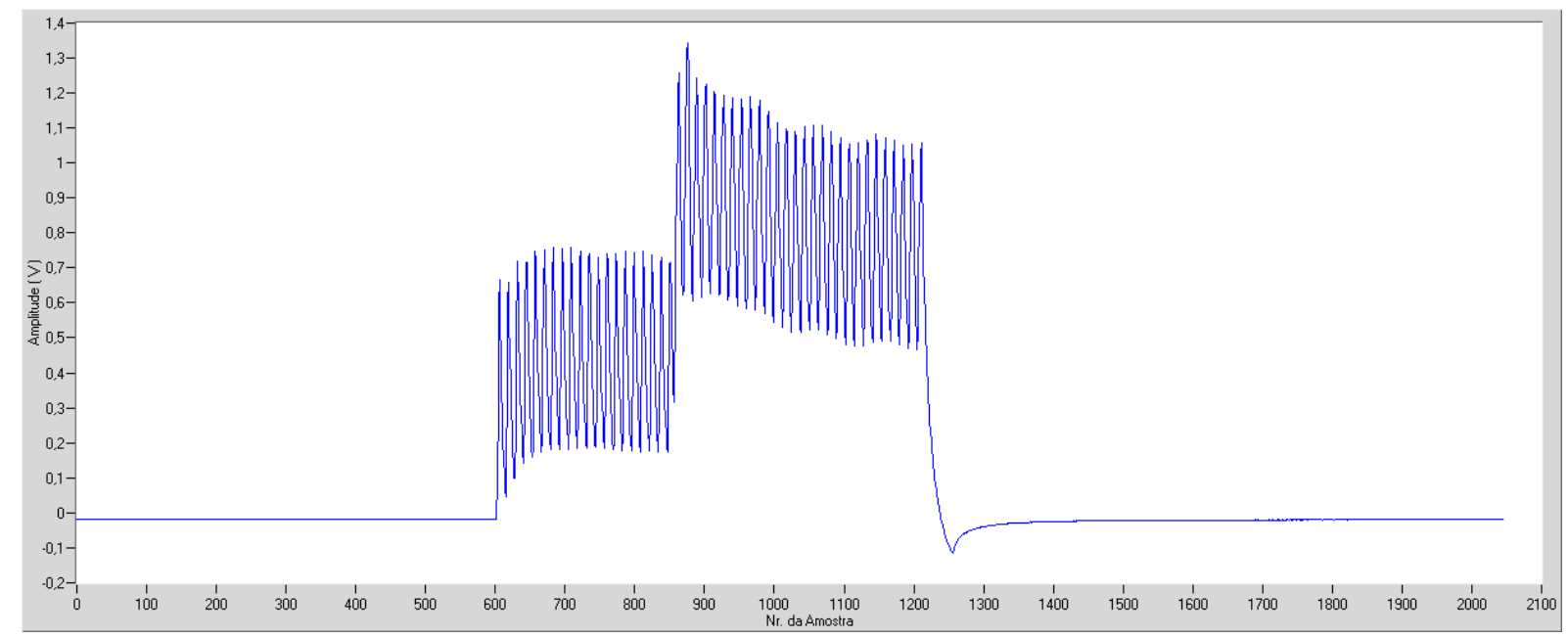

Figura 3.9 - Curva dos dados brutos da variação de tensão durante o PSPR 


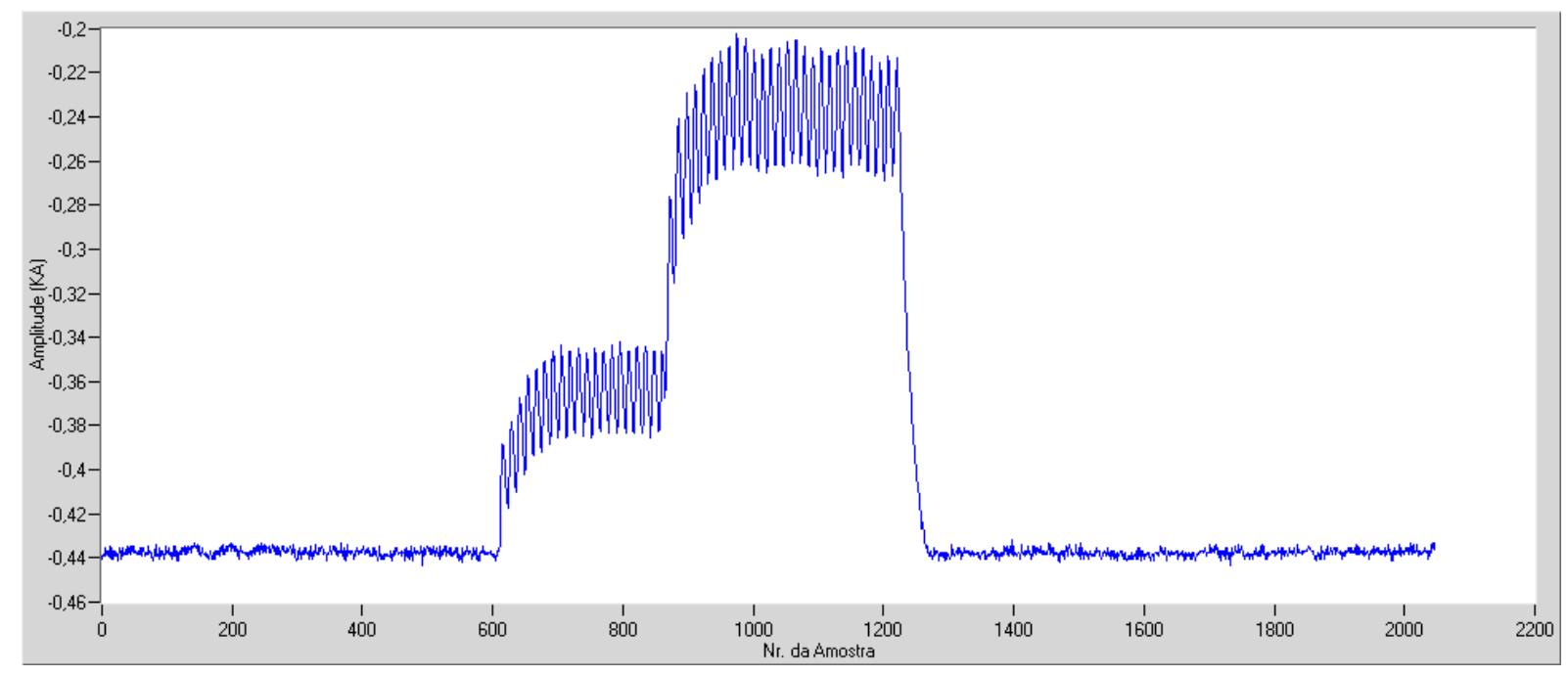

Figura 3.10 - Curva dos dados brutos da variação de corrente durante o PSPR

Analisando o gráfico dos dados brutos da tensão, pode-se verificar que existe um pequeno deslocamento horizontal do gráfico, isto é, no início do gráfico, quando há ausência de sinal, ele deveria apresentar o valor zero, mas apresenta um pequeno valor negativo devido a um pequeno offset gerado pela placa de aquisição de dados, o qual deve ser corrigido. Verifica-se também que antes do início efetivo da solda e após o seu término, existem dados desnecessários, que, por não apresentarem informação do processo, não necessitam ser salvos. Surge então e necessidade de eliminá-los de forma a reduzir o tamanho do arquivo e consequentemente o espaço físico necessário para armazená-lo, sem prejuízo aos dados que realmente carregam as informações do processo.

Com relação aos dados brutos de corrente, pode-se verificar que também existe a necessidade de se corrigir um determinado offset horizontal gerado pela placa de aquisição de dados e eliminar os dados desnecessários. Além disso, existe a necessidade de se corrigir o fator de proporcionalidade da bobina Rogowski utilizada, que é de 20 vezes, ou seja, os valores medidos devem ser multiplicados por 20. Foi detectado através de testes com valores constantes de corrente aplicados à placa de aquisição de dados, que a mesma também 
apresenta um pequeno erro causado pelo integrador analógico usado para integrar o sinal de corrente, que foi determinado como sendo de $9.1 * 10^{-6} \mathrm{kA} /$ amostra, que deve ser corrigido.

De posse dessas observações e desses dados, foram desenvolvidos alguns plug-ins. Um primeiro para efetuar as correções necessárias nos dados brutos de tensão, chamado de "Volt offset corection". O segundo para fazer as correções necessárias nos dados brutos de corrente, chamado de "CurrentManipulation". Foi criado também um terceiro plug-in para eliminar os dados desnecessários de ambas as curvas, que foi chamado de "Cut Curve (Begin End)".

Como já comentado, os plug-ins são conectados um após o outro, formando um encadeamento de tarefas. Este sequenciamento de plug-ins é chamado na ferramenta TOMAHAWK de Work list. Foi então criada e executada a Work list mostrada na figura 3.11.

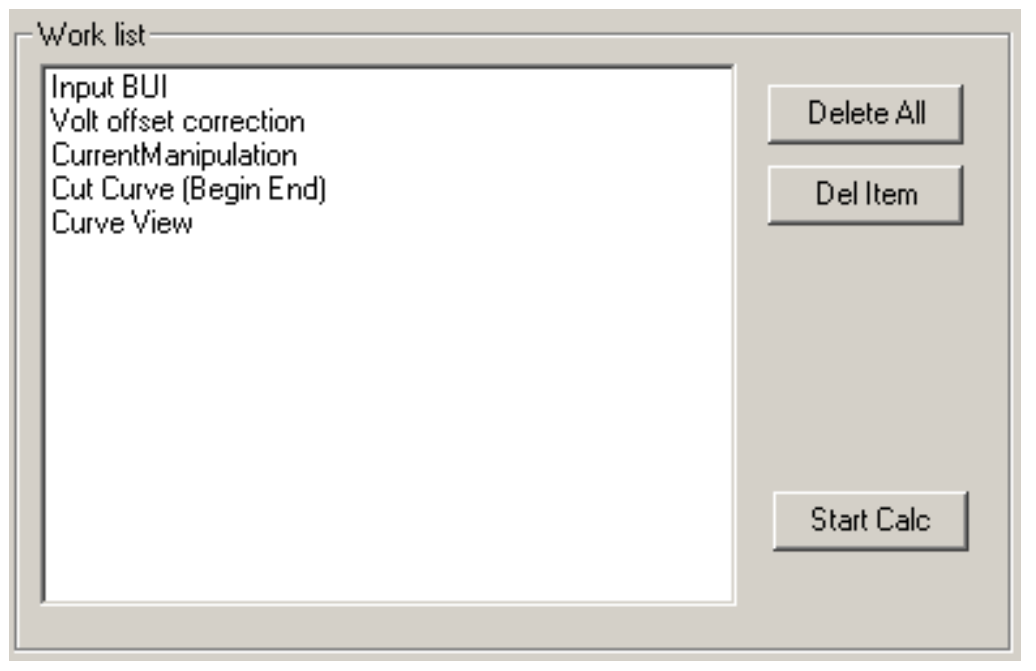

Figura 3.11- Work list para pré-processamento dos dados de tensão e corrente

Inicialmente os dados do processo são lidos pelo plug-in "Input BUI"; então os dados da tensão de soldagem são corrigidos pelo plug-in "Volt offset correction"; depois os dados da corrente de soldagem são corrigidos pelo plug-in "CurrentManipulation"; estes dados passam então pelo plug-in "Cut Curve (Begin End)" que elimina os dados desnecessários e 
finalmente o plug-in "Curve View” é executado, mostrando esses dados em forma de gráfico em uma tela. Os resultados obtidos após a execução desse Work list são mostrados nas figuras 3.12 e 3.13 para a curva de tensão e corrente, respectivamente.

A figura 3.14 mostra simultaneamente as duas curvas e pode-se notar que existe uma defasagem entre os sinais de tensão e corrente, o que é esperado, devido à indutância presente no circuito secundário do processo de soldagem. Como será abordada no próximo item, essa componente indutiva não é desejada e necessita ser suprimida.

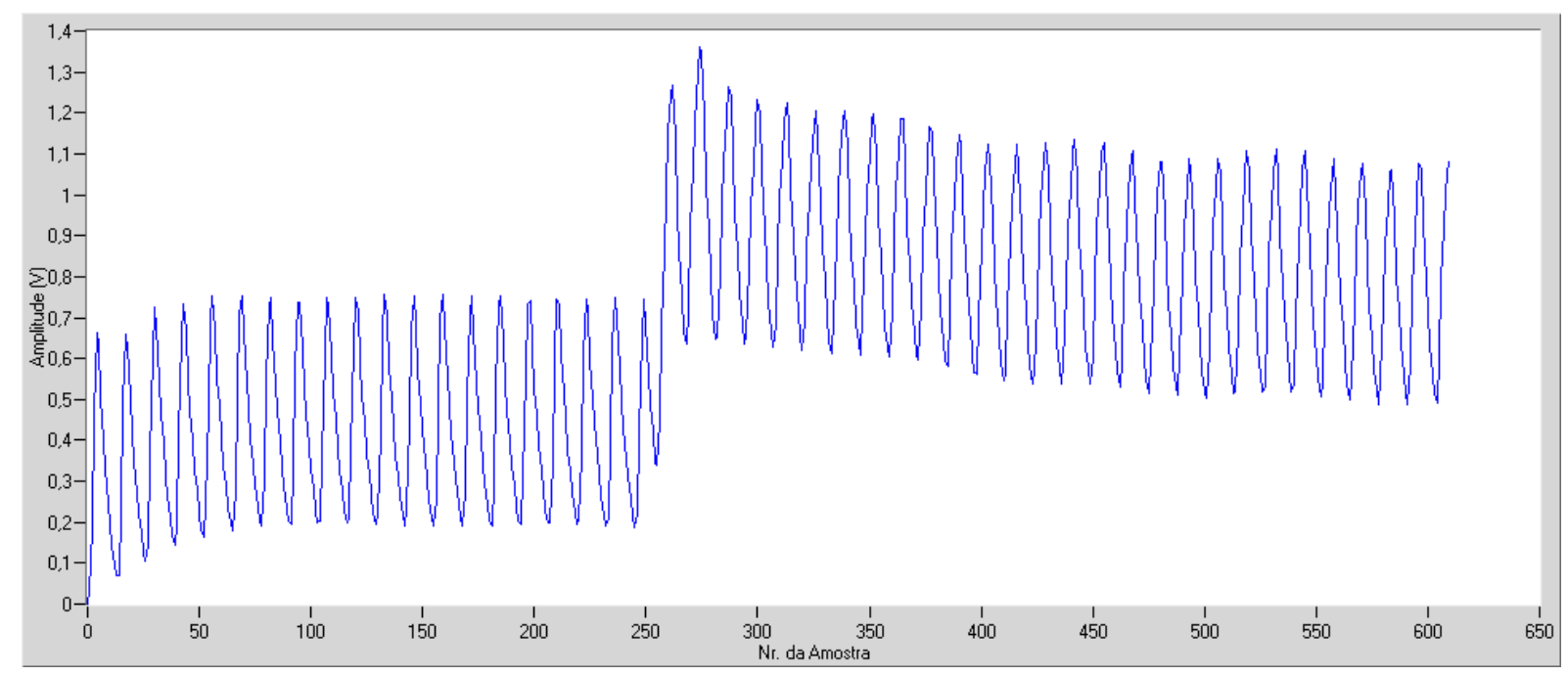

Figura 3.12 - Curva da variação de tensão durante o PSPR após correções

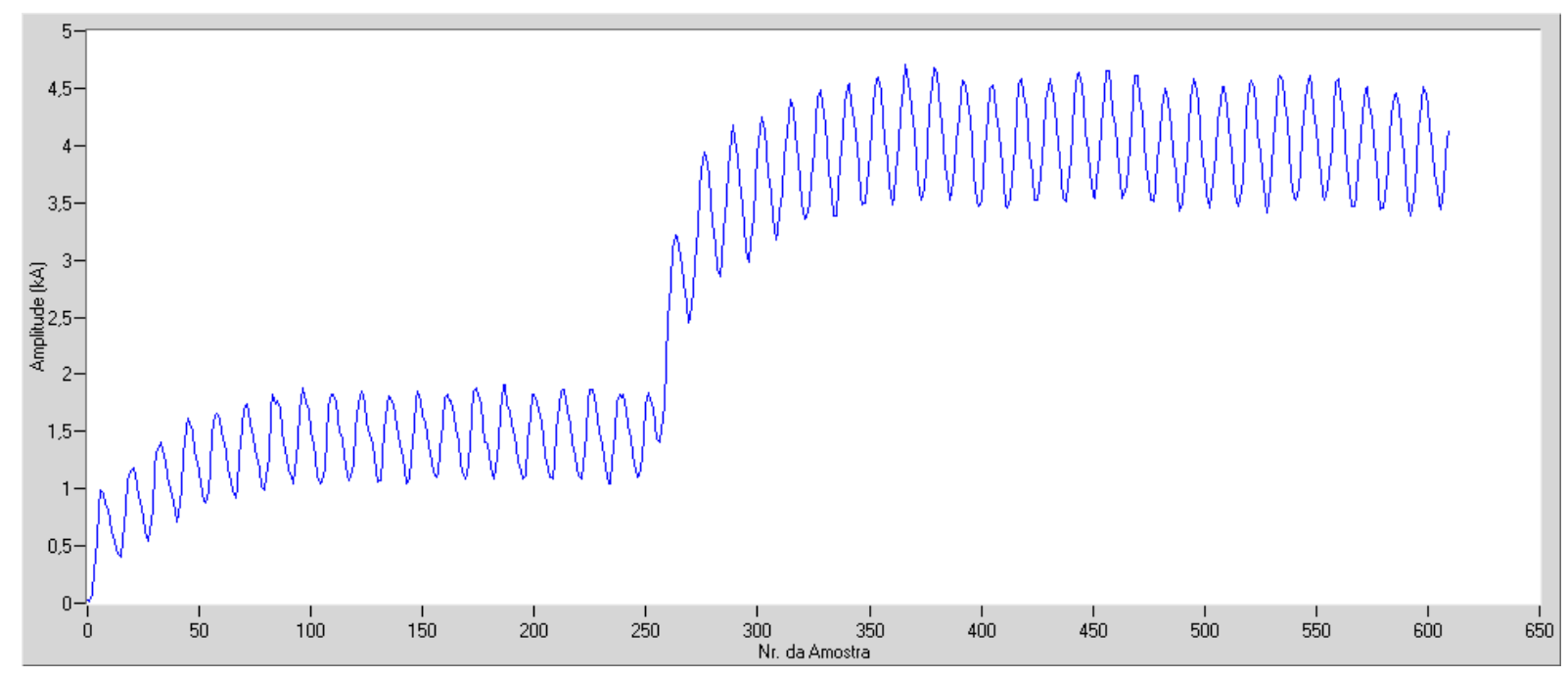

Figura 3.13 - Curva da variação de corrente durante o PSPR após correções 


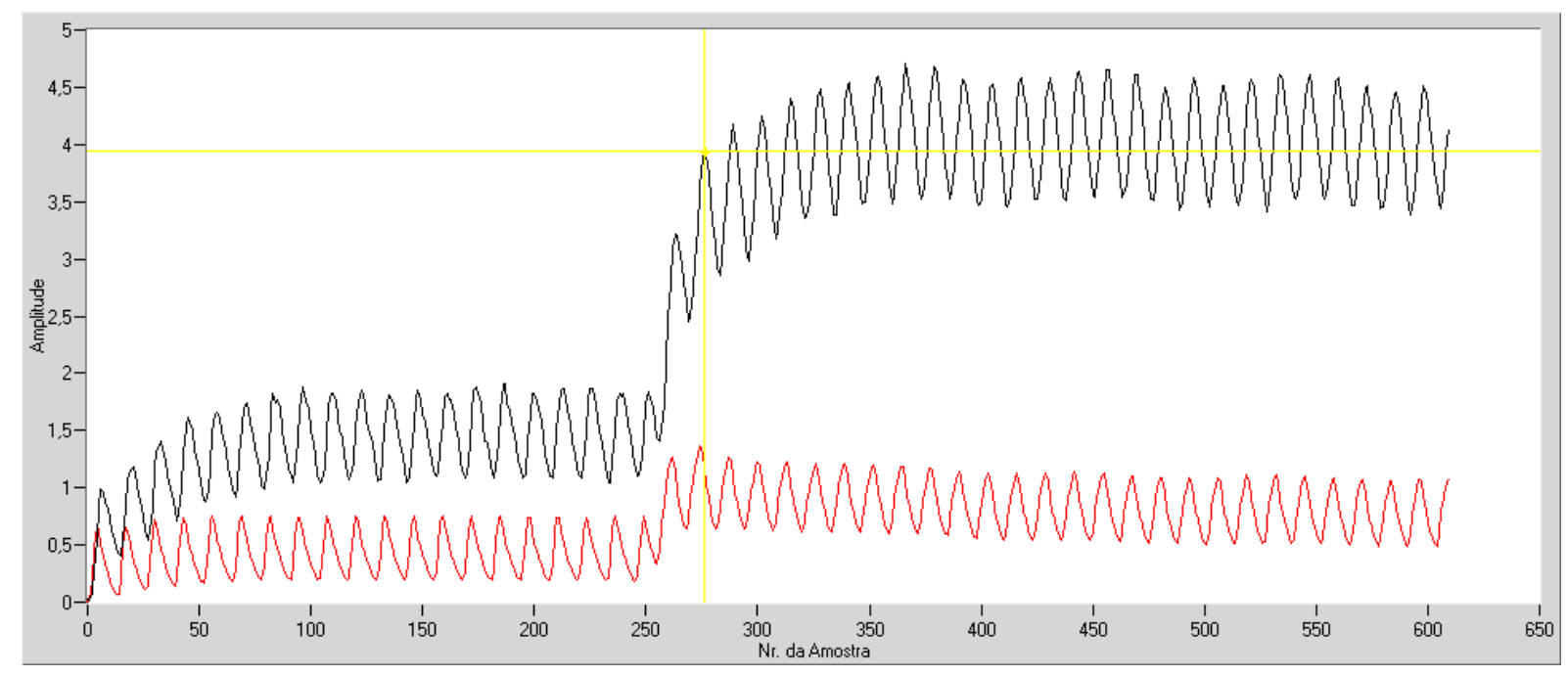

Figura 3.14 - Defasagem entre as curvas de tensão (V) (vermelho) e corrente (kA) (preto)

\subsubsection{Obtenção da Curva da Resistência Elétrica Dinâmica}

Como dito anteriormente, não é possível medir diretamente a curva de variação da resistência elétrica durante o processo de soldagem. Ela é obtida de forma indireta, medindose as curvas de tensão e corrente.

Caso a curva de tensão seja dividida ponto a ponto pela curva de corrente, a curva de resistência resultante inclui tanto as componentes resistivas quanto as componentes indutivas do circuito secundário do PSPR. Deseja-se somente a curva que represente as componentes resistivas do circuito, chamada na literatura de curva de resistência dinâmica do PSPR. Para isso, as componentes indutivas devem ser suprimidas.

Existem na literatura dois métodos principais para suprimir a componente indutiva da curva de resistência (GARZA; DAS, 2001). O método escolhido neste trabalho é o dos picos da curva de corrente. Este método, além de suprimir as componentes indutivas, também realiza uma compressão nos dados, já que cada semi-ciclo é representado por apenas um dado. Este método se baseia no fato da tensão devido à componente indutiva poder ser calculada pela equação 3.1, característica de um indutor: 


$$
V_{L}=L \frac{d i}{d t}
$$

onde: $V_{L}=$ tensão da componente indutiva;

$L=$ indutância equivalente total;

$d i / d t=$ derivada da corrente no tempo.

Sabendo-se que a derivada da corrente nos picos da curva de corrente é zero, temos nestes instantes, na curva de tensão, somente a tensão devido à parte resistiva do circuito, ou seja, dividindo-se a tensão instantânea pela corrente instantânea somente nos instantes de pico da corrente, eliminam-se da curva de resistência os efeitos indutivos. Vale lembrar que dessa maneira é feita uma grande compressão dos dados já que em cada meio ciclo somente um valor de resistência é tomado. Foi desenvolvido um plug-in para obter-se a curva da variação da resistência elétrica real durante o PSPR, chamado de "Real Resistance". Incluindo este plug-in na Work list mostrada na figura 3.11 após o plug-in "Cut Curve (Begin End)" e executando-se esta nova Work list, obtêm-se a curva da variação da resistência elétrica resultante da produção de um contato elétrico mostrada na figura 3.15.

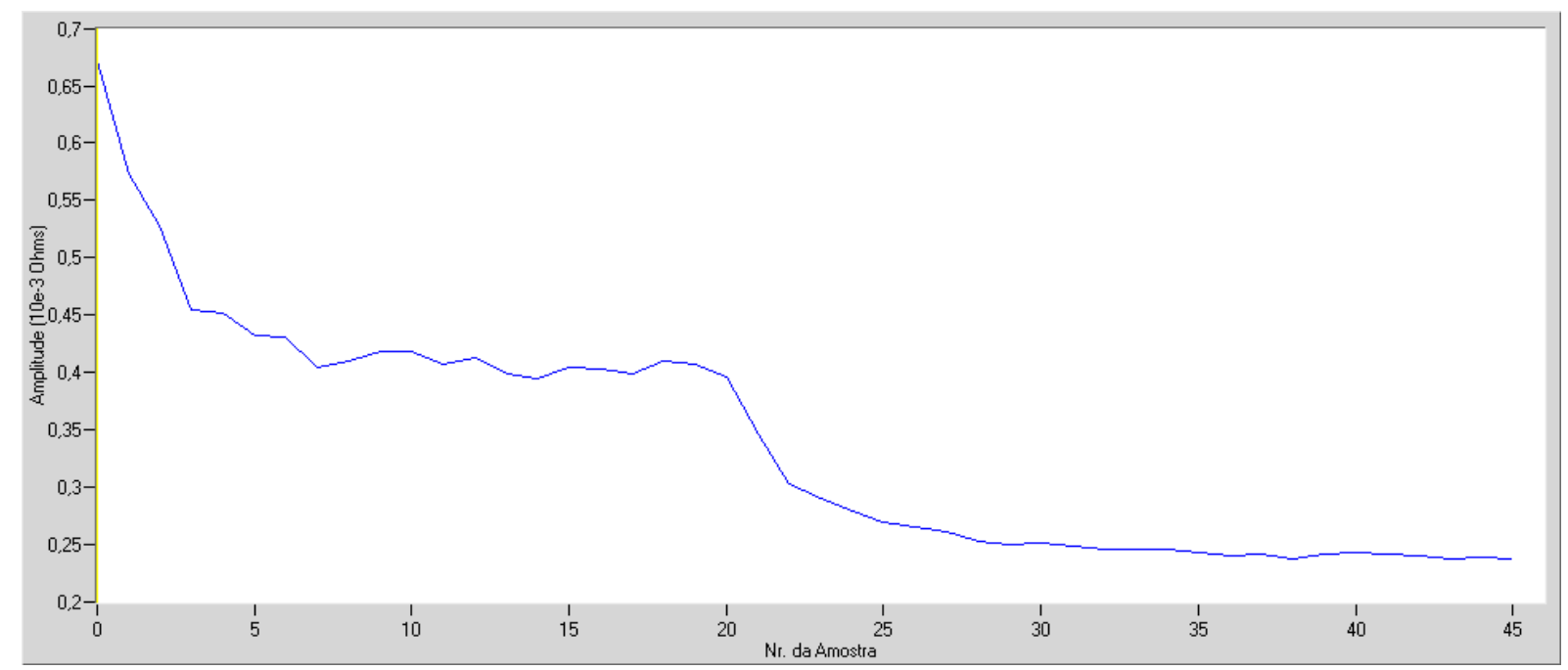

Figura 3.15 - Curva da variação da resistência elétrica durante a produção de um contato elétrico 


\subsection{Modelo Matemático Parametrizável do Processo}

O modelo matemático parametrizável é a base do sistema proposto neste trabalho. Ele não é criado com a intenção de ser usado para fins de simulação e nem abordar todos os detalhes do processo. Ele é criado para descrever as propriedades físicas fundamentais da grandeza observada do processo em estudo, no caso da solda a ponto resistiva, ou seja, descrever os princípios físicos fundamentais das variações da resistência elétrica durante o PSPR.

Foi criado então um modelo para descrever as variações da resistência elétrica do PSPR chamado de modelo V1. O modelo V1 tem como foco o processo de solda a ponto da produção de contatos elétricos e considera a temperatura igual em todos os pontos do processo devido à espessura não expressiva das partes soldadas.

Sendo a resistência elétrica a grandeza em estudo, determinaremos a resistência elétrica $(R)$ do sistema em estudo como a combinação das resistências de contato entre as partes, da resistência dos materiais a serem soldados e a resistência dos eletrodos, afetadas por leis e propriedades físicas definidas. Desta forma, as variações em $R$ seguirão estas propriedades e leis, sendo invariantes com relação à estratégia de controle usada na máquina de soldagem. Um desenho esquemático do arranjo do PSPR usado para definir o modelo V1 de $R$ é mostrado na figura 3.16 .

Assumindo a simetria do arranjo, $R(t)$ é definida pela equação 3.2 como:

$$
R(t)=2 \cdot R_{B}(t)+R_{C}(t)+2 \cdot R_{E L M}(t)
$$

A resistência elétrica $R$ é a soma da resistência elétrica do material bruto $\left(R_{B}\right)$ com a da interface entre os materiais (resistência de contato $R_{C}$ ) e com a resistência elétrica da interface entre o material e o eletrodo somada com a do próprio eletrodo $\left(R_{E L M}\right)$. Cada um desses parâmetros será considerado e discutido individualmente. 


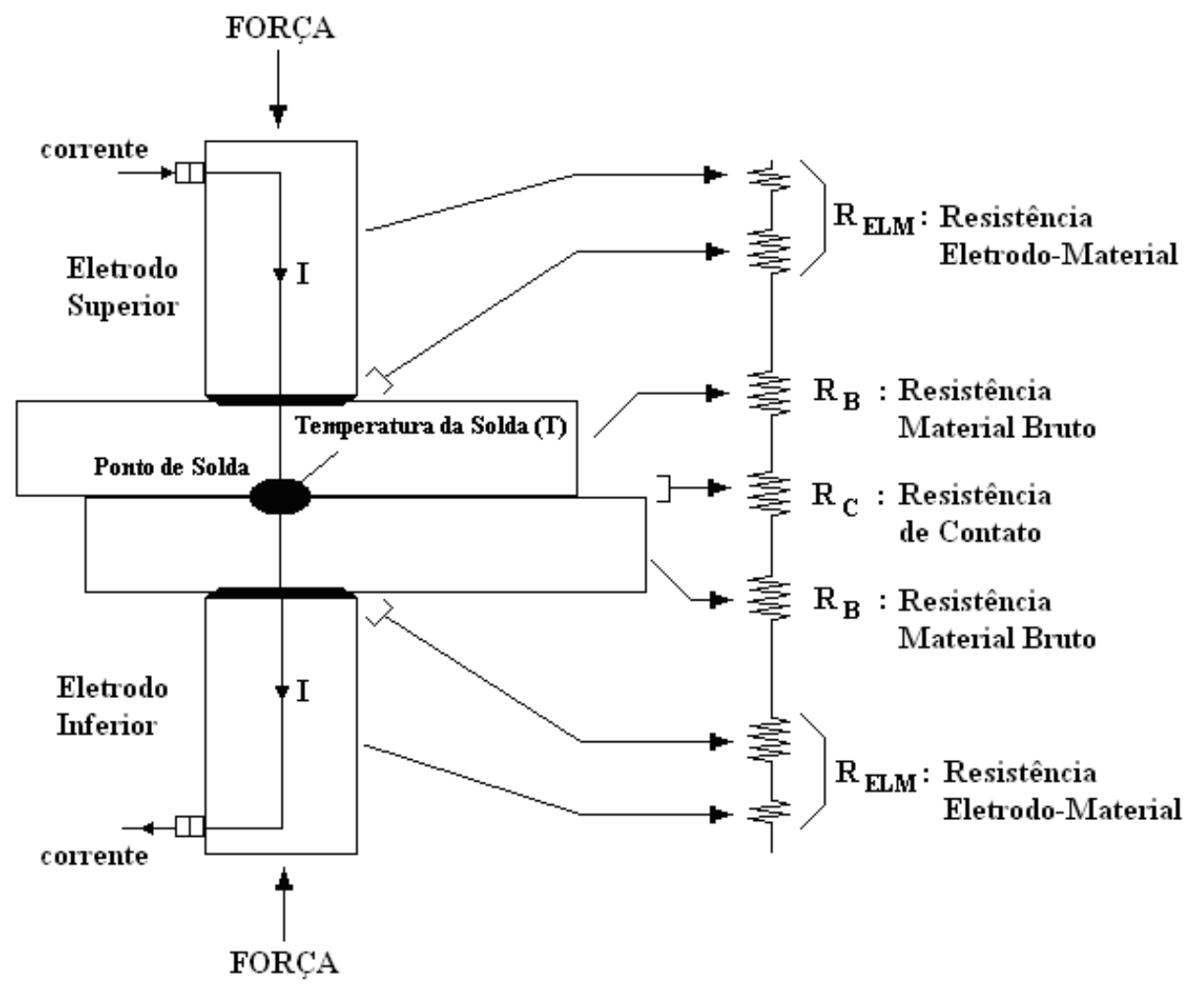

Figura 3.16 - Desenho esquemático do arranjo do PSPR

Uma importante informação no PSPR é o calor produzido. Este calor causa o aumento da temperatura que é a base do PSPR. A resistência elétrica é diretamente dependente da temperatura e este será o primeiro parâmetro a ser definido.

O calor produzido pela corrente circulante $I$ e a reestruturação dos materiais tem um efeito na temperatura do sistema que será modelado por um comportamento exponencial mostrado na figura 3.17. A temperatura do processo $T$ aumenta aproximando-se assintoticamente da temperatura de fusão. Os principais fatores que influenciam na variação da temperatura $T$ são os materiais a serem soldados, a intensidade da corrente circulante e a força aplicada no sistema.

É assumido neste modelo V1 que a temperatura é considerada igual em todo o sistema (materiais muito finos) e que a resistência dos eletrodos é constante. 


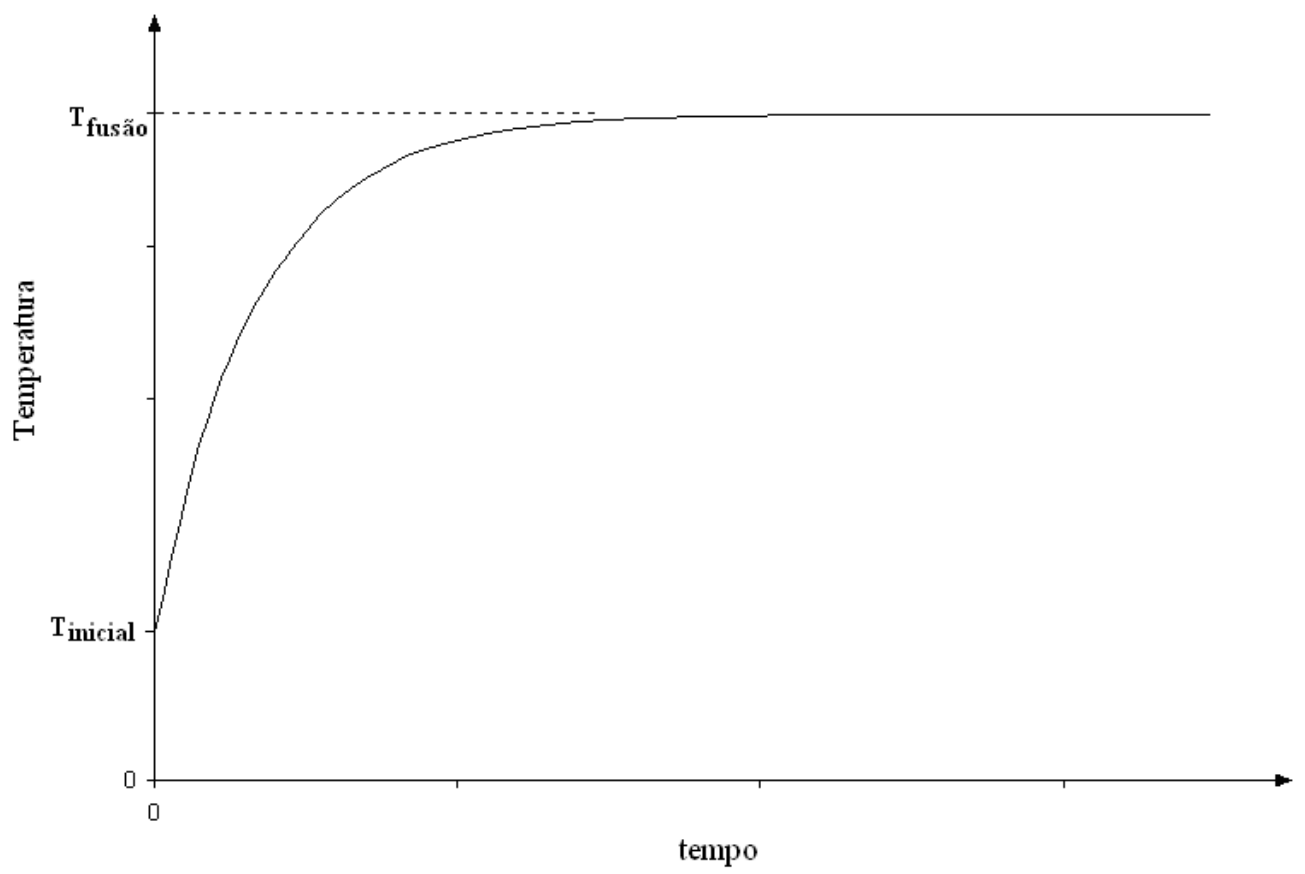

Figura 3.17 - Temperatura $\mathrm{x}$ Tempo

Portanto $T(t)$ pode ser caracterizada pela Eq. 3.3:

$$
T(t)=T_{0}+\left(T_{\text {fusao }}-T_{0}\right) *\left(1-e^{-\left(I(t)^{*} K_{T}^{*} t\right)}\right)
$$

onde:

$T(t)$ : temperatura do processo estimada;

$T_{0}$ : temperatura inicial;

$T_{\text {fusao: }}:$ temperatura de fusão;

$I(t)$ : intensidade da corrente no tempo $t$;

$K_{T}$ : fator de variação da temperatura;

$t$ : tempo atual de soldagem.

A resistência elétrica de um material depende da resistividade elétrica do material ( $\rho)$. A resistividade do material depende da temperatura e consequentemente a resistência elétrica irá igualmente depender da temperatura. Esta dependência está ligada ao coeficiente térmico 
de resistência $(\alpha)$ que é característico para cada material. A área e o comprimento também serão afetados pela temperatura devido à expansão dos materiais, mas seus efeitos na resistência elétrica final podem ser considerados desprezíveis, comparados com aquele causado pela variação da resistividade.

A resistência elétrica do material bruto, $R_{B}(t)$, será caracterizada pela Eq. 3.4:

$$
R_{B}(t)=R_{0 B} *[1+(\alpha * T(t))]
$$

onde:

$R_{B}$ : resistência elétrica do material bruto;

$R_{O B}:$ resistência elétrica inicial do material bruto;

$\alpha$ : coeficiente térmico de resistência;

$T(t)$ : temperatura do processo estimada pela Eq. 3.3.

A resistência do material bruto apresenta no tempo, usando a Eq. 3.4, o comportamento mostrado na figura 3.18.

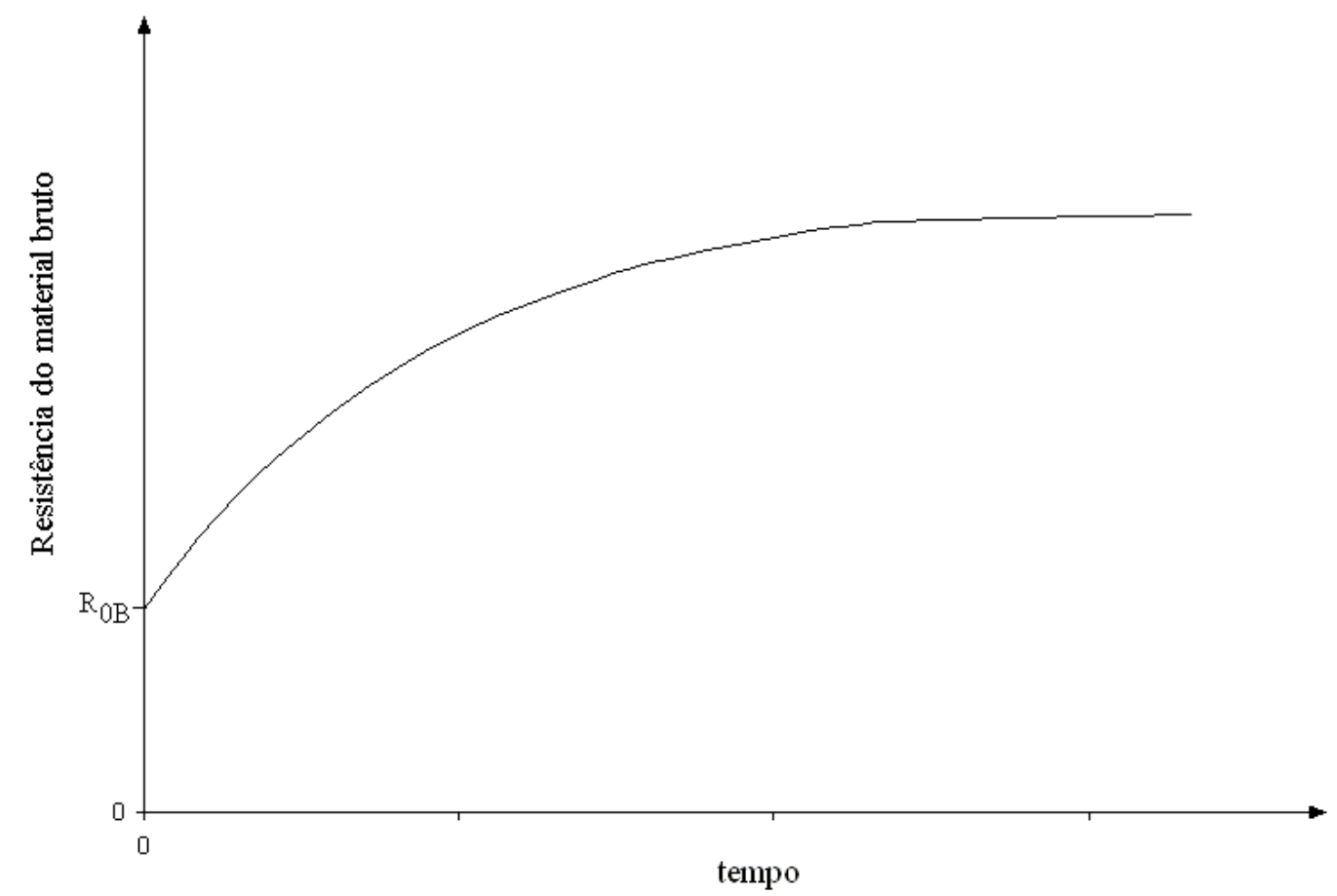

Figura 3.18 - Resistência do material bruto x Tempo 
Outro componente da resistência elétrica do processo em estudo é a resistência elétrica do eletrodo somada à resistência elétrica da interface entre os eletrodos e os materiais que serão consideradas como sendo uma única resistência chamada de $R_{E L M}$.

Em um primeiro momento do PSPR, os eletrodos terão uma determinada área de contato com os materiais a serem soldados. Quando os materiais vão ficando mais moles devido ao aumento da temperatura, os eletrodos se ajustarão melhor a eles e até mesmo poderá haver uma penetração aumentando a área de contato. Desta forma, a resistência entre os eletrodos e os materiais diminuirá, já que a corrente terá uma superfície maior para fluir. Esta penetração está também diretamente relacionada com a força aplicada nos eletrodos.

A parcela de resistência elétrica $R_{E L M}(t)$ pode então ser caracterizada pela Eq. 3.5:

$$
R_{E L M}(t)=R_{0 E L M} * e^{\left[-\left(t /\left(K_{E L M} * T(t)\right)\right)\right]}
$$

onde:

$R_{E L M}$ : resistência elétrica do eletrodo e da interface entre eletrodos e materiais;

$R_{0 E L M}:$ resistência elétrica inicial de $R_{E L M}$

$t$ : tempo atual de soldagem;

$K_{E L M}$ : fator de variação eletrodo-material;

$T(t)$ : temperatura do processo estimada pela Eq. 3.3.

A resistência elétrica do eletrodo e da interface entre eletrodos e materiais apresenta no tempo, usando Eq. 3.5, o comportamento mostrado na figura 3.19.

A resistência elétrica da interface entre os materiais será chamada de resistência de contato $R_{C}$ e é a maior responsável pelo calor produzido e necessária para o êxito do PSPR. No início da soldagem, esta resistência é relativamente alta, comparada com as outras duas discutidas e definidas anteriormente, apresentando uma diminuição ao longo do processo, com o melhor ajuste das superfícies dos materiais sendo soldados, devido ao seu amolecimento. Depois disso, $R_{C}$ continuará a diminuir lentamente até que certo valor de 
estabilidade seja atingido. A explicação para este fato é que o aumento da temperatura fará com que os materiais se tornem mais moles e consequentemente se ajustem melhor um no outro. Esta parcela de resistência é basicamente influenciada pela força aplicada nos eletrodos e ao tipo de superfície dos materiais a serem soldados.

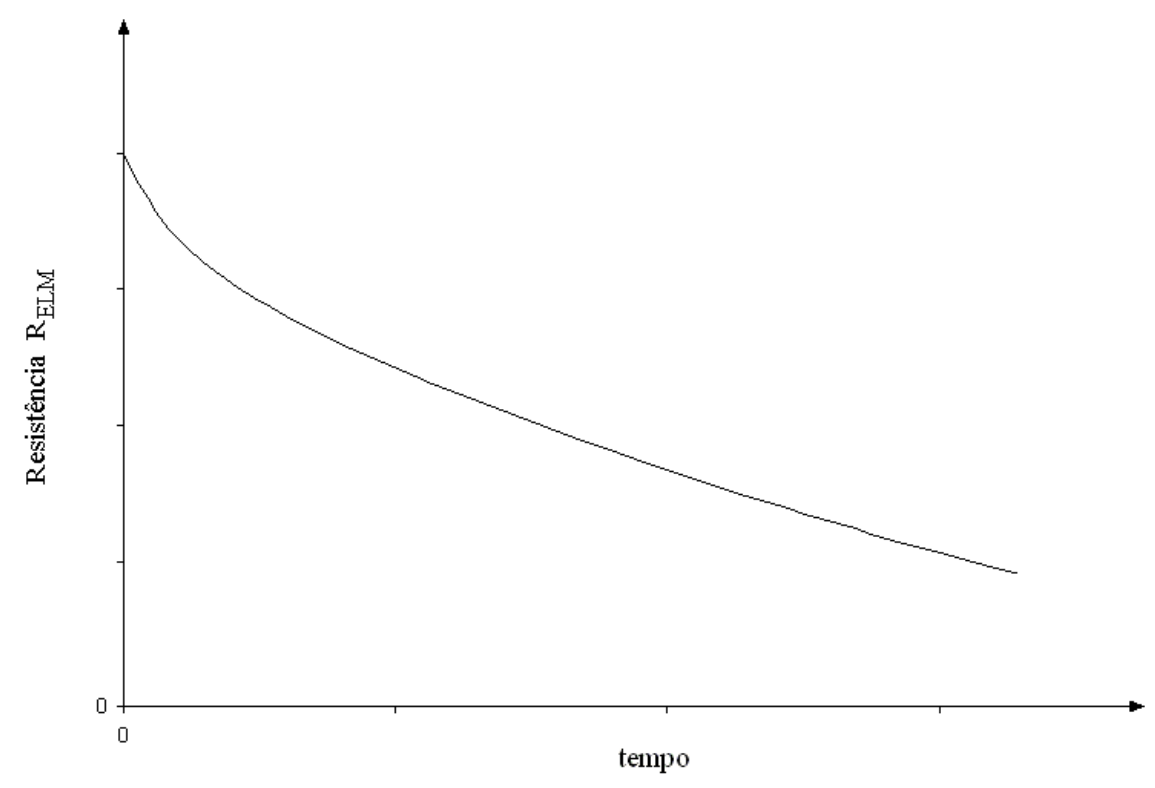

Figura 3.19 - $\mathrm{R}_{\mathrm{ELM}} \mathrm{x}$ Tempo

Depois que a fusão tem início, esta resistência tende a um leve aumento, por ser a resistência nos líquidos normalmente maior que nos sólidos, mas este efeito será desprezado neste modelo.

A resistência elétrica $R_{C}(t)$ será então caracterizada pela Eq. 3.6:

$$
R_{C}(t)=R_{0 C}-\left[\left(R_{0 C} * K_{C-\text { soft }}\right) *\left(1-e^{-t^{*} K_{C} * T(t)}\right)\right]
$$

onde:

$R_{C}$ : resistência elétrica da interface entre os materiais;

$R_{0 C}$ : resistência elétrica inicial de $R_{C}$;

$K_{C \text {-Soft: }}$ fator de amolecimento dos materiais;

$K_{C}$ : fator de variação da resistência de contato.

$R_{C}$ apresenta no tempo, usando a Eq. 3.6, o comportamento mostrado na figura 3.20. 


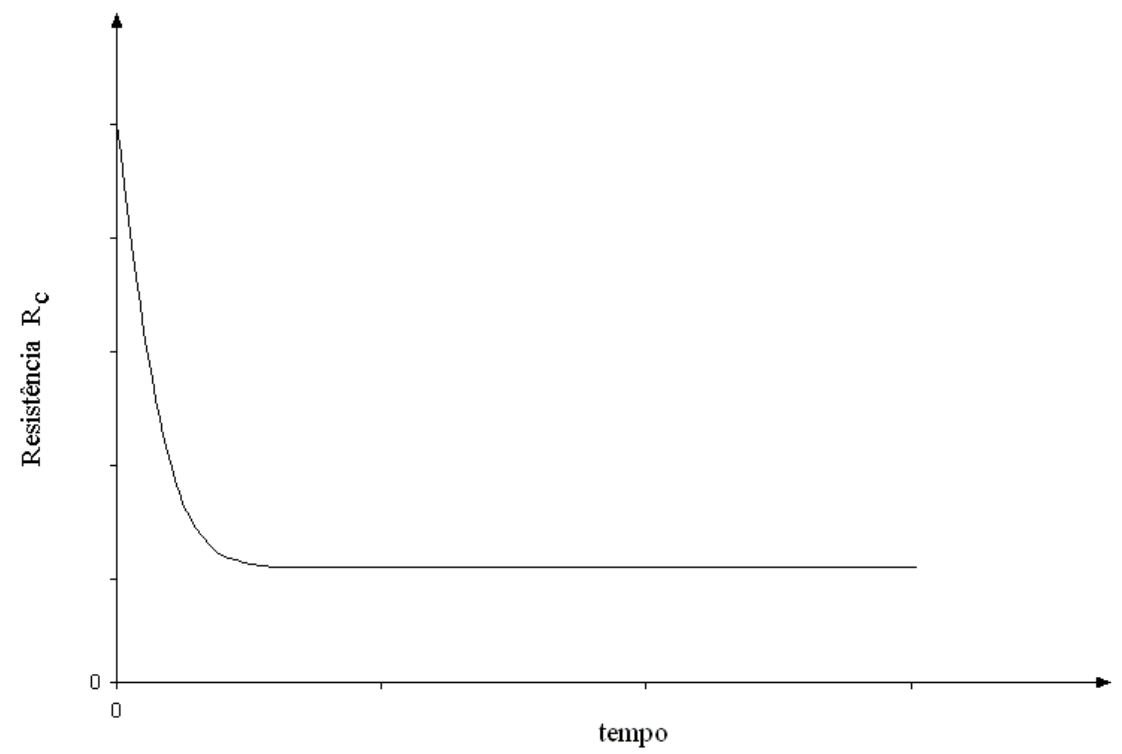

Figura 3.20 - $\mathrm{R}_{\mathrm{C}} \mathrm{x}$ Tempo

Depois que todas as resistências parciais foram definidas, a resistência elétrica do processo em estudo pode ser calculada utilizando a Eq. 3.2. Adotando valores para os parâmetros das equações, uns baseados nas propriedades dos materiais presentes no processo e outros baseados nas características da curva do processo, a curva mostrada na figura 3.21 foi obtida. Esta curva apresenta o mesmo comportamento do chamado "perfil de resistência clássico" que caracteriza uma boa solda de metais (CHO; RHEE, 2004).

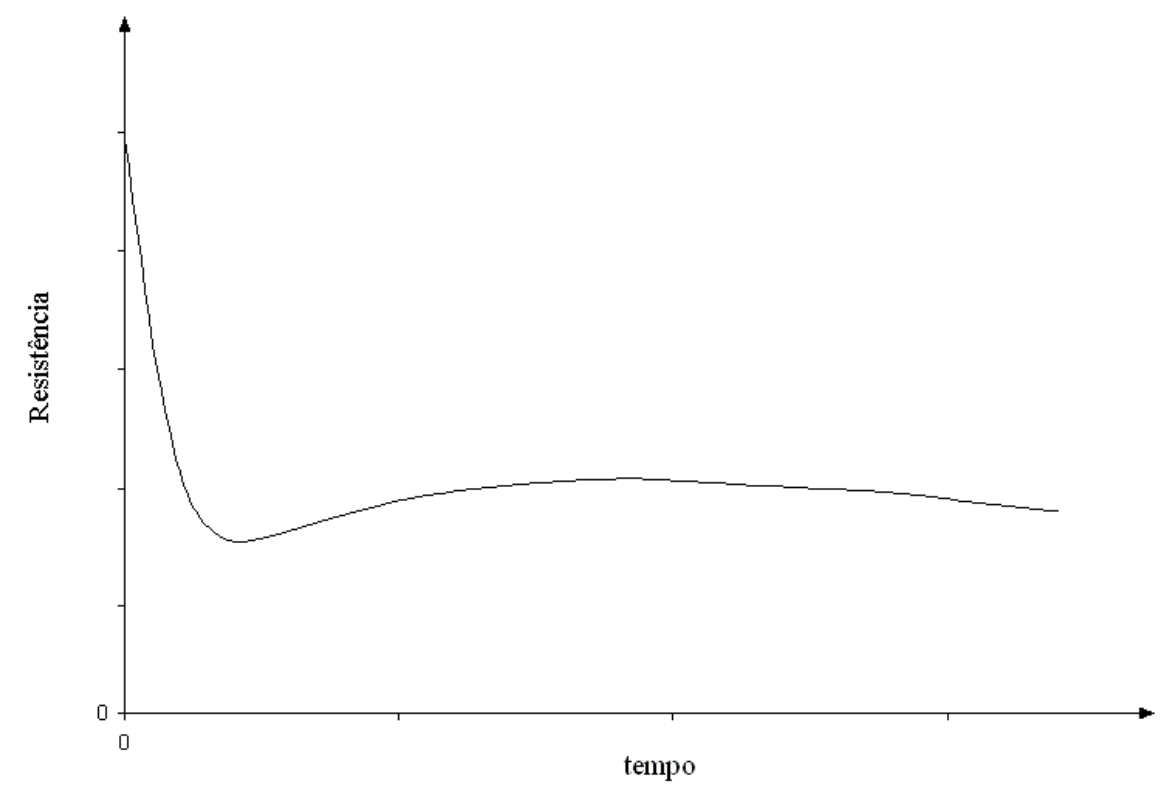

Figura 3.21 - Resistência Elétrica $R$ x Tempo 


\subsection{Ajuste do Modelo não-Linear}

\subsubsection{Aspectos Iniciais}

Diferentemente do ajuste de equações lineares cuja minimização de erro é obtida pela resolução de um sistema linear de equações, o ajuste de equações com dependência não-linear é feito de modo iterativo. Considerando que um modelo depende de forma não-linear de um conjunto de $\mathrm{M}$ parâmetros desconhecidos $\mathrm{a}_{\mathrm{k}}$, com $\mathrm{k}=1,2,3, \ldots, \mathrm{M}$, deve-se obter uma função de mérito de $\chi^{2}$ ("chi-square") e determinar os valores dos parâmetros do modelo que melhor proporcionam um ajuste através da minimização do erro. Dando valores de tentativa aos parâmetros, desenvolve-se um processo que melhora a solução obtida pelos valores desta tentativa. O processo é então repetido até que $\chi^{2}$ pare de diminuir ou sua diminuição seja menor que um pequeno valor pré-definido (PRESS et al., 1992). Suficientemente próximo ao mínimo, espera-se que a função $\chi^{2}$ seja muito próxima a uma função quadrática, podendo ser descrita como:

$$
\chi^{2}(a) \approx \gamma-d \cdot a+\frac{1}{2} a \cdot D \cdot a
$$

onde $d$ é um vetor $M$ e $D$ é uma matriz $M \times M$. Se a aproximação for boa, para se saltar dos parâmetros da tentativa atual $a_{c u r}$ para os parâmetros com uma solução minimizada $a_{\min }$ em um simples laço faz-se:

$$
a_{\min }=a_{\text {cur }}+D^{-1} \cdot\left[-\nabla \chi^{2}\left(a_{\text {cur }}\right)\right]
$$

Por outro lado, a equação 3.7 pode ser uma aproximação a um mínimo local do contorno da função que está sendo minimizada com $a_{\text {cur }}$. Nesse caso, pode-se fazer o gradiente retroceder um degrau, pelo método do declínio do gradiente ("steepest descent method") da forma mostrada na Eq. 3.9. 


$$
a_{\text {next }}=a_{\text {cur }}-\text { constante } \times \nabla \chi^{2}\left(a_{\text {cur }}\right)
$$

onde a constante é pequena o suficiente para não exaurir a direção descendente do contorno.

É necessário também obter a matriz Hessiana $D$, sabendo que a matriz Hessiana de uma função de $n$ variáveis é a matriz quadrada $n X n$ das derivadas parciais de segunda ordem da função. Como a função do modelo que se quer ajustar é conhecida, sabe-se exatamente a forma de $\chi^{2}$ e também da matriz Hessiana. Então se pode utilizar a Eq. 3.8 sempre que necessário. Caso a Eq. 3.8 falhe em melhorar o ajuste, significando que a aproximação usada para se obter a Eq. 3.7 falhou na obtenção de uma melhor aproximação ao mínimo global, deve-se então utilizar a Eq. 3.9, que é mais completa, para se buscar um melhor ajuste (PRESS et al., 1992).

\subsubsection{Gradiente e a Matriz Hessiana}

O modelo a ser ajustado é:

$$
y=y(x ; a)
$$

E a função de mérito $\chi^{2}$ é:

$$
\chi^{2}(a)=\sum_{i=1}^{N}\left[\frac{y_{i}-y\left(x_{i} ; a\right)}{\sigma_{i}}\right]^{2}
$$

O gradiente de $\chi^{2}$ com relação aos parâmetros $a$, que será zero quando $\chi^{2}$ for mínimo, tem componentes:

$$
\frac{\partial^{2} \chi^{2}}{\partial a_{k}}=-2 \sum_{i=1}^{N} \frac{\left[y_{i}-y\left(x_{i} ; a\right)\right]}{\sigma_{i}^{2}} \frac{\partial y\left(x_{i} ; a\right)}{\partial a_{k}} ; k=1,2, \ldots, M
$$

Tomando uma derivada parcial adicional, tem-se:

$$
\frac{\partial \chi^{2}}{\partial a_{k} \partial a_{l}}=2 \sum_{i=1}^{N} \frac{1}{\sigma_{i}^{2}}\left[\frac{\partial y\left(x_{i} ; a\right)}{\partial a_{k}} \frac{\partial y(x ; a)}{\partial a_{l}}-\left[y_{i}-y\left(x_{i} ; a\right)\right] \frac{\partial^{2} y\left(x_{i} ; a\right)}{\partial a_{l} \partial a_{k}}\right]
$$


É convencional remover-se os fatores multiplicativos " 2 ", definindo-se:

$$
\beta_{k} \equiv-\frac{1}{2} \frac{\partial \chi^{2}}{\partial a_{k}} \quad \alpha_{k l} \equiv \frac{1}{2} \frac{\partial^{2} \chi^{2}}{\partial a_{k} \partial a_{l}}
$$

Fazendo $[\alpha]=\frac{1}{2} D$ na Eq. 3.8, essa equação pode ser reescrita como um conjunto de equações lineares:

$$
\sum_{l=1}^{M} \alpha_{k l} \delta a_{l}=\beta_{k}
$$

Esse conjunto é resolvido pelos incrementos $\delta a_{l}$ que, adicionados à aproximação atual, fornecem a próxima aproximação. No contexto de mínimos quadrados, a matriz $[\alpha]$, igual à matriz Hessiana multiplicada por 1/2, é geralmente conhecida como a matriz de curvatura.

A Eq. 3.9, fórmula do declínio do gradiente, pode ser escrita como:

$$
\delta a_{l}=\beta_{l} . \text { constante }
$$

É possível observar que as componentes $\alpha_{k l}$ da matriz Hessiana da Eq. 3.13 dependem tanto da derivada primeira como da derivada segunda das funções básicas com relação aos seus parâmetros. A derivada segunda pode ser desconsiderada. A derivada segunda ocorre porque o gradiente da Eq. 3.12 depende de $\partial y / \partial a_{k}$, então a próxima derivada deverá conter termos envolvendo $\partial^{2} y / \partial a_{l} \partial a_{k}$. O termo de derivada segunda pode ser desconsiderado quando é igual a zero ou pequeno o suficiente quando comparado ao termo envolvendo a derivada primeira. Ele tem também outra possibilidade de ser consideravelmente pequeno na prática que é o termo que multiplica a derivada segunda na Eq. 3.13, $\left[y_{i}-y\left(x_{i} ; a\right)\right]$, para um modelo bem sucedido, deve ser apenas um erro randômico de medida de cada ponto. Esse erro também pode conter sinal, e geralmente não deve ter correlação com o modelo. Portanto, os termos da derivada segunda tendem a se cancelar quando somados com relação a $i$. 
A inclusão dos termos da derivada segunda pode causar instabilidade, se o modelo se ajustar mal ou se o modelo for afetado por "outliers". Sendo assim, será utilizado como definição de $\alpha_{k l}$ a Eq. 3.17.

$$
\alpha_{k l}=\sum_{i=1}^{N} \frac{1}{\sigma_{i}^{2}}\left[\frac{\partial y\left(x_{i} ; a\right)}{\partial a_{k}} \frac{\partial y\left(x_{i ; a}\right)}{\partial a_{l}}\right]
$$

Uma menor (ou maior) manipulação de $[\alpha]$ não afeta em como o conjunto final de parâmetros $a$ é alcançado, somente afeta a rota iterativa que é tomada para se chegar lá. A condição quando o $\chi^{2}$ mínimo é atingido, em que $\beta_{k}=0$ para todo $k$, é independente de como $[\alpha]$ é definido (PRESS et al., 1992).

\subsubsection{Algoritmo de Levenberg-Marquardt}

O algoritmo de Levenberg-Marquardt proporciona uma solução numérica para o problema de minimizar uma função não-linear de posse de um conjunto de parâmetros dessa função. É um método relativamente robusto que na maioria dos casos encontra uma solução para o problema, mesmo que os parâmetros iniciais estejam muito longe do mínimo desejado. Mas é considerado um algoritmo algumas vezes lento, em virtude do número de iterações que pode necessitar para atingir uma solução satisfatória.

Marquardt melhorou um método anteriormente sugerido por Levenberg, variando suavemente entre os extremos do método Hessiano inverso (Eq. 3.15) e do método do declínio do gradiente (Eq. 3.16). Este último método é usado quando se está longe do mínimo, alternando continuamente para o primeiro método, à medida que vai-se aproximando do mínimo. Este método de Levenberg-Marquardt funciona muito bem na prática e se tornou o padrão para rotinas de mínimos quadrados não-lineares (PRESS et al., 1992). 
O método de Levenberg-Marquardt é baseado em duas elementares, mas importantes, percepções. Considerando a "constante" da Eq. 3.16, não há informação no gradiente sobre sua magnitude ou escala. O gradiente indica apenas a inclinação mas não o quanto esta se estende. A primeira percepção de Marquardt é de que as componentes da matriz Hessiana, mesmo que não seja de forma precisa, oferecem alguma informação sobre a escala da ordem de magnitude do problema (PRESS et al., 1992). A variável $\chi^{2}$ é adimensional, ou seja, é um número puro, o que é evidente a partir de sua definição na Eq. 3.11. Por outro lado, $\beta_{k}$ tem a dimensão de $1 / a_{k}$, que pode ser dimensional, ou seja, possuir unidades como centímetro quadrado, ou quilowatt-hora, entre outros (cada componente de $\beta_{k}$ pode ter diferentes unidades). A constante de proporcionalidade entre $\beta_{k}$ e $\delta a_{k}$ deve ter, portanto, a dimensão de $a_{k}^{2}$.

Observando as componentes de $[\alpha]$, é possível verificar que há apenas uma variável com essas dimensões, que é $1 / \alpha_{k k}$, o elemento correspondente na diagonal principal. Esta deve ser portanto a escala da "constante", mas como esta pode ser muito grande, divide-se a constante por um fator adimensional $\lambda$, em que $\lambda>>1$, para reduzir o degrau. Em outras palavras, substitui-se a Eq. 3.16 por:

$$
\delta a_{l}=\frac{1}{\lambda \alpha_{l l}} \beta_{l} \text { ou } \lambda \alpha_{l l} \delta a_{l}=\beta_{l}
$$

É necessário que $a_{l l}$ seja positivo, mas isso é garantido por definição (Eq. 3.17).

A segunda percepção de Marquardt é que a Eq. 3.18 e a Eq. 3.15 podem ser combinadas, se for definida uma nova matriz $\alpha^{\prime}$ com as seguintes descrições:

$$
\alpha_{j j}^{\prime} \equiv \alpha_{j j}(1+\lambda)
$$




$$
\alpha_{j k}^{\prime} \equiv \alpha_{j k} \quad(j \neq k)
$$

Utilizando $\alpha^{\prime}$ e combinando a Eq. 3.18 com a Eq. 3.15, obtem-se a Eq. 3.20:

$$
\sum_{l=1}^{M} \alpha_{k l}^{\prime} \delta a_{l}=\beta_{k}
$$

Quando $\lambda$ é muito grande, a matriz $\alpha^{\prime}$ é forçada a ser diagonalmente dominante, então a Eq. 3.20 direciona-se para ser idêntica a Eq. 3.18. Por outro lado, se $\lambda$ se aproxima de zero, a Eq. 3.20 direciona-se para ser idêntica a Eq. 3.15 (PRESS et al., 1992).

Atribuindo-se um valor inicial para o conjunto de parâmetros " $a$ " a serem ajustados, Marquardt sugere os seguintes passos:

$1^{\circ}$ passo: Calcular $\chi^{2}(a)$;

$2^{\circ}$ passo: Escolher um valor modesto para $\lambda$, como por exemplo $\lambda=0,001$;

$3^{\circ}$ passo: Resolver a equação linear (3.20) para $\delta a$ e estimar $\chi^{2}(a+\delta a)$;

$4^{\circ}$ passo: Se $\chi^{2}(a+\delta a) \geq \chi^{2}(a)$, multiplicar $\lambda$ por um fator de 10 (ou qualquer outro fator significativo) e voltar para o $3^{\circ}$ passo;

$5^{\circ}$ passo: Se $\chi^{2}(a+\delta a)<\chi^{2}(a)$, dividir $\lambda$ por um fator de 10 e atualizar a possível solução $a \leftarrow a+\delta a$, retornando ao $3^{\circ}$ passo.

Também é necessária uma condição para parar as iterações. Iterar até obter a precisão do processador é geralmente desnecessário, já que o mínimo é na melhor das hipóteses apenas uma estimativa estatística dos parâmetros $a$. Uma mudança nos parâmetros que mudam $\chi^{2}$ de um valor $<<1$ não é significativo estatisticamente; além disso, não é incomum encontrar parâmetros rodeando próximos ao mínimo em um vale de topologia complicada (PRESS et al., 1992). 
Essas considerações sugerem que, na prática, deve-se parar a iteração na primeira ou segunda ocasião em que $\chi^{2}$ decresce de um valor desprezível, digamos menor do que 0,01 ou algum valor da ordem de $10^{-3}$. Não se deve parar, caso após algum passo $\chi^{2}$ cresça; isso apenas indica que $\lambda$ ainda não atingiu um ajuste ótimo.

Uma vez que um mínimo aceitável seja encontrado, deve-se fazer $\lambda=0$ e calcular a matriz da eq. 3.25 que é a matriz de covariância estimada dos padrões de erros dos parâmetros de ajuste " $a$ ".

$$
[C] \equiv[\alpha]^{-1}
$$

\subsubsection{Criação de Plug-in para Ajuste do Modelo}

Foi então criado um plug-in para a ferramenta de software "TOMAHAWK" com a implementação do método de Levenberg-Marquardt e com todos os parâmetros do modelo matemático parametrizável descrito no item 3.5. Este plug-in tem a função de realizar o ajuste da curva gerada pelo modelo com a curva real do processo, através do ajuste dos parâmetros do modelo selecionados como variáveis na tela de configuração desse plug-in, que foi chamado de "Model_CalcVariables". A tela de configuração desse plug-in é mostrada na figura 3.22 .

Como é possível observar na figura 3.22, após selecionar o método de LevenbergMarquardt é necessário configurar outras quatro variáveis. A primeira chamada de "Prec.” é onde se define a condição de precisão mínima de ajuste aceitável para encerrar as iterações. A segunda chamada de "Iter." é onde se define o número máximo de iterações permitido de forma a se evitar que o algoritmo entre em um looping infinito caso não se atinja a precisão 
desejada de ajuste entre as curvas. As variáveis "Mult." e "Div." são os fatores de multiplicação e divisão, respectivamente, usados no $4^{\circ}$ e $5^{\circ}$ passo descritos no item anterior.

Outro item importante da tela de configuração é encontrado no campo "Extras" chamado de "Sample Frequency" que é onde se coloca o valor da frequência de amostragem atual dos dados da curva real que será utilizada como base para o ajuste da curva do modelo.

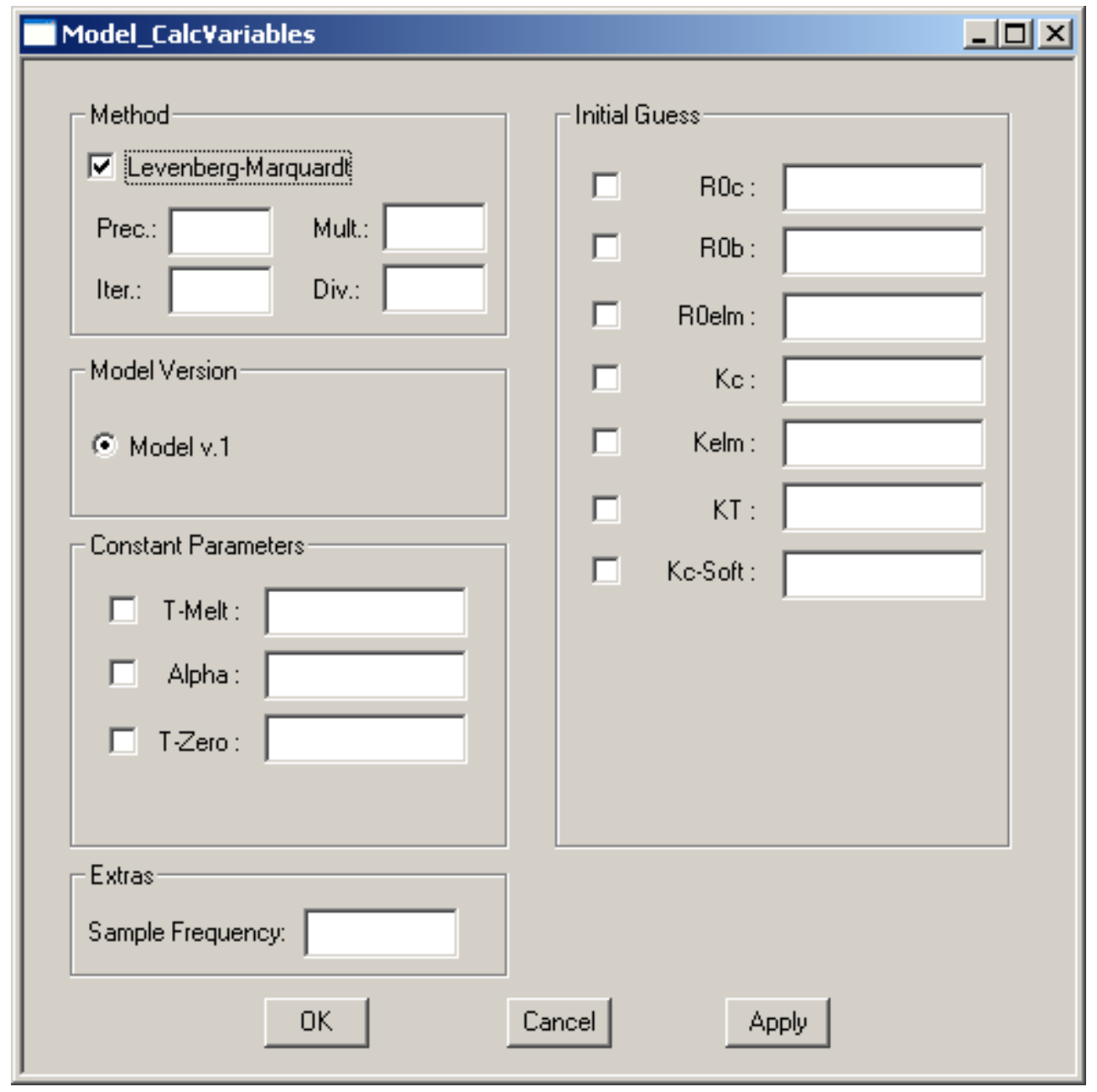

Figura 3.22 - Tela de Configuração do Plug-in "Model_CalcVariables"

Os demais itens da tela são os parâmetros do modelo matemático parametrizável criado que devem ser inicializados antes da execução do plug-in. É possível, através de um quadrado de checagem, selecionar os parâmetros do modelo que podem ter seus valores 
alterados durante o procedimento de ajuste das curvas, ou seja, estes parâmetros serão definidos como parâmetros variáveis. Os parâmetros que não tiverem o quadrado de checagem selecionado terão o valor inicial mantido ao longo do processo de ajuste, ou seja, serão definidos como parâmetros fixos.

\subsection{Estimação da Qualidade Utilizando Redes Neurais}

A utilização de redes neurais torna possível encontrar a relação entre os dados do processo (a variação da corrente e tensão no tempo) e a qualidade do ponto de solda, sem nenhum conhecimento das variáveis que possam afetar o processo durante a soldagem. Diferente de outros métodos, as redes neurais são capazes de aprender através de amostras.

As redes neurais apresentam algumas características que são importantes para a realização deste trabalho. Uma rede neural pode ser projetada para representar funções nãolineares, o que vai ao encontro das necessidades do PSPR. Ela realiza um mapeamento entre entrada e saída através de amostras do processo, modelando um fenômeno não-linear, uma tarefa de difícil execução, visto que as relações entre as variáveis de entrada e saída não são totalmente conhecidas. A rede neural tem a habilidade de aprender com seu ambiente e com isso melhorar seu desempenho através de um processo iterativo de ajustes aplicado nos seus pesos sinápticos. Portanto quanto maior a diversidade de situações apresentadas no treinamento da rede, melhor será seu desempenho, apesar de sua generalização. A generalização em redes neurais pode ser explicada como a capacidade da rede para fornecer respostas coerentes para padrões desconhecidos. O benefício proporcionado pela capacidade de generalização de um modelo neural é considerável, em função da resposta da rede a padrões desconhecidos ou diferentes dos padrões de treinamento. A alta capacidade de 
generalização também proporciona robustez ao modelo quando os dados ou exemplos estão sob o efeito de ruído.

Neste trabalho, serão utilizadas redes neurais artificiais do tipo multicamadas. O algoritmo de back-propagation será utilizado para efetuar o treinamento da rede. No anexo A encontra-se a teoria básica de redes neurais artificiais e do algoritmo de back-propagation.

Portanto, é necessário treinar as redes neurais antes de utilizá-las para estimar a qualidade do processo de solda a ponto resistiva. As figuras 3.23 e 3.24 ilustram o processo de treinamento e aplicação de uma rede neural.

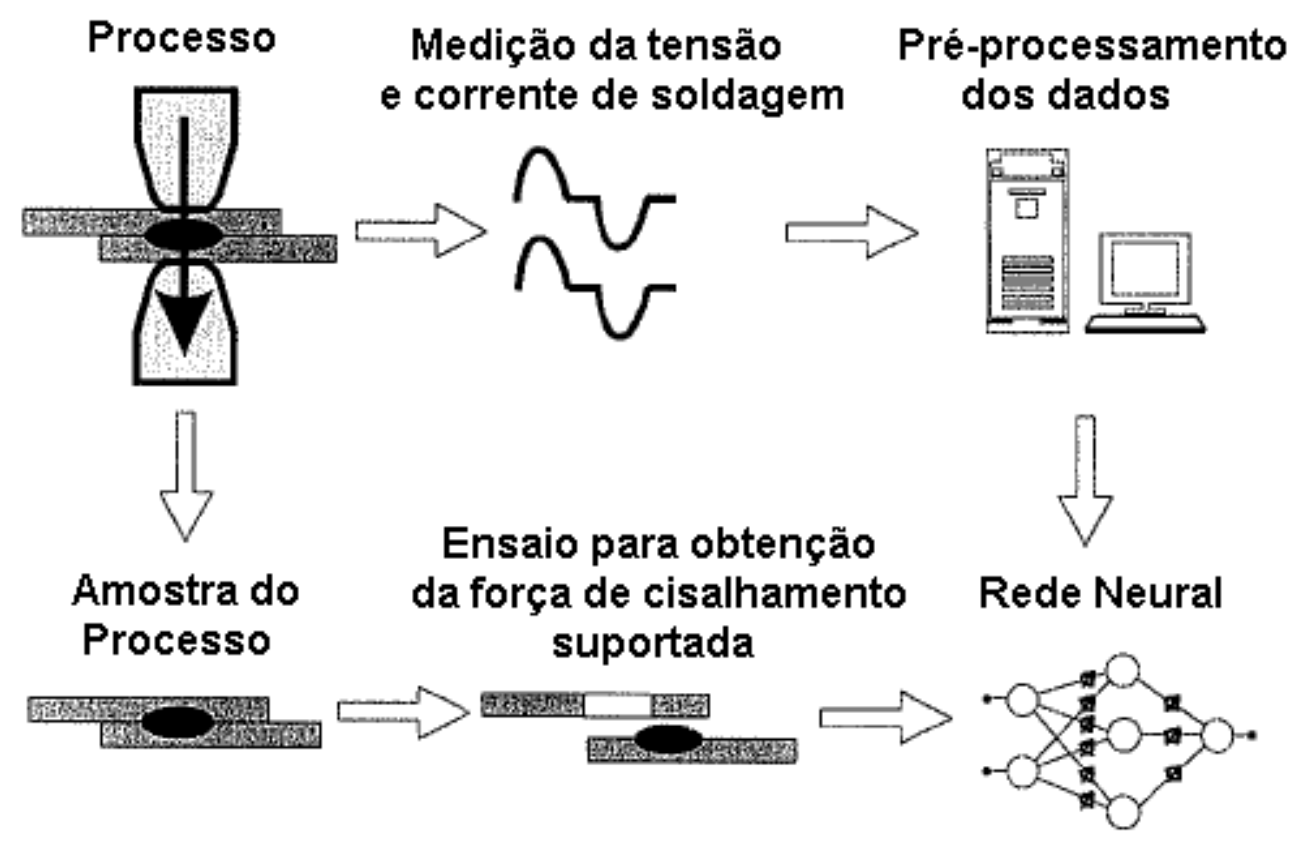

Figura 3.23 - Processo de treinamento da rede neural artificial

No treinamento, para cada amostra do processo, são apresentados à entrada da rede os parâmetros estimados do modelo matemático criado e à saída da rede, o valor da força de cisalhamento suportada obtida através de ensaio destrutivo. Desta forma, através do algoritmo de back-propagation, a rede é treinada para estimar a qualidade da solda. Depois de ser treinada, ao se apresentar à entrada da rede os parâmetros estimados do modelo matemático 
que representam uma determinada solda, ela é capaz de estimar a qualidade dessa solda produzida, ou seja, de estimar a força de cisalhamento suportada pela solda.

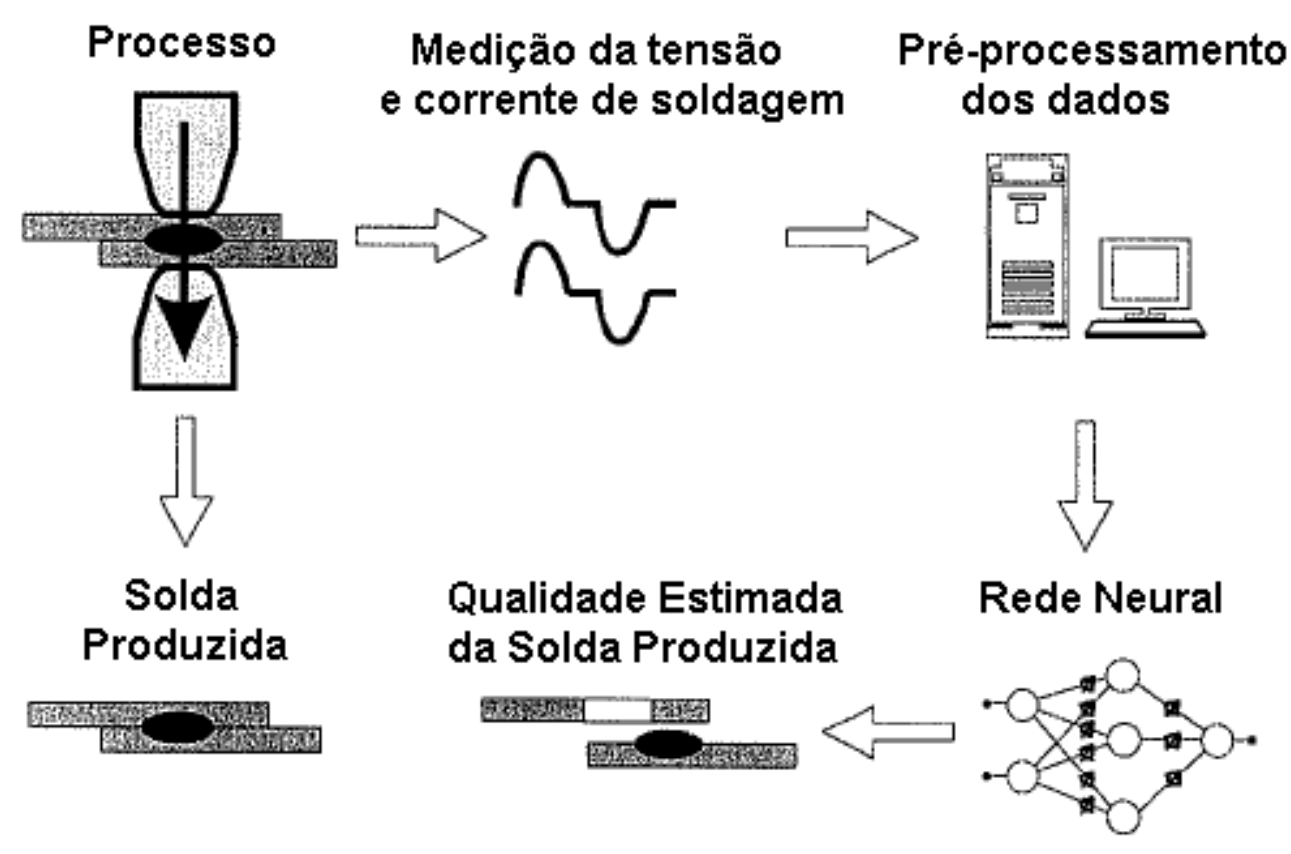

Figura 3.24 - Processo de aplicação da rede neural artificial

No capítulo 4 o sistema de monitoramento proposto será avaliado com dados reais e os resultados serão apresentados.

\subsubsection{Software para Simulação de Redes Neurais}

Desde 1989, o Instituto para Sistemas Paralelos e Distribuídos de Alta Performance da Universidade de Stuttgart, na Alemanha, disponibiliza um simulador de redes neurais artificiais chamado SNNS (Stuttgarter Neuronaler Netzwerk Simulator). A motivação para o desenvolvimento desse simulador foi criar uma ferramenta de software que simulasse redes neurais artificiais sem a necessidade de grandes configurações e tempo de desenvolvimento.

O simulador SNNS consiste de dois componentes principais, um núcleo de simulação e uma interface gráfica para o usuário. O núcleo de simulação opera na estrutura de dados 
interna da rede neural artificial e executa todas as operações de aprendizado e verificação. Este núcleo pode também ser usado sem outras partes como um programa em C incorporado em uma aplicação personalizada. A ferramenta suporta qualquer tipo de topologia de rede. $\mathrm{O}$ SNNS pode ser expandido pelo usuário através de funções de ativação, funções de saída e procedimentos de aprendizagem, os quais devem ser escritos em linguagem $\mathrm{C}$ e conectados ao núcleo de simulação.

Esta foi a ferramenta escolhida para simular as redes neurais neste trabalho, principalmente por ser um open source code. Foi desenvolvido um plug-in na ferramenta TOMAHAWK, chamado "SNNS Output", que cria um arquivo de lote (também conhecidos por .bat) que executa o núcleo de simulação do SNNS, calculando e apresentando na topologia de rede neural desejada os seus resultados.

\subsection{Identificação de Causas de Perda de Qualidade no PSPR}

A rápida identificação de perda de qualidade e também das possíveis causas para esta perda de qualidade são extremamente importantes, para minimizar custos e aumentar a produtividade.

O sistema proposto tem o potencial de fornecer uma grande ajuda na manutenção do processo, já que pode relacionar os parâmetros do modelo com condições ou estados do processo, fornecendo possíveis causas para problemas que possam surgir e serem identificados durante a produção, auxiliando assim para que a manutenção seja realizada o mais breve possível, de forma a minimizar as consequências da perda de qualidade do processo.

Através da obtenção de amostras do processo, por meio da execução de um procedimento de testes que englobe simulações das principais perturbações do processo, é 
possível analisar e comprovar o comportamento dos parâmetros do modelo matemático criado e, assim, encontrar os valores que estes assumem em condições normais e em condições de perda de qualidade devido a essas perturbações. Quanto melhor for este procedimento de testes, melhor será a obtenção da correlação dos valores dos parâmetros do modelo com as perturbações do processo que acarretam perda da qualidade.

Esse potencial de identificação de causas de perda de qualidade é investigado neste trabalho e os resultados serão mostrados no capítulo 4.

\subsection{Banco de Dados com Histórico de Produção}

Os dados do PSPR podem ser armazenados em um banco de dados formando assim um histórico de produção que pode ser usado para certificação do processo e em futuras análises. Essa característica de arquivamento e acompanhamento dos produtos se tornou uma condição necessária em muitos padrões industriais de qualidade e as informações da produção devem ser documentadas para se atingir este objetivo.

Além disso, essa informação pode ser usada para Data Mining. No caso do processo de solda a ponto resistiva, é possível utilizar-se Data Mining para buscar-se um procedimento de soldagem otimizado para um determinado processo ou definir um procedimento de soldagem para um novo processo de soldagem que se adapte à medida que novos dados vão sendo armazenados.

A construção e utilização do banco de dados não foi investigada neste trabalho e ficará como sugestão para futuros trabalhos. Como referência ficam os trabalhos de Zhang et al. (2003) e Tuovinen et al. (2007). 


\section{Avaliação e Validação do Sistema Proposto}

Neste capítulo serão feitas a avaliação e validação do sistema proposto. Inicialmente serão apresentados os dados que foram usados para avaliar e validar o sistema e a forma e condições nas quais eles foram adquiridos. Depois será avaliado se o modelo matemático parametrizável criado é capaz de reproduzir o comportamento da curva da resistência dinâmica que ele descreve. Após esta etapa, os parâmetros ajustados do modelo serão utilizados nas próximas etapas do sistema. Primeiramente será analisada a capacidade de esses parâmetros serem usados para treinar uma rede neural artificial tornando-a capaz de estimar a qualidade final da solda. Para isso, é feito um estudo para identificar qual a melhor combinação de parâmetros do modelo na entrada da rede e qual a melhor topologia de rede para estimar a qualidade final da solda. Através dos resultados obtidos, será possível concluir se o sistema proposto é capaz de fazer uma boa estimação da qualidade final da solda, através de comparação com resultados encontrados na literatura e obtidos utilizando outras características da curva de resistência dinâmica. Será então avaliada a capacidade do sistema de fornecer possíveis causas para problemas que possam surgir durante a produção dos contatos elétricos.

\subsection{Dados Utilizados na Avaliação e Validação do Sistema}

Dois conjuntos de dados foram obtidos diretamente na linha de produção de contatos elétricos produzidos através do PSPR. A aquisição dos dados foi realizada com uma diferença de 10 meses entre cada conjunto, em duas máquinas similares. O segundo conjunto de dados

apresenta um roteiro de testes mais completo que o do primeiro. É composto por 240 amostras 
do processo, enquanto o primeiro é composto por 185 amostras. A seguir, cada conjunto de dados será detalhado, mostrando as particularidades do processo e a forma como os dados foram adquiridos.

\subsubsection{Primeiro Conjunto de Dados}

O primeiro conjunto de dados obtido é relativo a uma linha de produção de contatos elétricos produzidos através do PSPR, usados principalmente na indústria eletro-eletrônica. Este processo de soldagem é caracterizado por um pequeno período de soldagem, de 25-40 ms, e pela velocidade de produção que pode chegar a 300 partes por minuto. Estes contatos elétricos são produzidos em quantidades de 50.000 até 500.000 partes por semana. Eles têm a função de pontes para as chaves de produtos como relés, termostatos e interruptores, exercendo assim um papel essencial já que se um contato falha, o produto como um todo perde sua função.

Os contatos elétricos produzidos neste teste têm a função de serem utilizados como mola auxiliar de contato em termostatos. Os materiais usados para confeccionar o contato elétrico foram uma pequena chapa de níquel-berílio de $28,3 \mathrm{~mm}$ de comprimento, 8,5 $\mathrm{mm}$ de largura e $0,1 \mathrm{~mm}$ de espessura, usada como material da base, e um pequeno contato de níquel-prata de 2,3mm de comprimento, 1,5 $\mathrm{mm}$ de largura e 0,7 $\mathrm{mm}$ de altura, usado como material de contato, como ilustrado na figura 4.1 .

O tipo de material e a espessura muito fina das partes a serem soldadas resultam em uma resistência de contato muito baixa entre elas. Para que o calor produzido pela circulação de corrente se concentre nessa região, e não na região entre os eletrodos e as partes, nesse tipo de processo é necessário um artifício, para aumentar a resistência de contato entre as partes a serem soldadas. Esse artifício é chamado de welding help, que se baseia na produção 
de pequenas saliências no material da base, na área que será soldada, obtidas por processo de prensagem.

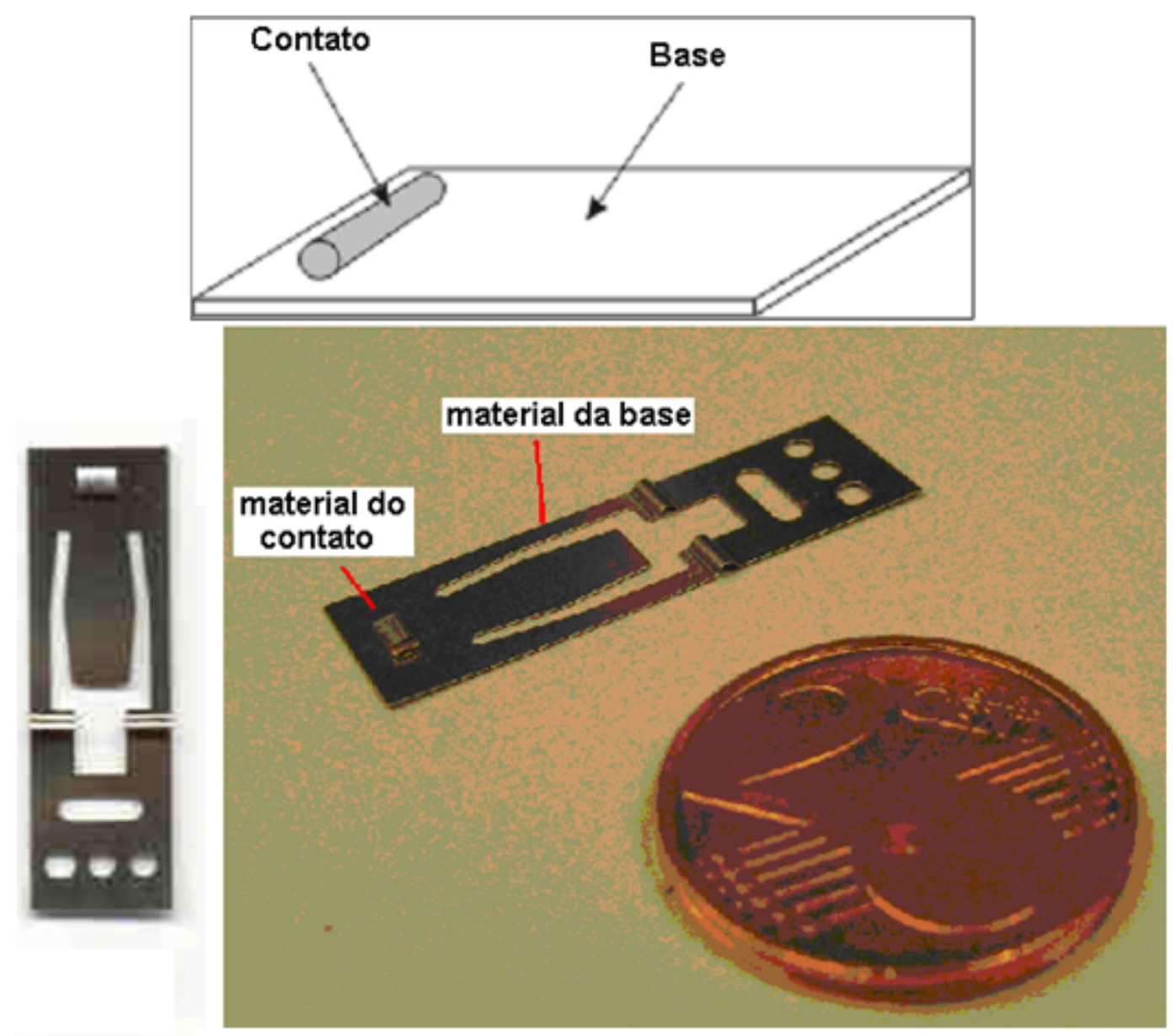

Figura 4.1 - Esquemático das partes a serem soldadas (superior) e contato elétrico após soldagem (inferior)

Todos os testes foram executados em uma máquina na linha de produção e não em laboratório, para prover condições reais de produção. O tipo de controle de alimentação presente na máquina de soldagem era o de média frequência com controle de corrente constante.

Foi possível instalar tanto a bobina Rogowski, para medição da corrente, quanto os cabos no eletrodo, para medição de tensão, sem necessidade de modificações ou adaptações 
na máquina de soldagem ou na linha de produção e sem obstruir a execução da solda. O lado de saída dos cabos da bobina Rogowski e da medição de tensão foi ligado à placa de aquisição de dados instalada em um computador pessoal montado em uma mesa junto à linha de produção.

Dentre os principais parâmetros do procedimento de soldagem padrão usado, destacase o tempo de soldagem total de 24 milissegundos, dividido em dois estágios, sendo o primeiro estágio somente para aquecimento e queima de impurezas presentes na superfície do material e o segundo estágio para a soldagem propriamente dita. $\mathrm{O}$ primeiro estágio possui um tempo de soldagem de 10 milissegundos, com uma corrente de 1,4 kA aplicada durante este estágio. O segundo estágio possui um tempo de soldagem de 14 milissegundos, com uma corrente de 3,7 kA aplicada durante este estágio. Outro parâmetro importante é a pressão exercida nos eletrodos. No caso desta máquina, essa pressão não é fornecida nem medida diretamente, mas ajustada por meio de uma mola. A unidade de medida é o comprimento da mola que foi comprimida, ou seja, a diferença entre o tamanho natural da mola e o tamanho após uma compressão. A figura 4.2 mostra um esquemático do ajuste da pressão.

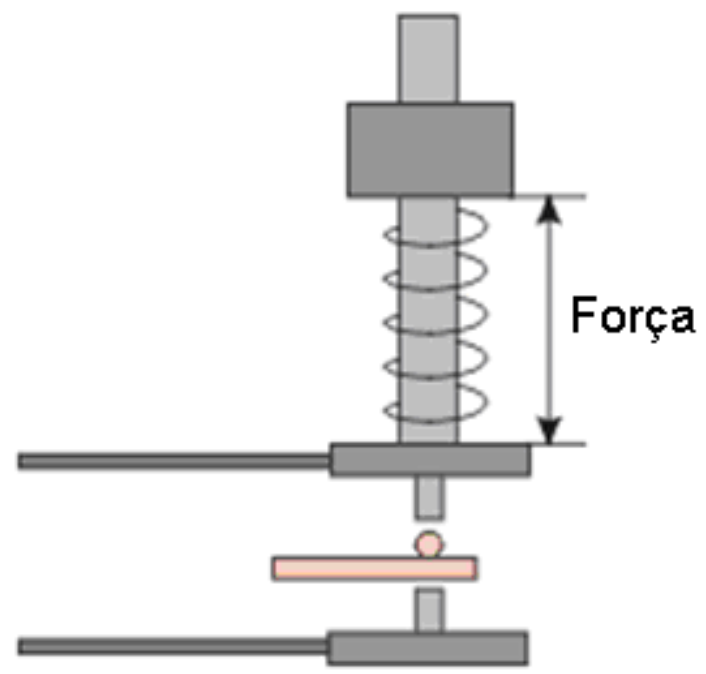

Figura 4.2 - Esquemático do ajuste da pressão dos eletrodos através de uma mola 
A temperatura dos eletrodos neste processo foi mantida em torno de $16^{\circ} \mathrm{C}$, através de um eficiente sistema de resfriamento baseado na circulação de um líquido refrigerante no seu interior.

O critério de qualidade definido para este tipo de solda a ponto resistiva é a força de cisalhamento obtida através de ensaio destrutivo. Portanto, todos os pontos de solda executados especialmente para compor este conjunto de dados passaram por um ensaio destrutivo para determinar a força de cisalhamento suportada por cada um deles. Pontos de solda que suportem uma força de cisalhamento maior que $400 \mathrm{~N}$ são considerados soldas de boa qualidade. Mas, para garantir soldas boas, o procedimento de soldagem padrão usado foi definido para tentar produzir soldas que suportem uma força de cisalhamento média de $550 \mathrm{~N}$.

Durante os testes, alguns parâmetros do procedimento de soldagem foram modificados de forma a artificialmente simular diferentes situações que podem ocorrer durante o processo de soldagem e possam vir a prejudicar a qualidade final do ponto de solda, ou seja, simular diferentes perturbações que possam estar presentes no processo. Em alguns testes, o valor da corrente nominal aplicada durante o segundo estágio de soldagem foi alterada. Em outros, a força nominal aplicada pelos eletrodos foi alterada e o artifício para aumentar a resistência de contato entre as partes a serem soldadas, o welding help, não foi utilizado. Essas variações são importantes para a fase de treinamento da rede neural artificial, para que esta se adapte melhor ao processo.

Este primeiro conjunto de dados é composto por 185 testes que foram executados seguindo o roteiro apresentado a seguir:

- Testes de números 1 a 15: procedimento de soldagem padrão;

- Testes de números 16 a 30: procedimento de soldagem padrão com aumento da força aplicada nos eletrodos em $6,3 \%$; 
- Testes de números 31 a 45: procedimento de soldagem padrão com aumento da força aplicada nos eletrodos em 9,5\%;

- Testes de números 46 a 60: procedimento de soldagem padrão com aumento da força aplicada nos eletrodos em $12,7 \%$;

- Testes de números 61 a 75: procedimento de soldagem padrão com aumento da força aplicada nos eletrodos em $15,8 \%$;

- Testes de números 76 a 90: procedimento de soldagem padrão;

- Testes de números 91 a 105: procedimento de soldagem padrão com redução da corrente do segundo estágio de soldagem de 3,7 kA para 3,5 kA;

- Testes de números 106 a 120: procedimento de soldagem padrão com redução da corrente do segundo estágio de soldagem de 3,7 kA para 3,2 kA;

- Testes de números 121 a 135: procedimento de soldagem padrão com redução da corrente do segundo estágio de soldagem de 3,7 kA para 2,8 kA;

- Testes de números 136 a 150: procedimento de soldagem padrão com redução da corrente do segundo estágio de soldagem de 3,7 kA para 2,4 kA;

- Testes de números 151 a 165: procedimento de soldagem padrão;

- Testes de números 166 a 185: procedimento de soldagem padrão em material sem welding help.

Os testes de número 70, 73 e 121 apresentaram problemas na execução do ensaio destrutivo para determinação da força de cisalhamento suportada e infelizmente tiveram que ser descartados.

A tabela B.1 do Anexo B mostra um detalhamento maior de cada teste realizado como o nome do arquivo em que os dados de tensão e corrente foram salvos, o procedimento de 
soldagem utilizado, o número de soldas que os eletrodos executaram até o momento do teste e o resultado do ensaio destrutivo de cada parte produzida.

\subsubsection{Segundo Conjunto de Dados}

O segundo conjunto de dados obtido para avaliar o sistema proposto neste trabalho é relativo também ao processo de produção de contatos elétricos produzidos através do PSPR, mas foram obtidos 10 meses após o primeiro conjunto de dados e em uma linha de produção similar, mas não a mesma do primeiro.

Os materiais usados para confeccionar o contato elétrico foram os mesmos. Uma pequena chapa de níquel-berílio de $28,3 \mathrm{~mm}$ de comprimento, $8,5 \mathrm{~mm}$ de largura e $0,1 \mathrm{~mm}$ de espessura, usada como material da base, e um pequeno contato de níquel-prata de 2,3 $\mathrm{mm}$ de comprimento, 1,5 $\mathrm{mm}$ de largura e $0,7 \mathrm{~mm}$ de altura, usado como material de contato, como ilustrado na figura 4.1, sendo, portanto, necessário o uso de welding help no material da base.

O procedimento de soldagem padrão foi o mesmo utilizado na obtenção do primeiro conjunto de dados, destacando-se o tempo de soldagem total de 24 milissegundos, dividido em dois estágios, sendo o primeiro estágio somente para aquecimento e queima de impurezas presentes na superfície do material e o segundo estágio para a soldagem propriamente dita. A pressão exercida nos eletrodos também é ajustada por meio de uma mola, como ilustrado na figura 4.2. A temperatura dos eletrodos também foi mantida em torno de $16{ }^{\circ} \mathrm{C}$, através de um eficiente sistema de resfriamento baseado na circulação de um líquido refrigerante no seu interior.

Todos os testes também foram executados em uma máquina na linha de produção, e não em laboratório, para prover condições reais de produção. $\mathrm{O}$ tipo de controle de alimentação presente na máquina de soldagem era o de média frequência com controle de 
corrente constante. O critério de qualidade é a força de cisalhamento obtida através de ensaio destrutivo. Pontos de solda que suportem uma força de cisalhamento maior que $400 \mathrm{~N}$ são considerados soldas de boa qualidade. Mas, para garantir soldas boas, o procedimento de soldagem padrão usado busca produzir soldas que suportem uma força de cisalhamento média de $550 \mathrm{~N}$.

Durante estes testes, parâmetros do procedimento de soldagem também foram modificados de forma a artificialmente simular diferentes situações que podem ocorrer durante o processo de soldagem e possam vir a prejudicar a qualidade final do ponto de solda, ou seja, simular diferentes perturbações que possam estar presentes no processo. Enquanto no primeiro conjunto de dados os valores da corrente de soldagem e da força de soldagem somente foram reduzidos, neste segundo conjunto de dados, estes valores, além de serem reduzidos, foram também aumentados durante os testes.

O segundo conjunto de dados é composto por 240 testes que foram executados seguindo o roteiro apresentado a seguir:

- Testes de números 1 a 15: procedimento de soldagem padrão;

- Testes de números 16 a 30: procedimento de soldagem padrão com aumento da força aplicada nos eletrodos em 6,3\%;

- Testes de números 31 a 45: procedimento de soldagem padrão com aumento da força aplicada nos eletrodos em $9,5 \%$;

- Testes de números 46 a 60: procedimento de soldagem padrão com aumento da força aplicada nos eletrodos em 12,7\%;

- Testes de números 61 a 75: procedimento de soldagem padrão com aumento da força aplicada nos eletrodos em $15,8 \%$;

- Testes de números 76 a 90: procedimento de soldagem padrão com redução da força aplicada nos eletrodos em 6,3\%; 
- Testes de números 91 a 105: procedimento de soldagem padrão;

- Testes de números 106 a 120: procedimento de soldagem padrão com redução da corrente do segundo estágio de soldagem de 3,7 kA para 3,5 kA;

- Testes de números 121 a 135: procedimento de soldagem padrão com redução da corrente do segundo estágio de soldagem de 3,7 kA para 3,2 kA;

- Testes de números 136 a 150: procedimento de soldagem padrão com redução da corrente do segundo estágio de soldagem de 3,7 kA para 2,8 kA;

- Testes de números 151 a 165: procedimento de soldagem padrão com redução da corrente do segundo estágio de soldagem de 3,7 kA para 2,4 kA;

- Testes de números 166 a 180: procedimento de soldagem padrão com aumento da corrente do segundo estágio de soldagem de 3,7 kA para 4,0 kA;

- Testes de números 181 a 195: novo procedimento de soldagem padrão (a corrente de soldagem padrão passou a ser de 3,8 kA);

- Testes de números 196 a 210: novo procedimento de soldagem padrão em material sem welding help.

- Testes de números 211 a 225: novo procedimento de soldagem padrão;

- Testes de números 226 a 240: novo procedimento de soldagem padrão após 2525 soldas do teste 225 ;

Os testes de número 24, 111, 203, 219, 220 e 221 apresentaram problemas na execução do ensaio destrutivo para determinação da força de cisalhamento suportada e tiveram que ser descartados.

A tabela B.2 do Anexo B mostra um detalhamento maior de cada teste deste segundo conjunto de dados como o nome do arquivo em que os dados de tensão e corrente foram salvos, o procedimento de soldagem utilizado, o número de soldas que os eletrodos 
executaram até o momento do teste e o resultado do ensaio destrutivo de cada parte produzida.

\subsection{Avaliação do Ajuste entre o Modelo e o Processo}

Inicialmente é necessário avaliar se o modelo matemático parametrizável criado é capaz de reproduzir o comportamento da grandeza que ele descreve. Para esse fim foram utilizadas as curvas da resistência dinâmica, obtidas da forma descrita no item 3.4, de cada teste que compõe o primeiro conjunto de dados. A curva da resistência dinâmica de um dos testes do primeiro conjunto de dados é mostrada em detalhes na figura 4.3.

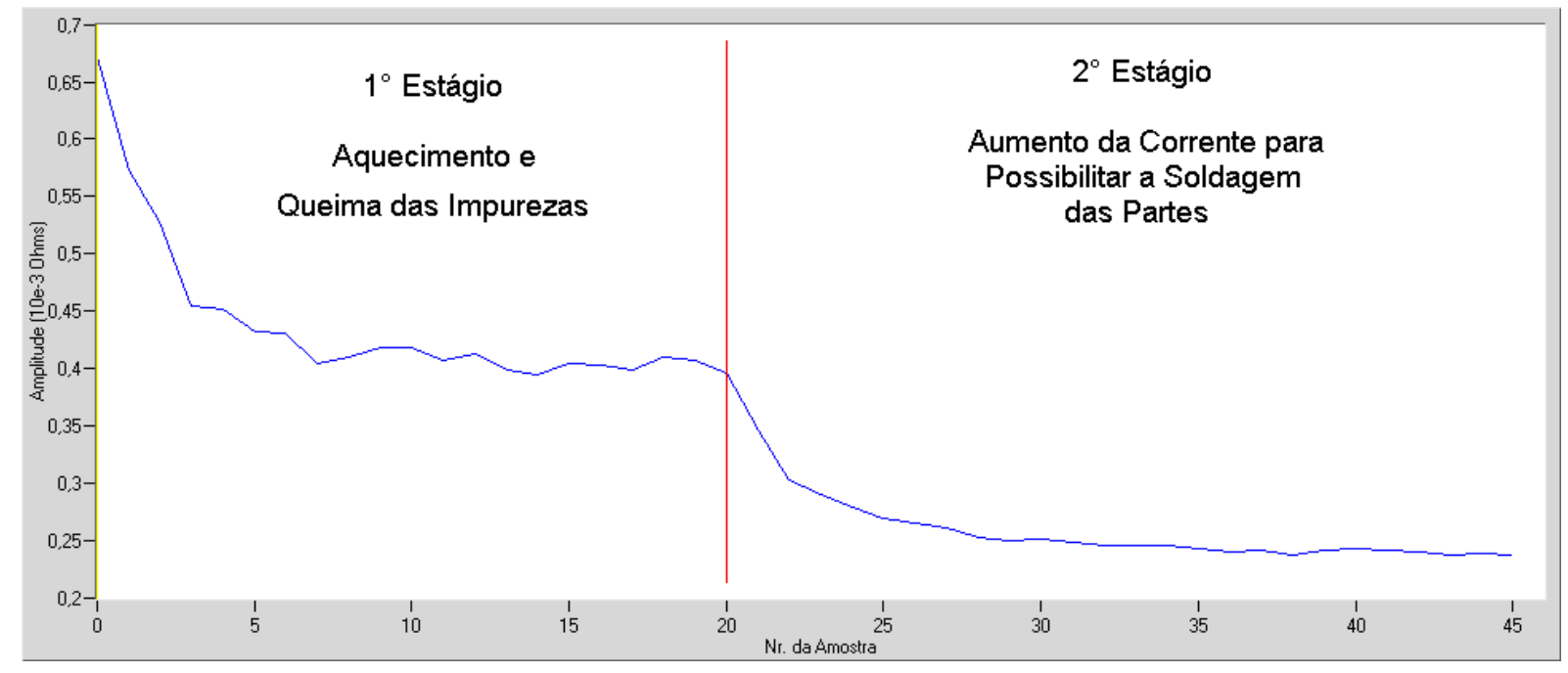

Figura 4.3 - Detalhes da curva da resistência dinâmica de um dos testes

$\mathrm{Na}$ figura 4.3 é possível identificar perfeitamente a divisão entre os dois estágios de soldagem que compõem o procedimento de soldagem dos contatos elétricos. O primeiro estágio é somente para aquecimento e queima de impurezas presentes na superfície do material, e o segundo estágio, para a soldagem propriamente dita. 
Portanto, somente o segundo estágio será usado para fins de ajuste do modelo, pois é onde efetivamente acontece a soldagem. Para isso, foi utilizado o plug-in "Cut Curve (Begin End)" já citado anteriormente que também pode ser configurado para excluir os dados anteriores a uma determinada amostra. Neste caso, o plug-in "Cut Curve (Begin End)" foi configurado para excluir as amostras anteriores a amostra de número 20 . O formato da curva da resistência dinâmica, considerando somente o segundo estágio de soldagem, usada para representar cada teste do primeiro conjunto de dados e também do segundo conjunto de dados, por estes serem similares, é mostrado na figura 4.4.

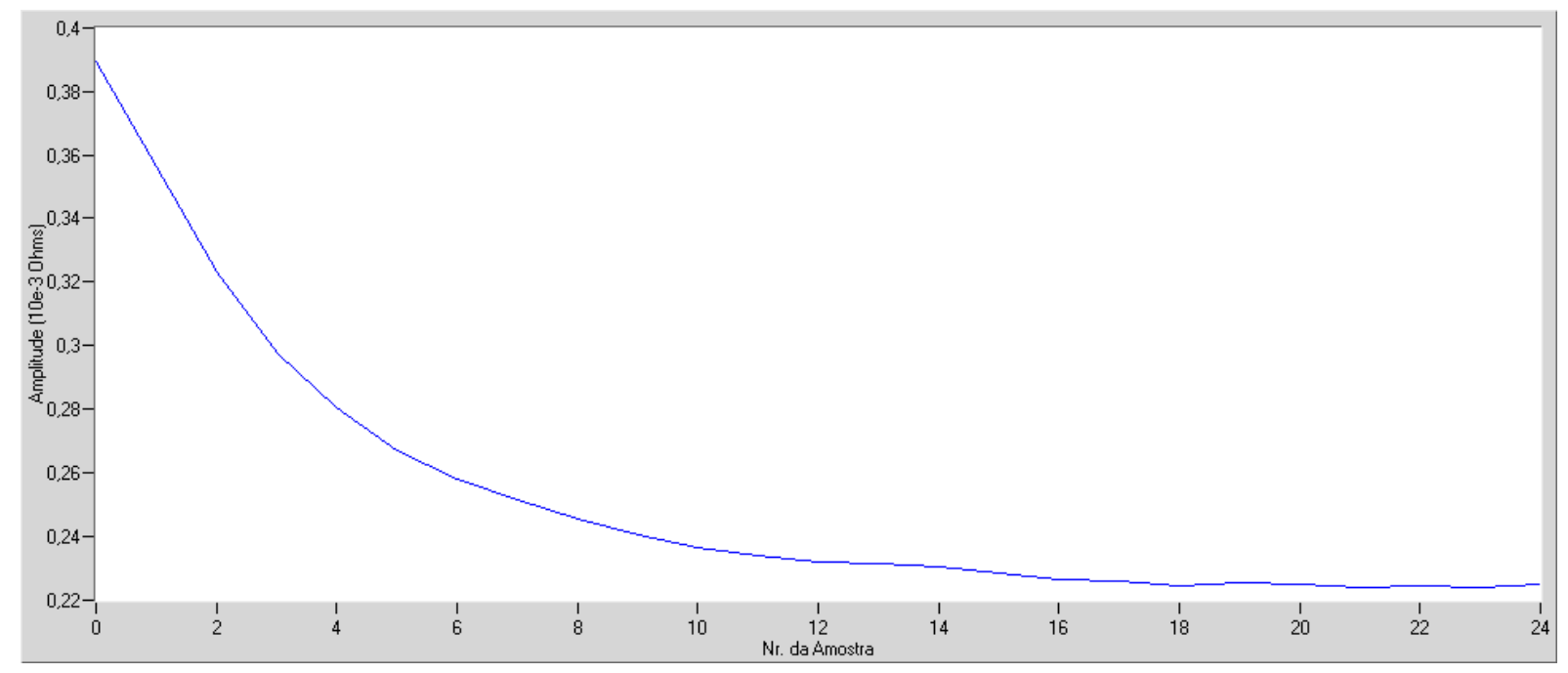

Figura 4.4 - Curva da resistência dinâmica considerando somente o segundo estágio

Utilizando-se agora o plug-in "Model CalcVariables", que foi criado para ajustar a curva obtida com os parâmetros do modelo e a curva real obtida do PSPR, é possível avaliar se o modelo matemático parametrizável criado consegue reproduzir o comportamento do processo em análise.

O primeiro passo é preencher os campos da tela de configuração do plug-in "Model CalcVariables". A tela de configuração já preenchida é mostrada na figura 4.5. 


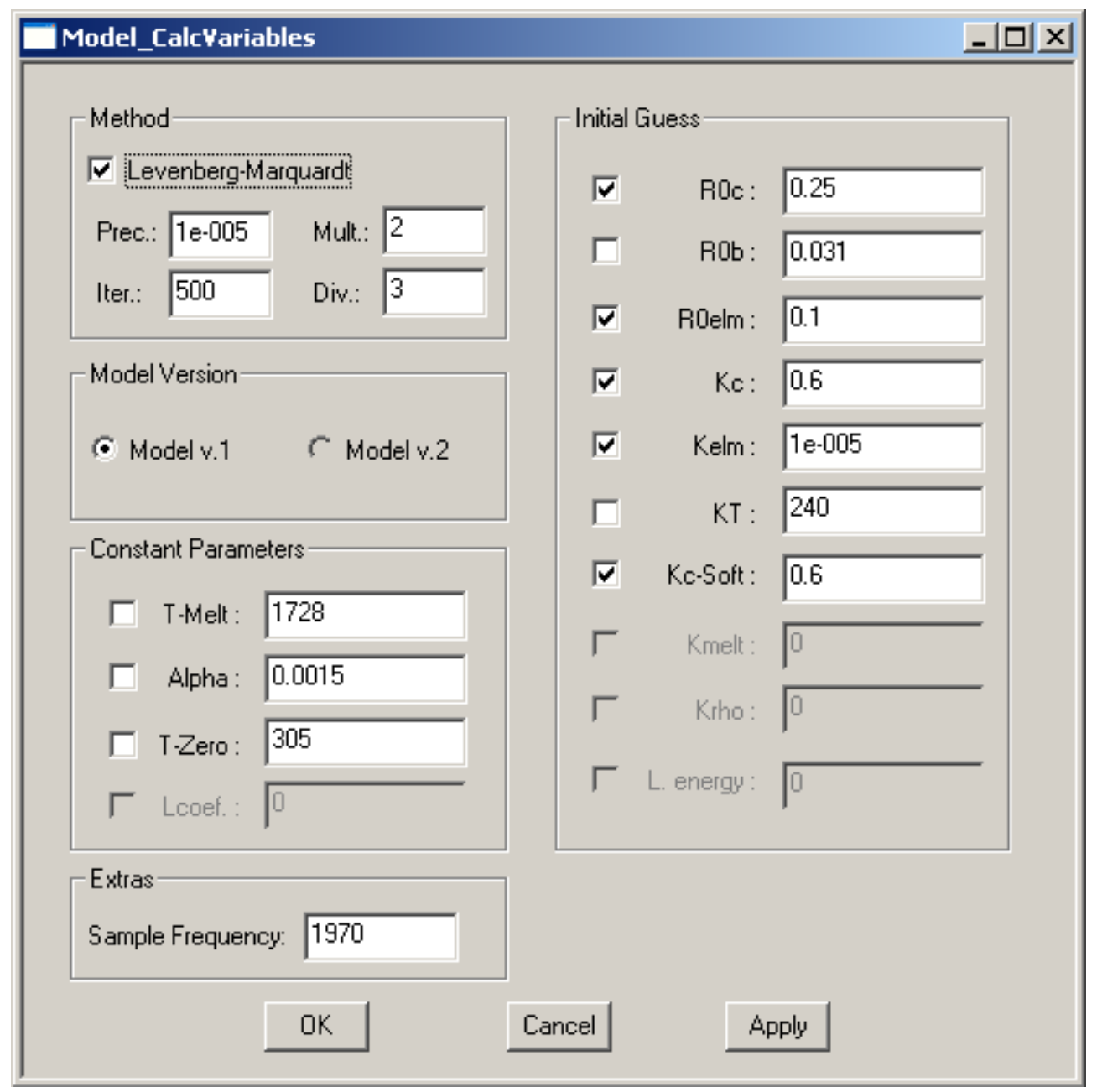

Figura 4.5 - Tela de configuração do plug-in “Model_CalcVariables” preenchida

Para o método de Levenberg-Marquardt, optou-se por uma precisão de 0,00001, um número máximo de iterações de 500 e as variáveis "Mult." e "Div." com os valores de 2 e 3 , respectivamente. Como o método usado para obter a resistência dinâmica seleciona apenas um valor de cada semi-ciclo, que é o valor no pico de corrente, e isso representa uma redução de aproximadamente 13 vezes no número de amostras total, a frequência de amostragem inicial que era de $25,6 \mathrm{kHz}$ também sofre uma redução de aproximadamente 13 vezes e passa a ser de 1970 Hz. Esse valor foi incluído no campo denominado "Sample Frequency”.

Com relação ao modelo matemático parametrizável, cinco parâmetros foram definidos como de valor fixo ( $T_{\text {melt }}$ alpha, $T_{0}, R_{0 B}$ e $K_{T}$ ) e cinco parâmetros foram definidos como de valor 
ajustável $\left(R_{O C}, R_{0 E L M}, K_{C}, K_{E L M}\right.$ e $\left.K_{C-S o f t}\right)$. O motivo dessa escolha é que os parâmetros referentes à temperatura de fusão dos materiais envolvidos, ao coeficiente térmico de resistência $(\alpha)$, à temperatura inicial, à resistência inicial do material bruto e à variação da temperatura nestes materiais podem ser considerados iguais em todos os testes. Os demais parâmetros podem sofrer variação de um teste para outro, de acordo com as condições do processo. Os valores escolhidos para os parâmetros do modelo foram baseados no valor real das propriedades dos materiais envolvidos ( $T_{\text {melt }}$, alpha, $\left.K_{T}\right)$, na condição ambiente do processo $\left(T_{0}\right)$, na proporção entre o valor da resistência total inicial média (de aproximadamente $0,38 \mathrm{~m} \Omega$ ) e suas componentes $R_{O C}, R_{O E L M}$ e $R_{O B}$, sendo $R_{O C}>R_{O E L M}>R_{O B}$ (foi utilizada uma proporção de aproximadamente 2,5 vezes). Para $K_{C}, K_{E L M}$ e $K_{C \text {-Soft, foram }}$ utilizados inicialmente os valores de 0,5, 0,00005 e 0,5, respectivamente. Foi realizado um ajuste da curva do modelo com uma curva da resistência dinâmica obtida pela média ponto a ponto das curvas da resistência dinâmica de cada teste. Obteve-se então para os valores ajustados de $K_{C}, K_{E L M}$ e $K_{C-S o f t}$, respectivamente, aproximadamente 0,6 , 0,00001 e 0,6, que passaram a ser os valores iniciais desses parâmetros.

Ao se executar uma nova "Work list" contendo esse plug-in, foi possível verificar a qualidade do ajuste entre a curva do modelo e a do processo. As figuras 4.6 e 4.7 mostram os resultados de dois testes do algoritmo de ajuste usando o modelo matemático parametrizável com a configuração descrita anteriormente e o primeiro conjunto de dados. 


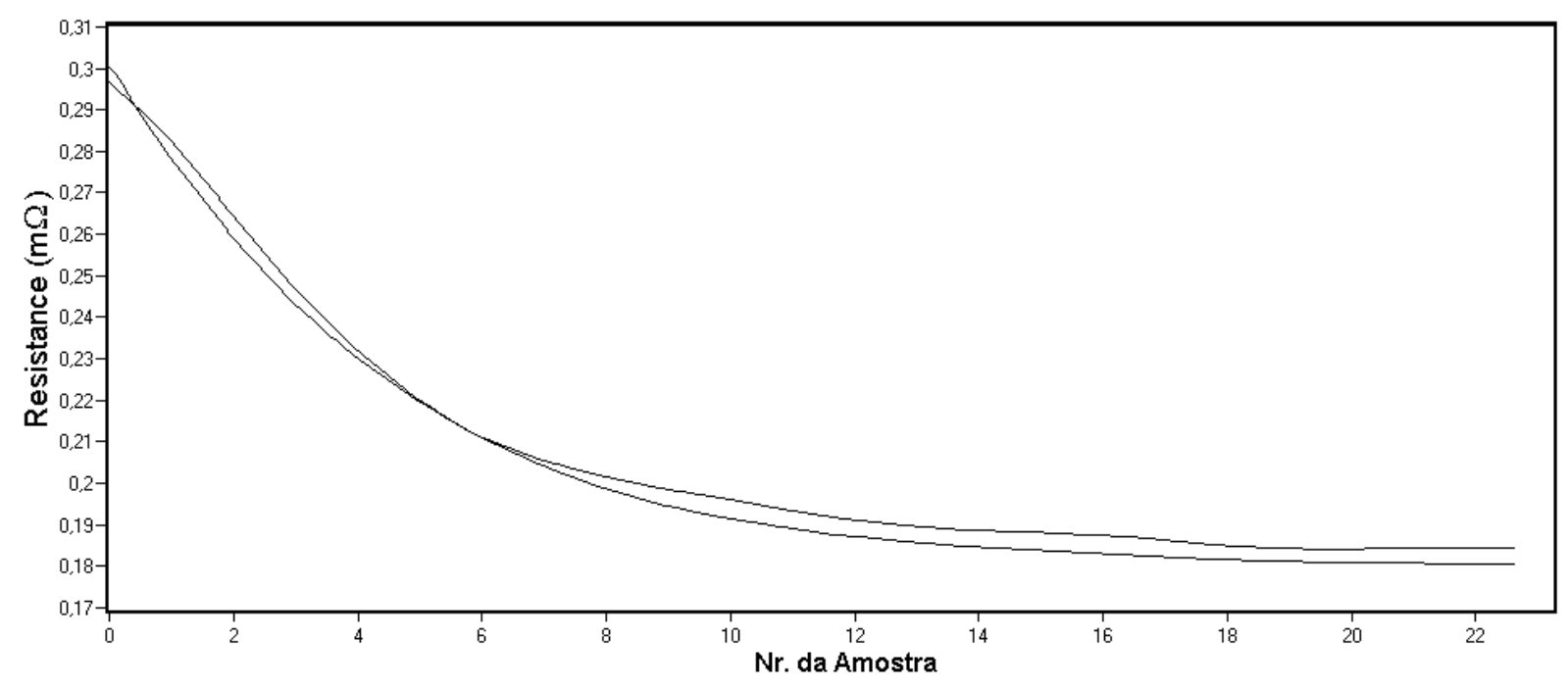

Figura 4.6 - Curva com pior ajuste entre os dados do conjunto analisado

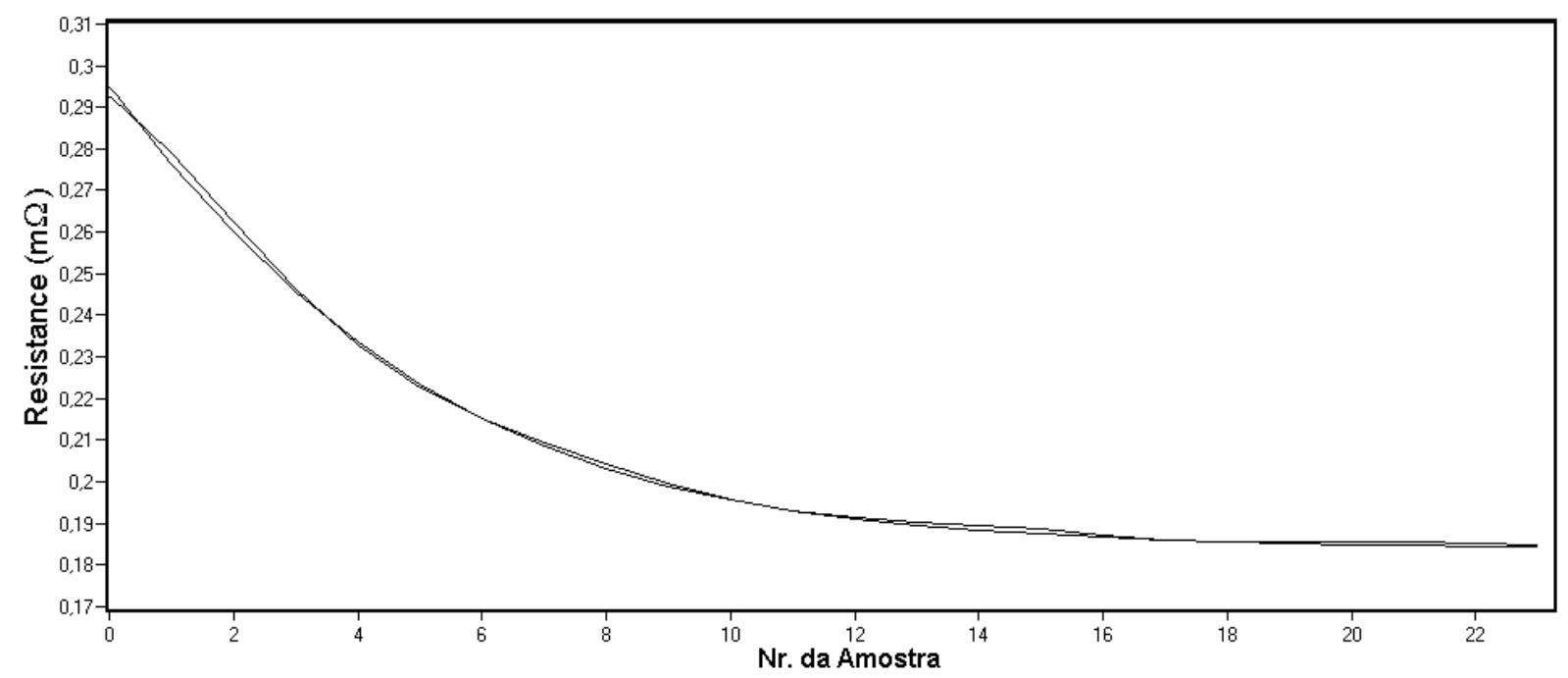

Figura 4.7 - Curva com bom ajuste entre os dados do conjunto analisado

A figura 4.6 ilustra a curva resultante dos parâmetros do modelo com pior ajuste entre todos os testes do referido conjunto de dados e a figura 4.7 mostra uma curva que obteve um bom ajuste. Comparando as duas, é possível verificar que a curva com pior ajuste apresenta um erro quadrático médio superior ao da curva com bom ajuste; mas esse erro ainda pode ser considerado baixo e, portanto, não há necessidade de isolá-la do conjunto principal de curvas e analisá-la separadamente. Além disso, essa variação pode ser causada por variações no 
processo que não são refletidas no modelo, mostrando que, conforme mencionado, as componentes do sinal adquirido que não são refletidas no modelo serão filtradas.

Com base nesses resultados, pode-se afirmar que o modelo matemático parametrizável criado é capaz de reproduzir com erro aceitável o comportamento da grandeza que ele descreve. Portanto, os valores dos cinco parâmetros ajustáveis podem ser usados como dados de entrada em uma rede neural artificial multicamadas, treinada com o algoritmo de back-propagation, para tentar-se estimar a qualidade final da solda.

\subsection{Estimação da Qualidade Final da Solda}

Após a comprovação que o modelo criado é capaz de reproduzir com erro aceitável o comportamento da curva de resistência dinâmica, é possível testar a etapa do sistema que faz a estimação da qualidade final da solda. Esta estimação será feita por uma rede neural artificial do tipo Perceptron multicamada, treinada com o algoritmo de back-propagation, usando a função de aprendizagem Rprop. Na etapa de treinamento da rede, os parâmetros do modelo que caracterizam cada teste serão utilizados como dados de entrada da rede e o valor da força de cisalhamento do respectivo teste será apresentado à saída da rede.

Usando o plug-in "SNNS Output", feito para acessar o simulador SNNS, conforme descrito no item 3.7 deste trabalho, alguns testes iniciais foram feitos usando topologias tanto com uma camada oculta como com duas camadas ocultas, assim como diferentes parâmetros de treinamento, de forma que a rede estimasse em seu único neurônio de saída a força de cisalhamento suportada por cada ponto de solda. Nestes testes iniciais de rede, foram utilizadas as 182 amostras de soldagem do primeiro conjunto de dados e todos os parâmetros ajustáveis do modelo; portanto, a rede foi configurada com 5 neurônios de entrada. Para o treinamento da rede neural, foram utilizadas 122 amostras e para a validação da rede, as 
outras 60 amostras. Nos dois grupos de dados, dados de treinamento e dados de validação, foram incluídas amostras com as diferentes condições de processo testadas em campo. As topologias usadas nestes testes iniciais foram 5-3-1, ou seja, 5 neurônios na camada de entrada, 3 neurônios em uma camada intermediária oculta e 1 neurônio na camada de saída, 55-1, 5-3-3-1 e 5-5-5-1. Para cada topologia, foram utilizadas diferentes configurações da função de aprendizagem Rprop, usada pela ferramenta SNNS para fazer o treinamento da rede. Para cada topologia e configuração, foram realizadas três inicializações da rede e respectivo treinamento, de forma que se pudessem comparar os resultados, diminuindo as chances de um falso resultado causado pela paralisação da rede em um mínimo local. Os resultados obtidos com apenas uma camada oculta foram cerca de $20 \%$ superiores aos obtidos com duas camadas ocultas. Para esta análise, levaram-se em consideração os seguintes itens, que serão utilizados ao longo de todo restante do trabalho:

- MSE: é o erro médio quadrático entre o valor estimado e o valor real de todas as amostras;

- $\quad \mathbf{R}^{\wedge} \mathbf{2}$ ou $\mathbf{R}^{2}$ : é o coeficiente de determinação. O chamado coeficiente de determinação $\left(\mathrm{R}^{2}\right)$ é o quadrado do coeficiente de correlação de Pearson. É uma medida da proporção da variabilidade em uma variável que é explicada pela variabilidade da outra. Esse coeficiente varia de 0 a 1 . Zero corresponde a nenhuma correlação entre as variações das variáveis em questão. 1 corresponde à correlação perfeita. É pouco comum que tenhamos uma correlação perfeita $\left(\mathrm{R}^{2}=1\right)$ na prática, porque existem muitos fatores que determinam as relações entre variáveis na vida real;

- Recog\%: é a taxa de reconhecimento. Considerando-se uma margem de erro aceitável, determina qual o percentual de amostras que se encaixa dentro desta margem. A margem de erro máxima aceitável neste trabalho é de $75 \mathrm{~N}$, o qual é um 
valor bem razoável, tendo em vista que o processo investigado trabalha com um ponto de operação de $550 \mathrm{~N}$.

- MAD: é o desvio absoluto máximo, ou seja, o erro absoluto máximo encontrado.

A melhor topologia entre as testadas inicialmente foi a 5-5-1, tendo como configuração da função de aprendizagem Rprop, usada pela ferramenta SNNS, um delta zero de 0,0001, um delta máximo de 3, um alpha de 3, e valores de inicialização dos pesos aleatórios variando de -1 a 1 (para mais informações sobre estes parâmetros, consultar o manual da ferramenta SNNS) (MACHE, 1995). Os resultados da melhor entre as três inicializações, obtidos na topologia 5-5-1, são mostrados na tabela 4.1.

Tabela 4.1 - Resultados iniciais obtidos com a topologia 5-5-1

\begin{tabular}{|c|c|r|c|c|c|r|c|}
\hline \multicolumn{9}{|c|}{ 5-5-1 } \\
\hline \multicolumn{7}{|c|}{ Treinamento } & \multicolumn{4}{c|}{ Validação } \\
\hline MSE & \multicolumn{1}{|c|}{$\mathbf{R}^{\wedge} \mathbf{2}$} & Recog \% & MAD & MSE & $\mathbf{R}^{\wedge} \mathbf{2}$ & Recog \% & MAD \\
\hline 0,11116 & 0,89951 & $97 \%$ & 1,06659 & 0,09933 & 0,90883 & $100 \%$ & 0,68959 \\
\hline
\end{tabular}

Os resultados mostrados na tabela 4.1 revelam que a etapa do sistema proposto que faz a estimação da qualidade da solda, no processo em análise, pode ser realizada com sucesso, já que um erro médio quadrático de 9,933 $\mathrm{N}$ para se estimar a força de cisalhamento, equivalendo a um erro percentual absoluto médio menor que $6 \%$, é um excelente resultado, pois é melhor do que os resultados encontrados na literatura. Além disso, o coeficiente de determinação em torno de 0,9 mostra uma excelente relação entre os parâmetros ajustáveis do modelo criado e a força de cisalhamento suportada pela solda. A figura 4.8 mostra um gráfico com os valores reais e os valores estimados da qualidade dos testes do conjunto de dados usado para validar a rede neural, mostrando que para a topologia 5-5-1 foi possível obter uma taxa de reconhecimento de $100 \%$, considerando a tolerância de 75 N. Esta figura foi obtida 
através da leitura dos resultados da ferramenta SNNS usando um programa relacionado à ferramenta chamado "NETRESULT".

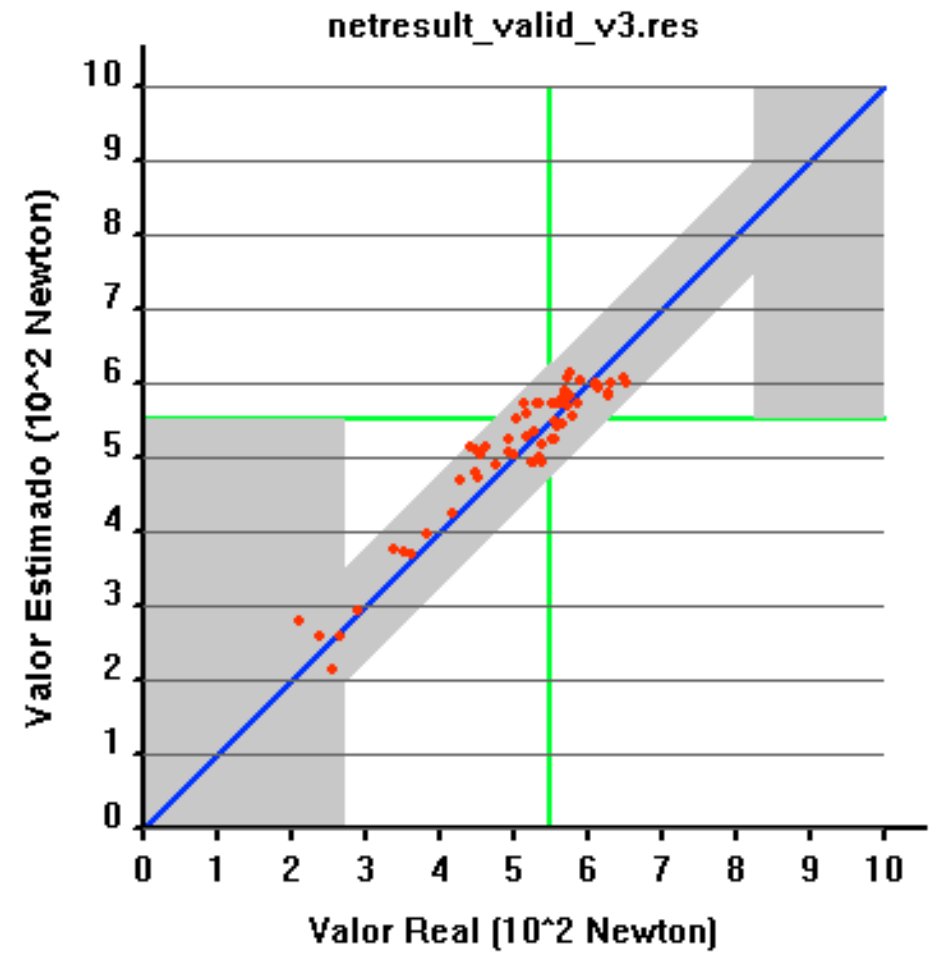

Number of samples: 60

Statistics:

MAD: $\quad 0.68959$

MSE: $\quad 0.09933$

SSE: $\quad 5.95977$

$R^{2}: \quad 0.90883$

Recognition values:

Tolerance: $\quad 0.75$

Correct classified: $\quad 60$

of: $\quad 60$

Recognition rate: $100 \%$

Figura 4.8 - Resultado da topologia 5-5-1 para os dados de validação

Apesar dos resultados iniciais serem satisfatórios, há a possibilidade de existir uma topologia melhor e, principalmente, pode haver entre os cinco parâmetros ajustáveis do modelo um ou mais parâmetros que não sejam necessários ou, mesmo, que prejudiquem a estimativa da qualidade final da solda por parte da rede neural. Para responder a esta questão, foi feito um estudo para identificar qual a melhor combinação de parâmetros do modelo na entrada da rede e qual a melhor topologia de rede, entre as usadas no estudo, para estimar a qualidade final da solda.

Neste estudo foram testadas, para cada combinação possível de parâmetros do modelo usada na entrada da rede, cinco topologias de rede com uma camada oculta, já que este tipo de topologia apresentou resultados superiores. O número de neurônios na camada oculta nessas 
cinco topologias de rede testadas foram, respectivamente, 3, 5, 8, 10 e 15 neurônios. Para cada topologia testada, foram realizadas três inicializações da rede e respectivos treinamentos e validações, sendo o melhor resultado entre as três inicializações o escolhido como resultado da topologia.

Como dito anteriormente, todas as combinações possíveis com os cinco parâmetros ajustáveis do modelo foram testadas na entrada da rede, ou seja, foi testado cada parâmetro individualmente, combinados dois a dois, combinados três a três, combinados quatro a quatro, e os cinco parâmetros juntos.

A configuração da função de aprendizagem Rprop, usada pela ferramenta SNNS, foi a mesma utilizada no melhor teste entre os testes realizados inicialmente, ou seja, utilizou-se um delta zero de 0,0001, um delta máximo de 3 e um alpha de 3 . Os valores de inicialização dos pesos também foram aleatórios, variando de -1 a 1 .

Inicialmente este estudo foi feito no primeiro conjunto de dados, utilizando, para o treinamento da rede neural, 122 testes, e para a validação da rede, seus outros 60 testes. Nos dois grupos de dados, dados de treinamento e dados de validação, foram incluídos testes com as diferentes condições de processo testadas em campo e estes grupos não foram alterados durante o estudo.

As tabelas 4.2, 4.3, 4.4, 4.5 e 4.6 mostram os resultados do estudo com as diferentes topologias testadas e com as possíveis combinações de um parâmetro, dois parâmetros, três parâmetros, quatro parâmetros e cinco parâmetros na entrada da rede, respectivamente.

$\mathrm{O}(\mathrm{s})$ parâmetro(s) utilizado(s) na entrada da rede aparecem do lado esquerdo das tabelas. A topologia utilizada aparece na linha superior de cada grupo de resultados, significando, por exemplo, o valor 1-3-1, que existe 1 neurônio na camada de entrada, 3 neurônios na camada intermediária oculta e 1 neurônio na camada de saída, sendo o resultado deste neurônio a estimativa da força de cisalhamento suportada pela solda. 
Os resultados destacados em vermelho são os da validação da melhor entre as cinco topologias de rede testadas para cada combinação de parâmetros utilizada na entrada da rede.

Tabela 4.2 - Resultados de diferentes topologias com 1 parâmetro na entrada da rede

\begin{tabular}{|c|c|c|c|c|c|c|c|c|}
\hline & \multicolumn{8}{|c|}{$1-3-1$} \\
\hline & \multicolumn{4}{|c|}{ Treinamento } & \multicolumn{4}{|c|}{ Validação } \\
\hline & MSE & $R^{\wedge} 2$ & Recog \% & MAD & MSE & $R^{\wedge} 2$ & Recog \% & MAD \\
\hline ROc & 0,79876 & 0,27794 & $76 \%$ & 3,33297 & 0,88457 & 0,18809 & $76 \%$ & 2,89173 \\
\hline R0elm & 0,41438 & 0,62541 & $81 \%$ & 1,75013 & 0,44388 & 0,59258 & $78 \%$ & 1,80921 \\
\hline Kc & 0,52995 & 0,52094 & $79 \%$ & 2,82026 & 0,39184 & 0,64034 & $83 \%$ & 2,25607 \\
\hline Kelm & 0,44873 & 0,51176 & $80 \%$ & 3,32995 & 0,44588 & 0,59074 & $83 \%$ & 2,52337 \\
\hline \multirow[t]{4}{*}{ Kc-soft } & 0,15979 & 0,85554 & $95 \%$ & 1,02598 & 0,1567 & 0,85616 & $93 \%$ & 0,9694 \\
\hline & \multicolumn{8}{|c|}{$1-5-1$} \\
\hline & \multicolumn{4}{|c|}{ Treinamento } & \multicolumn{4}{|c|}{ Validação } \\
\hline & MSE & $R^{\wedge} 2$ & $\operatorname{Recog} \%$ & MAD & MSE & $R^{\wedge} 2$ & Recog \% & MAD \\
\hline ROc & 0,80043 & 0,27642 & $76 \%$ & 3,34969 & 0,88345 & 0,18912 & $75 \%$ & 2,89009 \\
\hline R0elm & 0,38923 & 0,64814 & $80 \%$ & 1,77608 & 0,43685 & 0,59903 & $73 \%$ & 1,80422 \\
\hline Kc & 0,52938 & 0,52145 & 79\% & 2,81761 & 0,3926 & 0,63964 & $83 \%$ & 2,25263 \\
\hline Kelm & 0,44542 & 0,59734 & $81 \%$ & 3,32378 & 0,39863 & 0,63411 & $83 \%$ & 2,46745 \\
\hline \multirow[t]{4}{*}{\begin{tabular}{|l} 
Kc-soft \\
\end{tabular}} & 0,15973 & 0,8556 & $95 \%$ & 1,02311 & 0,15626 & 0,85657 & $93 \%$ & 0,96378 \\
\hline & \multicolumn{8}{|c|}{ 1-8-1 } \\
\hline & \multicolumn{4}{|c|}{ Treinamento } & \multicolumn{4}{|c|}{ Validação } \\
\hline & MSE & $R^{\wedge} 2$ & $\operatorname{Recog} \%$ & MAD & MSE & $R^{\wedge} 2$ & Recog \% & MAD \\
\hline ROc & 0,80061 & 0,27627 & 76\% & 3,3805 & 0,88484 & 0,18784 & $73 \%$ & 2,8938 \\
\hline R0elm & 0,39573 & 0,64226 & 79\% & 1,78512 & 0,43599 & 0,59982 & $73 \%$ & 1,7961 \\
\hline Kc & 0,53208 & 0,51901 & $80 \%$ & 2,81181 & 0,39263 & 0,63962 & $81 \%$ & 2,24558 \\
\hline Kelm & 0,43801 & 0,60405 & $81 \%$ & 3,31711 & 0,4123 & 0,62156 & $85 \%$ & 2,55953 \\
\hline \multirow[t]{4}{*}{ Kc-soft } & 0,15952 & 0,85579 & $95 \%$ & 1,02567 & 0,15611 & 0,85671 & $93 \%$ & 0,9613 \\
\hline & \multicolumn{8}{|c|}{$1-10-1$} \\
\hline & \multicolumn{4}{|c|}{ Treinamento } & \multicolumn{4}{|c|}{ Validação } \\
\hline & MSE & $R^{\wedge} 2$ & $\operatorname{Recog} \%$ & MAD & MSE & $R^{\wedge} 2$ & Recog \% & MAD \\
\hline ROC & 0,82195 & 0,25697 & $76 \%$ & 3,30457 & 0,88925 & 0,18078 & $70 \%$ & 2,83942 \\
\hline R0elm & 0,39096 & 0,64658 & $80 \%$ & 1,79444 & 0,43854 & 0,59747 & $70 \%$ & 1,80838 \\
\hline Kc & 0,53313 & 0,51806 & 79\% & 2,80567 & 0,39244 & 0,63979 & $81 \%$ & 2,24509 \\
\hline Kelm & 0,43938 & 0,60281 & $81 \%$ & 3,33564 & 0,41297 & 0,62095 & $85 \%$ & 2,53333 \\
\hline \multirow[t]{4}{*}{ Kc-soft } & 0,15955 & 0,85576 & 95\% & 1,02471 & 0,15611 & 0,85671 & $93 \%$ & 0,9618 \\
\hline & \multicolumn{8}{|c|}{$1-15-1$} \\
\hline & \multicolumn{4}{|c|}{ Treinamento } & \multicolumn{4}{|c|}{ Validação } \\
\hline & MSE & $R^{\wedge} 2$ & Recog \% & MAD & MSE & $R^{\wedge} 2$ & Recog \% & MAD \\
\hline ROC & 0,826 & 0,25331 & $76 \%$ & 3,31931 & 0,89684 & 0,17682 & $71 \%$ & 2,84769 \\
\hline R0elm & 0,41752 & 0,62257 & $77 \%$ & 1,82311 & 0,44431 & 0,59218 & $76 \%$ & 1,80551 \\
\hline Kc & 0,5401 & 0,51176 & $80 \%$ & 2,85571 & 0,388 & 0,64387 & $85 \%$ & 2,29939 \\
\hline Kelm & 0,44644 & 0,59643 & $81 \%$ & 3,35432 & 0,41898 & 0,61543 & $85 \%$ & 2,53334 \\
\hline Kc-soft & 0,15963 & 0,85569 & $95 \%$ & 1,02643 & 0,15649 & 0,85636 & $93 \%$ & 0,96612 \\
\hline
\end{tabular}


Tabela 4.3 - Resultados de diferentes topologias com 2 parâmetros na entrada da rede

\begin{tabular}{|c|c|c|c|c|c|c|c|c|}
\hline & \multicolumn{8}{|c|}{$2-3-1$} \\
\hline & \multicolumn{4}{|c|}{ Treinamento } & \multicolumn{4}{|c|}{ Validação } \\
\hline & MSE & $R^{\wedge} 2$ & Recog \% & MAD & MSE & $R^{\wedge} 2$ & Recog \% & MAD \\
\hline ROc_ROelm & 0,22139 & 0,79986 & $89 \%$ & 1,31257 & 0,25173 & 0,76894 & $83 \%$ & 1,10807 \\
\hline ROc_Kc & 0,41972 & 0,62058 & $88 \%$ & 3,13716 & 0,33133 & 0,69588 & $93 \%$ & 2,46041 \\
\hline R0c_Kelm & 0,80067 & 0,27622 & $76 \%$ & 3,36655 & 0,88533 & 0,18739 & $78 \%$ & 2,88677 \\
\hline R0c_Kc-soft & 0,13582 & 0,87722 & $98 \%$ & 0,89231 & 0,12576 & 0,88457 & $98 \%$ & 0,82558 \\
\hline R0elm_Kc & 0,31379 & 0,71633 & $81 \%$ & 1,50705 & 0,24193 & 0,77794 & $85 \%$ & 1,38636 \\
\hline R0elm_Kelm & 0,44049 & 0,6018 & $77 \%$ & 1,81156 & 0,45996 & 0,57782 & $76 \%$ & 1,57923 \\
\hline R0elm_Kc-soft & 0,13172 & 0,88092 & $98 \%$ & 1,05499 & 0,13398 & 0,87702 & $98 \%$ & 0,85613 \\
\hline Kc_Kelm & 0,52945 & 0,52138 & $80 \%$ & 2,82247 & 0,3924 & 0,63983 & $83 \%$ & 2,25491 \\
\hline Kc_Kc-soft & 0,13717 & 0,876 & $98 \%$ & 0,99267 & 0,12304 & 0,88706 & $96 \%$ & 0,80768 \\
\hline \multirow[t]{4}{*}{ Kelm_Kc-soft } & 0,15953 & 0,85578 & $95 \%$ & 1,02521 & 0,15595 & 0,85686 & $93 \%$ & 0,96203 \\
\hline & \multicolumn{8}{|c|}{$2-5-1$} \\
\hline & \multicolumn{4}{|c|}{ Treinamento } & \multicolumn{4}{|c|}{ Validação } \\
\hline & MSE & $R^{\wedge} 2$ & Recog \% & MAD & MSE & $R^{\wedge} 2$ & Recog \% & MAD \\
\hline \begin{tabular}{|l|} 
R0c_R0elm \\
\end{tabular} & 0,22992 & 0,79215 & $90 \%$ & 1,33727 & 0,26092 & 0,7605 & $81 \%$ & 1,12662 \\
\hline ROc Kc & 0,42436 & 0,61638 & $89 \%$ & 3,10142 & 0,31458 & 0,71126 & $93 \%$ & 2,44053 \\
\hline ROc_Kelm & 0,8008 & 0,27609 & $77 \%$ & 3,34326 & 0,88282 & 0,18969 & $75 \%$ & 2,88685 \\
\hline R0c_Kc-soft & 0,13592 & 0,87713 & $98 \%$ & 0,89302 & 0,12586 & 0,88447 & $98 \%$ & 0,82234 \\
\hline R0elm Kc & 0,32571 & 0,70556 & $81 \%$ & 1,54333 & 0,24135 & 0,77847 & $85 \%$ & 1,38147 \\
\hline R0elm_Kelm & 0,4399 & 0,60234 & $77 \%$ & 1,80496 & 0,45887 & 0,57882 & $76 \%$ & 1,58066 \\
\hline R0elm_Kc-soft & 0,13113 & 0,88145 & $98 \%$ & 1,0573 & 0,13488 & 0,87619 & $98 \%$ & 0,86213 \\
\hline Kc_Kelm & 0,53243 & 0,51869 & $81 \%$ & 2,82499 & 0,39138 & 0,64076 & $83 \%$ & 2,25697 \\
\hline Kc_Kc-soft & 0,13509 & 0,87788 & $98 \%$ & 0,97467 & 0,12395 & 0,88623 & $96 \%$ & 0,80168 \\
\hline \multirow[t]{4}{*}{ Kelm_Kc-soft } & 0,1594 & 0,8559 & $95 \%$ & 1,02664 & 0,15609 & 0,85673 & $93 \%$ & 0,96238 \\
\hline & \multicolumn{8}{|c|}{$2-8-1$} \\
\hline & \multicolumn{4}{|c|}{ Treinamento } & \multicolumn{4}{|c|}{ Validação } \\
\hline & MSE & $\mathrm{R}^{\wedge} 2$ & Recog \% & MAD & MSE & $R^{\wedge} 2$ & $\operatorname{Recog} \%$ & MAD \\
\hline ROC_ROelm & 0,2669 & 0,75872 & $90 \%$ & 2,11064 & 0,26694 & 0,75498 & $86 \%$ & 1,10016 \\
\hline ROC_Kc & 0,42431 & 0,61643 & $88 \%$ & 3,1085 & 0,30976 & 0,71568 & $95 \%$ & 2,43483 \\
\hline R0c_Kelm & 0,82651 & 0,25285 & $76 \%$ & 3,30902 & 0,89643 & 0,1772 & $70 \%$ & 2,83305 \\
\hline R0c_Kc-soft & 0,1357 & 0,87733 & $97 \%$ & 0,88338 & 0,12594 & 0,8844 & $98 \%$ & 0,82348 \\
\hline R0elm_Kc & 0,32179 & 0,7091 & $81 \%$ & 1,53585 & 0,24203 & 0,77784 & $85 \%$ & 1,37103 \\
\hline R0elm_Kelm & 0,44036 & 0,60192 & $78 \%$ & 1,81076 & 0,45954 & 0,57821 & $76 \%$ & 1,57674 \\
\hline R0elm_Kc-soft & 0,13123 & 0,88137 & $98 \%$ & 1,05463 & 0,13487 & 0,8762 & $98 \%$ & 0,85742 \\
\hline Kc Kelm & 0,5366 & 0,51492 & $81 \%$ & 2,81099 & 0,3919 & 0,64029 & $81 \%$ & 2,24764 \\
\hline Kc Kc-soft & 0,13856 & 0,87473 & $97 \%$ & 1,02559 & 0,12241 & 0,88764 & $96 \%$ & 0,84054 \\
\hline \multirow[t]{4}{*}{ Kelm_Kc-soft } & 0,15925 & 0,85603 & $95 \%$ & 1,02549 & 0,15564 & 0,85713 & $93 \%$ & 0,96331 \\
\hline & & & & $2-1$ & & & & \\
\hline & & Treina & mento & & & Valid & ação & \\
\hline & MSE & $R^{\wedge 2}$ & Recog \% & MAD & $\overline{M S E}$ & $R^{\wedge} 2$ & $\operatorname{Recog} \%$ & MAD \\
\hline ROc_ROelm & 0,25069 & 0,77338 & $89 \%$ & 2,3259 & 0,29606 & 0,72825 & $76 \%$ & 1,37327 \\
\hline ROC Kc & 0,4292 & 0,61201 & $86 \%$ & 3,06729 & 0,31654 & 0,70946 & $93 \%$ & 2,40978 \\
\hline R0c_Kelm & 0,82737 & 0,25208 & $76 \%$ & 3,3055 & 0,89697 & 0,1767 & $70 \%$ & 2,8359 \\
\hline ROC_Kc-soft & 0,13586 & 0,87718 & $97 \%$ & 0,88096 & 0,12594 & 0,8844 & $98 \%$ & 0,83774 \\
\hline R0elm_Kc & 0,31909 & 0,71155 & $80 \%$ & 1,53203 & 0,24048 & 0,77926 & $85 \%$ & 1,38972 \\
\hline R0elm_Kelm & 0,44003 & 0,60222 & $78 \%$ & 1,80885 & 0,45817 & 0,57946 & $76 \%$ & 1,57693 \\
\hline R0elm_Kc-soft & 0,13189 & 0,88077 & $98 \%$ & 1,06136 & 0,13475 & 0,87631 & $98 \%$ & 0,8624 \\
\hline Kc_Kelm & 0,53224 & 0,51886 & $81 \%$ & 2,81718 & 0,39189 & 0,6403 & $83 \%$ & 2,25106 \\
\hline Kc_Kc-soft & 0,1329 & 0,87985 & $97 \%$ & 0,95507 & 0,12218 & 0,88785 & $95 \%$ & 0,80916 \\
\hline Kelm_Kc-soft & 0,15979 & 0,85555 & $95 \%$ & 1,01852 & 0,15596 & 0,85684 & $93 \%$ & 0,95884 \\
\hline & & & & $2-1$ & & & & \\
\hline & & Treil & mento & & & Valid & ação & \\
\hline & MSE & $R^{\wedge} 2$ & Recog \% & MAD & MSE & $\overline{R^{\wedge} 2}$ & Recog \% & MAD \\
\hline ROC_ROelm & 0,23363 & 0,7888 & $87 \%$ & 1,37326 & 0,24876 & 0,77167 & $83 \%$ & 1,04374 \\
\hline ROC_Kc & 0,44296 & 0,59957 & $86 \%$ & 3,02746 & 0,31074 & 0,71478 & $91 \%$ & 2,3821 \\
\hline R0c_Kelm & 0,82666 & 0,25272 & $76 \%$ & 3,30755 & 0,89708 & 0,1766 & $68 \%$ & 2,83107 \\
\hline R0c_Kc-soft & 0,13545 & 0,87755 & $97 \%$ & 0,87914 & 0,1268 & 0,88361 & $98 \%$ & 0,83104 \\
\hline R0elm_Kc & 0,30478 & 0,72448 & $81 \%$ & 1,49918 & 0,23952 & 0,78015 & $86 \%$ & 1,38604 \\
\hline R0elm_Kelm & 0,44072 & 0,60159 & $77 \%$ & 1,81566 & 0,45969 & 0,57807 & $76 \%$ & 1,57512 \\
\hline \begin{tabular}{|l|} 
R0elm_Kc-soft \\
\end{tabular} & 0,13212 & 0,88056 & $98 \%$ & 1,06 & 0,13413 & 0,87688 & $98 \%$ & 0,85878 \\
\hline Kc_Kelm & 0,52977 & 0,5211 & $80 \%$ & 2,8168 & 0,39289 & 0,63937 & $83 \%$ & 2,24986 \\
\hline Kc_Kc-soft & 0,1375 & 0,8757 & $97 \%$ & 1,01146 & 0,12272 & 0,88736 & $96 \%$ & 0,83452 \\
\hline Kelm_Kc-soft & 0,15946 & 0,85585 & $95 \%$ & 1,0252 & 0,15645 & 0,85639 & $93 \%$ & 0,97178 \\
\hline
\end{tabular}


Tabela 4.4 - Resultados de diferentes topologias com 3 parâmetros na entrada da rede

\begin{tabular}{|c|c|c|c|c|c|c|c|c|}
\hline & \multicolumn{8}{|c|}{ 3-3-1 } \\
\hline & \multicolumn{4}{|c|}{ Treinamento } & \multicolumn{4}{|c|}{ Validação } \\
\hline & MSE & $R^{\wedge} 2$ & Recog \% & MAD & MSE & $R^{\wedge} 2$ & \begin{tabular}{|l|} 
Recog \% \\
\end{tabular} & MAD \\
\hline$\overline{\text { ROc_ROelm_Kc }}$ & 0,20516 & 0,81453 & $90 \%$ & 1,25778 & 0,16318 & 0,8522 & $91 \%$ & 1,03874 \\
\hline R0c_ROelm_Kelm & 0,23734 & 0,78544 & $91 \%$ & 1,73469 & 0,2524 & 0,76832 & $85 \%$ & 1,09242 \\
\hline R0c_R0elm_Kc-soft & 0,12144 & 0,89022 & $99 \%$ & 0,98122 & 0,12371 & 0,88645 & $98 \%$ & 0,90066 \\
\hline R0c_Kc_Kelm & 0,42155 & 0,61893 & $89 \%$ & 3,11391 & 0,33184 & 0,69541 & $93 \%$ & 2,43928 \\
\hline R0c_Kc_Kc-soft & 0,12189 & 0,88981 & $99 \%$ & 0,8869 & 0,10243 & 0,90597 & $100 \%$ & 0,71198 \\
\hline R0c_Kelm_Kc-soft & 0,13881 & 0,87451 & $98 \%$ & 0,91251 & 0,12715 & 0,88329 & $98 \%$ & 0,83311 \\
\hline R0elm_Kc_Kelm & 0,31421 & 0,71596 & $80 \%$ & 1,51255 & 0,24021 & 0,77951 & $85 \%$ & 1,38484 \\
\hline R0elm_Kc_Kc-soft & 0,11881 & 0,89259 & $97 \%$ & 1,11977 & 0,10341 & 0,90508 & $100 \%$ & 0,69445 \\
\hline R0elm Kelm Kc-soft & 0,13147 & 0,88114 & $98 \%$ & 1,05876 & 0,13379 & 0,87719 & $98 \%$ & 0,86057 \\
\hline \multirow[t]{4}{*}{ Kc_Kelm_Kc-soft } & 0,1396 & 0,8738 & $98 \%$ & 1,04656 & 0,12578 & 0,88454 & $96 \%$ & 0,76868 \\
\hline & \multicolumn{8}{|c|}{$3-5-1$} \\
\hline & \multicolumn{4}{|c|}{ Treinamento } & \multicolumn{4}{|c|}{ Validação } \\
\hline & MSE & $R^{\wedge} 2$ & Recog \% & MAD & MSE & $R^{\wedge} 2$ & Recog \% & MAD \\
\hline ROC_R & 0,20449 & 0,81514 & $90 \%$ & 1,2528 & 0,16589 & 0,84773 & $93 \%$ & 1,05371 \\
\hline R0c_ROelm_Kelm & 0,22544 & 0,7962 & $90 \%$ & 1,35802 & 0,24825 & 0,77214 & $83 \%$ & 1,07935 \\
\hline R0c_R0elm_Kc-soft & 0,12373 & 0,88814 & $98 \%$ & 1,00819 & 0,12451 & 0,88571 & $98 \%$ & 0,91732 \\
\hline ROc_Kc_Kelm & 0,43105 & 0,61034 & $86 \%$ & 3,10196 & 0,3115 & 0,71408 & $91 \%$ & 2,44534 \\
\hline R0c Kc Kc-soft & 0,1223 & 0,88943 & $98 \%$ & 0,90859 & 0,10079 & 0,90748 & $100 \%$ & 0,73426 \\
\hline R0c Kelm Kc-soft & 0,13607 & 0,87699 & $97 \%$ & 0,89245 & 0,12565 & 0,88329 & $98 \%$ & $\overline{, 83311}$ \\
\hline R0elm Kc Kelm & 0,32616 & 0,7 & $81 \%$ & 1,57179 & 0,24102 & 0,77877 & $83 \%$ & 40629 \\
\hline Kc-soft & 0,1159 & 0,8 & $98 \%$ & 1,10024 & 0,10339 & 0,90509 & $100 \%$ & 0,65365 \\
\hline m_Kc-soft & 0,13115 & 144 & $98 \%$ & 1,05259 & 0,13484 & 0,87623 & $98 \%$ & 0,85574 \\
\hline \multirow[t]{4}{*}{ Kc_Kelm_Kc-soft } & 0,13831 & 0,87496 & $97 \%$ & 1,01222 & 0,12241 & 0,88764 & $96 \%$ & 0,82731 \\
\hline & \multicolumn{8}{|c|}{ 3-8 } \\
\hline & \multicolumn{4}{|c|}{ Treinamento } & \multicolumn{4}{|c|}{ Validação } \\
\hline & MSE & $\mathrm{R}^{\wedge} \mathbf{2}$ & $\operatorname{Recog} \%$ & MAD & MSE & $\overline{R^{\wedge} 2}$ & Recog \% & MAD \\
\hline $\mathrm{Kc}$ & 0,19747 & 0,82148 & $93 \%$ & 1,20066 & 0,16095 & 0,85226 & $95 \%$ & 1,02841 \\
\hline 20c_R0elm_Kelm & 0,26285 & 0,76238 & $89 \%$ & 1,92217 & 0,25893 & 0,76233 & $86 \%$ & 1,0849 \\
\hline Kc-soft & 12245 & 0,8893 & $99 \%$ & 0,98385 & 2188 & 0,88813 & $98 \%$ & 0,88736 \\
\hline R0c_Kc & 42351 & 0,61716 & $89 \%$ & 3,10676 & 619 & 0,71895 & $95 \%$ & 2,43688 \\
\hline c-soft & 12321 & 0,88861 & $99 \%$ & 0,91571 & 038 & 0,90786 & $100 \%$ & 0,73785 \\
\hline R0c_Kelm_Kc-soft & 13578 & 0,87725 & $97 \%$ & 0,88253 & 2613 & 0,88422 & $98 \%$ & 0,82376 \\
\hline R0elm_Kc_Kelm & 0,32398 & 0,70713 & $80 \%$ & 1,57593 & 24032 & 0,77941 & $85 \%$ & 1,40997 \\
\hline R0elm_Kc_Kc-soft & 0,11835 & 0,893 & $98 \%$ & 1,1171 & 0,10308 & 0,90538 & $100 \%$ & 0,69329 \\
\hline R0elm_Kelm_Kc-so & 0,13203 & 0,88064 & $98 \%$ & 1,05949 & 0,13481 & 0,87625 & $98 \%$ & 0,86092 \\
\hline \multirow[t]{4}{*}{ Kc_Kelm Kc-soft } & 0,13299 & 0,87978 & $97 \%$ & 0,94594 & 0,12533 & 0,88473 & $96 \%$ & 0,80787 \\
\hline & & & & & & & & \\
\hline & & Trei & U & & & Valic & lação & \\
\hline & MSE & $R^{\wedge} 2$ & Recog \% & MAD & MSE & $R^{\wedge} 2$ & Recog \% & MAD \\
\hline ROC_ROelm_Kc & 0,22866 & 0,79329 & $90 \%$ & 1,27106 & 0,16758 & 0,84618 & $95 \%$ & 0,8855 \\
\hline R0c_ROelm_Kelm & 0,26476 & 0,76066 & $89 \%$ & 1,85354 & 0,26395 & 0,75772 & $81 \%$ & 1,13604 \\
\hline R0c_R0elm_Kc-soft & 0,12018 & 0,89135 & $99 \%$ & 0,96295 & 0,12317 & 0,88694 & $98 \%$ & 0,88853 \\
\hline R0c_Kc_Kelm & 0,4339 & 0,60776 & $85 \%$ & 3,04421 & 0,31788 & 0,70823 & $91 \%$ & 2,38643 \\
\hline R0c_Kc_Kc-soft & 0,12248 & 0,88928 & $99 \%$ & 0,90356 & 0,10044 & 0,9078 & $100 \%$ & 0,7235 \\
\hline R0c_Kelm_Kc-soft & 0,1367 & 0,87642 & $97 \%$ & 0,89558 & 0,12589 & 0,88445 & $98 \%$ & 0,83129 \\
\hline R0elm_Kc_Kelm & 0,33006 & 0,70163 & $81 \%$ & 1,56093 & 0,24154 & 0,77829 & $85 \%$ & 1,40994 \\
\hline R0elm_Kc_Kc-soft & 0,11895 & 0,89246 & $97 \%$ & 1,11872 & 0,10361 & 0,9049 & $100 \%$ & 0,70205 \\
\hline R0elm_Kelm_Kc-sc & 0,13175 & 0,88089 & $98 \%$ & 1,05464 & 0,1337 & 0,87727 & $98 \%$ & 0,85274 \\
\hline Kc_Kelm_Kc-soft & 0,13275 & 0,87999 & $97 \%$ & 0,94446 & 0,12542 & 0,88487 & $96 \%$ & 0,80923 \\
\hline & & & & & & & & \\
\hline & & Tre & & & & $v_{0}$ & lação & \\
\hline & MSE & $R^{\wedge} 2$ & $2 \operatorname{cog} \%$ & MAD & MSE & $R^{\wedge} 2$ & Recog \% & MAD \\
\hline R0c_ROelm_Kc & 0,23702 & 0,78573 & $88 \%$ & 1,30936 & 0,17277 & 0,84141 & $91 \%$ & 0,92476 \\
\hline R0c_ROelm_Kelm & 0,23219 & 0,7901 & $88 \%$ & 1,34369 & 0,26393 & 0,75774 & $81 \%$ & 1,13758 \\
\hline R0c_R0elm_Kc-soft & 0,12052 & 0,89105 & $99 \%$ & 0,96753 & 0,12437 & 0,88584 & $98 \%$ & 0,89783 \\
\hline R0c_Kc_Kelm & 0,44463 & 0,59806 & $86 \%$ & 3,02044 & 0,31065 & 0,714866 & $91 \%$ & 2,39636 \\
\hline R0c_Kc_Kc-soft & 0,12653 & 0,88562 & $99 \%$ & 0,93412 & 0,10186 & 0,9065 & $100 \%$ & 0,70456 \\
\hline R0c_Kelm_Kc-soft & 0,13651 & 0,87659 & $97 \%$ & 0,89479 & 0,12585 & 0,88448 & $98 \%$ & 0,82741 \\
\hline R0elm_Kc_Kelm & 0,32641 & 0,70492 & $81 \%$ & 1,54546 & 0,24057 & 0,77918 & $85 \%$ & 1,37624 \\
\hline R0elm_Kc_Kc-soft & 0,11822 & 0,89313 & $97 \%$ & 1,11803 & 0,10306 & 0,9054 & $100 \%$ & 0,69085 \\
\hline Kc-soft & 0,13176 & 0,88088 & $98 \%$ & 1,05947 & 0,13445 & 0,87659 & $98 \%$ & 0,86027 \\
\hline Kc_Kelm_Kc-soft & 0,13226 & 0,88043 & $97 \%$ & 0,94911 & 0,12211 & 0,88791 & $95 \%$ & 0,81466 \\
\hline
\end{tabular}


Tabela 4.5 - Resultados de diferentes topologias com 4 parâmetros na entrada da rede

\begin{tabular}{|c|c|c|c|c|c|c|c|c|}
\hline & \multicolumn{8}{|c|}{ 4-3-1 } \\
\hline & \multicolumn{4}{|c|}{ Treinamento } & \multicolumn{4}{|c|}{ Validação } \\
\hline & MSE & $R^{\wedge} 2$ & $\operatorname{Recog} \%$ & MAD & MSE & $R^{\wedge} 2$ & Recog \% & MAD \\
\hline R0c_ROelm_Kc_Kelm & 0,20369 & 0,81587 & $90 \%$ & 1,26197 & 0,16052 & 0,85265 & $91 \%$ & 0,99526 \\
\hline R0c_R0elm_Kc_Kc-soft & 0,11806 & 0,89327 & $96 \%$ & 1,1126 & 0,10054 & 0,90771 & $100 \%$ & 0,72797 \\
\hline R0c_R0elm_Kelm_Kc-soft & 0,12093 & 0,89068 & $99 \%$ & 0,97299 & 0,12423 & 0,88596 & $98 \%$ & 0,89948 \\
\hline R0c_Kc_Kelm_Kc-soft & 0,12174 & 0,88994 & $99 \%$ & 0,88633 & 0,1023 & 0,9061 & $100 \%$ & 0,70672 \\
\hline \multirow[t]{4}{*}{ R0elm_Kc_Kelm_Kc-soft } & 0,11878 & 0,89262 & $97 \%$ & 1,12087 & 0,10324 & 0,90524 & $100 \%$ & 0,69475 \\
\hline & \multicolumn{8}{|c|}{ 4-5-1 } \\
\hline & \multicolumn{4}{|c|}{ Treinamento } & \multicolumn{4}{|c|}{ Validação } \\
\hline & MSE & $R^{\wedge} 2$ & Recog \% & MAD & MSE & $R^{\wedge} 2$ & Recog \% & MAD \\
\hline R0c_ROelm_Kc_Kelm & 0,18652 & 0,83138 & $93 \%$ & 1,16491 & 0,15848 & 0,85453 & $95 \%$ & 0,91603 \\
\hline R0c_R0elm_Kc_Kc-soft & 0,11232 & 0,89846 & $97 \%$ & 1,07672 & 0,09775 & 0,91027 & $100 \%$ & 0,70668 \\
\hline R0c_R0elm_Kelm_Kc-soft & 0,12164 & 0,89003 & $99 \%$ & 0,98673 & 0,12366 & 0,88649 & $98 \%$ & 0,90048 \\
\hline R0c_Kc_Kelm_Kc-soft & 0,11986 & 0,89164 & $98 \%$ & 0,90358 & 0,1025 & 0,90591 & $98 \%$ & 0,77399 \\
\hline \multirow[t]{4}{*}{ R0elm_Kc_Kelm_Kc-soft } & 0,11938 & 0,89207 & $97 \%$ & 1,12838 & 0,10381 & 0,90471 & $100 \%$ & 0,685 \\
\hline & \multicolumn{8}{|c|}{ 4-8-1 } \\
\hline & \multicolumn{4}{|c|}{ Treinamento } & \multicolumn{4}{|c|}{ Validação } \\
\hline & MSE & $R^{\wedge} 2$ & Recog \% & MAD & MSE & $R^{\wedge} 2$ & $\operatorname{Recog} \%$ & MAD \\
\hline R0c_ROelm_Kc_Kelm & 0,19208 & 0,82636 & $93 \%$ & 0,82636 & 0,16021 & 0,85294 & $95 \%$ & 0,88315 \\
\hline R0c_R0elm_Kc_Kc-soft & 0,11413 & 0,89682 & $97 \%$ & 1,09501 & 0,09856 & 0,90952 & $100 \%$ & 0,71769 \\
\hline R0c_R0elm_Kelm_Kc-soft & 0,12085 & 0,89074 & $99 \%$ & 0,97311 & 0,12541 & 0,88489 & $98 \%$ & 0,90753 \\
\hline R0c_Kc_Kelm_Kc-soft & 0,12351 & 0,88834 & $99 \%$ & 0,93037 & 0,10025 & 0,90798 & $100 \%$ & 0,72351 \\
\hline \multirow[t]{4}{*}{ R0elm_Kc_Kelm_Kc-soft } & 0,11966 & 0,89182 & $97 \%$ & 1,13206 & 0,1036 & 0,90491 & $100 \%$ & 0,68569 \\
\hline & \multicolumn{8}{|c|}{$4-10-1$} \\
\hline & \multicolumn{4}{|c|}{ Treinamento } & \multicolumn{4}{|c|}{ Validação } \\
\hline & MSE & $R^{\wedge} 2$ & $\operatorname{Recog} \%$ & MAD & MSE & $\mathbf{R}^{\wedge} \mathbf{2}$ & $\operatorname{Recog} \%$ & MAD \\
\hline R0c_R0elm_Kc_Kelm & 0,21673 & 0,80407 & $92 \%$ & 1,23236 & 0,16132 & 0,85192 & $95 \%$ & 1,00926 \\
\hline R0c_R0elm_Kc_Kc-soft & 0,11143 & 0,89926 & $97 \%$ & 1,06371 & 0,09754 & 0,91047 & $100 \%$ & 0,70023 \\
\hline R0c_R0elm_Kelm_Kc-soft & 0,12113 & 0,89049 & $99 \%$ & 0,97859 & 0,12491 & 0,88535 & $98 \%$ & 0,90195 \\
\hline R0c_Kc_Kelm_Kc-soft & 0,12221 & 0,88952 & $99 \%$ & 0,90596 & 0,10071 & 0,90756 & $100 \%$ & 0,74031 \\
\hline \multirow[t]{4}{*}{ R0elm_Kc_Kelm_Kc-soft } & 0,11975 & 0,89174 & $97 \%$ & 1,13752 & 0,10345 & 0,90504 & $100 \%$ & 0,69101 \\
\hline & \multicolumn{8}{|c|}{ 4-15-1 } \\
\hline & \multicolumn{4}{|c|}{ Treinamento } & \multicolumn{4}{|c|}{ Validação } \\
\hline & MSE & $R^{\wedge} 2$ & Recog \% & MAD & MSE & $R^{\wedge} 2$ & $\operatorname{Recog} \%$ & MAD \\
\hline R0c_R0elm_Kc_Kelm & 0,18655 & 0,83135 & $93 \%$ & 1,17979 & 0,16326 & 0,85014 & $91 \%$ & 0,90355 \\
\hline R0c_R0elm_Kc_Kc-soft & 0,11149 & 0,8992 & $97 \%$ & 1,06888 & 0,09797 & 0,91007 & $100 \%$ & 0,69572 \\
\hline R0c_R0elm_Kelm_Kc-soft & 0,12173 & 0,88995 & $99 \%$ & 0,98474 & 0,12523 & 0,88505 & $98 \%$ & 0,90817 \\
\hline R0c_Kc_Kelm_Kc-soft & 0,12471 & 0,88726 & $99 \%$ & 0,92881 & 0,10105 & 0,90724 & $100 \%$ & 0,74299 \\
\hline R0elm_Kc_Kelm_Kc-soft & 0,11696 & 0,89426 & $98 \%$ & 1,11225 & 0,10261 & 0,90581 & $100 \%$ & 0,67696 \\
\hline
\end{tabular}

Tabela 4.6 - Resultados de diferentes topologias com 5 parâmetros na entrada da rede

\begin{tabular}{|c|c|c|c|c|c|c|c|c|}
\hline & \multicolumn{8}{|c|}{ 5-3-1 } \\
\hline & \multicolumn{4}{|c|}{ Treinamento } & \multicolumn{4}{|c|}{ Validação } \\
\hline & MSE & $\mathbf{R}^{\wedge} \mathbf{2}$ & $\operatorname{Recog} \%$ & MAD & MSE & $\mathbf{R}^{\wedge} \mathbf{2}$ & $\operatorname{Recog} \%$ & MAD \\
\hline \multirow[t]{4}{*}{ R0c_R0elm_Kc_Kelm_Kc-soft } & 0,11804 & 0,89329 & $96 \%$ & 1,11316 & 0,10051 & 0,90773 & $100 \%$ & 0,73618 \\
\hline & \multicolumn{8}{|c|}{$\overline{5-5-1}$} \\
\hline & \multicolumn{4}{|c|}{ Treinamento } & \multicolumn{4}{|c|}{ Validação } \\
\hline & MSE & $\overline{R^{\wedge} 2}$ & Recog \% & MAD & MSE & $\overline{R^{\wedge} 2}$ & $\operatorname{Recog} \%$ & MAD \\
\hline \multirow[t]{4}{*}{ R0c_R0elm_Kc_Kelm_Kc-soft } & 0,11116 & 0,89951 & $97 \%$ & 1,06659 & 0,09933 & 0,90883 & $100 \%$ & 0,68959 \\
\hline & \multicolumn{8}{|c|}{ 5-8-1 } \\
\hline & \multicolumn{4}{|c|}{ Treinamento } & \multicolumn{4}{|c|}{ Validação } \\
\hline & MSE & $\mathbf{R}^{\wedge} \mathbf{2}$ & Recog \% & MAD & MSE & $\mathbf{R}^{\wedge} 2$ & Recog \% & MAD \\
\hline \multirow[t]{4}{*}{ R0c_R0elm_Kc_Kelm_Kc-soft } & 0,11194 & 0,8988 & $97 \%$ & 1,0725 & 0,0968 & 0,91114 & $100 \%$ & 0,69913 \\
\hline & \multicolumn{8}{|c|}{$5-10-1$} \\
\hline & \multicolumn{4}{|c|}{ Treinamento } & \multicolumn{4}{|c|}{ Validação } \\
\hline & MSE & $R^{\wedge} 2$ & Recog \% & MAD & MSE & $\mathbf{R}^{\wedge} \mathbf{2}$ & Recog \% & MAD \\
\hline \multirow[t]{4}{*}{ R0c_R0elm_Kc_Kelm_Kc-soft } & 0,11683 & 0,89438 & $96 \%$ & 1,11267 & 0,09996 & 0,90825 & $100 \%$ & 0,72543 \\
\hline & \multicolumn{8}{|c|}{ 5-15-1 } \\
\hline & \multicolumn{4}{|c|}{ Treinamento } & \multicolumn{4}{|c|}{ Validação } \\
\hline & MSE & $\mathbf{R}^{\wedge} \mathbf{2}$ & Recog \% & MAD & MSE & $\mathbf{R}^{\wedge} \mathbf{2}$ & Recog \% & MAD \\
\hline ROc_ROelm_Kc_Kelm_Kc-soft & 0,11932 & 0,89213 & $97 \%$ & 1,12576 & 0,09934 & 0,90881 & $100 \%$ & 0,72097 \\
\hline
\end{tabular}


Após a realização do estudo com o primeiro conjunto de dados, este foi repetido com o segundo conjunto de dados, utilizando-se as mesmas configurações descritas anteriormente, com a única diferença que, como este segundo conjunto possui mais testes, foram utilizados para o treinamento da rede neural 154 testes e para a validação da rede, seus outros 80 testes. As tabelas $4.7,4.8,4.9,4.10$ e 4.11 mostram os resultados do estudo com as diferentes topologias testadas e com as possíveis combinações de um parâmetro, dois parâmetros, três parâmetros, quatro parâmetros e cinco parâmetros na entrada da rede, respectivamente.

Tabela 4.7 - Resultados de diferentes topologias com 1 parâmetro na entrada da rede

\begin{tabular}{|c|c|c|c|c|c|c|c|c|}
\hline & \multicolumn{8}{|c|}{$1-3-1$} \\
\hline & \multicolumn{4}{|c|}{ Treinamento } & \multicolumn{4}{|c|}{ Validação } \\
\hline & MSE & $R^{\wedge} 2$ & Recog \% & MAD & MSE & $R^{\wedge} 2$ & $\operatorname{Recog} \%$ & MAD \\
\hline R0c & 1,15365 & 0,0846 & $67 \%$ & 3,08723 & 0,95439 & 0,06407 & $71 \%$ & 2,8373 \\
\hline R0elm & 0,67358 & 0,46553 & $77 \%$ & 3,0659 & 0,55762 & 0,45316 & $68 \%$ & 1,93166 \\
\hline Kc & 0,89562 & 0,28934 & $67 \%$ & 3,32002 & 0,53655 & 0,47382 & $78 \%$ & 2,6145 \\
\hline Kelm & 1,26036 & 0,00006 & $66 \%$ & 3,16307 & 1,01973 & 0,00001 & $61 \%$ & 2,78307 \\
\hline \multirow[t]{4}{*}{ Kc-soft } & 0,30627 & 0,75698 & $85 \%$ & 2,17796 & 0,27406 & 0,73124 & $87 \%$ & 1,83626 \\
\hline & \multicolumn{8}{|c|}{$1-5-1$} \\
\hline & \multicolumn{4}{|c|}{ Treinamento } & \multicolumn{4}{|c|}{ Validação } \\
\hline & MSE & $R^{\wedge} 2$ & Recog \% & MAD & MSE & $R^{\wedge} 2$ & Recog \% & MAD \\
\hline ROC & 1,15538 & 0,08323 & $66 \%$ & 3,09099 & 0,95468 & 0,063679 & $68 \%$ & 2,83259 \\
\hline R0elm & 0,67817 & 0,46189 & $77 \%$ & 3,05451 & 0,55937 & 0,45144 & $68 \%$ & 1,91804 \\
\hline $\mathrm{Kc}$ & 0,88803 & 0,29536 & $70 \%$ & 3,28546 & 0,51818 & 0,49184 & $80 \%$ & 2,65152 \\
\hline Kelm & 1,26028 & 0,00001 & $66 \%$ & 3,17085 & 1,01977 & 0,00004 & $61 \%$ & 2,79085 \\
\hline \multirow[t]{4}{*}{ Kc-soft } & 0,30631 & 0,75695 & $85 \%$ & 2,1738 & 0,27414 & 0,73116 & $87 \%$ & 1,8345 \\
\hline & \multicolumn{8}{|c|}{$1-8-1$} \\
\hline & \multicolumn{4}{|c|}{ Treinamento } & \multicolumn{4}{|c|}{ Validação } \\
\hline & MSE & $R^{\wedge} 2$ & Recog \% & MAD & MSE & $R^{\wedge} 2$ & Recog \% & MAD \\
\hline ROc & 1,26014 & 0,00011 & $66 \%$ & 3,1558 & 1,0201 & 0,00036 & $61 \%$ & 2,78073 \\
\hline R0elm & 0,7032 & 0,44202 & $76 \%$ & 3,01127 & 0,56962 & 0,4414 & $68 \%$ & 1,86451 \\
\hline $\mathrm{Kc}$ & 0,89538 & 0,28954 & $68 \%$ & 3,3366 & 0,5342 & 0,47612 & $77 \%$ & 2,60656 \\
\hline Kelm & 1,26031 & 0,00002 & $66 \%$ & 3,16617 & 1,01973 & 0,00001 & $61 \%$ & 2,78617 \\
\hline \multirow[t]{4}{*}{ Kc-soft } & 0,30637 & 0,7569 & $85 \%$ & 2,17052 & 0,27435 & 0,73095 & $87 \%$ & 1,83405 \\
\hline & \multicolumn{8}{|c|}{ 1-10-1 } \\
\hline & \multicolumn{4}{|c|}{ Treinamento } & \multicolumn{4}{|c|}{ Validação } \\
\hline & MSE & $R^{\wedge} 2$ & Recog \% & MAD & MSE & $R^{\wedge} 2$ & $\operatorname{Recog} \%$ & MAD \\
\hline R0c & 1,26016 & 0,00009 & $66 \%$ & 3,15299 & 1,02009 & 0,00035 & $61 \%$ & 2,77799 \\
\hline R0elm & 0,67543 & 0,46405 & $77 \%$ & 3,06127 & 0,55849 & 0,45231 & $68 \%$ & 1,9259 \\
\hline Kc & 0,90561 & 0,28142 & $66 \%$ & 3,1655 & 0,54416 & 0,46636 & $78 \%$ & 2,63463 \\
\hline Kelm & 1,26029 & 0,00001 & $66 \%$ & 3,16868 & 1,01975 & 0,00001 & $61 \%$ & 2,78868 \\
\hline \multirow[t]{4}{*}{ Kc-soft } & 0,30632 & 0,75693 & $85 \%$ & 2,17735 & 0,27402 & 0,73128 & $87 \%$ & 1,83756 \\
\hline & \multicolumn{8}{|c|}{ 1-15-1 } \\
\hline & \multicolumn{4}{|c|}{ Treinamento } & \multicolumn{4}{|c|}{ Validação } \\
\hline & MSE & $R^{\wedge} 2$ & Recog \% & MAD & MSE & $R^{\wedge} 2$ & Recog \% & MAD \\
\hline ROC & 1,26018 & 0,00007 & $66 \%$ & 3,15166 & 1,02009 & 0,00035 & $61 \%$ & 2,77664 \\
\hline R0elm & 0,69254 & 0,45048 & $77 \%$ & 3,02929 & 0,56372 & 0,44718 & $68 \%$ & 1,88546 \\
\hline Kc & 1,00208 & 0,20487 & $68 \%$ & 3,58408 & 0,63435 & 0,37792 & $75 \%$ & 2,52039 \\
\hline Kelm & 1,26029 & 0,00001 & $66 \%$ & 3,16832 & 1,01974 & 0,00001 & $61 \%$ & 2,78832 \\
\hline Kc-soft & 0,3063 & 0,75695 & $85 \%$ & 2,17503 & 0,27409 & 0,73121 & $87 \%$ & 1,8347 \\
\hline
\end{tabular}


Tabela 4.8 - Resultados de diferentes topologias com 2 parâmetros na entrada da rede

\begin{tabular}{|c|c|c|c|c|c|c|c|c|}
\hline & \multicolumn{8}{|c|}{$2-3-1$} \\
\hline & \multicolumn{4}{|c|}{ Treinamento } & \multicolumn{4}{|c|}{ Validação } \\
\hline & MSE & $R^{\wedge} 2$ & Recog \% & MAD & MSE & $R^{\wedge} 2$ & Recog \% & MAD \\
\hline R0c_R0elm & 0,55203 & 0,56197 & $78 \%$ & 2,84376 & 0,48867 & 0,52078 & $78 \%$ & 2,19354 \\
\hline ROc_Kc & 0,66253 & 0,4743 & $79 \%$ & 2,78685 & 0,45483 & 0,55396 & $85 \%$ & 2,75669 \\
\hline ROC_Kelm & 1,15341 & 0,08479 & $66 \%$ & 3,08295 & 0,95485 & 0,06362 & $71 \%$ & 2,83358 \\
\hline ROc_Kc-soft & 0,23579 & 0,8129 & $88 \%$ & 1,66798 & 0,1995 & 0,80435 & $92 \%$ & 1,18682 \\
\hline ROelm_Kc & 0,55831 & 0,55699 & $79 \%$ & 3,31938 & 0,34987 & 0,6569 & $78 \%$ & 1,39692 \\
\hline R0elm_Kelm & 0,7082 & 0,43806 & $76 \%$ & 3,00319 & 0,57326 & 0,43881 & $67 \%$ & 1,85629 \\
\hline R0elm_Kc-soft & 0,24729 & 0,80377 & $88 \%$ & 1,54219 & 0,2545 & 0,75742 & $90 \%$ & 1,7327 \\
\hline Kc Kelm & 0,89428 & 0,29041 & $67 \%$ & 3,31703 & 0,53623 & 0,47413 & $78 \%$ & 2,62444 \\
\hline Kc_Kc-soft & 0,30031 & 0,7617 & $86 \%$ & 2,288 & 0,24273 & 0,76196 & $87 \%$ & 1,36783 \\
\hline \multirow[t]{4}{*}{ Kelm_Kc-soft } & 0,30628 & 0,75697 & $85 \%$ & 2,17653 & 0,27414 & 0,73115 & $87 \%$ & 1,83576 \\
\hline & \multicolumn{8}{|c|}{$2-5-1$} \\
\hline & \multicolumn{4}{|c|}{ Treinamento } & \multicolumn{4}{|c|}{ Validação } \\
\hline & MSE & $R^{\wedge} 2$ & Recog \% & MAD & MSE & $R^{\wedge} 2$ & Recog \% & MAD \\
\hline$\overline{\text { R0c_ROelm }}$ & 0,55443 & 0,56007 & $75 \%$ & 2,82655 & 0,46948 & 0,5396 & $81 \%$ & 2,33268 \\
\hline ROc_Kc & 0,69792 & 0,44621 & $78 \%$ & 3,08306 & 0,42663 & 0,58162 & $87 \%$ & 2,72351 \\
\hline ROc_Kelm & 1,15619 & 0,08259 & $66 \%$ & 3,06401 & 0,9546 & 0,0639 & $71 \%$ & 2,81329 \\
\hline ROc_Kc-soft & 0,23327 & 0,81489 & $88 \%$ & 1,66068 & 0,19848 & 0,80535 & $92 \%$ & 1,16934 \\
\hline ROelm_Kc & 0,45645 & 0,63781 & $83 \%$ & 2,97432 & 0,34121 & 0,66539 & $81 \%$ & 1,44859 \\
\hline R0elm_Kelm & 0,69484 & 0,44865 & $77 \%$ & 3,03682 & 0,56376 & 0,44714 & $68 \%$ & 1,89141 \\
\hline R0elm_Kc-soft & 0,24974 & 0,80183 & $87 \%$ & 1,54617 & 0,25489 & 0,75004 & $90 \%$ & 1,71135 \\
\hline Kc Kelm & 0,90119 & 0,28493 & $66 \%$ & 3,24018 & 0,54128 & 0,46918 & $78 \%$ & 2,61346 \\
\hline Kc_Kc-soft & 0,27216 & 0,78404 & $87 \%$ & 1,84084 & 0,22225 & 0,78205 & $90 \%$ & 1,35291 \\
\hline \multirow[t]{4}{*}{ Kelm_Kc-soft } & 0,30627 & 0,75697 & $85 \%$ & 2,17596 & 0,27421 & 0,73109 & $87 \%$ & 1,83626 \\
\hline & \multicolumn{8}{|c|}{$2-8-1$} \\
\hline & \multicolumn{4}{|c|}{ Treinamento } & \multicolumn{4}{|c|}{ Validação } \\
\hline & $\overline{M S E}$ & $R^{\wedge} 2$ & Recog \% & MAD & $\overline{M S E}$ & $R^{\wedge} 2$ & Recog \% & MAD \\
\hline$\overline{R 0 c \_R 0 e l m}$ & 0,54176 & 0,57012 & $77 \%$ & 2,84912 & 0,47388 & 0,53528 & $81 \%$ & 2,35586 \\
\hline ROC_Kc & 0,68872 & 0,45351 & $79 \%$ & 3,0654 & 0,43067 & 0,57766 & $86 \%$ & 2,77289 \\
\hline ROc_Kelm & 1,26017 & 0,00008 & $66 \%$ & 3,1521 & 1,02008 & 0,00034 & $61 \%$ & 2,77707 \\
\hline ROc_Kc-soft & 0,23451 & 0,81392 & $88 \%$ & 1,64941 & 0,1986 & 0,80524 & $92 \%$ & 1,16859 \\
\hline ROelm_Kc & 0,4293 & 0,65935 & $85 \%$ & 2,34143 & 0,34508 & 0,66159 & $81 \%$ & 1,46134 \\
\hline R0elm_Kelm & 0,71103 & 0,43581 & $74 \%$ & 3,04924 & 0,57652 & 0,43463 & $67 \%$ & 1,89247 \\
\hline R0elm_Kc-soft & 0,24975 & 0,80182 & $87 \%$ & 1,53754 & 0,25523 & 0,7497 & $90 \%$ & 1,68518 \\
\hline Kc Kelm & 0,90526 & 0,28169 & $66 \%$ & 3,23294 & 0,54242 & 0,46807 & $78 \%$ & 2,79804 \\
\hline Kc_Kc-soft & 0,27308 & 0,78331 & $88 \%$ & 1,81087 & 0,22466 & 0,77968 & $90 \%$ & 1,35657 \\
\hline \multirow[t]{4}{*}{ Kelm_Kc-soft } & 0,30641 & 0,75686 & $85 \%$ & 2,18007 & 0,2738 & 0,73149 & $87 \%$ & 1,84052 \\
\hline & & & & $2-1$ & & & & \\
\hline & & Treina & mento & & & Valid & ação & \\
\hline & MSE & $R^{\wedge} 2$ & Recog \% & MAD & MSE & $R^{\wedge} 2$ & Recog \% & MAD \\
\hline R0c_R0elm & 0,5539 & 0,56048 & $76 \%$ & 2,82192 & 0,46867 & 0,54039 & $81 \%$ & 2,33886 \\
\hline ROC_Kc & 0,70228 & 0,44275 & $79 \%$ & 3,09794 & 0,42999 & 0,57832 & $87 \%$ & 2,73528 \\
\hline ROc_Kelm & 1,26015 & 0,00001 & $66 \%$ & 3,15435 & 1,02009 & 0,00035 & $61 \%$ & 2,77933 \\
\hline ROc_Kc-soft & 0,23594 & 0,81278 & $88 \%$ & 1,68183 & 0,20043 & 0,80344 & $92 \%$ & 1,18702 \\
\hline ROelm_Kc & 0,47055 & 0,62662 & $82 \%$ & 0,59751 & 0,33875 & 0,66781 & $81 \%$ & 1,43501 \\
\hline ROelm_Kelm & 0,70285 & 0,4423 & $76 \%$ & 3,01031 & 0,56956 & 0,44145 & $68 \%$ & 1,86508 \\
\hline R0elm_Kc-soft & 0,25054 & 0,8012 & $87 \%$ & 1,56106 & 0,25586 & 0,74908 & $90 \%$ & 1,73923 \\
\hline Kc Kelm & 0,90418 & 0,28255 & $66 \%$ & 3,18945 & 0,54442 & 0,4661 & $78 \%$ & 2,62498 \\
\hline Kc_Kc-soft & 0,27173 & 0,78438 & $87 \%$ & 1,83333 & 0,22351 & 0,78081 & $90 \%$ & 1,36568 \\
\hline Kelm_Kc-soft & 0,30632 & 0,75693 & $85 \%$ & 2,17712 & 0,27421 & 0,73109 & $87 \%$ & 1,83803 \\
\hline & & & & $2-1$ & & & & \\
\hline & & Treina & imento & & & Valid & ação & \\
\hline & MSE & $R^{\wedge} 2$ & Recog \% & MAD & MSE & $R^{\wedge} 2$ & Recog \% & MAD \\
\hline R0c_R0elm & 0,60231 & 0,52207 & $76 \%$ & 2,91091 & 0,51528 & 0,49468 & $76 \%$ & 1,94553 \\
\hline ROc_Kc & 0,68451 & 0,45685 & $77 \%$ & 2,7706 & 0,4377 & 0,57076 & $85 \%$ & 2,72947 \\
\hline ROc Kelm & 1,26014 & 0,00001 & $66 \%$ & 3,15514 & 1,0201 & 0,00036 & $61 \%$ & 2,78017 \\
\hline ROc Kc-soft & 0,23642 & 0,8124 & $88 \%$ & 1,66939 & 0,19996 & 0,8039 & $92 \%$ & 1,17831 \\
\hline ROelm_Kc & 0,48514 & 0,61508 & $81 \%$ & 2,72462 & 0,33314 & 0,6733 & $81 \%$ & 1,42531 \\
\hline R0elm_Kelm & 0,68267 & 0,45831 & $77 \%$ & 3,04383 & 0,56047 & 0,45036 & $68 \%$ & 1,90413 \\
\hline R0elm_Kc-soft & 0,25125 & 0,80063 & $87 \%$ & 1,54919 & 0,25541 & 0,74952 & $90 \%$ & 1,69418 \\
\hline Kc Kelm & 0,90671 & 0,28054 & $66 \%$ & 3,20842 & 0,5408 & 0,46966 & $78 \%$ & 2,61722 \\
\hline Kc_Kc-soft & 0,27101 & 0,78496 & $86 \%$ & 1,82973 & 0,22607 & 0,77829 & $90 \%$ & 1,37525 \\
\hline Kelm_Kc-soft & 0,3063 & 0,75695 & $85 \%$ & 2,18057 & 0,27384 & 0,73145 & $87 \%$ & 1,8382 \\
\hline
\end{tabular}


Tabela 4.9 - Resultados de diferentes topologias com 3 parâmetros na entrada da rede

\begin{tabular}{|c|c|c|c|c|c|c|c|c|}
\hline & \multicolumn{8}{|c|}{ 3-3-1 } \\
\hline & \multicolumn{4}{|c|}{ Treinamento } & \multicolumn{4}{|c|}{ Validação } \\
\hline & MSE & $R^{\wedge} 2$ & Recog \% & MAD & MSE & $R^{\wedge} 2$ & Recog \% & MAD \\
\hline ROc_ROelm_Kc & 0,3039 & 0,75885 & $92 \%$ & 2,32071 & 0,21181 & 0,79228 & $91 \%$ & 1,26392 \\
\hline R0c_ROelm_Kelm & 0,56504 & 0,55165 & $80 \%$ & 2,79031 & 0,47835 & 0,5309 & $80 \%$ & 2,31158 \\
\hline ROc_R0elm_Kc-soft & 0,20759 & 0,83527 & $91 \%$ & 1,21685 & 0,22404 & 0,78029 & $91 \%$ & 1,3805 \\
\hline R0c_Kc_Kelm & 0,67568 & 0,46386 & $79 \%$ & 3,00849 & 0,42285 & 0,58533 & $90 \%$ & 2,7418 \\
\hline ROc_Kc_Kc-soft & 0,23867 & 0,81062 & $90 \%$ & 1,70626 & 0,23258 & 0,77191 & $88 \%$ & 1,40271 \\
\hline R0c_Kelm_Kc-soft & 0,23581 & 0,81288 & $88 \%$ & 1,66989 & 0,1994 & 0,80445 & $92 \%$ & 1,18618 \\
\hline R0elm_Kc_Kelm & 0,5702 & 0,54756 & $79 \%$ & 3,4741 & 0,34899 & 0,65776 & $78 \%$ & 1,40557 \\
\hline R0elm_Kc_Kc-soft & 0,23199 & 0,81592 & $88 \%$ & 1,36594 & 0,20404 & 0,7999 & $92 \%$ & 1,36932 \\
\hline R0elm_Kelm_Kc-soft & 0,24812 & 0,80311 & $88 \%$ & 1,53829 & 0,25385 & 0,75105 & $90 \%$ & 1,67809 \\
\hline \multirow[t]{4}{*}{ Kc_Kelm_Kc-soft } & 0,3014 & 0,76084 & $86 \%$ & 2,27424 & 0,24207 & 0,7626 & $87 \%$ & 1,34887 \\
\hline & \multicolumn{8}{|c|}{$3-5-1$} \\
\hline & \multicolumn{4}{|c|}{ Treinamento } & \multicolumn{4}{|c|}{ Validação } \\
\hline & MSE & $\mathbf{R}^{\wedge 2}$ & Recog \% & MAD & MSE & $\mathbf{R}^{\wedge} \mathbf{2}$ & Recog \% & MAD \\
\hline R0c_ROelm_Kc & 0,32973 & 0,73836 & $89 \%$ & 2,37521 & 0,19994 & 0,80392 & 91\% & 1,04599 \\
\hline R0c_R0elm_Kelm & 0,55913 & 0,55634 & $75 \%$ & 2,80498 & 0,47158 & 0,53754 & $81 \%$ & 2,3334 \\
\hline ROc_R0elm_Kc-soft & 0,20286 & 0,83902 & $91 \%$ & 1,17777 & 0,21233 & 0,79177 & $91 \%$ & 1,31426 \\
\hline R0c_Kc_Kelm & 0,67722 & 0,46263 & $79 \%$ & 2,97711 & 0,42472 & 0,58349 & $87 \%$ & 2,75564 \\
\hline R0c_Kc_Kc-soft & 0,21663 & 0,8281 & $89 \%$ & 1,34276 & 0,20158 & 0,80231 & 91\% & 1,05853 \\
\hline R0c_Kelm_Kc-soft & 0,22897 & 0,81831 & $90 \%$ & 1,55495 & 0,19784 & 0,80598 & $92 \%$ & 1,14183 \\
\hline R0elm_Kc_Kelm & 0,43756 & 0,6528 & $83 \%$ & 2,32773 & 0,34271 & 0,66391 & $81 \%$ & 1,46813 \\
\hline R0elm_Kc_Kc-soft & 0,23155 & 0,81627 & $89 \%$ & 1,41599 & 0,20386 & 0,80008 & $92 \%$ & 1,35313 \\
\hline R0elm_Kelm_Kc-soft & 0,24812 & 0,80311 & $88 \%$ & 1,53829 & 0,25385 & 0,75105 & $90 \%$ & 1,67809 \\
\hline \multirow[t]{4}{*}{ Kc_Kelm_Kc-soft } & 0,27607 & 0,78094 & $88 \%$ & 1,84614 & 0,23578 & 0,76877 & $87 \%$ & 1,32268 \\
\hline & \multicolumn{8}{|c|}{$3-8-1$} \\
\hline & \multicolumn{4}{|c|}{ Treinamento } & \multicolumn{4}{|c|}{ Validação } \\
\hline & MSE & $R^{\wedge} 2$ & Recog \% & MAD & MSE & $R^{\wedge} 2$ & $\operatorname{Recog} \%$ & MAD \\
\hline R0c_R0elm_Kc & 0,33464 & 0,73446 & $90 \%$ & 2,28164 & 0,23306 & 0,77144 & $90 \%$ & 1,51006 \\
\hline R0c_ROelm_Kelm & 0,55397 & 0,56043 & $75 \%$ & 2,84018 & 0,46616 & 0,54285 & $80 \%$ & 2,32012 \\
\hline ROc_R0elm_Kc-soft & 0,21004 & 0,83333 & $92 \%$ & 1,2406 & 0,2195 & 0,78474 & $91 \%$ & 1,33329 \\
\hline R0c_Kc_Kelm & 0,67676 & 0,463 & $79 \%$ & 2,96903 & 0,42442 & 0,58378 & $87 \%$ & 2,75271 \\
\hline ROc_Kc_Kc-soft & 0,2544 & 0,79813 & $87 \%$ & 1,95217 & 0,22791 & 0,77649 & $90 \%$ & 1,41852 \\
\hline R0c_Kelm_Kc-soft & 0,23392 & 0,81438 & $88 \%$ & 1,60232 & 0,20004 & 0,80382 & $92 \%$ & 1,16446 \\
\hline R0elm_Kc_Kelm & 0,50883 & 0,59625 & $81 \%$ & 2,7697 & 0,33731 & 0,66921 & $82 \%$ & 1,43056 \\
\hline R0elm_Kc_Kc-soft & 0,23497 & 0,81355 & $89 \%$ & 1,37056 & 0,20495 & 0,799 & $92 \%$ & 1,34408 \\
\hline R0elm_Kelm_Kc-soft & 0,24975 & 0,80182 & $87 \%$ & 1,54401 & 0,25558 & 0,74935 & $90 \%$ & 1,71265 \\
\hline \multirow[t]{4}{*}{ Kc_Kelm_Kc-soft } & 0,27192 & 0,78423 & $87 \%$ & 1,82651 & 0,22452 & 0,77982 & $90 \%$ & 1,36894 \\
\hline & & & & $3-1$ & & & & \\
\hline & & Treina & mento & & & Valid & ação & \\
\hline & MSE & $R^{\wedge} 2$ & Recog \% & MAD & MSE & $R^{\wedge} 2$ & Recog \% & MAD \\
\hline R0c_R0elm_Kc & 0,36328 & 0,71174 & $88 \%$ & 2,51973 & 0,23182 & 0,77266 & $90 \%$ & 1,17732 \\
\hline ROc_ROelm_Kelm & 0,56481 & 0,55183 & $75 \%$ & 2,79695 & 0,48019 & 0,52909 & $78 \%$ & 2,32839 \\
\hline R0c_ROelm_Kc-Soft & 0,18811 & 0,85073 & $94 \%$ & 1,02804 & 0,20284 & 0,80107 & $92 \%$ & 1,24354 \\
\hline ROc_Kc_Kelm & 0,67397 & 0,46522 & $79 \%$ & 2,84876 & 0,43415 & 0,57424 & $88 \%$ & 2,7614 \\
\hline R0c_Kc_Kc-soft & 0,2044 & 0,83781 & $90 \%$ & 1,32757 & 0,21565 & 0,78851 & $91 \%$ & 1,53439 \\
\hline R0c_Kelm_Kc-soft & 0,23532 & 0,81327 & $88 \%$ & 1,6817 & 0,19952 & 0,80433 & $92 \%$ & 1,17798 \\
\hline R0elm_Kc_Kelm & 0,4268 & 0,66134 & $83 \%$ & 2,40997 & 0,34026 & 0,66632 & $80 \%$ & 1,41508 \\
\hline R0elm_Kc_Kc-soft & 0,22799 & 0,81909 & $88 \%$ & 1,40666 & 0,20598 & 0,798 & $92 \%$ & 1,44998 \\
\hline R0elm_Kelm_Kc-soft & 0,25115 & 0,80071 & $87 \%$ & 1,545 & 0,25486 & 0,75006 & $90 \%$ & 1,68873 \\
\hline Kc_Kelm_Kc-soft & 0,2722 & 0,78401 & $88 \%$ & 1,83156 & 0,2234 & 0,78091 & $90 \%$ & 1,36057 \\
\hline & & & & $3-1$ & & & & \\
\hline & & Treina & mento & & & $\overline{\text { Valid }}$ & |ação & \\
\hline & MSE & $R^{\wedge} \mathbf{2}$ & Recog \% & MAD & MSE & $R^{\wedge} 2$ & Recog \% & MAD \\
\hline R0c_ROelm_Kc & 0,36408 & 0,71111 & $85 \%$ & 2,48939 & 0,2445 & 0,76022 & $87 \%$ & 1,2796 \\
\hline R0c_ROelm_Kelm & 0,55781 & 0,55739 & $75 \%$ & 2,83344 & 0,4738 & 0,53536 & $80 \%$ & 2,31641 \\
\hline R0c_ROelm_Kc-soft & 0,21115 & 0,83245 & $92 \%$ & 1,23522 & 0,22111 & 0,78316 & $91 \%$ & 1,34664 \\
\hline R0c Kc Kelm & 0,69481 & 0,44868 & $76 \%$ & 2,97679 & 0,42316 & 0,58502 & $85 \%$ & 2,76938 \\
\hline R0c_Kc_Kc-soft & 0,28066 & 0,77729 & $88 \%$ & 2,04523 & 0,23879 & 0,76583 & $88 \%$ & 1,66291 \\
\hline R0c_Kelm_Kc-soft & 0,23664 & 0,81222 & $88 \%$ & 1,67531 & 0,20023 & 0,80364 & $92 \%$ & 1,1886 \\
\hline ROelm_Kc_Kelm & 0,55653 & 0,5584 & $79 \%$ & 3,05698 & 0,34545 & 0,66122 & $80 \%$ & 1,39787 \\
\hline R0elm_Kc_Kc-soft & 0,23616 & 0,81261 & $89 \%$ & 1,38686 & 0,20278 & 0,80113 & $93 \%$ & 1,30815 \\
\hline R0elm_Kelm_Kc-soft & 0,25185 & 0,80016 & $87 \%$ & 1,55556 & 0,25617 & 0,74878 & $90 \%$ & 1,72881 \\
\hline Kc_Kelm_Kc-soft & 0,27083 & 0,7851 & $88 \%$ & 1,85489 & 0,22296 & 0,78134 & $90 \%$ & 1,36669 \\
\hline
\end{tabular}


Tabela 4.10 - Resultados de diferentes topologias com 4 parâmetros na entrada da rede

\begin{tabular}{|c|c|c|c|c|c|c|c|c|}
\hline & \multicolumn{8}{|c|}{ 4-3-1 } \\
\hline & \multicolumn{4}{|c|}{ Treinamento } & \multicolumn{4}{|c|}{ Validação } \\
\hline & MSE & $R^{\wedge} 2$ & $\operatorname{Recog} \%$ & MAD & MSE & $R^{\wedge} 2$ & Recog \% & MAD \\
\hline R0c_ROelm_Kc_Kelm & 0,32341 & 0,74338 & $90 \%$ & 2,34089 & 0,2064 & 0,79758 & $91 \%$ & 1,02555 \\
\hline R0c_R0elm_Kc_Kc-soft & 0,18287 & 0,85489 & $92 \%$ & 1,16514 & 0,18754 & 0,81608 & $95 \%$ & 1,50338 \\
\hline R0c_R0elm_Kelm_Kc-soft & 0,19656 & 0,84403 & $93 \%$ & 1,13595 & 0,20787 & 0,79615 & $92 \%$ & 1,27457 \\
\hline R0c_Kc_Kelm_Kc-soft & 0,23787 & 0,81125 & $88 \%$ & 1,61882 & 0,22777 & 0,77662 & $90 \%$ & 1,23115 \\
\hline \multirow[t]{4}{*}{ R0elm_Kc_Kelm_Kc-soft } & 0,23255 & 0,81547 & $88 \%$ & 1,34728 & 0,20177 & 0,80213 & $92 \%$ & 1,32051 \\
\hline & \multicolumn{8}{|c|}{ 4-5-1 } \\
\hline & \multicolumn{4}{|c|}{ Treinamento } & \multicolumn{4}{|c|}{ Validação } \\
\hline & MSE & $R^{\wedge} 2$ & Recog \% & MAD & MSE & $R^{\wedge} 2$ & $\operatorname{Recog} \%$ & MAD \\
\hline R0c_ROelm_Kc_Kelm & 0,33056 & 0,7377 & $89 \%$ & 2,386 & 0,21599 & 0,78818 & $90 \%$ & 1,05624 \\
\hline R0c_ROelm Kc_Kc-soft & 0,17791 & 0,85882 & $91 \%$ & 1,22044 & 0,17954 & 0,82393 & $96 \%$ & 1,31496 \\
\hline R0c_R0elm_Kelm_Kc-soft & 0,18805 & 0,85078 & $93 \%$ & 1,02885 & 0,21062 & 0,79345 & $92 \%$ & 1,39109 \\
\hline R0c_Kc_Kelm_Kc-soft & 0,20276 & 0,83911 & $90 \%$ & 1,15464 & 0,19371 & 0,81003 & $92 \%$ & 1,3432 \\
\hline \multirow[t]{4}{*}{ R0elm_Kc_Kelm_Kc-soft } & 0,23402 & 0,8143 & $89 \%$ & 1,35011 & 0,20546 & 0,79851 & $92 \%$ & 1,37449 \\
\hline & \multicolumn{8}{|c|}{ 4-8-1 } \\
\hline & \multicolumn{4}{|c|}{ Treinamento } & \multicolumn{4}{|c|}{ Validação } \\
\hline & MSE & $R^{\wedge} 2$ & Recog \% & MAD & MSE & $R^{\wedge} 2$ & $\operatorname{Recog} \%$ & MAD \\
\hline R0c_ROelm_Kc_Kelm & 0,36875 & 0,7074 & $85 \%$ & 2,41678 & 0,22228 & 0,78202 & $90 \%$ & 1,15814 \\
\hline R0c_R0elm_Kc_Kc-soft & 0,18479 & 0,85336 & $92 \%$ & 1,20733 & 0,18312 & 0,82042 & $96 \%$ & 1,41888 \\
\hline R0c_R0elm_Kelm_Kc-soft & 0,19317 & 0,84671 & $93 \%$ & 1,06662 & 0,18742 & 0,8162 & $92 \%$ & 1,21535 \\
\hline R0c_Kc_Kelm_Kc-soft & 0,2181 & 0,82694 & $90 \%$ & 1,38899 & 0,20912 & 0,79491 & $90 \%$ & 1,04625 \\
\hline \multirow[t]{4}{*}{ R0elm_Kc_Kelm_Kc-soft } & 0,23137 & 0,8164 & $89 \%$ & 1,39634 & 0,20234 & 0,80157 & $92 \%$ & 1,3419 \\
\hline & \multicolumn{8}{|c|}{$4-10-1$} \\
\hline & \multicolumn{4}{|c|}{ Treinamento } & \multicolumn{4}{|c|}{ Validação } \\
\hline & MSE & $R^{\wedge} 2$ & Recog \% & MAD & MSE & $R^{\wedge} 2$ & Recog \% & MAD \\
\hline R0c_R0elm_Kc_Kelm & 0,34646 & 0,72508 & $88 \%$ & 2,42901 & 0,25077 & 0,75407 & $87 \%$ & 1,55918 \\
\hline R0c_R0elm_Kc_Kc-soft & 0,16463 & 0,86936 & $92 \%$ & 1,22534 & 0,17654 & 0,82686 & $95 \%$ & 1,40116 \\
\hline R0c_R0elm_Kelm_Kc-soft & 0,19266 & 0,84712 & $94 \%$ & 1,13127 & 0,21322 & 0,7909 & $92 \%$ & 1,30438 \\
\hline R0c_Kc_Kelm_Kc-soft & 0,21425 & 0,82999 & $90 \%$ & 1,39319 & 0,20793 & 0,79609 & $91 \%$ & 1,04683 \\
\hline \multirow[t]{4}{*}{ R0elm_Kc_Kelm_Kc-soft } & 0,23331 & 0,81487 & $89 \%$ & 1,42676 & 0,2046 & 0,79935 & $93 \%$ & 1,3354 \\
\hline & \multicolumn{8}{|c|}{$4-15-1$} \\
\hline & \multicolumn{4}{|c|}{ Treinamento } & \multicolumn{4}{|c|}{ Validação } \\
\hline & MSE & $R^{\wedge} 2$ & Recog \% & MAD & MSE & $R^{\wedge} 2$ & $\operatorname{Recog} \%$ & MAD \\
\hline R0c_R0elm_Kc_Kelm & 0,3349 & 0,73426 & $90 \%$ & 2,37255 & 0,2381 & 0,7665 & $92 \%$ & 1,52912 \\
\hline R0c_R0elm_Kc_Kc-soft & 0,17376 & 0,86212 & $91 \%$ & 1,16866 & 0,17967 & 0,82379 & $95 \%$ & 1,30004 \\
\hline R0c_R0elm_Kelm_Kc-soft & 0,20274 & 0,83913 & $92 \%$ & 1,22406 & 0,21478 & 0,78937 & 91\% & 1,35759 \\
\hline R0c_Kc_Kelm_Kc-soft & 0,22685 & 0,81999 & $88 \%$ & 1,62889 & 0,23524 & 0,76931 & $90 \%$ & 1,86779 \\
\hline R0elm_Kc_Kelm_Kc-soft & 0,23448 & 0,81393 & $89 \%$ & 1,36522 & 0,20336 & 0,80057 & $92 \%$ & 1,31749 \\
\hline
\end{tabular}

Tabela 4.11 - Resultados de diferentes topologias com 5 parâmetros na entrada da rede

\begin{tabular}{|c|c|c|c|c|c|c|c|c|}
\hline & \multicolumn{8}{|c|}{ 5-3-1 } \\
\hline & \multicolumn{4}{|c|}{ Treinamento } & \multicolumn{4}{|c|}{ Validação } \\
\hline & MSE & $R^{\wedge} 2$ & $\operatorname{Recog} \%$ & MAD & MSE & $R^{\wedge} 2$ & $\operatorname{Recog} \%$ & MAD \\
\hline \multirow{4}{*}{ R0c_R0elm_Kc_Kelm_Kc-soft } & 0,18656 & 0,85196 & $92 \%$ & 1,24883 & 0,18761 & 0,81601 & $96 \%$ & 1,56306 \\
\hline & \multicolumn{8}{|c|}{$5-5-1$} \\
\hline & \multicolumn{4}{|c|}{ Treinamento } & \multicolumn{4}{|c|}{ Validação } \\
\hline & MSE & $R^{\wedge} 2$ & $\operatorname{Recog} \%$ & MAD & MSE & $R^{\wedge} 2$ & $\operatorname{Recog} \%$ & MAD \\
\hline \multirow[t]{4}{*}{ R0c_R0elm_Kc_Kelm_Kc-soft } & 0,17712 & 0,85945 & $92 \%$ & 1,18347 & 0,17654 & 0,82686 & $95 \%$ & 1,40116 \\
\hline & \multicolumn{8}{|c|}{ 5-8-1 } \\
\hline & \multicolumn{4}{|c|}{ Treinamento } & \multicolumn{4}{|c|}{ Validação } \\
\hline & MSE & $\mathbf{R}^{\wedge} \mathbf{2}$ & Recog \% & MAD & MSE & $R^{\wedge} 2$ & $\operatorname{Recog} \%$ & MAD \\
\hline \multirow[t]{4}{*}{ R0c_ROelm_Kc_Kelm_Kc-soft } & 0,16549 & 0,86868 & $92 \%$ & 0,97479 & 0,16495 & 0,83823 & $93 \%$ & 1,25517 \\
\hline & \multicolumn{8}{|c|}{$5-10-1$} \\
\hline & \multicolumn{4}{|c|}{ Treinamento } & \multicolumn{4}{|c|}{ Validação } \\
\hline & MSE & $R^{\wedge} 2$ & Recog \% & MAD & MSE & $R^{\wedge} 2$ & Recog \% & MAD \\
\hline \multirow[t]{4}{*}{ R0c_R0elm_Kc_Kelm_Kc-soft } & 0,18525 & 0,853 & $91 \%$ & 1,29668 & 0,18571 & 0,81787 & $96 \%$ & 1,44941 \\
\hline & \multicolumn{8}{|c|}{ 5-15-1 } \\
\hline & \multicolumn{4}{|c|}{ Treinamento } & \multicolumn{4}{|c|}{ Validação } \\
\hline & MSE & $R^{\wedge} 2$ & $\operatorname{Recog} \%$ & MAD & MSE & $R^{\wedge} 2$ & Recog \% & MAD \\
\hline ROc_R0elm_Kc_Kelm_Kc-soft & 0,17935 & 0,85768 & $92 \%$ & 1,26363 & 0,18693 & 0,81667 & $96 \%$ & 1,49718 \\
\hline
\end{tabular}


Analisando os resultados do estudo dos dois conjuntos de dados, verifica-se que a combinação de parâmetros que apresenta o menor MSE e o melhor $\mathrm{R}^{2}$ na validação é a mesma, ou seja, é a combinação utilizando todos os cinco parâmetros ajustáveis do modelo criado. Além disso, verifica-se que a topologia que apresenta o melhor resultado também é a mesma nos dois estudos, ou seja, a topologia 5-8-1.

Apesar de parecer que alguns parâmetros apresentam uma correlação muito pequena com a qualidade final da solda $\left(R_{O C}\right.$ e $\left.K_{E L M}\right)$, ao analisarmos os resultados obtidos com apenas um parâmetro na entrada da rede, verifica-se ao final que, em conjunto com os outros parâmetros, a contribuição desses leva a rede neural a estimar de forma mais precisa a qualidade final da solda.

As figuras 4.9 e 4.10 mostram o gráfico com os valores reais e os valores estimados da qualidade da solda dos testes com o conjunto de dados usado para validar a rede neural, utilizando os cinco parâmetros ajustáveis do modelo na topologia 5-8-1, para o primeiro e segundo conjunto de dados, respectivamente.

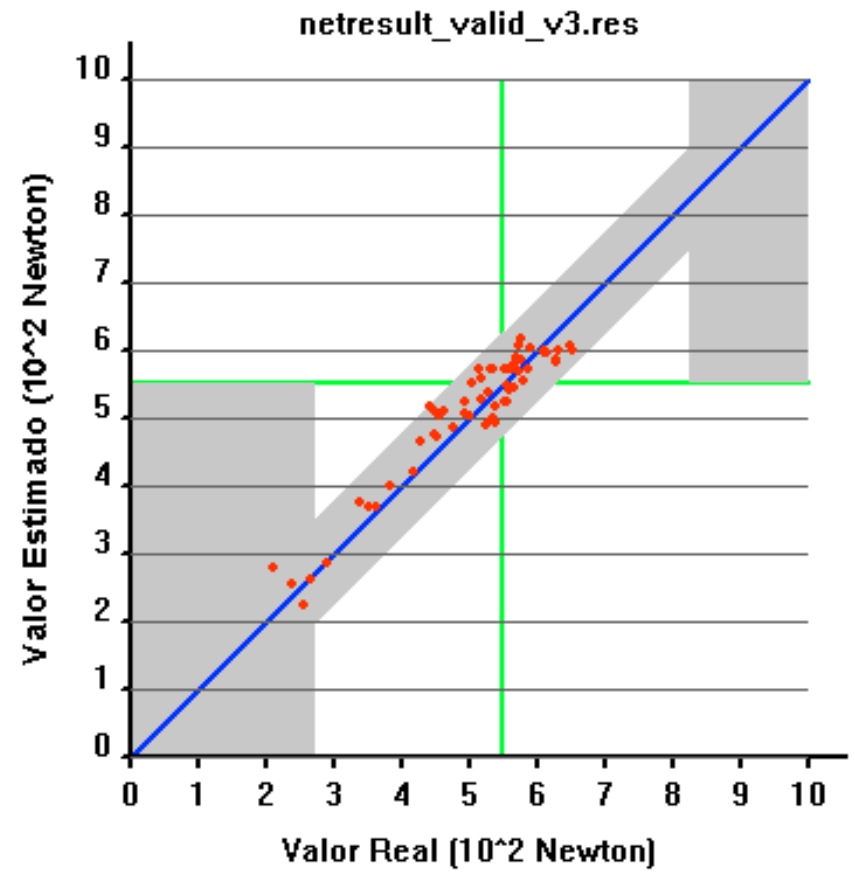

Number of samples: 60

Statistics:

MAD: $\quad 0.69913$

MSE: $\quad 0.09680$

SSE: $\quad \mathbf{5 . 8 0 8 2 6}$

$R^{2}: \quad 0.91114$

Recognition values:

Tolerance:

0.75

Correct classified: $\quad 60$

of:

60

Recognition rate: $100 \%$

Figura 4.9 - Resultado da melhor combinação de parâmetros (5 parâmetros) e da melhor topologia entre as testadas (5-8-1) para o primeiro conjunto de dados 


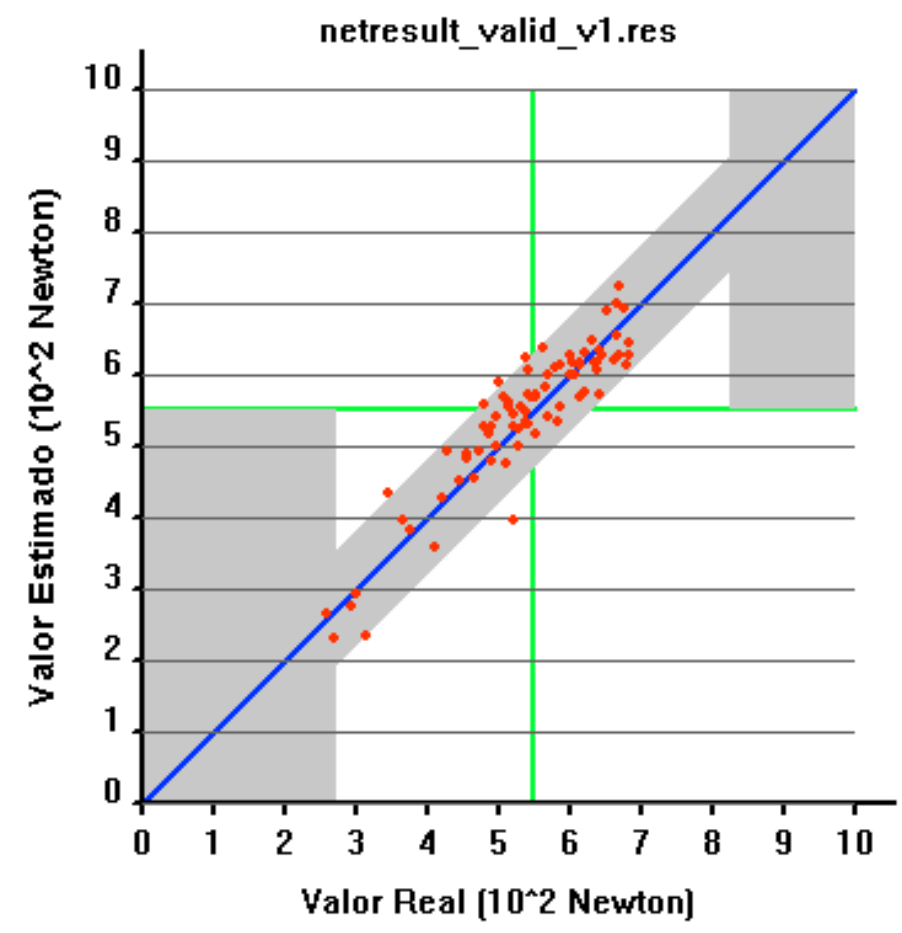

Number of samples: 80

Statistics:

MAD: $\quad 1.25517$

MSE: $\quad 0.16495$

SSE: $\quad 13.19665$

$R^{2}: \quad 0.83823$

Recognition values:

Tolerance: $\quad 0.75$

Correct classified: 75

of: $\quad \mathbf{8 0}$

Recognition rate: $\quad 93 \%$

Figura 4.10 - Resultado da melhor combinação de parâmetros (5 parâmetros) e da melhor topologia entre as testadas (5-8-1) para o segundo conjunto de dados

Como resultado do primeiro conjunto de dados, tem-se um MSE de 9,68 N, um $\mathrm{R}^{2}$ de 0,91114, uma taxa de reconhecimento de 100\% e um MAD de 69,913 N. Como resultado do segundo conjunto de dados, tem-se um MSE de 16,495 N, um $\mathrm{R}^{2}$ de 0,83823 , uma taxa de reconhecimento de $93 \%$ e um MAD de 1,25517 N. Comparando os resultados, verifica-se que os resultados obtidos do primeiro conjunto de dados são melhores que os obtidos no segundo conjunto de dados. Essa diferença pode se dever ao fato de o segundo conjunto de dados ser mais abrangente que o primeiro, submetendo a rede a mais condições de perturbação do processo. Além disso, apesar de serem similares, o processo de produção da primeira máquina parece ser mais estável que o da segunda, provavelmente devido às características internas da máquina, como pode ser verificado pelas variações maiores da qualidade final da solda em condições normais no segundo processo quando comparadas ao primeiro (Anexo B). 
Também, os resultados do segundo conjunto de dados podem ser considerados bons, uma vez que o MSE é de apenas 16,495 $\mathrm{N}$ em um processo ajustado para produzir soldas que suportem 550 N. Ainda, ao analisarem-se os dados da tabela B.2 do anexo B, observa-se que, no procedimento padrão de soldagem, a qualidade das soldas produzidas normalmente é superior a $600 \mathrm{~N}$. Analisando-se o gráfico da figura 4.10, observa-se que entre os testes com a qualidade estimada fora da tolerância de $75 \mathrm{~N}$, apenas a estimativa de um teste está realmente distante do limite. Os demais estão muito próximos a este limite.

\subsection{Comparação com Sistemas Propostos na Literatura}

No item 2.4 foram abordados os sistemas de monitoramento encontrados na literatura que utilizam características das variáveis elétricas (tensão e corrente) medidas durante o PSPR e redes neurais artificiais para estimar a qualidade final da solda.

Os sistemas apresentados nos trabalhos de Cho e Rhee (2002), Subramanian et al. (2004) e Ling et al. (2009) não são possíveis de serem aplicados no processo de produção de contatos elétricos investigado neste trabalho. Isso ocorre devido às características da curva de resistência dinâmica utilizada por estes autores serem típicas da soldagem de ligas de aço, tais como o pico de resistência dinâmica, o tempo para se atingir esse pico, o ângulo de inclinação durante o crescimento da resistência, que não são aplicáveis no processo investigado devido ao comportamento diferenciado da sua curva de resistência dinâmica.

O sistema proposto por Dilthey e Dichersbach (1999) é possível de ser reproduzido e testado com os conjuntos de dados desse trabalho, pois utiliza o valor da corrente máxima em cada meio ciclo senoidal e o respectivo valor de tensão neste mesmo tempo como dados de entrada da rede neural. Como estes valores também são usados no cálculo da resistência dinâmica utilizada neste trabalho, para reproduzir o sistema só foi necessário criar um plug-in 
para unir as curvas de tensão e corrente em um único vetor. Esse plug-in foi chamado de "JoinVectors". O tamanho do vetor resultante da aplicação deste plug-in nos dados no processo investigado é de 60 amostras. Este sistema foi testado utilizando as mesmas configurações de rede e os mesmos testes para treinamento e validação dos dois conjuntos de dados usados para analisar o sistema proposto neste trabalho. Só foi alterada a topologia, devido à diferença no tamanho do vetor de dados de entrada da rede, sendo testadas as topologias 60-20-1, 60-40-1, 60-60-1, 60-80-1 e 60-100-1. Os resultados obtidos para o primeiro conjunto de dados e para o segundo conjunto de dados são mostrados nas tabelas 4.12 e 4.13 , respectivamente.

A melhor topologia entre as testadas para o primeiro conjunto de dados foi a $60-20-1$. Os resultados da validação dessa topologia mostram um MSE de $0,10462 \mathrm{~N}$, um $\mathrm{R}^{2}$ de 0,90397, uma taxa de reconhecimento de 98\% e um MAD de 0,81902 N. Estes resultados são ligeiramente inferiores aos obtidos com o sistema proposto neste trabalho.

Tabela 4.12 - Resultados do sistema proposto por Dilthey e Dichersbach (1999) aplicado no primeiro conjunto de dados com diferentes topologias de rede

\begin{tabular}{|c|c|c|c|c|c|c|c|}
\hline \multicolumn{8}{|c|}{ 60-20-1 } \\
\hline \multicolumn{4}{|c|}{ Treinamento } & \multicolumn{4}{|c|}{ Validação } \\
\hline MSE & $R^{\wedge} 2$ & Recog \% & MAD & MSE & $R^{\wedge} 2$ & Recog \% & MAD \\
\hline 0,11936 & 0,89209 & $95 \%$ & 1,06716 & 0,10462 & 0,90397 & $98 \%$ & 0,81902 \\
\hline \multicolumn{8}{|c|}{$60-40-1$} \\
\hline \multicolumn{4}{|c|}{ Treinamento } & \multicolumn{4}{|c|}{ Validação } \\
\hline MSE & $\overline{R^{\wedge} 2}$ & Recog \% & MAD & MSE & $\overline{R^{\wedge} 2}$ & Recog \% & MAD \\
\hline 0,1102 & 0,90037 & $97 \%$ & 1,03535 & 0,11889 & 0,89087 & $96 \%$ & 0,91397 \\
\hline \multicolumn{8}{|c|}{ 60-60-1 } \\
\hline \multicolumn{4}{|c|}{ Treinamento } & \multicolumn{4}{|c|}{ Validação } \\
\hline MSE & $\mathrm{R}^{\wedge 2}$ & Recog \% & MAD & MSE & $R^{\wedge} 2$ & Recog \% & MAD \\
\hline 0,10658 & 0,90365 & $97 \%$ & 0,99871 & 0,11156 & 0,8976 & $96 \%$ & 0,89752 \\
\hline \multicolumn{8}{|c|}{$60-80-1$} \\
\hline \multicolumn{4}{|c|}{ Treinamento } & \multicolumn{4}{|c|}{ Validação } \\
\hline MSE & $R^{\wedge} 2$ & Recog \% & MAD & MSE & $R^{\wedge} 2$ & Recog \% & MAD \\
\hline 0,11214 & 0,89862 & $97 \%$ & 1,04407 & 0,13267 & 0,87822 & $96 \%$ & 1,02338 \\
\hline \multicolumn{8}{|c|}{$60-100-1$} \\
\hline \multicolumn{4}{|c|}{ Treinamento } & \multicolumn{4}{|c|}{ Validação } \\
\hline MSE & $\mathrm{R}^{\wedge} 2$ & Recog \% & MAD & MSE & $R^{\wedge} 2$ & Recog \% & MAD \\
\hline 0,10974 & 0,90079 & $97 \%$ & 0,99264 & 0,12053 & 0,88936 & $96 \%$ & 0,97631 \\
\hline
\end{tabular}


Tabela 4.13 - Resultados do sistema proposto por Dilthey e Dichersbach (1999) aplicado no segundo conjunto de dados com diferentes topologias de rede

\begin{tabular}{|c|c|c|c|c|c|c|c|}
\hline \multicolumn{8}{|c|}{$60-20-1$} \\
\hline \multicolumn{4}{|c|}{ Treinamento } & \multicolumn{4}{|c|}{ Validação } \\
\hline MSE & $R^{\wedge} 2$ & Recog \% & MAD & MSE & $R^{\wedge} 2$ & $\operatorname{Recog} \%$ & MAD \\
\hline 0,25616 & 0,79673 & $88 \%$ & 1,36706 & 0,17343 & 0,82992 & $93 \%$ & 1,07105 \\
\hline \multicolumn{8}{|c|}{$60-40-1$} \\
\hline \multicolumn{4}{|c|}{ Treinamento } & \multicolumn{4}{|c|}{ Validação } \\
\hline MSE & $\mathrm{R}^{\wedge} 2$ & Recog \% & MAD & MSE & $R^{\wedge} 2$ & Recog \% & MAD \\
\hline 0,26697 & 0,78816 & $88 \%$ & 1,39314 & 0,17818 & 0,82526 & $93 \%$ & 1,18598 \\
\hline \multicolumn{8}{|c|}{$60-60-1$} \\
\hline \multicolumn{4}{|c|}{ Treinamento } & \multicolumn{4}{|c|}{ Validação } \\
\hline MSE & $R^{\wedge} 2$ & Recog \% & MAD & MSE & $R^{\wedge} 2$ & Recog \% & MAD \\
\hline 0,24034 & 0,80929 & $88 \%$ & 1,37212 & 0,17736 & 0,82606 & $95 \%$ & 0,94161 \\
\hline \multicolumn{8}{|c|}{$60-80-1$} \\
\hline \multicolumn{4}{|c|}{ Treinamento } & \multicolumn{4}{|c|}{ Validação } \\
\hline MSE & $R^{\wedge} 2$ & Recog \% & MAD & MSE & $R^{\wedge} 2$ & Recog \% & MAD \\
\hline 0,25274 & 0,79945 & $86 \%$ & 1,28647 & 0,17753 & 0,82982 & $95 \%$ & 1,01423 \\
\hline \multicolumn{8}{|c|}{$60-100-1$} \\
\hline \multicolumn{4}{|c|}{ Treinamento } & \multicolumn{4}{|c|}{ Validação } \\
\hline MSE & $R^{\wedge} 2$ & Recog \% & MAD & MSE & $R^{\wedge} 2$ & Recog \% & MAD \\
\hline 0,2414 & 0,80845 & $88 \%$ & 1,27954 & 0,17452 & 0,82885 & $93 \%$ & 1,1048 \\
\hline
\end{tabular}

Para o segundo conjunto de dados, a melhor topologia entre as testadas também foi a 60-20-1. Os resultados da validação dessa topologia mostram um MSE de 0,17343 N, um R ${ }^{2}$ de 0,82992 , uma taxa de reconhecimento de $93 \%$ e um MAD de 1,07105 N. Estes resultados também são ligeiramente inferiores aos obtidos com o sistema proposto neste trabalho.

O sistema proposto por Aravinthan et al. (2001) também é possível de se reproduzir e testar neste trabalho, pois utiliza os pontos de máximo da corrente e tensão divididos um pelo outro, ou seja, a curva de resistência dinâmica, como entrada da rede neural. Testando este sistema com o mesmo procedimento utilizado para testar o proposto por Dilthey e Dichersbach (1999), só que alterando as topologias testadas para 30-10-1, 30-20-1, 30-30-1, 30-40-1 e 30-50-1, devido ao número de amostras da curva de resistência dinâmica que é de 30, os resultados obtidos para o primeiro conjunto de dados e para o segundo conjunto de dados são mostrados nas tabelas 4.14 e 4.15 , respectivamente. 
Tabela 4.14 - Resultados do sistema proposto por Aravinthan et al. (2001) aplicado no primeiro conjunto de dados com diferentes topologias de rede

\begin{tabular}{|c|c|c|c|c|c|c|c|}
\hline \multicolumn{8}{|c|}{$30-10-1$} \\
\hline \multicolumn{4}{|c|}{ Treinamento } & \multicolumn{4}{|c|}{ Validação } \\
\hline MSE & $R^{\wedge} 2$ & Recog \% & MAD & MSE & $R^{\wedge} 2$ & Recog \% & MAD \\
\hline 0,10692 & 0,90334 & $98 \%$ & 0,82309 & 0,10778 & 0,90106 & $98 \%$ & 0,85088 \\
\hline \multicolumn{8}{|c|}{$30-20-1$} \\
\hline \multicolumn{4}{|c|}{ Treinamento } & \multicolumn{4}{|c|}{ Validação } \\
\hline MSE & $R^{\wedge} 2$ & Recog \% & MAD & MSE & $R^{\wedge} 2$ & $\operatorname{Recog} \%$ & MAD \\
\hline 0,11177 & 0,89895 & $98 \%$ & 0,92838 & 0,10195 & 0,90641 & $98 \%$ & 0,76874 \\
\hline \multicolumn{8}{|c|}{$30-30-1$} \\
\hline \multicolumn{4}{|c|}{ Treinamento } & \multicolumn{4}{|c|}{ Validação } \\
\hline MSE & $R^{\wedge} 2$ & Recog \% & MAD & MSE & $R^{\wedge} 2$ & Recog \% & MAD \\
\hline 0,12363 & 0,88824 & $97 \%$ & 1,08535 & 0,10959 & 0,8994 & $95 \%$ & 0,83142 \\
\hline \multicolumn{8}{|c|}{$30-40-1$} \\
\hline \multicolumn{4}{|c|}{ Treinamento } & \multicolumn{4}{|c|}{ Validação } \\
\hline MSE & $R^{\wedge} 2$ & Recog \% & MAD & MSE & $R^{\wedge} 2$ & $\operatorname{Recog} \%$ & MAD \\
\hline 0,12374 & 0,88695 & $96 \%$ & 1,12374 & 0,10952 & 0,89946 & $98 \%$ & 0,83256 \\
\hline \multicolumn{8}{|c|}{$30-50-1$} \\
\hline \multicolumn{4}{|c|}{ Treinamento } & \multicolumn{4}{|c|}{ Validação } \\
\hline MSE & $\overline{R^{\wedge} 2}$ & $\operatorname{Recog} \%$ & MAD & MSE & $\overline{R^{\wedge} 2}$ & $\operatorname{Recog} \%$ & MAD \\
\hline 0,12394 & 0,88795 & $96 \%$ & 1,12504 & 0,10758 & 0,90125 & $96 \%$ & 0,91933 \\
\hline
\end{tabular}

Tabela 4.15 - Resultados do sistema proposto por Aravinthan et al. (2001) aplicado no segundo conjunto de dados com diferentes topologias de rede

\begin{tabular}{|c|c|c|c|c|c|c|c|}
\hline \multicolumn{8}{|c|}{$30-10-1$} \\
\hline \multicolumn{4}{|c|}{ Treinamento } & \multicolumn{4}{|c|}{ Validação } \\
\hline MSE & $R^{\wedge} 2$ & Recog \% & MAD & MSE & $R^{\wedge} 2$ & Recog \% & MAD \\
\hline 0,25129 & 0,8006 & $87 \%$ & 1,32252 & 0,17515 & 0,82823 & $96 \%$ & 0,9444 \\
\hline \multicolumn{8}{|c|}{$30-20-1$} \\
\hline \multicolumn{4}{|c|}{ Treinamento } & \multicolumn{4}{|c|}{ Validação } \\
\hline MSE & $\mathrm{R}^{\wedge} 2$ & Recog \% & MAD & MSE & $R^{\wedge} 2$ & Recog \% & MAD \\
\hline 0,24288 & 0,80728 & $87 \%$ & 1,38727 & 0,17353 & 0,82982 & $96 \%$ & 0,89773 \\
\hline \multicolumn{8}{|c|}{$30-30-1$} \\
\hline \multicolumn{4}{|c|}{ Treinamento } & \multicolumn{4}{|c|}{ Validação } \\
\hline MSE & $R^{\wedge} 2$ & Recog \% & MAD & MSE & $R^{\wedge} 2$ & Recog \% & MAD \\
\hline 0,24207 & 0,80791 & $87 \%$ & 1,41391 & 0,17387 & 0,82948 & $95 \%$ & 0,89675 \\
\hline \multicolumn{8}{|c|}{$30-40-1$} \\
\hline \multicolumn{4}{|c|}{ Treinamento } & \multicolumn{4}{|c|}{ Validação } \\
\hline MSE & $R^{\wedge} 2$ & Recog \% & MAD & MSE & $R^{\wedge} 2$ & Recog \% & MAD \\
\hline 0,24648 & 0,80442 & $87 \%$ & 1,35962 & 0,17911 & 0,82435 & $95 \%$ & 0,90526 \\
\hline \multicolumn{8}{|c|}{$30-50-1$} \\
\hline \multicolumn{4}{|c|}{ Treinamento } & \multicolumn{4}{|c|}{ Validação } \\
\hline MSE & $R^{\wedge} 2$ & Recog \% & MAD & MSE & $R^{\wedge} 2$ & Recog \% & MAD \\
\hline 0,25184 & 0,80016 & $86 \%$ & 1,36184 & 0,18043 & 0,82305 & $96 \%$ & 0,9556 \\
\hline
\end{tabular}


A melhor topologia entre as testadas para o primeiro conjunto de dados foi a 30-20-1. Os resultados da validação dessa topologia mostram um MSE de 0,10195 N, um $\mathrm{R}^{2}$ de 0,90641, uma taxa de reconhecimento de $98 \%$ e um MAD de 0,76874 N. Estes resultados são ligeiramente superiores aos obtidos com o sistema de Dilthey e Dichersbach (1999) mas ainda ligeiramente inferiores aos obtidos com o sistema proposto neste trabalho.

Para o segundo conjunto de dados, a melhor topologia entre as testadas também foi a 60-20-1. Os resultados da validação dessa topologia mostram um MSE de 0,17353 N, um $\mathrm{R}^{2}$ de 0,82982, uma taxa de reconhecimento de $96 \%$ e um MAD de 0,89773 N. Analisando todos os itens, estes resultados também são ligeramente superiores aos obtidos com o sistema de Dilthey e Dichersbach (1999), mas são ainda um pouco inferiores aos obtidos com o sistema proposto neste trabalho.

O trabalho de Mártin et al. (2006) utiliza como características do sistema o tempo de soldagem, o tipo de eletrodo e a curva de corrente de soldagem. Como os dois primeiros são valores fixos no processo investigado neste trabalho, não faz sentido testar a utilização somente da curva de corrente para estimar a qualidade final da solda. O sistema proposto por Wen, Zhang e outros (2009) utiliza quase as mesmas características que o trabalho de Mártin et al. (2006), mas, ao invés do tipo de eletrodo, utiliza como característica o valor final da curva de resistência dinâmica. Este sistema será reproduzido excluindo o tempo de soldagem das variáveis de entrada da rede, porque este é fixo neste processo investigado. Utilizando um plug-in chamado "Select Values", foi selecionada a última amostra da curva de resistência dinâmica e, utilizando o plug-in "JoinVectors", esta amostra foi adicionado ao final da curva de corrente.

Testando este sistema com o mesmo procedimento utilizado anteriormente, só que alterando as topologias testadas para 31-10-1, 31-20-1, 31-30-1, 31-40-1 e 31-50-1, devido ao número de amostras do vetor de entrada ser 31 , os resultados obtidos para o primeiro 
conjunto de dados e para o segundo conjunto de dados são mostrados nas tabelas 4.16 e 4.17, respectivamente.

Tabela 4.16 - Resultados do sistema proposto por Wen et al. (2009) aplicado no primeiro conjunto de dados com diferentes topologias de rede

\begin{tabular}{|c|c|c|c|c|c|c|c|}
\hline \multicolumn{8}{|c|}{$31-10-1$} \\
\hline \multicolumn{4}{|c|}{ Treinamento } & \multicolumn{4}{|c|}{ Validação } \\
\hline MSE & $R^{\wedge} 2$ & Recog \% & MAD & MSE & $R^{\wedge} 2$ & Recog \% & MAD \\
\hline 0,11443 & 0,89655 & $97 \%$ & 1,34046 & 0,14333 & 0,86843 & $95 \%$ & 1,25811 \\
\hline \multicolumn{8}{|c|}{$31-20-1$} \\
\hline \multicolumn{4}{|c|}{ Treinamento } & \multicolumn{4}{|c|}{ Validação } \\
\hline MSE & $\overline{R^{\wedge} 2}$ & $\overline{\operatorname{Recog} \%}$ & MAD & MSE & $\overline{R^{\wedge} 2}$ & Recog \% & MAD \\
\hline 0,121 & 0,89061 & $95 \%$ & 1,29447 & 0,144 & 0,86782 & $93 \%$ & 1,19801 \\
\hline \multicolumn{8}{|c|}{$31-30-1$} \\
\hline \multicolumn{4}{|c|}{ Treinamento } & \multicolumn{4}{|c|}{ Validação } \\
\hline MSE & $R^{\wedge} 2$ & Recog \% & MAD & MSE & $R^{\wedge} 2$ & Recog \% & MAD \\
\hline 0,12571 & 0,88635 & $97 \%$ & 1,32601 & 0,1505 & 0,86185 & $93 \%$ & 1,14618 \\
\hline \multicolumn{8}{|c|}{$31-40-1$} \\
\hline \multicolumn{4}{|c|}{ Treinamento } & \multicolumn{4}{|c|}{ Validação } \\
\hline MSE & $R^{\wedge} 2$ & $\operatorname{Recog} \%$ & MAD & MSE & $R^{\wedge} 2$ & $\operatorname{Recog} \%$ & MAD \\
\hline 0,12197 & 0,88973 & $96 \%$ & 1,34853 & 0,14842 & 0,86376 & $93 \%$ & 1,27685 \\
\hline \multicolumn{8}{|c|}{ 31-50-1 } \\
\hline \multicolumn{4}{|c|}{ Treinamento } & \multicolumn{4}{|c|}{ Validação } \\
\hline MSE & $\overline{R^{\wedge} 2}$ & Recog \% & MAD & MSE & $\overline{R^{\wedge} 2}$ & Recog \% & MAD \\
\hline 0,12016 & 0,89137 & $96 \%$ & 1,27507 & 0,14566 & 0,86629 & $95 \%$ & 1,12894 \\
\hline
\end{tabular}

Tabela 4.17 - Resultados do sistema proposto por Wen et al. (2009) aplicado no segundo conjunto de dados com diferentes topologias de rede

\begin{tabular}{|c|c|c|c|c|c|c|c|}
\hline \multicolumn{8}{|c|}{$31-10-1$} \\
\hline \multicolumn{4}{|c|}{ Treinamento } & \multicolumn{4}{|c|}{ Validação } \\
\hline MSE & $R^{\wedge} 2$ & Recog \% & MAD & MSE & $R^{\wedge} 2$ & Recog \% & MAD \\
\hline 0,28204 & 0,7762 & $85 \%$ & 1,54678 & 0,23814 & 0,76646 & $90 \%$ & 1,04687 \\
\hline \multicolumn{8}{|c|}{$31-20-1$} \\
\hline \multicolumn{4}{|c|}{ Treinamento } & \multicolumn{4}{|c|}{ Validação } \\
\hline MSE & $R^{\wedge} 2$ & Recog \% & MAD & MSE & $R^{\wedge} 2$ & Recog \% & MAD \\
\hline 0,26788 & 0,78744 & $83 \%$ & 1,54711 & 0,22294 & 0,78136 & $88 \%$ & 1,00305 \\
\hline \multicolumn{8}{|c|}{$31-30-1$} \\
\hline \multicolumn{4}{|c|}{ Treinamento } & \multicolumn{4}{|c|}{ Validação } \\
\hline MSE & $R^{\wedge} 2$ & Recog \% & MAD & MSE & $R^{\wedge} 2$ & Recog \% & MAD \\
\hline 0,27568 & 0,78125 & $84 \%$ & 1,58823 & 0,22964 & 0,77479 & $88 \%$ & 1,03651 \\
\hline \multicolumn{8}{|c|}{$31-40-1$} \\
\hline \multicolumn{4}{|c|}{ Treinamento } & \multicolumn{4}{|c|}{ Validação } \\
\hline MSE & $R^{\wedge} 2$ & Recog \% & MAD & MSE & $R^{\wedge} 2$ & Recog \% & MAD \\
\hline 0,26962 & 0,78606 & $84 \%$ & 1,54661 & 0,22845 & 0,77596 & $90 \%$ & 1,04379 \\
\hline \multicolumn{8}{|c|}{$31-50-1$} \\
\hline \multicolumn{4}{|c|}{ Treinamento } & \multicolumn{4}{|c|}{ Validação } \\
\hline MSE & $R^{\wedge} 2$ & Recog \% & MAD & MSE & $R^{\wedge} 2$ & Recog \% & MAD \\
\hline 0,26899 & 0,78655 & $84 \%$ & 1,54502 & 0,23238 & 0,7721 & $90 \%$ & 1,06593 \\
\hline
\end{tabular}


Analisando os resultados obtidos com o sistema proposto por Wen et al. (2009), verifica-se que são inferiores aos obtidos neste trabalho e também aos obtidos com os sistemas propostos por Dilthey e Dichersbach (1999) e Aravinthan et al. (2001). Esse resultado já era esperado tendo em vista que o sistema proposto por Wen et al. (2009) é baseado na curva de corrente e somente no valor final da curva de resistência dinâmica, sendo prejudicado pelo tipo de controle de alimentação utilizado no processo de soldagem de contatos elétricos em análise, que utiliza um controle de alimentação de corrente constante.

Embora os resultados dos trabalhos apresentados por outros autores, como visto acima, se aproximem dos resultados alcançados pela presente pesquisa, há que se ressaltar que o sistema de monitoramento proposto por aqueles não permite a identificação de possíveis causas para a degradação da qualidade da solda, característica importante do sistema proposto neste trabalho que será abordada no próximo item.

\subsection{Identificação de Causas de Problemas no Processo}

Outro objetivo do sistema proposto neste trabalho é o de identificar possíveis problemas que possam estar prejudicando a qualidade do processo, através da interpretação dos valores assumidos pelos parâmetros do modelo. Para o processo investigado, as principais perturbações são:

- Corrente de Soldagem: o valor real da corrente de soldagem no processo é diferente do valor selecionado pelo operador;

- Força de Soldagem: o valor real da força de soldagem no processo é diferente do valor selecionado pelo operador;

- "Welding Help": ausência de "Welding Help" no material sendo soldado. 
Inicialmente será feita uma análise de cada variável do modelo com relação à qualidade final do contato elétrico produzido (QC), ou seja, a força de cisalhamento suportada por este, em cada um dos conjuntos de dados, para estabelecer limites de valores para os parâmetros do modelo representativos das perturbações presentes no roteiro de testes dos conjuntos de dados.

A figura 4.11 mostra a relação entre QC e o parâmetro $K_{C-S O F T}$ para o primeiro conjunto de dados.

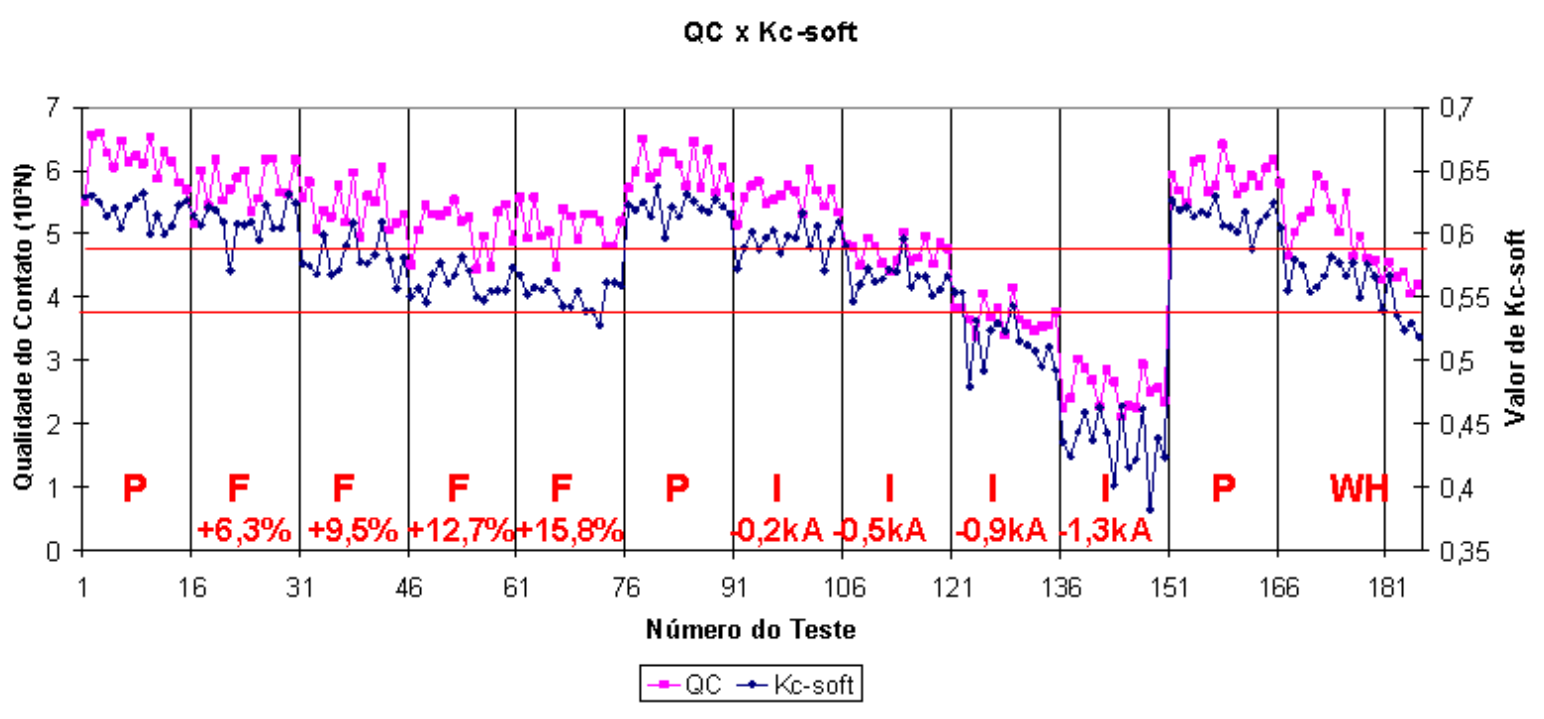

Figura 4.11 - Relação entre QC e o parâmetro $\mathrm{K}_{\mathrm{C}-\mathrm{SOFT}}$ para o primeiro conjunto de dados

O parâmetro $K_{C-S O F T}$ reflete o amolecimento do material durante o processo. Sendo assim, quanto maior o valor de $K_{C-S O F T}$, melhor a qualidade da solda, pois significa que mais calor foi concentrado na interface material-material durante a soldagem. Analisando os valores assumidos pelo parâmetro $K_{C-S O F T}$ nas diferentes condições dos testes realizados, é possível tirar as seguintes conclusões:

- $\quad$ Se $K_{C-S O F T}<0,543$, a qualidade da solda é ruim; 
- Se $0,582>K_{C-S O F T}>0,543$, é necessário atenção pois o processo está operando com o valor de algum parâmetro diferente do definido no procedimento padrão de soldagem, mas a qualidade da solda ainda pode ser considerada boa;

- Se $K_{C-S O F T}>0,582$, a solda é seguramente boa mesmo podendo haver pequeno desvio no valor de algum parâmetro com relação ao definido no procedimento padrão de soldagem.

A figura 4.12 mostra a relação entre QC e o parâmetro $R_{0 C}$ para o primeiro conjunto de dados.

QC $\times$ ROC

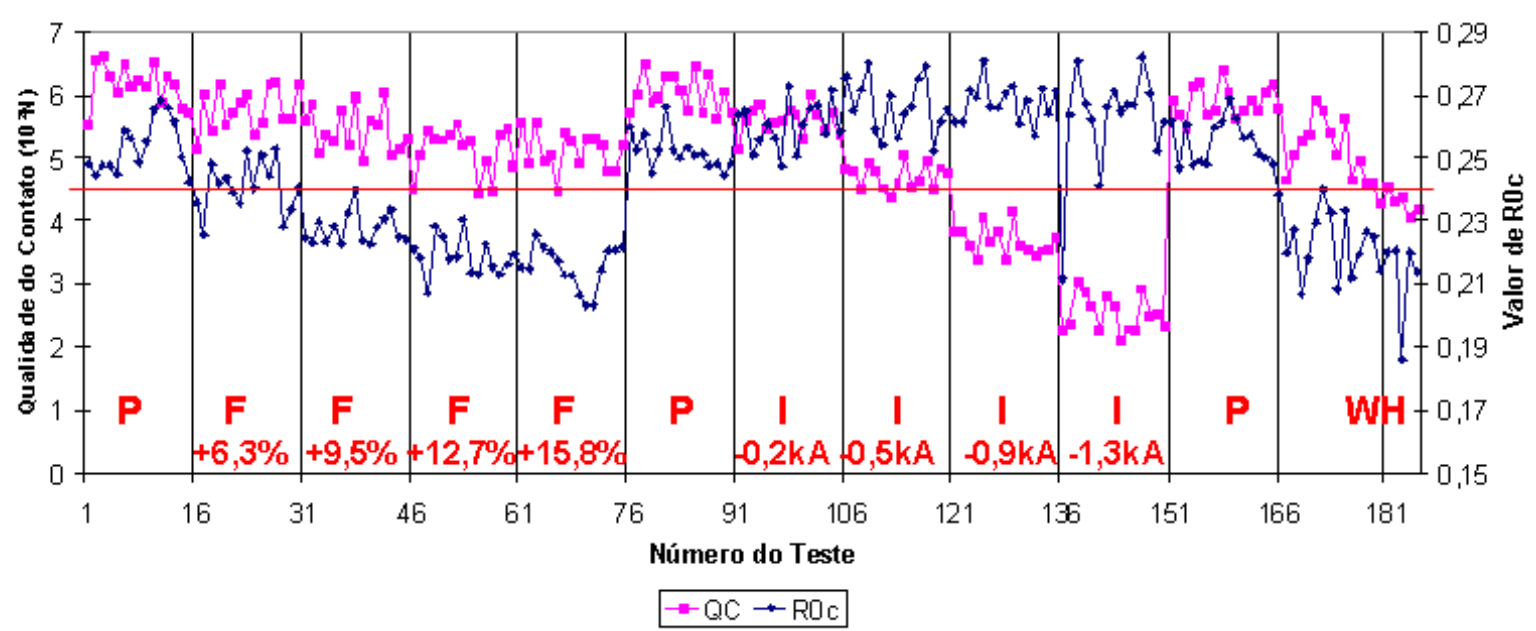

Figura 4.12 - Relação entre QC e o parâmetro $R_{0 C}$ para o primeiro conjunto de dados

O parâmetro $R_{O C}$ é relacionado com a resistência da interface material-material logo após o início da soldagem. Sendo assim, um valor mais alto de $R_{O C}$ significa que o colapso da rugosidade entre as partes foi menor, o que pode ser causado por uma diminuição da força de soldagem ou pela diminuição da corrente de soldagem. Analisando os valores assumidos pelo parâmetro $R_{O C}$ nas diferentes condições dos testes realizados, é possível tirar as seguintes conclusões: 
- Se $R_{0 C}>0,241$, o processo está operando de acordo com o definido no procedimento padrão de soldagem ou o valor da corrente de soldagem está abaixo do definido;

- Se $R_{0 C}<0,241$, o processo está operando sem welding help ou com o valor da força de soldagem maior que o definido no procedimento padrão de soldagem.

A figura 4.13 mostra a relação entre QC e o parâmetro $K_{E L M}$ para o primeiro conjunto de dados.

QC $\times$ Kelm

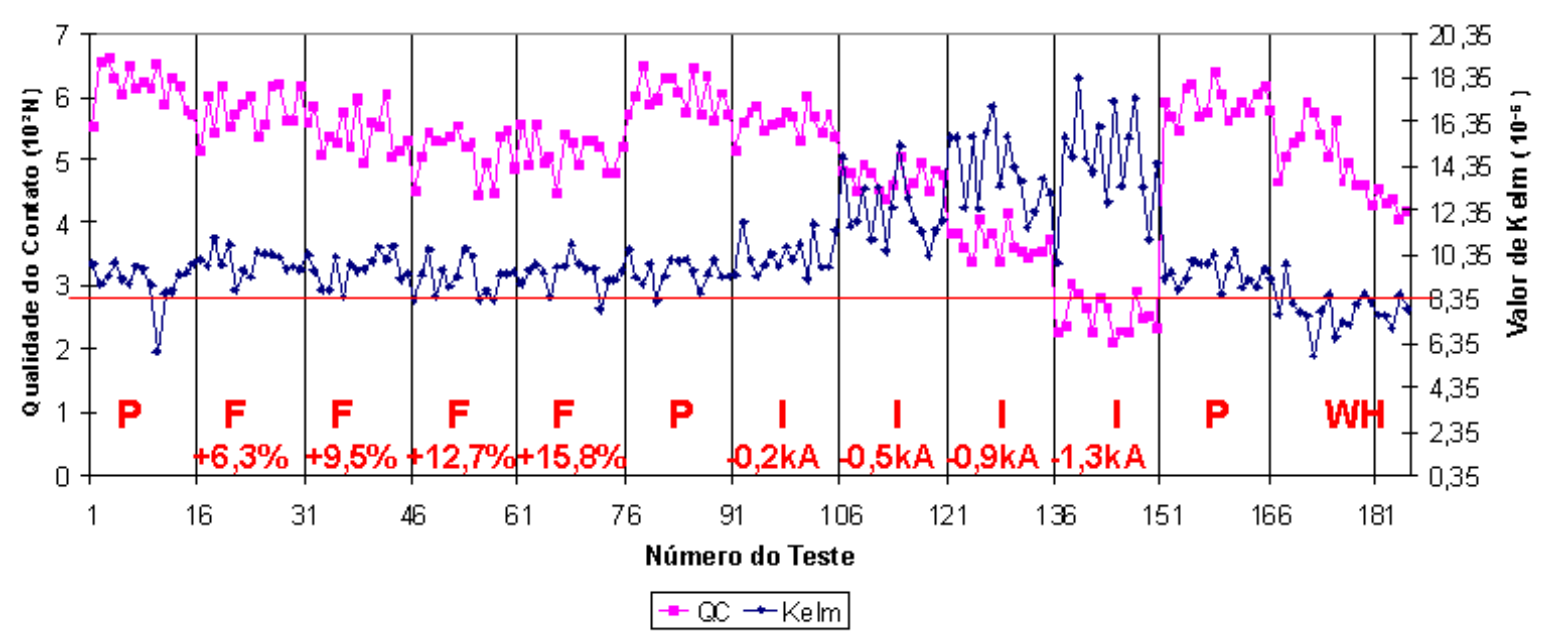

Figura 4.13 - Relação entre QC e o parâmetro $K_{E L M}$ para o primeiro conjunto de dados

O parâmetro $K_{E L M}$ é relacionado com a variação da resistência da interface eletrodomaterial. Este parâmetro é diretamente proporcional a força de soldagem e inversamente proporcional a corrente de soldagem. Analisando os valores assumidos pelo parâmetro $K_{E L M}$ nas diferentes condições dos testes realizados, é possível tirar as seguintes conclusões:

- Se $K_{E L M}>8,55 \times 10^{-6}$, existe uma grande probabilidade de o processo estar operando com uma força de soldagem maior que a definida no procedimento padrão de soldagem e uma pequena probabilidade de estar operando sem welding help; 
- Se $K_{E L M}<8,55 \times 10^{-6}$, existe uma grande probabilidade de o processo estar operando sem welding help e uma pequena probabilidade de estar operando com uma força de soldagem maior que a definida no procedimento padrão de soldagem.

A figura 4.14 mostra a relação entre QC e o parâmetro $R_{0 E L M}$ para o primeiro conjunto de dados.

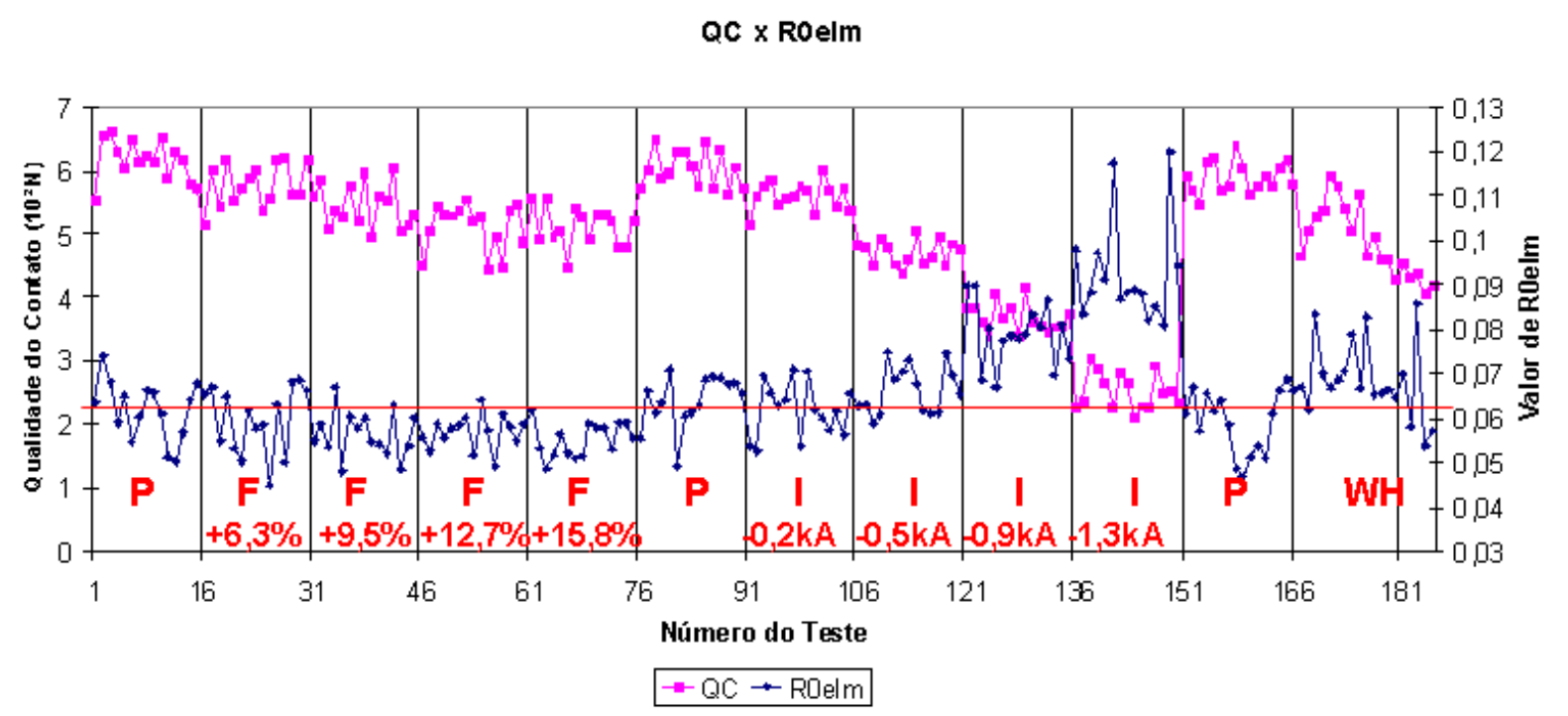

Figura 4.14 - Relação entre QC e o parâmetro $R_{O E L M}$ para o primeiro conjunto de dados

O parâmetro $R_{O E L M}$ é relacionado com a resistência da interface eletrodo-material logo após o início da soldagem. Sendo assim, um valor mais alto de $R_{O E L M}$ significa um pior ajuste entre o eletrodo e as partes soldadas, o que pode ser causado por uma diminuição da força de soldagem ou pela diminuição da corrente de soldagem. Analisando os valores assumidos pelo parâmetro $R_{O E L M}$ nas diferentes condições dos testes realizados, é possível tirar as seguintes conclusões:

- Se $R_{\text {OELM }}>0,063$, existe uma grande probabilidade de o processo estar operando sem welding help e uma pequena probabilidade de estar operando com uma força de soldagem maior que a definida no procedimento padrão de soldagem; 
- Se $R_{O E L M}<0,063$, existe uma grande probabilidade de o processo estar operando com uma força de soldagem maior que a definida no procedimento padrão de soldagem e uma pequena probabilidade de estar operando sem welding help.

A figura 4.15 mostra a relação entre QC e o parâmetro $K_{C}$ para o primeiro conjunto de dados.

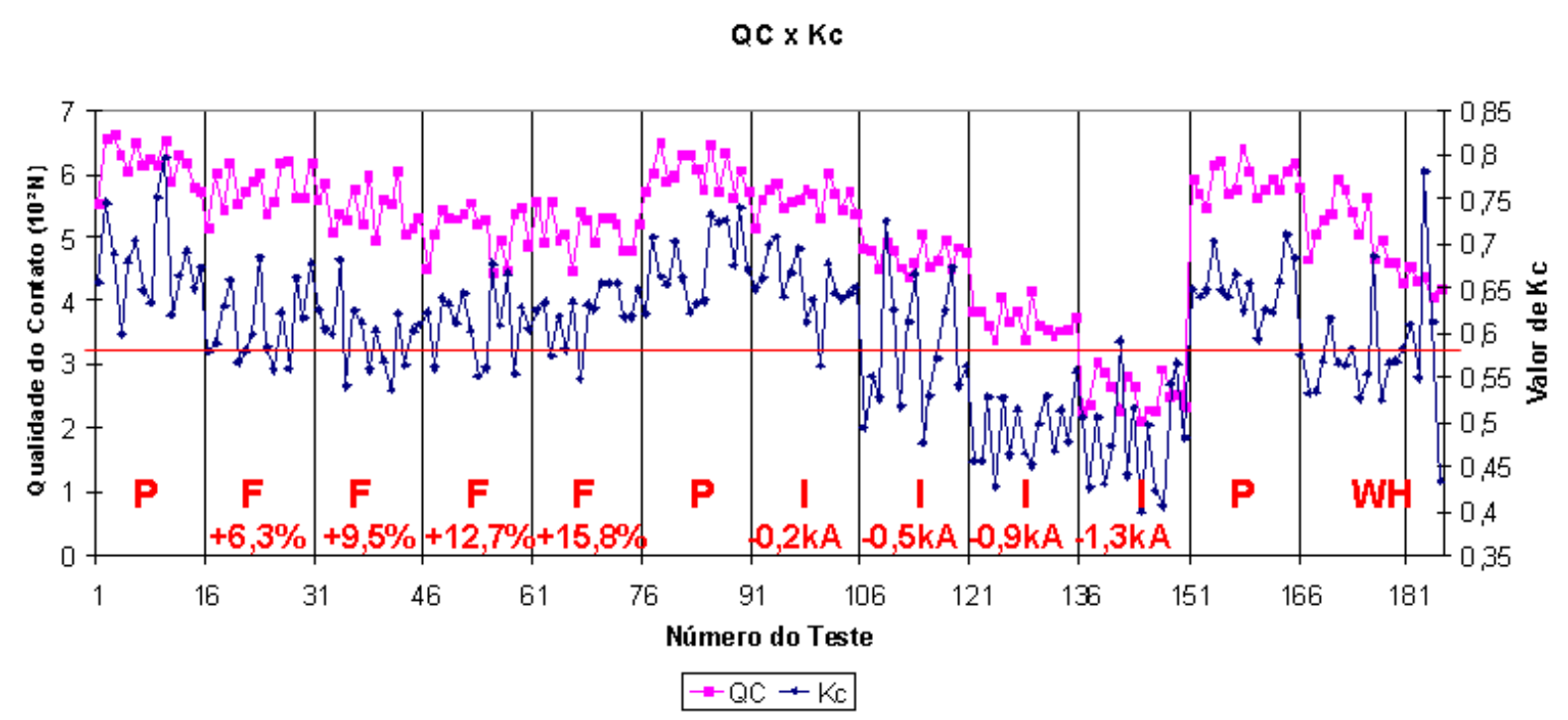

Figura 4.15 - Relação entre QC e o parâmetro $K_{C}$ para o primeiro conjunto de dados

O parâmetro $K_{C}$ é relacionado com a variação da resistência da interface materialmaterial. Este parâmetro é inversamente proporcional a força de soldagem e diretamente proporcional a corrente de soldagem. Analisando os valores assumidos pelo parâmetro $\mathrm{K}_{\mathrm{C}}$ nas diferentes condições dos testes realizados, é possível tirar as seguintes conclusões:

- Se $K_{C}>0,58$, o processo opera como no procedimento padrão de soldagem ou com desvio no valor de algum parâmetro, mas a qualidade da solda é aceitável;

- Se $K_{C}<0,58$, o processo opera com o valor de algum parâmetro diferente do definido no procedimento padrão de soldagem com provável perda de qualidade por parte da solda. 
Após esta análise foi possível estabelecer um procedimento para identificar a causa no caso de perda de qualidade por parte da solda. Este procedimento é mostrado no fluxograma da figura 4.16.

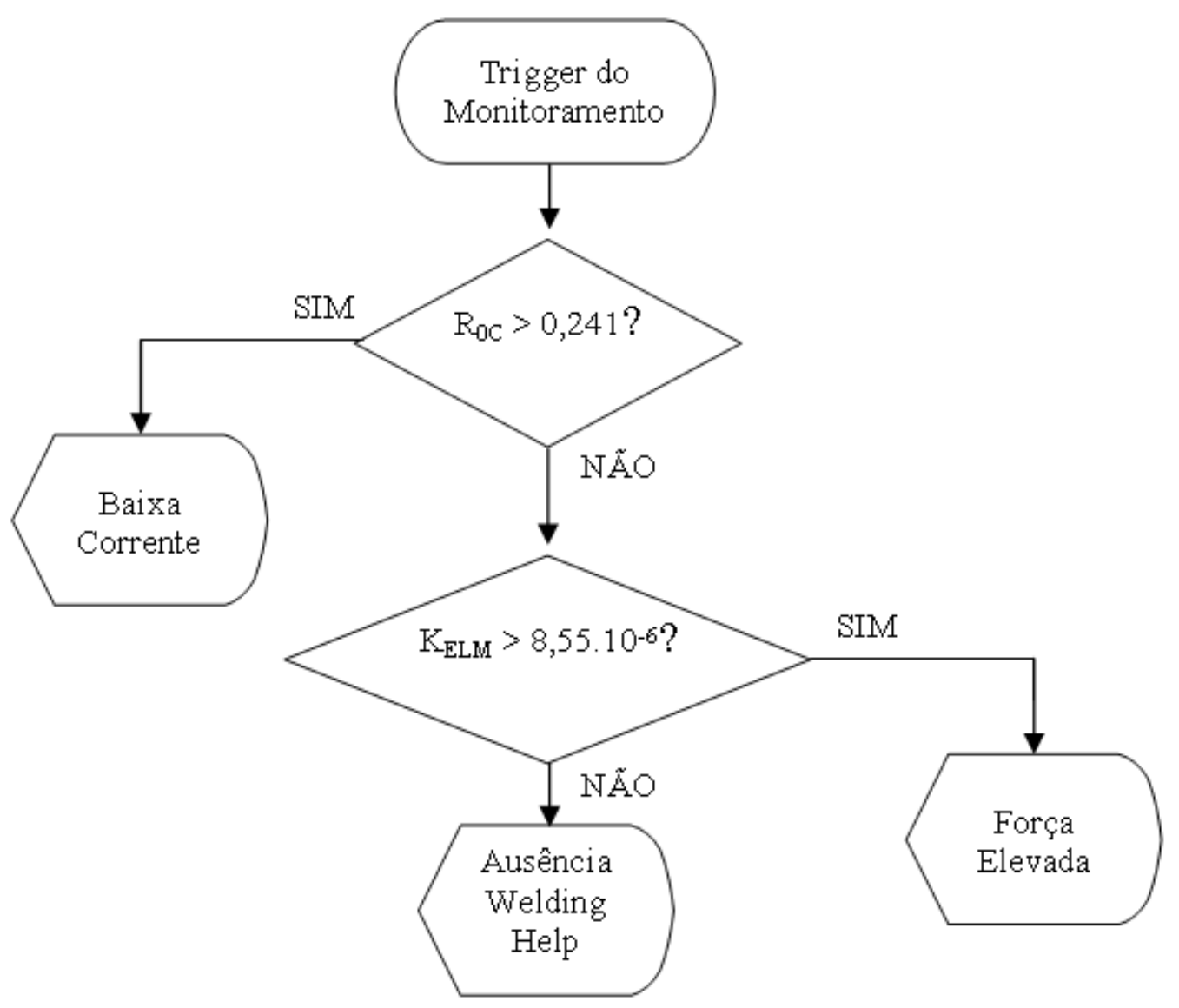

Figura 4.16 - Fluxograma do procedimento usado para identificar a causa no caso de perda de qualidade por parte da solda para o primeiro conjunto de dados

Ao estimar a qualidade de uma solda abaixo do mínimo exigido, o sistema inicia a execução do procedimento apresentado na figura 4.16. Este procedimento foi testado no primeiro conjunto de dados, usando como qualidade mínima exigida uma força de cisalhamento de $475 \mathrm{~N}$. De 39 amostras que tiveram a qualidade estimada abaixo de $475 \mathrm{~N}$ somente 1 teve um diagnóstico errado da causa de perda de qualidade, obtendo o sistema uma taxa de acerto acima de $97,4 \%$. 
O mesmo estudo foi realizado no segundo conjunto de dados. As figuras 4.17, 4.18, $4.19,4.20$ e 4.21 mostram a relação entre QC e $K_{C-S O F T}, R_{O C}, K_{E L M}, R_{O E L M}$ e $K_{C}$, respectivamente.

QC $\times$ Kc-soft

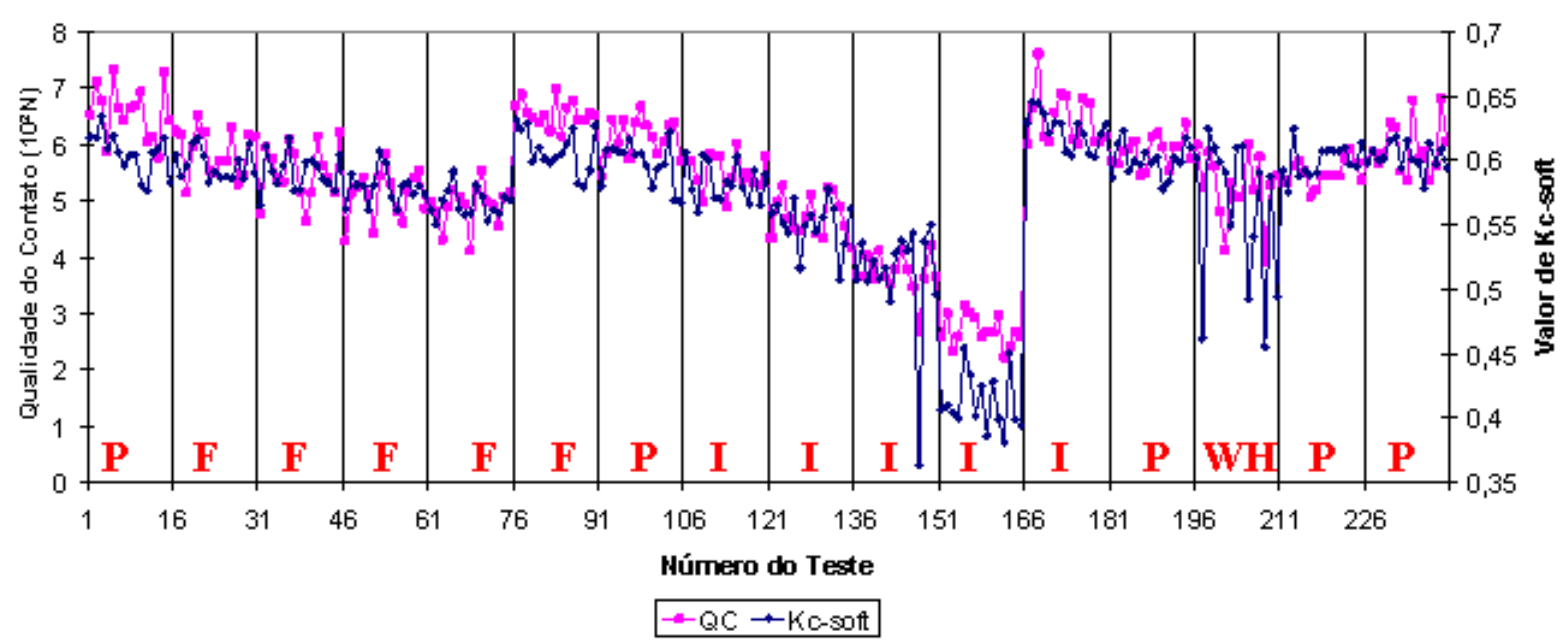

Figura 4.17 - Relação entre QC e o parâmetro $K_{C \text {-SOFT }}$ para o segundo conjunto de dados

QC $\times$ ROC

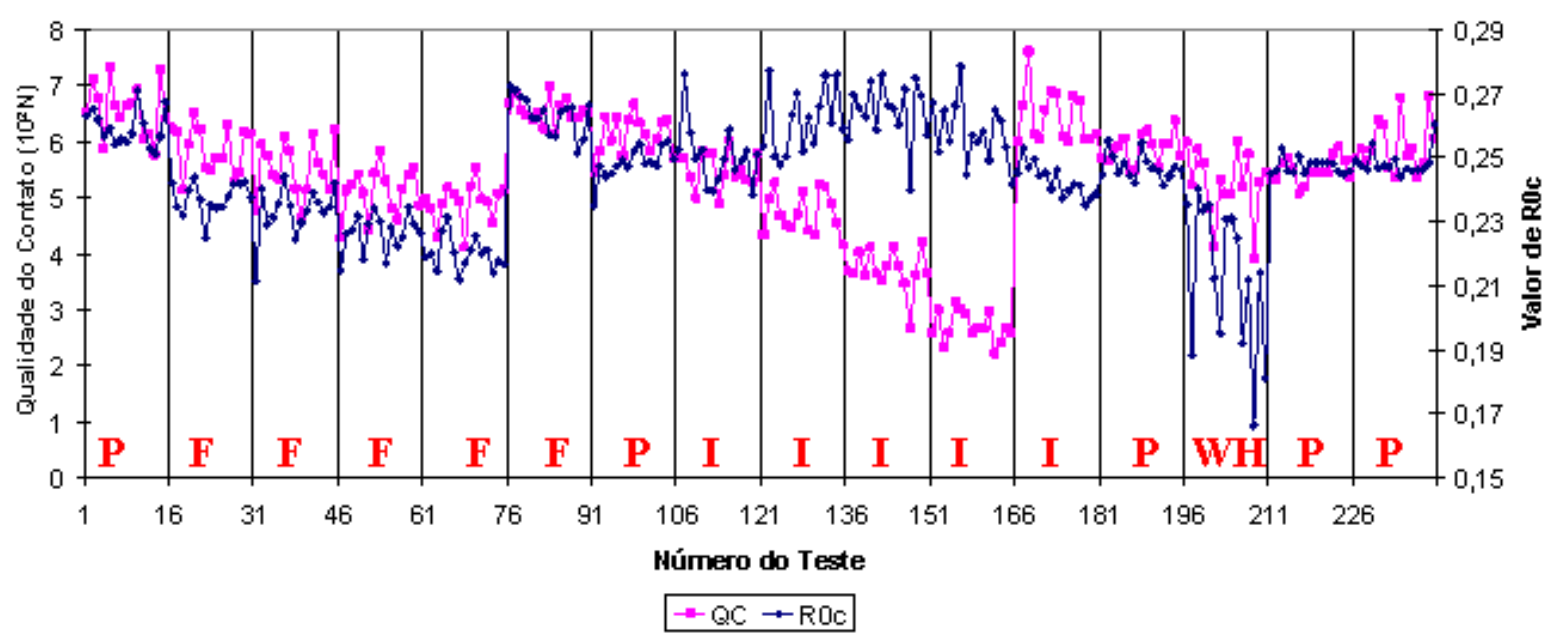

Figura 4.18 - Relação entre QC e o parâmetro $R_{0 C}$ para o segundo conjunto de dados 
QC x KeIm

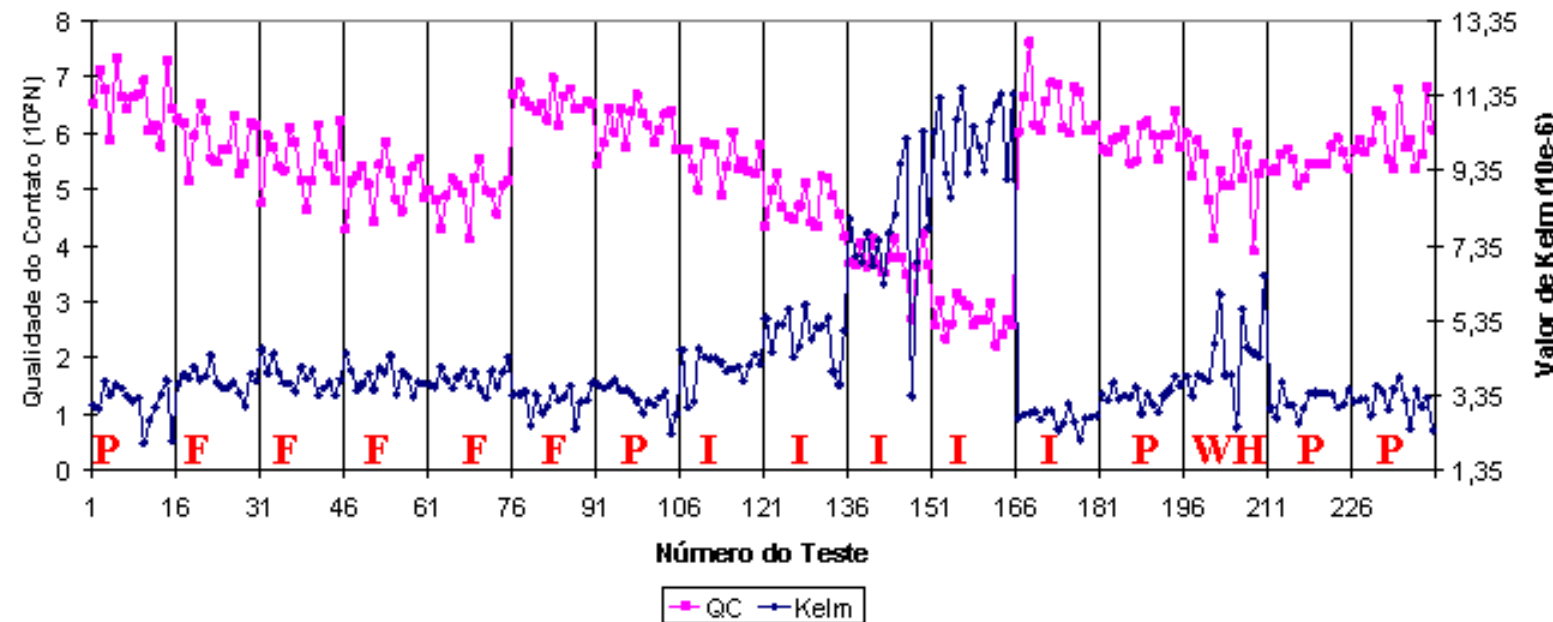

Figura 4.19 - Relação entre QC e o parâmetro $K_{E L M}$ para o segundo conjunto de dados

OC x R0elm

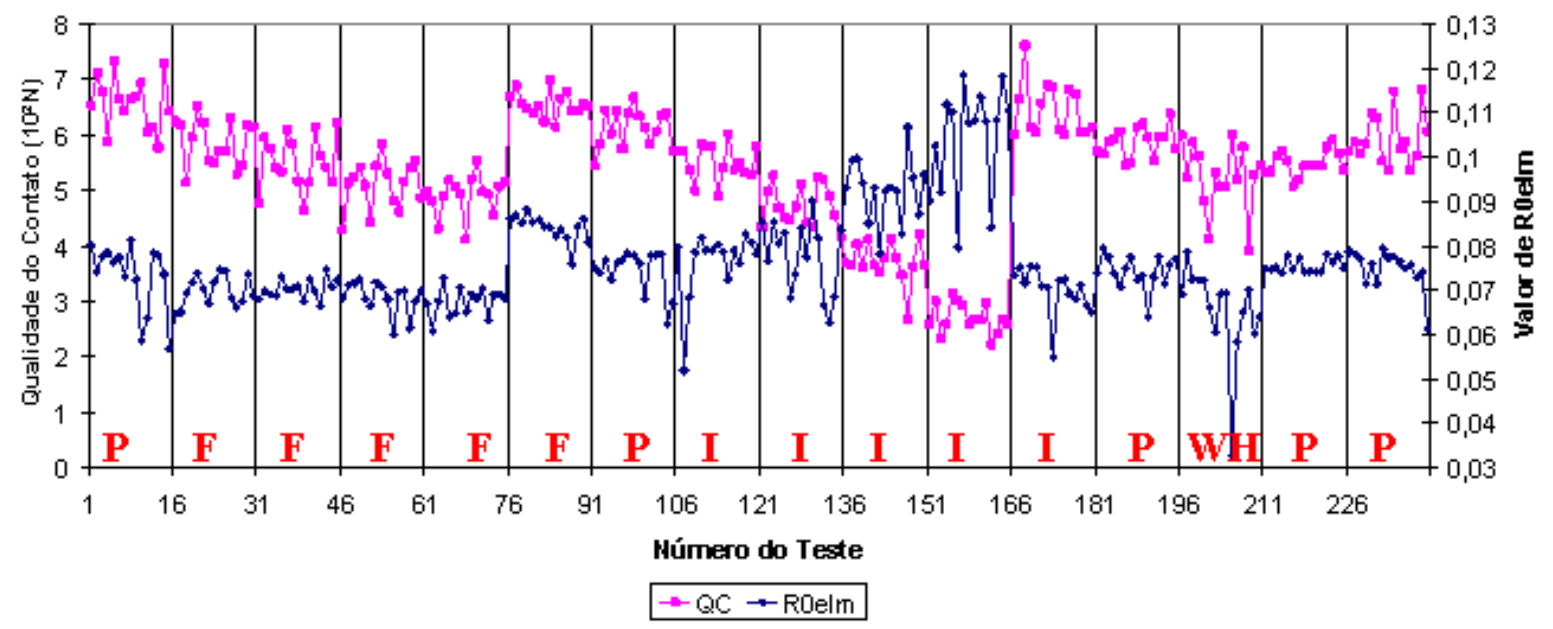

Figura 4.20 - Relação entre QC e o parâmetro $R_{O E L M}$ para o segundo conjunto de dados $\mathrm{QC} \times \mathrm{Kc}$

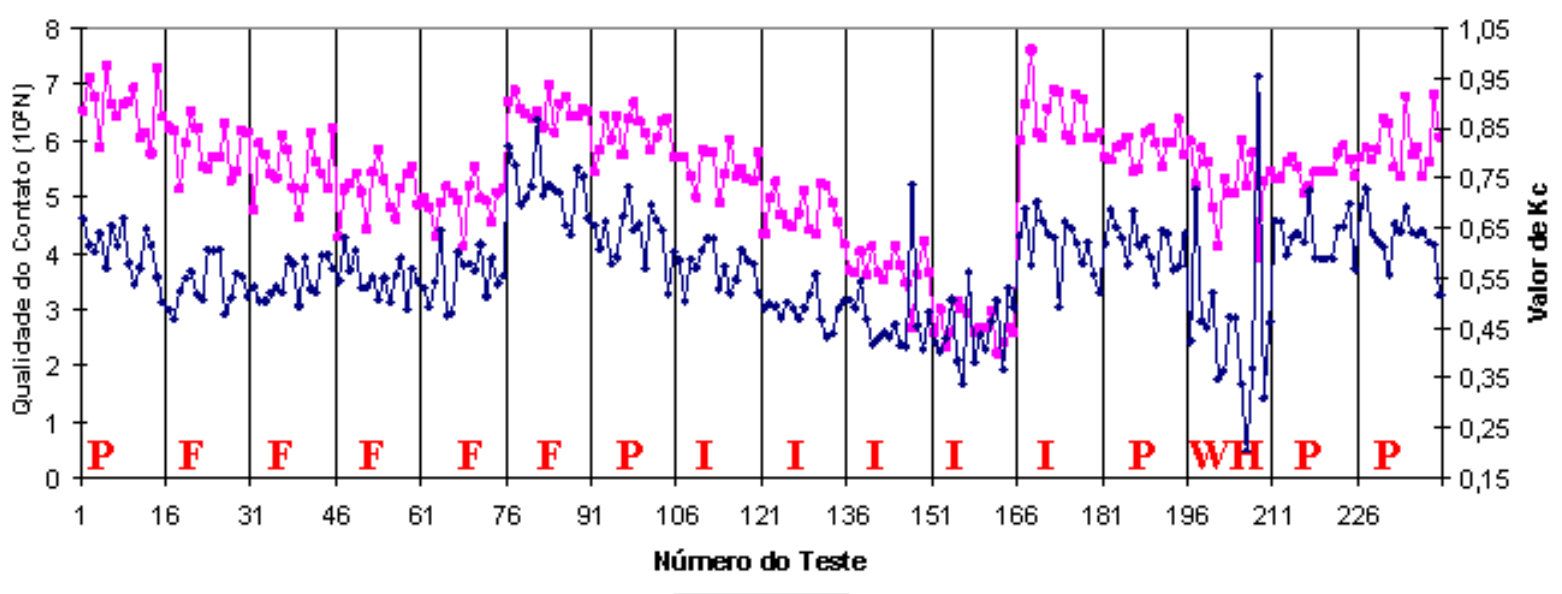

$-\mathrm{QC} \rightarrow \mathrm{KC}$

Figura 4.21 - Relação entre QC e o parâmetro $K_{C}$ para o segundo conjunto de dados 
Após a análise dessas figuras foi possível estabelecer um procedimento para identificar a causa no caso de perda de qualidade por parte da solda para o segundo conjunto de dados. Este procedimento é mostrado no fluxograma da figura 4.22.

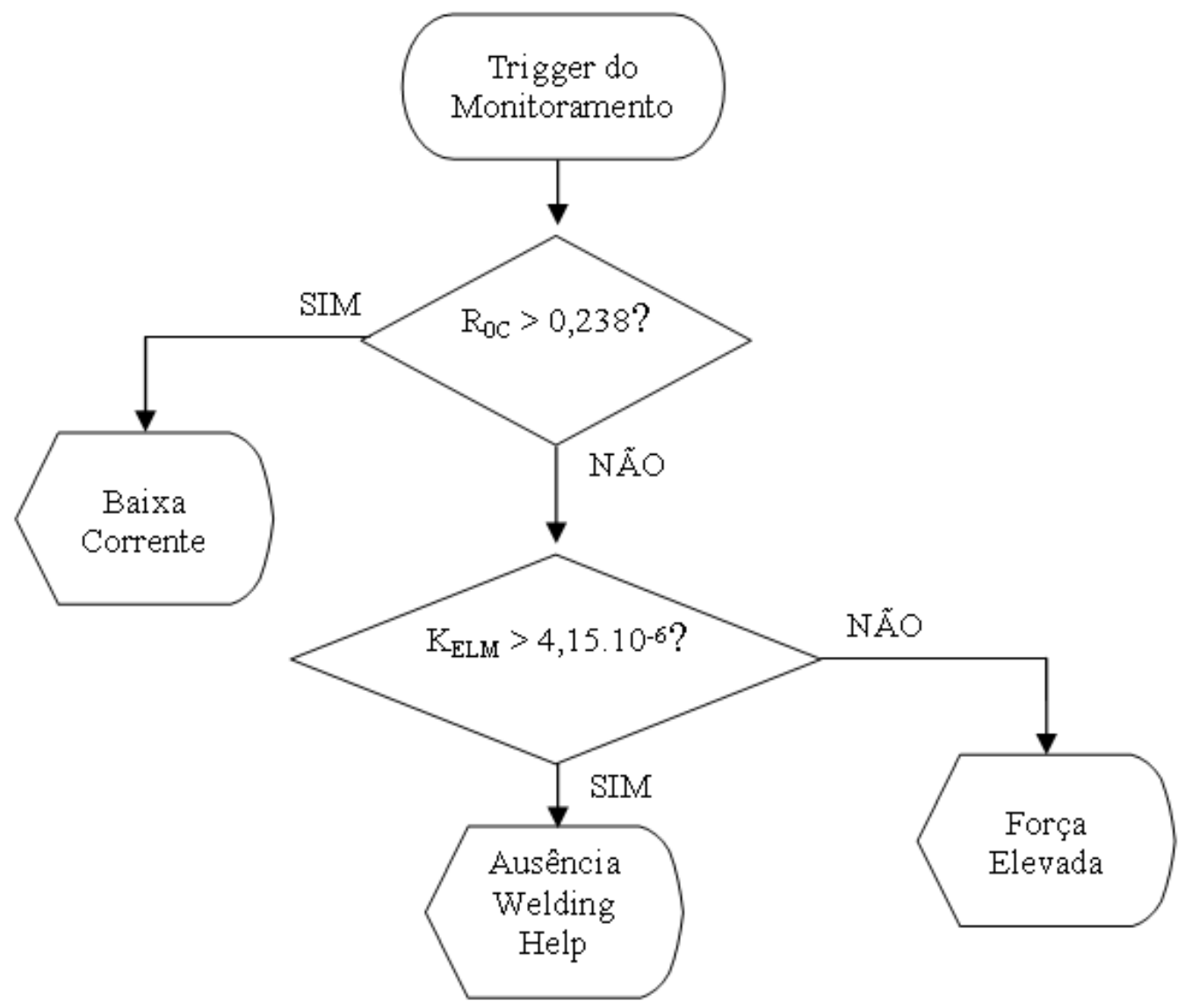

Figura 4.22 - Fluxograma do procedimento usado para identificar a causa no caso de perda de qualidade por parte da solda para o segundo conjunto de dados

Este procedimento foi testado no segundo conjunto de dados, usando como qualidade mínima exigida uma força de cisalhamento de 475N. De 37 amostras que tiveram a qualidade estimada abaixo de $475 \mathrm{~N}$ somente 1 teve um diagnóstico errado da causa de perda de qualidade, obtendo o sistema uma taxa de acerto acima de $97,2 \%$. 


\section{Conclusão}

Neste trabalho foi apresentado um sistema de monitoramento baseado no reconhecimento de padrões através de redes neurais artificiais que se mostrou eficaz no monitoramento da qualidade do processo de solda a ponto resistiva.

Embora o sistema proposto tenha sido aplicado no PSPR, seus componentes são genéricos e podem ser aplicados também em outros processos produtivos, desde que alguma(s) grandeza(s) relacionada(s) com a qualidade possa(m) ser medida(s) e um modelo que incorpore essa(s) grandeza(s) seja concebível. É importante destacar que basta que o modelo reflita as propriedades da(s) grandeza(s) medida(s), não necessitando englobar todos os detalhes do processo, graças à capacidade de generalização das redes neurais que podem fornecer respostas coerentes para padrões desconhecidos. Esta é uma importante vantagem em processos não-determinísticos, onde não estão disponíveis modelos precisos e que englobem todas variáveis atuantes, o que ocorre com freqüência no mundo industrial.

Baseado nos resultados obtidos, o sistema proposto foi capaz de monitorar a qualidade dos pontos de solda produzidos de forma não-destrutiva, não invasiva, individualizada, em tempo real, já que o tempo de processamento necessário para analisar cada solda, cerca de 31 ms, é suficiente para verificar cada ponto de solda produzido, mesmo em um processo com alta taxa de produção como o investigado neste trabalho.

Como os dados foram obtidos diretamente da linha de produção sem causar problemas a essa, e como o sistema proposto não necessita de dados diferentes dos obtidos, ou seja, tensão e corrente durante o processo de soldagem, pode-se dizer que o sistema proposto neste trabalho é capaz de operar em um ambiente industrial.

Como previsto, os resultados mostraram que existe uma correlação entre as perturbações mais comuns que podem prejudicar a qualidade final da solda e os valores dos parâmetros do modelo. Dessa forma, o sistema proposto pode automaticamente analisar os 
valores dos parâmetros obtidos, após o ajuste da curva do modelo com a curva real, e apontar a causa para soldas cuja qualidade estimada foi considerada baixa, com taxa de acerto acima de $97,2 \%$. Esta característica do sistema é de grande valia para a manutenção do processo produtivo. Essa contribuição não foi encontrada nos sistemas propostos por outros autores. Embora estes sistemas, como mostrado, apresentem uma precisão na estimação da qualidade final da solda comparável com a obtida no sistema proposto neste trabalho, de cerca de 9,5 $\mathrm{N}$ para o primeiro conjunto de dados e $16,5 \mathrm{~N}$ para o segundo conjunto, não são capazes de apontar causas.

Após implementar todos os componentes do sistema no PSPR, ou seja, medir a tensão e corrente de soldagem, criar o modelo matemático parametrizável, treinar a rede neural usando os parâmetros ajustados do modelo e a força de cisalhamento obtida através de ensaio destrutivo, validar a rede treinada, interpretar os valores assumidos pelos parâmetros do modelo, encontrando os limites de valores que possibilitem identificar a causa de baixa qualidade, o sistema proposto está pronto para automaticamente estimar a força de cisalhamento suportada pelas soldas produzidas e identificar causas para soldas estimadas como sendo de baixa qualidade.

Como trabalhos futuros, pode-se investigar a utilização dos parâmetros ajustáveis do modelo criado como realimentação do processo em uma malha de controle ponto a ponto que ajuste os parâmetros do procedimento de soldagem. Outra sugestão é a implementação de um banco de dados com o histórico de produção no qual Data Mining pode ser aplicado para otimizar o procedimento de soldagem ao longo do tempo. 


\section{REFERÊNCIAS BIBLIOGRÁFICAS}

ARAVINTHAN, A., SIVAYOGANATHAN, K., AL-DABASS, D., BALENDRAN, V., A Neural Network System for Spot Weld Strength Prediction, UKSIM2001, Conf. Proc. of the UK Simulation Society, 2001, pag. 156-160.

BISHOP, C. M., Neural Networks for Pattern Recognition, Oxford University Press, 1995.

BROOMHEAD, J.H.W., Resistance Spot Welding Quality Assurance, Welding and Metal Fabrication. vol. 58, No. 6, 1990, pag. 172-179.

BROWN, J.D., RODD, M.G., WILLIAMS, N.T., Application of artificial intelligence techniques to resistance spot welding, Ironmaking and Steelmaking, vol. 25, issue 3, 1998, pag. 199-204.

BROWN, L.J., SCHWABER, J.S., Identifying operating conditions from pre-weld information for resistance spot welding, Proceedings of the 2000 American Control Conference, vol. 3, 2000, pag. 1535-1539.

CHEN, X., ARAKI, K., Fuzzy adaptive process control of resistance spot welding with a current reference model, IEEE International Conference on Intelligent Processing Systems, 1997, ICIPS '97, vol.1, out. 1997, pag. 190-194.

CHEN, J., FARSON, D.F., ELY, K., FRECH, T., Modeling small-scale resistance spot welding machine dynamics for process control, The International Journal of Advanced Manufacturing Technology, volume 27, números 7-8, janeiro 2006, pag. 672-676.

CHO, Y., RHEE, S., New technology for measuring dynamic resistance and estimating strength in resistance spot welding, Measurement Science and Technology, n.11, pag. 1173$1178,2000$. 
CHO, Y., RHEE, S., Primary Circuit Dynamic Resistance Monitoring and its Application to Quality Estimation during Resistance Spot Welding, Welding Journal, NEW YORK, junho 2002, pag.104-111.

CHO Y., RHEE, S., Experimental Study of Nugget Formation in Resistance Spot Welding, Welding Research - Supplement to the Welding Journal, n. 8, Agosto, 2003.

CHO, Y., RHEE, S., Quality Estimation of Resistance Spot Welding by Using Pattern Recognition with Neural Networks, IEEE Transactions on Instrumentation and Measurement, vol. 53, n.2, abril, 2004, pag. 330-334.

CULlEN, J.D., ATHI, N., AL-JADER, M., JOHNSON, P., AL-SHAMMA, A.I., Multisensor fusion for on line monitoring of the quality of spot welding in automotive industry, Measurement, volume 41, 2008, pag. 412-423.

DENISOV, A.A., SHAKARJI, C.M., LAWFORD, B.B., MAEV, R., PAILlE, J.M., Spot Weld Analysis With 2D Ultrasonic Arrays, Journal of Research of the National Institute of Standards and Technology, Volume 109, Number 2, March-April, pag. 233-244, 2004.

DILTHEY, U., DICKERSBACH, J., Application of neural networks for quality evaluation of resistance spot welds, ISIJ International, vol. 39, n. 1, 1999, pag. 1061-1066.

DOYUM, A., SONAT M., Ultrasonic examination of resistance spot weld, Journal of Nondestructive Testing (NDT), vol.8, issue 12, 2003. Disponível em: $<$ http://www.ndt.net/v08n12.htm>.

EISAZADEH, H, HAMEDI, M. HALVAEE A., New parametric study of nugget size in resistance spot welding process using finite element method, Materials and Design, volume 31, 2010, pag. 149-157.

EL-BANNA, M., FILEV, D., CHINNAM, R. B., Intelligent Constant Current Control for Resistance Spot Welding, IEEE International Conference on Fuzzy Systems'06, pag. 15701577, Julho, 2006. 
EL-BANNA, M., FILEV D., CHINNAM. R.B., Online qualitative nugget classification by using a linear vector quantization neural network for resistance spot welding, International Journal Adv. Manuf. Technology, vol. 36, 2008, pag.237-248.

FurlanetTo, V., MOTOMURA, G. M., BATAlHA, G. F., Técnicas de Inteligência Artificial na Modelagem e Controle do Processo de Solda a Ponto por Resistência Elétrica, V Congresso Nacional de Engenharia Mecânica - COBEM 2008, agosto, 2008.

GARZA, F. J., DAS, M., Identification of time-varying resistance during welding, Proceedings of the 17th IEEE Instrumentation and Measurement Technology Conference, vol. 3, pag. 1534-1539, 2000.

GARZA, F. J., DAS, M., On Real time Monitoring and Control of Resistance Spot Welds using Dynamic Resistance Signatures, Proceedings of the 44th IEEE Midwest Symposium on Circuits and Systems'01, vol. 1, pag. 41-44, 2001.

GONG, L., LIU, C.L, ZHA, X.F., Model-Based Real-Time Dynamic Power Factor Measurement in AC Resistance Spot Welding With an Embedded ANN, IEEE Transactions on Industrial Electronics, vol. 54, n. 3, junho 2007, pag. 1442-1448.

HARDT, M., Welding, Wikipedia, the free encyclopedia. Disponível em: $<$ http://en.wikipedia.org/wiki/Welding\#Quality>. Acessado em: 16 de julho de 2009.

HALMSHAW, R., Introduction to the Non-Destructive Testing of Welded Joints, The Welding Institute, Cambridge, UK, 1988.

HAYKIN, S., Neural Networks. A Comprehensive Foundation, Prentice Hall, New Jersey, 2a edição, 1999.

HIRSCH, R.B., Tip Force Control Equals Spot Weld Quality, Welding Journal, vol. 72, No. 3, pag. 57-60, 1993.

HOLDREN, R.L., What Are the Causes of and Solutions to Weld Quality Control, Welding Journal. vol. 72, No. 8, 1993. 
IRVING, B., Search Goes on for the Perfect Resistance Welding Control, Welding Journal, vol. 75, No. 1, pag. 63-68, 1996.

IVEZIC, N., ALIEN, J.D., ZACHARIA JUNIOR, T., Neural network-based resistance spot welding control and quality prediction, Proceedings of the Second International Conference on Intelligent Processing and Manufacturing of Materials, 1999. IPMM '99., vol. 2, 1999, pag 989-994.

JOU, M., Experimental Investigation of Resistance Spot Welding for Sheet Metals Used in Automotive Industry, JSME International Journal, series C, vol. 44, n.2, 2001, pag. 544552.

JOU, M., Real time monitoring weld quality of resistance spot welding for the fabrication of sheet metal assemblies, Journal of Materials Processing Technology, vol. 132, pag. 102-113, 2003.

KHOO, L.P., A Prototype Fuzzy Resistance Spot Welding System, Int. Journal Prod. Res., vol. 33, No. 7, pag. 2023-36, 1995.

KOON, W., Current sensing for energy metering, Conference Proceedings IIC-CHINA/ ESC-CHINA'02, pag 321-324, 2002.

LEE, R.S., CHOO, Y. J., LEE, T. Y., KIM, M. H., CHOI, S. K., A Quality Assurance Technique for Resistance Spot Welding Using a Neuro-Fuzzy Algorithm, Journal of Manufacturing Systems, vol. 20, issue 5, 2001, pag. 320-328.

LI, W., HU, S. J., NI, J., On-line Quality Estimation in Resistance Spot Welding, J. Manuf. Sci. Eng., vol. 122, issue 3, agosto 2000, pag. 511-512.

LI, W., CHENG, S., HU, S.J., SHRIVER, J., Statistical Investigation on Resistance Spot Welding Quality Using a Two-State Sliding-Level Experiment, Journal of Manufacturing Science and Engineering, vol. 123, issue 3, agosto 2001, pag. 513-520. 
LI, W., Modeling and On-Line Estimation of Electrode Wear in Resistance Spot Welding, Journal of Manufacturing Science and Engineering, vol. 127, novembro 2005, pag. 709-717.

LIANG, C., LIU, X., Strength prediction of sheet to tube single sided resistance spot welding, Materials and Design, vol. 30, n 10, dezembro 2009, p 4328-4334.

LING, S., WAN, L., WONG, Y., LI, D., Input electrical impedance as quality monitoring signature for characterizing resistance spot welding, NDT \& E International, 2009.

MACHE, N., Manual da Ferramenta de Simulação de Redes Neurais - SNNS, Instituto para Sistemas Paralelos e Distribuídos de Alta Performance da Universidade de Stuttgart. Disponível em: http://www.ra.cs.uni-tuebingen.de/SNNS/UserManual/UserManual.html, 1995.

MANSOUR, T. M., Ultrasonic Inspection of Spot Welds in Thin-Gage Steel, Materials Evaluation, Vol. 46, n.5, Abril, 1988, pag. 640-658.

MARTÍN, O. , LÓPEZ, M. , MARTÍN, F., Artificial neural networks for prediction of quality in resistance spot welding, Revista de Metalurgia, volume 42, issue 5, setembro 2006, pag. 345-353.

MARTÍN, O., LÓPEZ, M., MARTÍN, F., Artificial neural networks for quality control by ultrasonic testing in resistance spot welding, Journal of Materials Processing Technology, n. 183, pag. 226-233, 2007.

MEOLA, C., SQUILLACE, A., MINUTOLO, F.M.C., MORACE, R.E., Analysis of stainless steel welded joints: a comparison between destructive and non-destructive techniques, Journal of Materials Processing Technology, vol. 155-156, pag.1893-1899, 2004.

MESSLER, R.W. Jr., An Intelligent Control System for Resistance Spot Welding Using A Neural network and Fuzzy Logic, IEEE Industry Applications Conference'95, vol. 2, pag. 1757-63, 1995. 
MEWBORNE, M., Advances made in resistance welding process control, Practical Welding Today, May/June, Volume 3, n. 3, 1999.

MITCHELL, T. M., Machine Learning, McGraw-Hill Higher Education, 1997.

NEGNEVITSKY, M., Artificial Intelligence: A Guide to Intelligent Systems, Pearson Education Limited, 2002.

PENGXIAN, Z., HONGJIE, Z., JIANHONG, C., YUEZHOU, M., Quality monitoring of resistance spot welding based on electrode displacement characteristics analysis, Front. Mech. Eng. China, vol. 2, número 3, 2007, pag.330-335.

PODOLA, N.V., RUDENKO, P.M., GAVRISH, V.S., Adaptive algorithm of quality control of resistance spot welding using neural networks, Paton Welding Journal, no.1, 2002.

PODRZAJ, P., POLAJNAR, I., DIACI, J., KARIZ, Z., Estimating the strength of resistance spot welds based on sonic emission, Science and Technology of Welding and Joining, vol. 10, número 4, 2005, pag. 399-405.

PODRZAJ, P., POLAJNAR, J., DIACI, J., KARIZ, Z., Overview of Resistance Spot Welding Control, Science and Technology of Welding and Joining, vol.13, n.3, pag. 215$224,2008$.

PRESS, W. H., TEUKOLSKY, S. A., VeTterling, W. T., FlanNERY, B. P., NUMERICAL RECIPES IN C: THE ART OF SCIENTIFIC COMPUTING, Cambridge University Press, second edition, 1992

RAMBOZ, J., Machinable rogowski coil design and calibration, IEEE Transactions on Instrumentation and Measurement, vol. 45, pag. 511-515, abril, 1996.

ROSENBLATT F., The Perceptron: A probabilistic model for information storage and organization in the brain, Psychological Review, vol. 68, pag. 386-408, 1958. 
ROYE, W., Nondestructive Inspection Methods in the automotive industry, $8^{\text {th }}$ ECNDT Conference, Barcelona (Spain), June 17-21, 2002.

RUISZ, J, BIBER, J, LOIPETSBERGER, M., Quality evaluation in resistance spot welding by analyzing the weld fingerprint on metal bands by computer vision, International Journal Adv Manuf. Technology, vol. 33, 2007, pag.952-960.

SAPP, MARK E., A History of Welding - from Hepheastus to Apollo. Disponível em: $<$ http://www.weldinghistory.org/whistoryfolder/welding/index.html $>$. Acessado em: 01 de maio de 2009.

SHVIRER, J., PENG, H., HU, S.J., Control of Resistance Spot Welding, Proceedings of the American Control Conference '99, San Diego, California, pag. 187-191., Junho, 1999.

SONG, Q., ZHANG, W., BAY, N., An Experimental Study Determines the Electrical Contact Resistance in Resistance Welding, Welding Research - Supplement to the Welding Journal, volume 84 , n.5, maio 2005, pag. 73-76.

STANWAY, J.D., Technological Advances in Resistance Welding Control, Welding and Metal Fabrication, Vol. 60, n. 4, pag. 159-164, 1992.

SUBRAMANIAN, D., DONGARKAR, G.K., DAS, M., V., FERNANDEZ, V., GRZADZINSKY, G., Real time monitoring and quality control of resistance spot welds using voltage, current, and force data, IEEE Electro/Information Technology Conference, 2004, EIT 2004, agosto 2004, pag. 211-220.

SUN, H., ZHANG, Y., LAI, X., CHEN, G., On-line inspection of weld quality based on dynamic resistance curve in resistance spot welding and weld bonding, Proc. of the Fourth International Symposium on Precision Mechanical Measurements, Vol. 7130, 2008.

TUOVINEN, L., LAURINEN, P., KOSKIMAKI, H., HAAPALAINEN, E., RUNING, J., Building a Database to Support Intelligent Computational Quality Assurance of Resistance Spot Welding Joints, IEEE International Symposium on Industrial Electronics ISIE 2007, pag. 1980-1985, 2007. 
VOGT, G., KÖHLER, C., RIEGER, D., State of art in ultrasonic spotweld testing - offline \& inline - new materials and coatings, 9th European NDT Conference (ECNDT`06), 2006. Disponível em: $<$ http://www.ndt.net/article/ecndt2006/doc/Th.3.4.5.pdf $>$.

XINMIN, L., XIAOYUN, Z., YANSONG, Z., GUANLONG, C., Weld Quality Inspection Based on Online Measured Indentation from Servo Encoder in Resistance Spot Welding, IEEE Transactions on Instrumentation and Measurement, vol. 56, n. 4, Agosto, 2007, pag. 1501-1505.

WARD, D.A., EXON, T., Using rogowski coil for transient current measurements, Engineering Science and Education Journal, pag. 105-114, 1993.

WEN, J., WANG, C. S., XUI G.S.AND ZHANGI, X. Q., Real Time Monitoring Weld Quality of Resistance Spot Welding for Stainless Steel, ISIJ International, vol. 49, número 4, 2009, pag. 553-556.

WEN, J., ZHANG, X., XU, G., WANG, C., ZHANG, X., HE, S., Quality estimation of resistance spot welding of stainless steel based on BP neural network, China Welding (English Edition), volume 18, issue 3, setembro 2009, pag. 16-20.

WILLIAMS, N. T., PARKER, J. D., Review of resistance spot welding of steel sheets Part 1 Modelling and control of weld nugget formation, International Materials Reviews, Maney Publishing, vol. 49, número 2, abril 2004a, pag. 45-75.

WILLIAMS, N. T., PARKER, J. D., Review of resistance spot welding of steel sheets Part 2 Factors influencing electrode life, International Materials Reviews, Maney Publishing, vol. 49, número 2, abril 2004b, pag. 77-108.

YANG, Y. P., BABU, S. S., ORTH, F. AND PETERSON, W., Integrated computational model to predict mechanical behavior of spot weld, Science and Technology of Welding and Joining, vol. 13, número 3, 2008, pag. 232-233. 
ZHANG, C., DI, L., AN, Z., Welding quality monitoring and management system based on data mining technology, Proceedings of the Second International Conference on Machine Learning and Cybernatics, Xi'an, novembro, 2003.

ZHANG, P., ZHANG, H., MA, Y., CHEN, J., On-line quality estimation of resistance spot welding based on extraction of signals feature, Transactions of the China Welding Institution, volume 26, issue 9, setembro 2005, pag. 52-57.

ZHANG, Y. S., WANG, H., CHENG, L., ZHANG, X. Q., Monitoring and intelligent control of electrode wear based on a measured electrode displacement curve in resistance spot welding, Meas. Sci. Technol., n.18, pag. 867-876, 2007.

ZHANG, H., HOU, Y., Quality evaluation of the resistance spot welding based on PCASVM, Hanjie Xuebao/Transactions of the China Welding Institution, volume 30, issue 4, abril 2009, pag. $97-100$. 


\section{ANEXO A - REDES NEURAIS ARTIFICIAIS}

\section{A.1 FUNDAMENTOS DE REDES NEURAIS ARTIFICIAIS}

Haykin descreveu uma rede neural como sendo uma máquina adaptável ou, mais especificamente: "Uma rede neural é um processador altamente paralelo e distribuído que possui uma propensão natural para armazenar conhecimento através de experiência e disponibilizá-lo para uso. Assemelha-se ao cérebro de duas formas: o conhecimento é adquirido pela rede através um processo de aprendizado e o peso entre as conexões entre neurônios, chamadas de sinapses, são utilizados para armazenar esse conhecimento" (HAYKIN, 1999).

Redes Neurais podem ser definidas como um modelo de raciocínio baseado no cérebro humano. O cérebro consiste em grupo de células nervosas, denso e altamente interconectado ou, basicamente, unidades de processamento chamados neurônios. O cérebro humano é formado por aproximadamente 10 bilhões de neurônios e 6 trilhões de conexões entre eles (NEGNEVITSKY, 2002). Desta forma, utilizando um processamento altamente paralelo, o cérebro tem condições de executar funções e atividades mais rápido que o mais poderoso computador existente atualmente.

Apesar de cada neurônio, individualmente, apresentar uma estrutura extremamente simples, o conjunto de tais elementos constitui um enorme poder de processamento. $\mathrm{O}$ neurônio consiste do corpo da célula, chamada soma, um número de fibras chamadas dendritos, e uma única e longa fibra chamada de axônio. Enquanto os dendritos alcançam regiões ao redor da soma, os axônios alcançam os dendritos e somas de outros neurônios. A Figura A.1 compara as conexões de um neurônio biológico e um neurônio artificial, e a Tabela A.1 apresenta uma analogia entre neurônios biológicos e neurônios artificiais. 


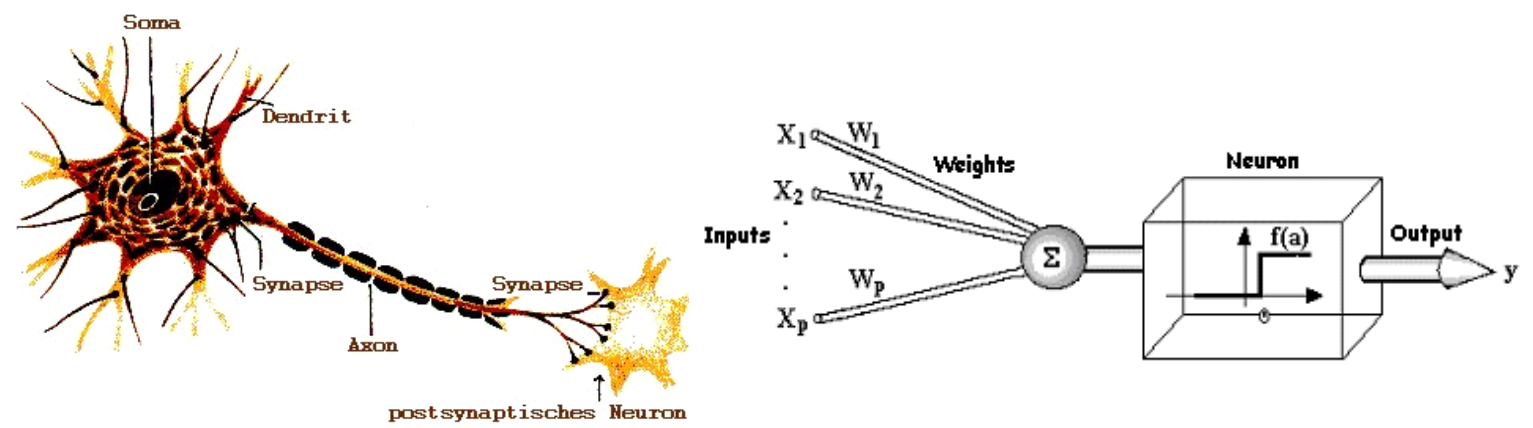

Figura A.1. Conexões de um Neurônio (a) Neurônio Biológico; (b) Neurônico Artificial

Tabela A.1 - Analogia entre Rede Neural Biológica e Artificial

\begin{tabular}{|c|c|}
\hline Rede Neural Biológica & Rede Neural Artificial \\
\hline Soma & Neurônio \\
\hline Dendrito & Entrada \\
\hline Axônio & Saída \\
\hline Sinapse & Pesos \\
\hline
\end{tabular}

Sinais são propagados de um neurônio a outro através de complexas reações eletroquímicas. Substâncias químicas liberadas pelas sinapses causam uma mudança no potencial elétrico do corpo da célula. Quando esse potencial atinge um limite, um pulso elétrico, chamado de potencial de ação, é enviado através do axônio. O pulso espalha-se e eventualmente atinge as sinapses, fazendo com que as sinapses aumentem ou diminuam seus potenciais. De qualquer forma, o ponto mais interessante é que a rede neural apresenta plasticidade. Em resposta ao padrão de estímulo, os neurônios demonstram, ao longo tempo, mudanças no peso entre suas conexões. Neurônios também podem formar novas conexões com outros neurônios. Até mesmo grupos inteiros de neurônios podem em alguns casos migrar de um lugar para outro. Esses mecanismos formam a base para o aprendizado no cérebro.

Nosso cérebro pode ser considerado um sistema de processamento de informações altamente complexo, paralelo e não-linear. Informações são armazenadas e processadas em 
uma rede neural simultaneamente através de toda a rede, ao invés de um local específico, ou seja, em redes neurais, ambos dados e processamento são globais ao invés de locais.

Devido à plasticidade, conexões entre neurônios que tendem à resposta correta à solicitação são fortalecidas, enquanto aquelas que levam à resposta errada são enfraquecidas. Como resultado, a rede neural tem a habilidade de aprender através de experiência. Aprendizado é uma característica fundamental e essencial de uma rede neural biológica. A tranqüilidade e naturalidade na qual as redes neurais podem aprender levaram à tentativa de simular uma rede neural biológica em um computador.

Apesar de atualmente as RNA não se parecerem muito com as redes neurais biológicas, isso por si só já é um grande avanço. As RNAs são capazes de aprender, ou seja, elas utilizam a experiência para aprimorar sua performance. Quando expostas a um número suficiente de amostras, as RNAs podem generalizar outras informações que não foram encontradas ou fornecidas. Uma RNA consiste de um número de processadores extremamente simples, porém altamente interconectados, também chamados de neurônios, análogos aos neurônios biológicos do cérebro. Os neurônios são conectados através de conexões com pesos, transmitindo sinais de um neurônio para outro. Cada neurônio recebe um número de sinais de entrada através dessas conexões. Apesar disso, o neurônio nunca produz mais de um único sinal de saída. O sinal de saída é transmitido através da conexão de saída do neurônio, correspondente ao axônio do neurônio biológico. A conexão de saída, por sua vez, é dividida em um ramo em que cada ramificação transmite o mesmo sinal. É importante observar que o sinal não é dividido entre os ramos e sim mantido para cada um. Esses ramos de saída terminam nas conexões de entrada de outros neurônios na rede. A Figura A.2 apresenta as conexões típicas de uma RNA. 


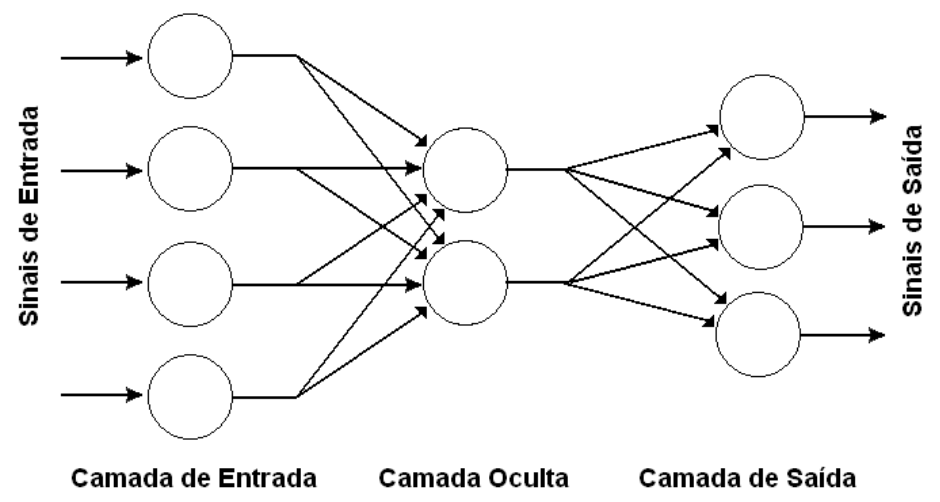

Figura A.2 - Arquitetura de uma RNA típica

\section{A.2 O Neurônio como um Simples Elemento Computacional}

Um neurônio recebe vários sinais das conexões de entrada, calcula um novo nível de ativação e envia o novo sinal para a saída através das conexões de saída. Os sinais de entrada podem ser dados externos ou saídas de outros neurônios. A Figura A.3 mostra um neurônio típico:

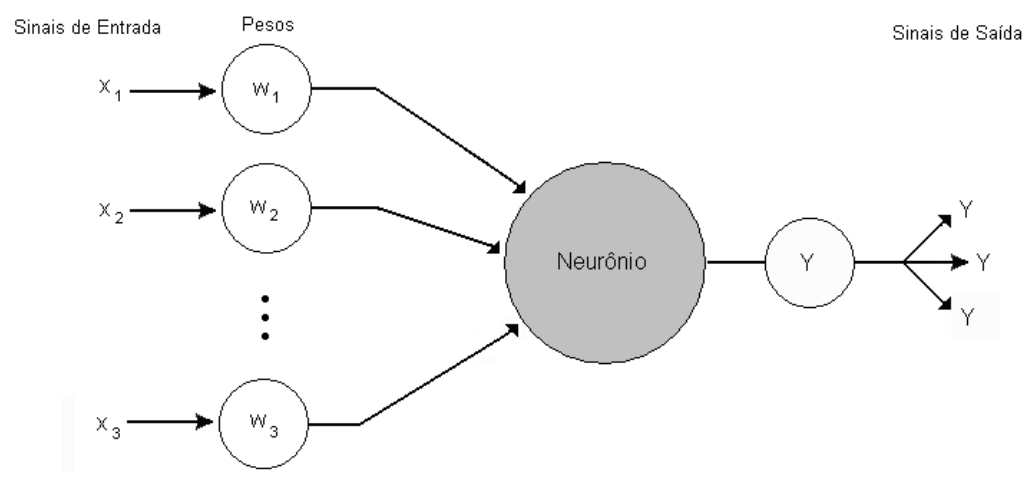

Figura A.3 - Diagrama de um neurônio

Em 1943, Warren McCulloch e Walter Pitts propuseram uma idéia simples e que ainda hoje é a base para a maioria das RNAs. O neurônio calcula a soma das entradas influenciadas pelo peso de cada conexão e compara o resultado com o valor de ativação, $\theta$. Se o valor da entrada do neurônio for menor que o de ativação, a saída do neurônio é -1. Porém, se o valor 
da entrada do neurônio for igual ou maior que o de ativação, o neurônio é ativado e sua saída atinge $\mathrm{o}$ valor +1 .

Em outras palavras, o neurônio utiliza as seguintes funções de ativação:

$$
\begin{aligned}
& X=\sum_{i=1}^{n} x_{i} w_{i} \\
& Y=\left\{\begin{array}{lll}
+1 & \text { se } \quad X \geq \theta \\
-1 & \text { se } & X<\theta
\end{array}\right.
\end{aligned}
$$

onde: $X$ é a entrada do neurônio influenciada pelo peso das conexões, $x_{i}$ é o valor da entrada $i$, $w_{i}$ é o peso da entrada $i, n$ é o número de entradas do neurônio e $Y$ é a saída do neurônio. Este tipo de função de ativação é chamado de função sinal.

Assim, a atual saída do neurônio com função de ativação sinal pode ser representada da seguinte forma:

$$
Y=\operatorname{sign}\left[\sum_{i=1}^{n} x_{i} w_{i}-\theta\right]
$$

Várias funções de ativação foram testadas, mas somente algumas apresentaram aplicações práticas. Quatro tipos são ilustrados na Figura A.4: degrau, sinal, linear e sigmoidal.

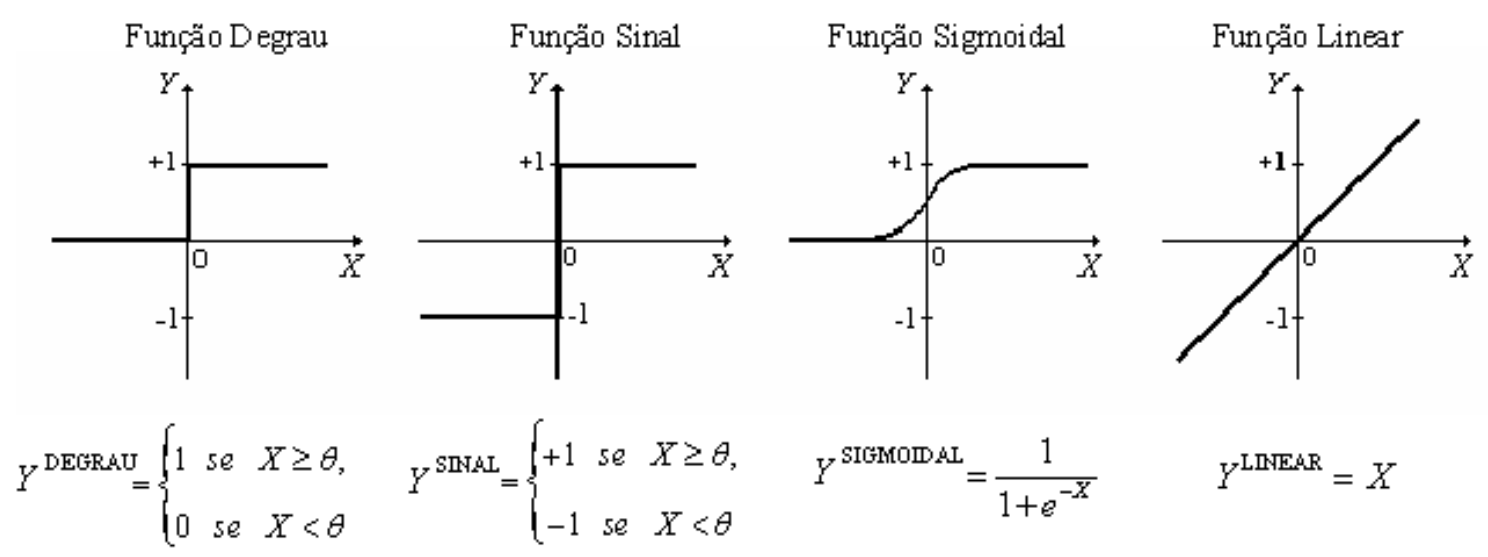

Figura A.4 - Funções de Ativação de um Neurônio 
A função sigmoidal transforma a entrada, a qual pode variar entre menos e mais infinito, em um valor razoável entre 0 e 1 . Neurônios com essa função são utilizados em redes com algoritmo back-propagation.

A função linear proporciona uma saída igual à entrada do neurônio. Neurônios com essa função são geralmente utilizados para aproximação linear.

\section{A.3 O Perceptron}

Em 1958, Frank Rosenblatt introduziu o primeiro algoritmo que proporcionou um procedimento para um treinamento de uma RNA, o perceptron, que consiste na forma de RNA mais simples possível. É constituído de um único neurônio com pesos ajustáveis e o valor de ativação.

O funcionamento do Perceptron é baseado no modelo de McCulloch e Pitts e consiste de uma combinação linear seguido pelo valor de ativação. A soma das entradas multiplicadas por seus respectivos pesos é comparada com o valor de ativação, que produz uma saída igual a +1 se essa soma for positiva e -1 se a soma for negativa. O objetivo do Perceptron é classificar as entradas, ou seja, estímulos externos $\mathrm{x}_{1}, \mathrm{x}_{2}, \ldots, \mathrm{x}_{\mathrm{n}}$, entre, por exemplo, duas classes $A_{1}$ e $A_{2}$. Assim, no caso de um Perceptron simples, o espaço n-dimensional é dividido por um hiperplano em duas regiões. Esse hiperplano é definido pela função linearmente separável:

$$
\sum_{i=1}^{n} x_{i} \cdot w_{i}-\theta=0
$$

onde $n$ é o número de entradas e $\theta$ é o valor de ativação aplicado no neurônio.

Para o caso de duas entradas, $x_{1}$ e $x_{2}$, a fronteira tem a forma de uma linha reta, mostrada na Figura A.5(a). O ponto 1 localizado acima da fronteira, pertence à classe $A_{1}$ e o 
ponto 2 , localizado abaixo da fronteira, pertence à classe $\mathrm{A}_{2}$. $\mathrm{O}$ valor de ativação $\theta$ pode ser utilizado para mover essa fronteira.

Com três entradas, o hiperplano ainda pode ser observado. A Figura A.5(b) mostra as três dimensões para o Perceptron com três entradas. Neste caso, a função é definida por:

$$
x_{1} \cdot w_{1}+x_{2} \cdot w_{2}+x_{3} \cdot w_{3}-\theta=0
$$

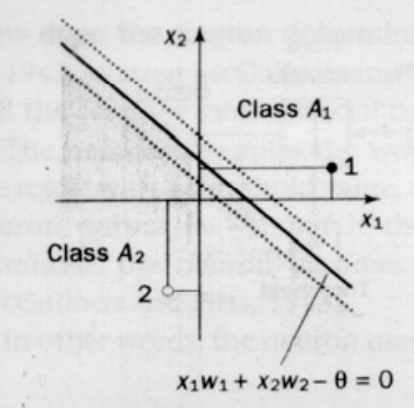

(a)

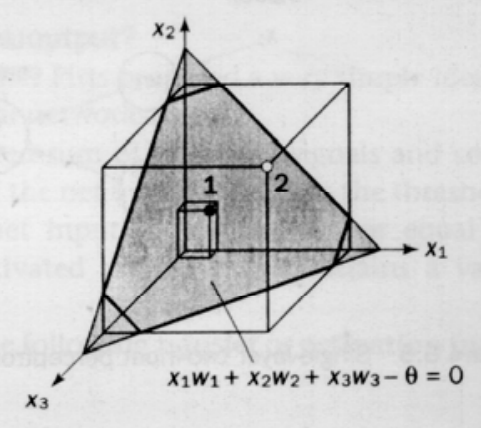

(b)

Figura A.5 - Separação Linear no Perceptron: (a) Perceptron com duas entradas; (b) Perceptron com três entradas

O Perceptron aprende a tarefa que foi designado a realizar através de pequenos ajustes nos pesos para reduzir a diferença entre a saída atual e a desejada. Inicialmente, os pesos são determinados de forma aleatória, normalmente entre $[-0.5,0.5]$, e assim atualizados para obter a saída através de exemplos para treinamento. A determinação do erro entre a saída atual e a desejada faz-se da seguinte forma, considerando que o Perceptron está na iteração $p$ :

$$
e(p)=Y_{d}(p)-Y(p)
$$

onde: $\mathrm{Y}(\mathrm{p})=$ saída atual;

$$
Y_{d}(p)=\text { saída desejada em } p=1,2,3 \ldots
$$

Se o erro e(p) for positivo, é necessário aumentar a saída $\mathrm{Y}(\mathrm{p})$, porém se for negativo, é necessário diminuir $\mathrm{Y}(\mathrm{p})$. Levando em consideração que uma entrada do Perceptron 
contribui $x_{i}(p) \times w_{i}(p)$ para a entrada total $X(p)$, pode-se notar que se o valor da entrada $x_{i}(p)$ for positivo, um incremento no peso $w_{i}(p)$ tende a aumentar a saída do Perceptron $\mathrm{Y}(\mathrm{p})$, enquanto se $x_{i}(p)$ for negativo, um aumento $w_{i}(p)$ tende a diminuir $\mathrm{Y}(\mathrm{p})$. Desta forma, a regra de aprendizado do Perceptron pode ser determinada como:

$$
w_{i}(p+1)=w_{i}(p)+\alpha \times x_{i}(p) \times e(p)
$$

onde $\alpha$ é a taxa de aprendizado, uma constante positiva menor que 1.

A regra de aprendizado do Perceptron foi proposta inicialmente por Rosenblatt em 1960. Através dessa regra pode-se chegar a um conjunto de tarefas para o treinamento do Perceptron:

\section{I) Inicialização}

Determinar os pesos iniciais $w_{1}, w_{1}, \ldots, w_{n}$ e o valor de ativação $\theta$. Normalmente os pesos são determinados aleatoriamente, entre valores de $[-0.5,0.5]$.

\section{II) Ativação}

Ativar o Perceptron aplicando as entradas $x_{1}(p), x_{2}(p), \ldots, x_{n}(p)$ e a saída desejada $Y_{d}(p)$. Calcular a saída atual na iteração $\mathrm{p}=1$.

$$
Y(p)=\operatorname{step}\left[\sum_{i=1}^{n} x_{i}(p) * w_{i}(p)-\theta\right]
$$

onde $n$ é o número de entradas do Perceptron e step é a função de ativação.

\section{III) Treinamento dos Pesos}

Atualizar os pesos do Perceptron.

$$
w_{i}(p+1)=w_{i}(p)+\Delta w_{i}(p)
$$

onde $\Delta w_{i}(p)$ é a correção do peso na iteração $p$. 
A correção do peso é realizada através da regra do delta:

$$
\Delta w_{i}(p)=\alpha \times x_{i}(p) \times e(p)
$$

\section{IV) Iteração}

Incrementar uma vez $p$, voltar ao passo de Ativação e repetir todo processo até convergir ao valor desejado.

O Perceptron com camada única pode classificar somente padrões linearmente separáveis, independente da função de ativação utilizada. Pode-se perceber claramente as limitações do Perceptron ao treinar uma rede para realizar as operações lógicas E, OU e Ou exclusivo. A tabela verdade de cada operação lógica é mostrada na Tabela A.2. A tabela apresenta todas as possíveis combinações para duas variáveis de entrada, $x_{1} \mathrm{e}^{x_{2}}$, e o resultado das operações. O Perceptron deve ser treinado para classificar os padrões de entrada.

Tabela A.2. Tabela Verdade para as operações lógicas básicas

\begin{tabular}{|cc|ccc|}
\hline \multicolumn{2}{|c|}{ Input Variables } & \multicolumn{4}{c|}{ Resultados } \\
\hline $\mathbf{x 1}$ & $\mathbf{x 2}$ & $\mathbf{E}$ & OU & OU Exclusivo \\
\hline 0 & 0 & 0 & 0 & 0 \\
0 & 1 & 0 & 1 & 1 \\
1 & 0 & 0 & 1 & 1 \\
1 & 1 & 1 & 1 & 0 \\
\hline
\end{tabular}

Considerando inicialmente a operação lógica E, após realizar a inicialização, o Perceptron é ativado pela seqüência de quatro padrões de entrada, que representa uma época. Os pesos do Perceptron são atualizados após cada ativação, repetindo-se esse processo até todos os pesos convergirem para um grupo de valores uniformes. Os resultados são mostrados na Tabela A.3, Valor de ativação $\theta=0.2$ e a taxa de aprendizado $\alpha=0.1$. 
Tabela A.3. Exemplo de treinamento do Perceptron: operação lógica E

\begin{tabular}{|c|c|c|c|c|c|c|c|c|c|}
\hline \multirow[b]{2}{*}{ Época } & \multicolumn{2}{|c|}{ Entradas } & \multirow{2}{*}{$\begin{array}{c}\text { Saída } \\
\text { Desejada } \\
\text { Yd }\end{array}$} & \multicolumn{2}{|c|}{$\begin{array}{l}\text { Pesos } \\
\text { Iniciais }\end{array}$} & \multirow{2}{*}{$\begin{array}{c}\text { Saída } \\
\text { Atual } \\
\text { Y }\end{array}$} & \multirow{2}{*}{$\begin{array}{c}\text { Erro } \\
\text { e }\end{array}$} & \multicolumn{2}{|c|}{$\begin{array}{l}\text { Pesos } \\
\text { Finais }\end{array}$} \\
\hline & $x 1$ & $x 2$ & & W1 & W2 & & & W1 & W2 \\
\hline \multirow[t]{4}{*}{1} & 0 & 0 & 0 & 0.3 & $-0,1$ & 0 & 0 & 0.3 & $-0,1$ \\
\hline & 0 & 1 & 0 & 0.3 & $-0,1$ & 0 & 0 & 0.3 & $-0,1$ \\
\hline & 1 & 0 & 0 & 0.3 & $-0,1$ & 1 & -1 & 0.2 & $-0,1$ \\
\hline & 1 & 1 & 1 & 0.2 & $-0,1$ & 0 & 1 & 0.3 & 0.0 \\
\hline \multirow[t]{4}{*}{2} & 0 & 0 & 0 & 0.3 & 0.0 & 0 & 0 & 0.3 & 0.0 \\
\hline & 0 & 1 & 0 & 0.3 & 0.0 & 0 & 0 & 0.3 & 0.0 \\
\hline & 1 & 0 & 0 & 0.3 & 0.0 & 1 & -1 & 0.2 & 0.0 \\
\hline & 1 & 1 & 1 & 0.2 & 0.0 & 1 & 0 & 0.2 & 0.0 \\
\hline \multirow[t]{4}{*}{3} & 0 & 0 & 0 & 0.2 & 0.0 & 0 & 0 & 0.2 & 0.0 \\
\hline & 0 & 1 & 0 & 0.2 & 0.0 & 0 & 0 & 0.2 & 0.0 \\
\hline & 1 & 0 & 0 & 0.2 & 0.0 & 1 & -1 & 0.1 & 0.0 \\
\hline & 1 & 1 & 1 & 0.1 & 0.0 & 0 & 1 & 0.2 & 0.1 \\
\hline \multirow[t]{4}{*}{4} & 0 & 0 & 0 & 0.2 & 0.1 & 0 & 0 & 0.2 & 0.1 \\
\hline & 0 & 1 & 0 & 0.2 & 0.1 & 0 & 0 & 0.2 & 0.1 \\
\hline & 1 & 0 & 0 & 0.2 & 0.1 & 1 & -1 & 0.1 & 0.1 \\
\hline & 1 & 1 & 1 & 0.1 & 0.1 & 1 & 0 & 0.1 & 0.1 \\
\hline \multirow[t]{4}{*}{5} & 0 & 0 & 0 & 0.1 & 0.1 & 0 & 0 & 0.1 & 0.1 \\
\hline & 0 & 1 & 0 & 0.1 & 0.1 & 0 & 0 & 0.1 & 0.1 \\
\hline & 1 & 0 & 0 & 0.1 & 0.1 & 0 & 0 & 0.1 & 0.1 \\
\hline & 1 & 1 & 1 & 0.1 & 0.1 & 1 & 0 & 0.1 & 0.1 \\
\hline
\end{tabular}

De maneira muito similar, o Perceptron pode aprender a operação lógica OU. Porém, um Perceptron com camada única não pode ser treinado para executar a operação lógica OU exclusivo.

A Figura A.6 representa as funções E, OU e OU exclusivo como gráficos bi-dimensionais baseados nos valores das duas entradas. Os pontos no espaço de entrada onde a saída da função é 1 são representados por pontos pretos e àqueles que a saída é 0 , pontos brancos.
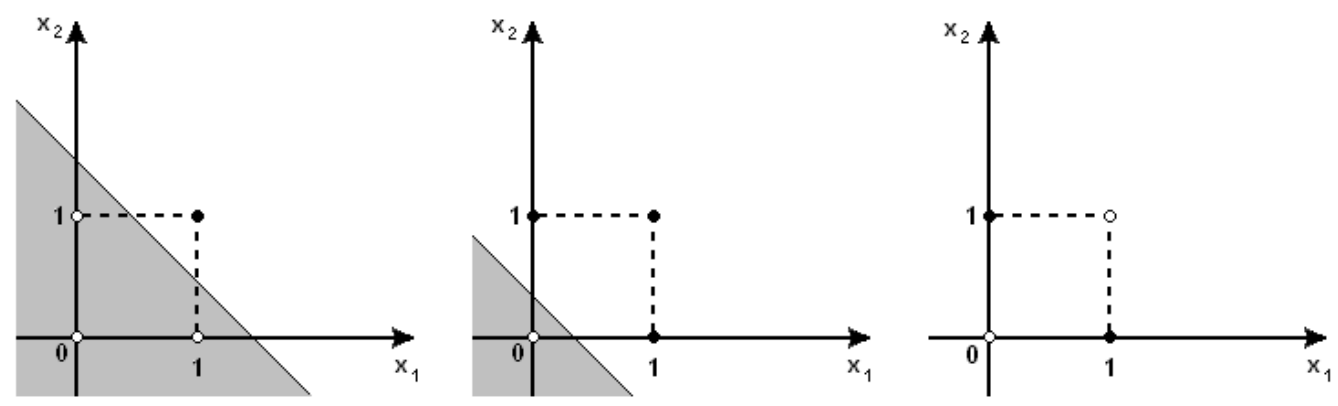

Figura A.6 - Gráficos bi-dimensionais de operações lógicas básicas: (a) E (x1คx2); (b) OU $(\mathrm{x} 1 \cup \mathrm{x} 2) ;(\mathrm{c})$ OU-exclusivo $(\mathrm{x} 1 \oplus \mathrm{x} 2)$ 
Nas Figuras A.6(a) e (b), pode-se separar os pontos pretos dos brancos através de uma linha. Porém os pontos na Figura A.6(c) não podem ser separados por uma linha. O Perceptron só pode representar funções que podem ser separadas linearmente. Porém, as limitações do Perceptron proposto por Rosenblatt podem ser superadas com a utilização de formas mais avançadas de RNA, como Perceptrons com várias camadas treinados com o algoritmo back-propagation.

\section{A.4 Redes Neurais Multicamadas}

Um Perceptron multicamadas é uma rede neural direta com uma ou mais camadas escondidas. Tipicamente, a rede consiste em uma camada de neurônios de interface como entrada, no mínimo uma camada escondida de neurônios computacionais e uma camada de neurônios computacionais de saída. Os sinais de entrada são propagados diretamente camada por camada. Um Perceptron multicamadas com duas camadas escondidas é mostrado na Figura A.7.

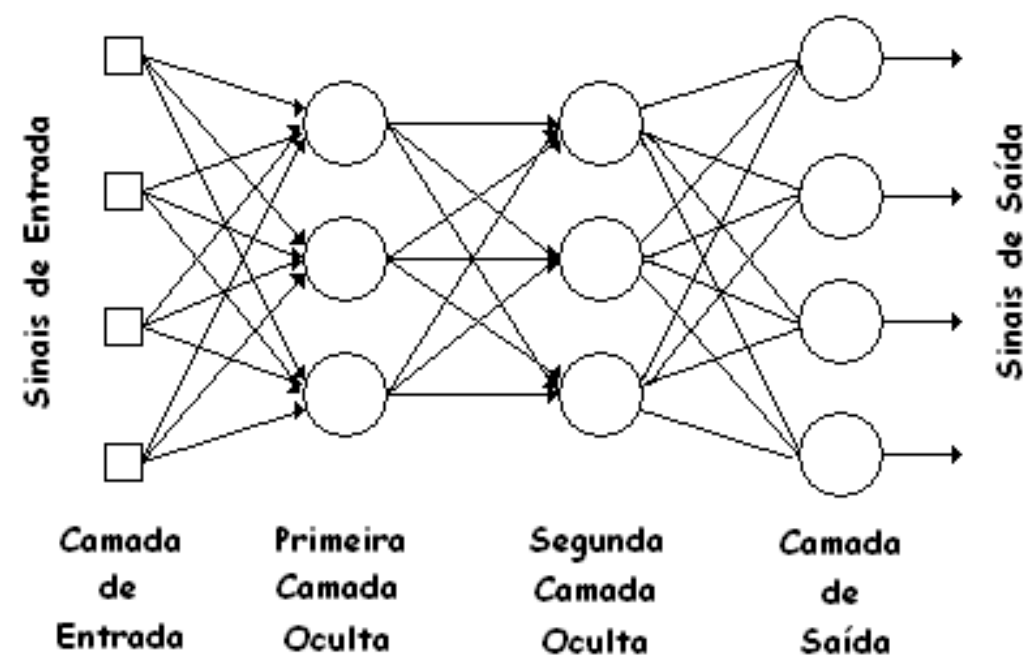

Figura A.7 - Perceptron com duas camadas

Cada camada em uma rede neural artificial multicamadas tem sua própria função específica. A camada de entrada recebe os sinais de entrada do mundo externo e redistribui 
esses sinais para todos os neurônios na camada escondida. Na verdade, neurônios na camada de entrada raramente possuem um valor ou influência computacional. A camada de saída aceita sinais de saída, ou em outras palavras padrões de estímulos provenientes das camadas escondidas e determina o padrão de saída de toda a rede neural

Os neurônios da camada escondida detectam as características. Os pesos dos neurônios representam as características escondidas nos padrões de entrada. Essas características são então utilizadas pelo neurônio de saída na determinação dos padrões de saída. Concluindo: os pesos da rede neural representam justamente o conhecimento acumulado através do treinamento

Com uma camada escondida, pode-se representar qualquer função contínua nos sinais de entrada e, com duas camadas escondidas, até mesmo funções descontínuas podem ser representadas

Em relação ao aprendizado de redes neurais multicamadas, centenas de algoritmos de aprendizados diferentes estão disponíveis, porém o método mais popular é o backpropagation que será descrito na seção A.5 a seguir

\section{A.5 Algoritmo de Aprendizado Back-Propagation}

Esse método foi inicialmente proposto em 1969 por A. E. Bryson e Y. O. Ho, mas foi ignorado devido à sua demanda computacional e, desta forma, foi redescoberto somente nos meados de 1980 .

O aprendizado em uma rede multicamadas procede da mesma maneira que um Perceptron. Um conjunto de padrões de entrada é apresentado para a rede para treinamento. A rede computa seu próprio padrão e na existência de um erro, ou seja, se a diferença entre a saída atual e a desejada for maior que um valor desejado, os pesos são ajustados para diminuir esse erro. Em um Perceptron, existe apenas um peso para cada entrada e apenas uma saída. 
Em uma rede multicamadas, porém, existem muitos pesos, cada qual contribui para mais de uma saída.

O algoritmo back-propagation possui duas fases para o aprendizado da rede. Inicialmente, um conjunto de padrões de entrada é apresentado para a rede para treinamento. A rede então propaga os padrões de entrada de camada em camada até que um padrão de saída é gerado pela camada de saída. Se esse padrão for diferente da saída desejada, um erro é calculado e então propagado para trás, da camada de saída até a camada de entrada através da rede. Os pesos são modificados à medida que o erro é propagado.

Assim como qualquer outra rede neural, a que utiliza o algoritmo back-propagation para aprendizado é determinada pela arquitetura da rede, pelas funções de ativação utilizadas pelos neurônios e pelo algoritmo de aprendizado, que especifica o procedimento para o ajuste dos pesos. Tipicamente, a rede que utiliza um algoritmo back-propagation é multicamadas e possui três ou quatro camadas. As camadas são completamente conectadas, ou seja, todos neurônios em cada camada são conectados em todos outros neurônios na camada seguinte.

O neurônio determina sua saída de maneira similar ao Perceptron de Rosenblatt (ROSENBLATT, 1958). Primeiro, ele computa as entradas influenciadas pelos pesos, conforme mostrado anteriormente na equação A.3.

A seguir, esse valor de entrada é passado através da função de ativação. Porém, diferentemente do Perceptron, os neurônios na rede que utiliza back-propagation utilizam a função de ativação sigmoidal. A derivada dessa função é fácil de se realizar e também garante que a saída do neurônio seja limitada entre 0 e 1.

$$
Y^{\text {sigmoidal }}=\frac{1}{1+e^{-X}}
$$

Para demonstrar a regra de aprendizado back-propagation, pode-se considerar uma rede com três camadas mostrada na Figura A.8. Os índices $i, j$ e $k$ são referentes aos neurônios de entrada, escondidos e de saída respectivamente. 


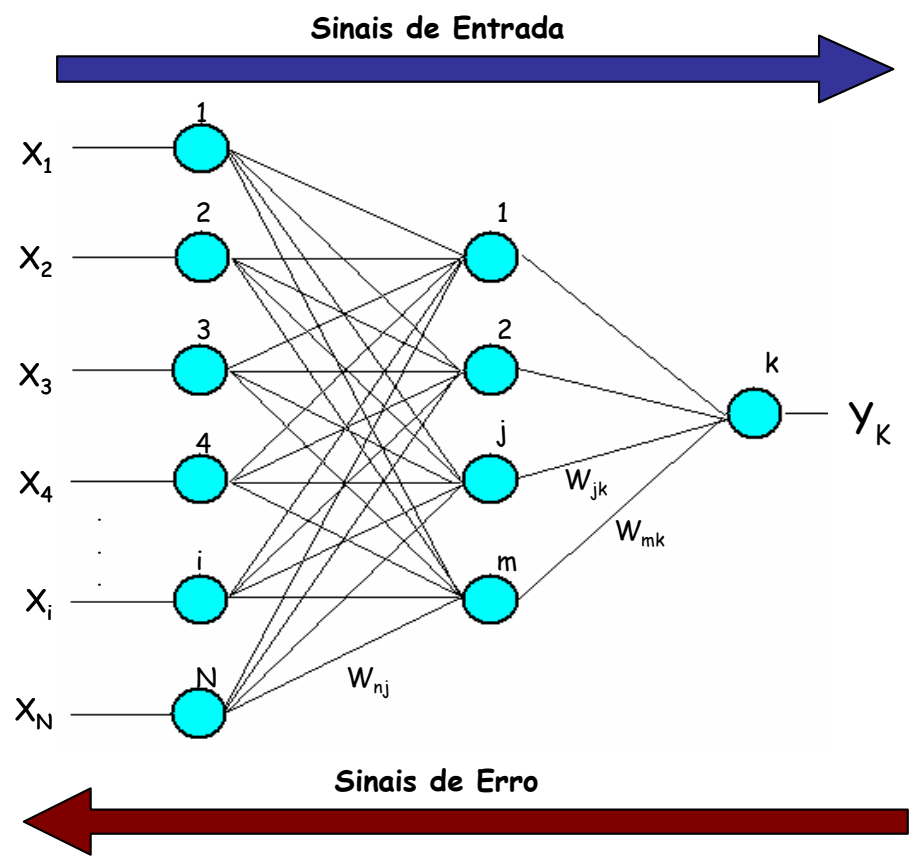

Figura A.8 - Rede Neural que utiliza back-propagation com três camadas

Os sinais de entrada, $x_{1}(p), x_{2}(p), \ldots, x_{n}(p)$, são propagados através da rede da esquerda para a direita, e o sinais de erro, $e_{1}, e_{2}, \ldots, e_{l}$, da direita para a esquerda. $O$ símbolo $w_{i j}$ denota o peso da conexão entre o neurônio $i$ da camada de entrada e o neurônio $j$ da camada escondida. Já o símbolo ${ }^{w_{j k}}$ representa o neurônio $j$ da camada escondida e o neurônio $k$ da camada de saída.

Para propagar o sinal de erro, é necessário começar na camada de saída e seguir para trás, na camada escondida. O sinal de erro no neurônio de saída $k$ na iteração $p$ é definido por:

$$
e_{k}(p)=y_{d, k}(p)-y_{k}(p)
$$

onde $y_{d, k}(p)$ é o valor de saída desejado do neurônio $k$ na iteração $p$.

O neurônio $k$, que é localizado na camada de saída, possui o próprio valor de saída desejado. Desta forma, pode-se utilizar o procedimento direto para atualizar o peso ${ }^{w_{j k}}$. Na 
verdade, a regra para atualizar o peso de neurônios de saída é similar à regra de aprendizado do Perceptron na equação A.8 como mostra a equação A.12:

$$
w_{j k}(p+1)=w_{j k}(p)+\Delta w_{j k}(p)
$$

onde ${ }^{\Delta w_{j k}(p)}$ é a correção do peso.

Ao determinar a correção de erro para o Perceptron, foi utilizado o sinal de entrada $x_{i}$. Porém na rede multicamadas, os neurônios de entrada na camada de saída são diferentes dos neurônios de entrada da camada de entrada. Utiliza-se agora a saída do neurônio $j$ na camada escondida, ${ }^{y_{j}(p)}$. A correção do peso na rede multicamadas é computado através de:

$$
\Delta w_{j k}(p)=\alpha \times y_{j}(p) \times \delta_{k}(p)
$$

onde $\delta_{k}(p)$ é o gradiente de erro no neurônio $k$ na camada de saída na iteração $p$.

O gradiente de erro é determinado como a derivada da função de ativação sigmoidal, F', multiplicado pelo erro do neurônio de saída. Assim, obtém-se para o neurônio $k$ na camada de saída:

$$
\delta_{k}(p)=F^{\prime}\left[X_{k}(p)\right] \times e_{k}(p)
$$

onde $X_{k}(p)$ é a entrada influenciada pelos pesos do neurônio $k$ na iteração $p$ :

$$
X_{k}(p)=\sum_{j=1}^{m} x_{j k}(p) \times w_{j k}(p)-\theta_{k}
$$

onde $m$ é o número de neurônios na camada escondida.

Assim, a equação A.14 pode ser representada por:

$$
\delta_{k}(p)=y_{k}(p) \times\left[1-y_{k}(p)\right] \times e_{k}(p)
$$


onde $y_{k}=\frac{1}{1+e^{-X_{k}(p)}}$.

Para calcular a correção dos pesos para a camada escondida, pode-se aplicar as mesma equações para a camada de saída:

$$
\Delta w_{i j}(p)=\alpha \times x_{i}(p) \times \delta_{j}(p)
$$

onde $\delta_{j}(p)$ representa o gradiente de erro no neurônio $j$ na camada escondida:

$$
\delta_{i}(p)=y_{j}(p) \times\left[1-y_{j}(p)\right] \times \sum_{k=1}^{l} \delta_{k}(p) \cdot w_{j k}(p)
$$

onde $l$ é $o$ número de neurônios na camada de saída, $y_{j}=\frac{1}{1+e^{-X_{j}(p)}}$, $X_{j}(p)=\sum_{i=1}^{n} x_{i}(p) \times w_{i j}(p)-\theta$

e $n$ é o número de neurônios na camada de entrada.

Desta forma, pode-se determinar o algoritmo de treinamento back-propagation:

\section{I) Inicialização}

Determinar o pesos iniciais $w_{1}, w_{1}, \ldots, w_{n}$ e o valor de ativação $\theta$.

\section{II) Ativação}

Ativar a rede neural com o algoritmo back-propagation aplicando as entradas $x_{1}(p), x_{2}(p), \ldots, x_{n}(p)$ e as saídas desejadas $y_{d, 1}(p), y_{d, 2}(p), \ldots, y_{d, n}(p)$

a. Calcular a saída atual dos neurônios na camada escondida:

$$
y_{j}(p)=\operatorname{sigmoidal}\left[\sum_{i=1}^{n} x_{i}(p) \times w_{i j}(p)-\theta_{j}\right]
$$

onde $n$ é o número de entradas do neurônio $j$ na camada escondida e sigmoidal é a função de ativação.

b. Calcular as saídas atuais dos neurônios da camada de saída: 


$$
y_{k}(p)=\operatorname{sigmoidal}\left[\sum_{i=1}^{m} x_{j k}(p) \times w_{j k}(p)-\theta_{k}\right]
$$

onde $m$ é o número de entradas do neurônio $k$ na camada de saída.

\section{III) Treinamento dos Pesos}

Atualizar os pesos na rede que utiliza o back-propagation propagando para trás os erros associados com os neurônios de saída.

a. Calcular o gradiente de erro para os neurônios na camada de saída:

$$
\delta_{k}(p)=y_{k}(p) \times\left[1-y_{k}(p)\right] \times e_{k}(p)
$$

onde

$$
e_{k}(p)=y_{d, k}(p)-y_{k}(p)
$$

Calcular as correções dos pesos:

$$
\Delta w_{j k}(p)=\alpha \times y_{j}(p) \times \delta_{k}(p) .
$$

Atualizar os pesos nos neurônios de saída:

$$
w_{j k}(p+1)=w_{j k}(p)+\Delta w_{j k}(p)
$$

b. Calcular o gradiente de erro para os neurônios na camada escondida:

$$
\delta_{i}(p)=y_{j}(p) \times\left[1-y_{j}(p)\right] \times \sum_{k=1}^{l} \delta_{k}(p) \cdot w_{j k}(p)
$$

Calcular a correção dos pesos:

$$
\Delta w_{i j}(p)=\alpha \times x_{i}(p) \times \delta_{j}(p)
$$

Atualizar os pesos na camada escondida:

$$
w_{i j}(p+1)=w_{i j}(p)+\Delta w_{i j}(p)
$$

\section{IV) Iteração}


Incrementar uma vez $p$, voltar ao passo de Ativação e repetir todo processo até que o critério de erro selecionado seja satisfeito.

Como um exemplo, pode-se considerar a rede que utiliza o back-propagation de três camadas mostrada na Figura A.9. Suponha que a rede tenha que realizar a operação lógica OU exclusivo. Redes com uma única camada não são capazes de realizar tal operação.

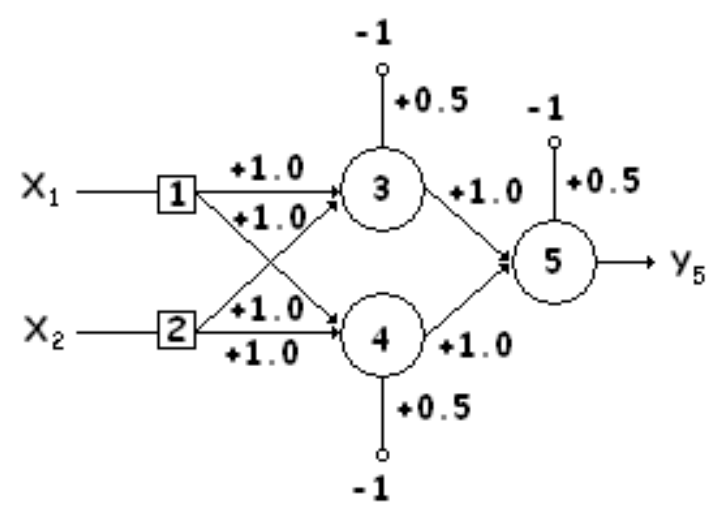

Figura A.9 - Rede Neural de três camadas para solucionar a operação OU exclusivo

Os neurônios 1 e 2 na camada de entrada recebem sinais através das entradas $x_{1} \mathrm{e}^{x_{2}}$, respectivamente, e redistribui essas entradas para os neurônios na camada escondida sem

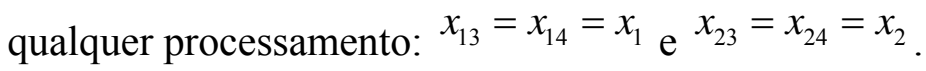

O efeito do valor de ativação aplicado a um neurônio da camada escondida ou de saída é representado pelos seus pesos, $\theta$, conectado a uma entrada fixa de -1 .

Os pesos iniciais e valores de ativação são determinados aleatoriamente, conforme segue:

$$
\begin{aligned}
& w_{13}=0.5, w_{14}=0.9, w_{23}=0.4, w_{24}=1.0, w_{35}=-1.2, w_{45}=1.1, \\
& \theta_{3}=0.8, \theta_{4}=-0.1, \theta_{5}=0.3
\end{aligned}
$$

Considere um grupo de treinamento onde as entradas ${ }^{x_{1}}$ e $^{x_{2}}$ são iguais a 1 e a saída desejada $y_{d, 5}$ é 0 . A saída atual dos neurônios de saída na camada escondida são calculados por: 


$$
\begin{aligned}
& y_{3}=\operatorname{sigmoidal}\left(x_{1} w_{13}+x_{2} w_{23}-\theta_{3}\right)=\frac{1}{1+e^{-(1 \times 0.5+1 \times 0.4-1 \times 0.8)}}=0.5250 \\
& y_{4}=\operatorname{sigmoidal}\left(x_{1} w_{14}+x_{2} w_{24}-\theta_{4}\right)=\frac{1}{1+e^{-(1 \times 0.9+1 \times 1.0+1 \times 0.1)}}=0.8808
\end{aligned}
$$

Agora, a saída atual do neurônio de saída 5 na camada de saída é determinado por:

$$
y_{5}=\operatorname{sigmoidal}\left(x_{3} w_{35}+x_{4} w_{45}-\theta_{5}\right)=\frac{1}{1+e^{-(0.5250 \times 1.2+0.8808 \times 1.1-1 \times 0.3)}}=0.5097
$$

Desta forma, o seguinte erro é obtido:

$e=y_{d, 5}-y_{5}=0-0.5097=-0.5097$

O próximo passo é o treinamento dos pesos. Para atualizar os pesos e os valores de ativação na rede, propaga-se o erro, $e$, da camada de saída para trás, até a camada de entrada.

Inicialmente, calcula-se o gradiente de erro para o neurônio 5 na camada de saída:

$\delta_{5}=y_{5} \cdot\left(1-y_{5}\right) \cdot e=0.5097 \times(1-0.5097) \times(-0.50970)=-0.1274$

Então, determina-se as correções dos erros assumindo que a taxa de aprendizado, $\alpha$, é igual a 0,1 :

$$
\begin{aligned}
& \Delta w_{35}=\alpha \times y_{3} \times \delta_{5}=0.1 \times 0.5250 \times(-0.1274)=-0.0067 \\
& \Delta w_{45}=\alpha \times y_{4} \times \delta_{5}=0.1 \times 0.8808 \times(-0.1274)=-0.0112 \\
& \Delta \theta_{5}=\alpha \times(-1) \times \delta_{5}=0.1 \times(-1) \times(-0.1274)=-0.0127
\end{aligned}
$$

Após isso, calcula-se o gradiente de erro para os neurônios 3 e 4 na camada escondida:

$$
\begin{aligned}
& \delta_{3}=y_{3} \cdot\left(1-y_{3}\right) \times \delta_{5} \times w_{35}=0.5250 \times(1-0.5250) \times(-0.1274) \times(-1.2)=0.0381 \\
& \left.\delta_{4}=y_{4} \cdot\left(1-y_{4}\right) \times \delta_{5} \times w_{45}=0.8808 \times(1-0.8808) \times(-0.1274) \times 1.1\right)=-0.0147
\end{aligned}
$$

Determina-se então as correções dos erros:

$$
\begin{aligned}
& \Delta w_{13}=\alpha \times x_{1} \times \delta_{3}=0.1 \times 1 \times 0.0381=0.0038 \\
& \Delta w_{23}=\alpha \times x_{2} \times \delta_{3}=0.1 \times 1 \times 0.0381=0.0038 \\
& \Delta \theta_{3}=\alpha \times(-1) \times \delta_{3}=0.1 \times(-1) \times 0.0381=-0.0038
\end{aligned}
$$




$$
\begin{aligned}
& \Delta w_{14}=\alpha \times x_{1} \times \delta_{4}=0.1 \times 1 \times(-0.0147)=-0.0015 \\
& \Delta w_{24}=\alpha \times X_{2} \times \delta_{4}=0.1 \times 1 \times(-0.0147)=-0.0015 \\
& \Delta \theta_{4}=\alpha \times(-1) \times \delta_{4}=0.1 \times(-1) \times(-0.0147)=0.0015
\end{aligned}
$$

Finalmente, os pesos e valores de ativação são atualizados:

$$
\begin{aligned}
& w_{13}=w_{13}+\Delta w_{13}=0.5+0.0038=0.5038 \\
& w_{14}=w_{14}+\Delta w_{14}=0.9-0.0015=0.8985 \\
& w_{23}=w_{23}+\Delta w_{23}=0.4+0.0038=0.4038 \\
& w_{24}=w_{24}+\Delta w_{24}=1.0+0.0015=0.9985 \\
& w_{35}=w_{35}+\Delta w_{35}=-1.2-0.0067=-1.2067 \\
& w_{45}=w_{45}+\Delta w_{45}=1.1-0.0112=1.0888 \\
& \theta_{3}=\theta_{3}+\Delta \theta_{3}=0.8-0.0038=0.7962 \\
& \theta_{4}=\theta_{4}+\Delta \theta_{4}=-0.1+0.0015=-0.0985 \\
& \theta_{5}=\theta_{5}+\Delta \theta_{5}=0.3+0.0127=0.3127
\end{aligned}
$$

O processo de treinamento é repetido até a soma dos erros quadráticos atingirem um valor menor que 0.001 . A soma dos erros quadráticos é um indicador muito prático referente à performance da rede neural. O algoritmo de treinamento back-propagation se esforça em minimizar esse critério.

Quando o valor do erro quadrático for suficientemente pequeno após a influência dos grupos de treinamento ou épocas, é considerado que a rede convergiu. No exemplo acima, esse valor suficientemente pequeno do erro quadrático é definido como sendo menor que 0,001. A Figura A.10 representa a curva de aprendizado: a soma dos erros quadráticos versus o número de épocas usadas no treinamento. A curva de aprendizado mostra quão rápido é o aprendizado da rede neural. 


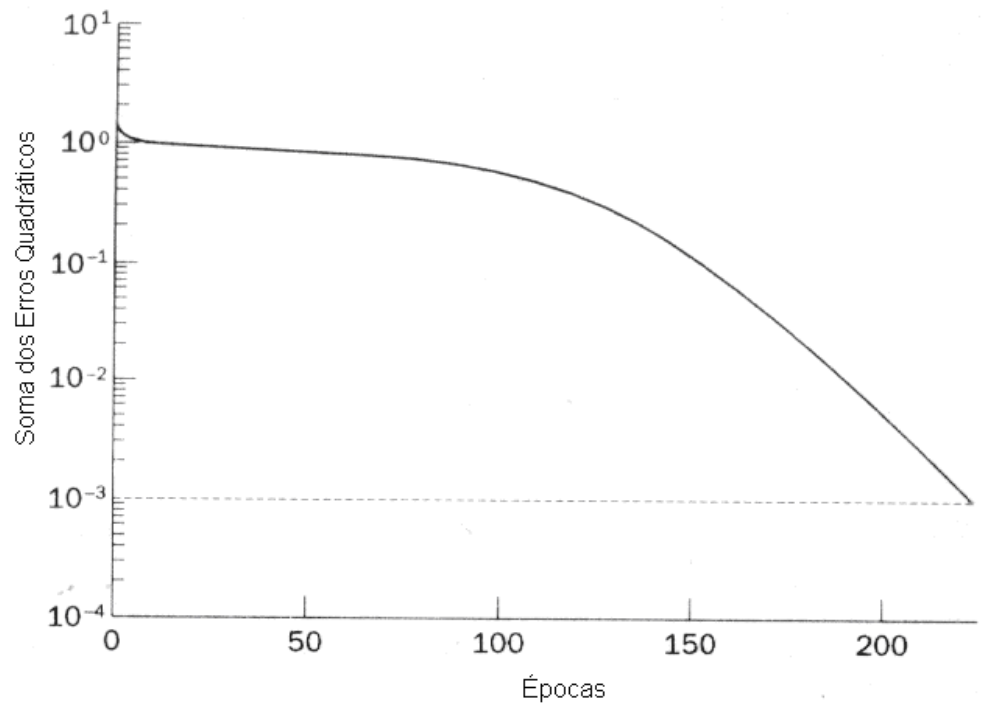

Figura A.10 - Curva de treinamento para a operação OU exclusivo.

Pode-se observar que demorou 224 épocas ou 896 iterações para treinar a rede, para que ela pudesse assim realizar a operação OU exclusivo. A seguir são mostrados os pesos e valores de ativação que satisfazem o critério de erro escolhido:

$$
\begin{aligned}
& w_{13}=4,7621, w_{14}=6.3917, w_{23}=4.7618, w_{24}=6.3917, w_{35}=-10.3788, \\
& w_{45}=9.7691, \theta_{3}=7.3061, \theta_{4}=2.8441, \theta_{5}=4.5589
\end{aligned}
$$

Agora, após a rede neural ter convergido, pode-se testar a rede apresentando o grupo de treinamento e calculando as saídas da rede. Os resultados são apresentados na Tabela A.4.

Tabela A.4. Resultados finais do aprendizado da rede de três camadas: a operação lógica OU

\begin{tabular}{|c|c|c|c|c|c|}
\hline \multicolumn{2}{|c|}{ Entradas } & \multirow{2}{*}{$\begin{array}{c}\text { Saídas } \\
\text { Desejadas } \\
\text { yd }\end{array}$} & \multirow{2}{*}{$\begin{array}{c}\text { Saída } \\
\text { Atual } \\
\text { y5 }\end{array}$} & \multirow{2}{*}{$\begin{array}{c}\text { Erro } \\
\text { e }\end{array}$} & \multirow{2}{*}{$\begin{array}{l}\text { Soma dos } \\
\text { Erros } \\
\text { Quadraticos }\end{array}$} \\
\hline$x 1$ & $x 2$ & & & & \\
\hline 1 & 1 & 0 & 0.0155 & $-0,0155$ & 0.001 \\
\hline 0 & 1 & 1 & 0.9849 & 0.0151 & \\
\hline 1 & 0 & 1 & 0.9849 & 0.0151 & \\
\hline 0 & 0 & 0 & 0.0175 & $-0,0175$ & \\
\hline
\end{tabular}
exclusivo

A rede obtém pesos e valores de ativação diferentes quando começa com condições iniciais diferentes. De qualquer forma, sempre se resolve o problema, alterando apenas o número de iterações necessárias para a rede convergir. 
A Figura A.11 mostra as regiões separadas agora por mais de uma linha. Desta forma, isolou-se o padrão de saída referente ao padrão de entrada, e a rede multicamadas provou ser capaz de representar funções linearmente inseparáveis.
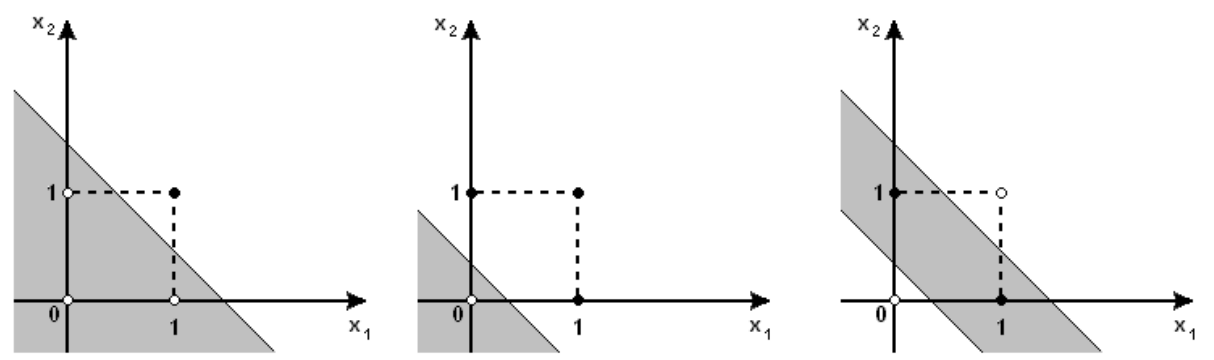

Figura A.11 - Limites de decisão construída pela rede neural: (a) E (x1คx2); (b) OU

$$
(\mathrm{x} 1 \cup \mathrm{x} 2) \text {; (c) OU-exclusivo }(\mathrm{x} 1 \oplus \mathrm{x} 2)
$$

O aprendizado de uma rede neural artificial costuma ser muito rápido, porém pode-se acelerar esse aprendizado incluindo um termo momento na regra Delta da equação A.9:

$$
\Delta w_{j k}(p)=\beta \times \Delta w_{j k}(p-1)+\alpha \times y_{j}(p) \times \delta_{k}(p)
$$

onde $\beta$ é um número positivo $(0 \leq \beta \leq 1)$, chamado de constante momento. Normalmente, essa constante tem o valor de 0,94. A equação A.28 é chamada de regra Delta generalizado. No caso especial em que $\beta=0$, obtém a equação A.9.

A utilização do momento tem um efeito estabilizador, ou seja, acelera quando o erro tende a cair, e diminui o processo quando a superfície do aprendizado apresenta um pico e vales.

Outro método muito utilizado e muito eficaz para acelerar a convergência do aprendizado via back-propagation é através de ajustes na taxa de aprendizado durante o treinamento da rede. Uma taxa de aprendizado $\alpha$ pequena causa pequenas variações nos pesos da rede de uma iteração para outra. Porém, se essa taxa for muito grande, a variação dos pesos pode ser muito grande, gerando instabilidade e, como conseqüência, a rede pode se tornar oscilatória. 


\section{ANEXO B}

Tabela B.1 - Detalhamento dos Testes do Primeiro Conjunto de Dados

\begin{tabular}{|c|c|c|c|c|c|c|c|}
\hline $\begin{array}{c}\text { Número } \\
\text { do } \\
\text { Teste }\end{array}$ & $\begin{array}{c}\begin{array}{c}\text { Nome } \\
\text { do }\end{array} \\
\text { Arquivo }\end{array}$ & $\begin{array}{c}\text { Corrente } \\
\text { usada } \\
\text { [kA] }\end{array}$ & $\begin{array}{c}\text { Força } \\
\text { usada } \\
\text { (mm da } \\
\text { mola) }\end{array}$ & $\begin{array}{c}\begin{array}{c}\text { Welding } \\
\text { Help }\end{array} \\
\text { 0=Sim/1=Não }\end{array}$ & \begin{tabular}{|c|} 
Uso \\
Eletrodo \\
(pontos) \\
\end{tabular} & $\begin{array}{c}\text { Força } \\
\text { Cisalham. } \\
{[\mathrm{N}]}\end{array}$ & Notas \\
\hline 1 & 000100002001 & 3.7 & 15,8 & 0 & 640 & 551 & \\
\hline 2 & 000100003001 & 3.7 & 15,8 & 0 & 641 & 655 & \\
\hline 3 & 000100004001 & 3.7 & 15,8 & 0 & 74 & 659 & \\
\hline 4 & 000100005001 & 3.7 & 15,8 & 0 & 75 & 628 & \\
\hline 5 & 000100006001 & 3.7 & 15,8 & 0 & 76 & 605 & \\
\hline 6 & 000100007001 & 3.7 & 15,8 & 0 & 77 & 646 & \\
\hline 7 & 000100008001 & 3.7 & 15,8 & 0 & 78 & 613 & \\
\hline 8 & 000100009001 & 3.7 & 15,8 & 0 & 79 & 622 & \\
\hline 9 & 000100010001 & 3.7 & 15,8 & 0 & 80 & 611 & \\
\hline 10 & 000100011001 & 3.7 & 15,8 & 0 & 81 & 652 & \\
\hline 11 & 000100012001 & 3.7 & 15,8 & 0 & 82 & 587 & \\
\hline 12 & 000100013001 & 3.7 & 15,8 & 0 & 83 & 629 & \\
\hline 13 & 000100014001 & 3.7 & 15,8 & 0 & 84 & 614 & \\
\hline 14 & 000100015001 & 3.7 & 15,8 & 0 & 85 & 581 & \\
\hline 15 & 000100016001 & 3.7 & 15,8 & 0 & 86 & 570 & \\
\hline 16 & 000100031001 & 3.7 & 14,8 & 0 & 142 & 515 & \\
\hline 17 & 000100032001 & 3.7 & 14,8 & 0 & 143 & 599 & \\
\hline 18 & 000100033001 & 3.7 & 14,8 & 0 & 144 & 544 & \\
\hline 19 & 000100034001 & 3.7 & 14,8 & 0 & 145 & 616 & \\
\hline 20 & 000100035001 & 3.7 & 14,8 & 0 & 146 & 552 & \\
\hline 21 & 000100036001 & 3.7 & 14,8 & 0 & 147 & 570 & \\
\hline 22 & 000100037001 & 3.7 & 14,8 & 0 & 148 & 588 & \\
\hline 23 & 000100038001 & 3.7 & 14,8 & 0 & 149 & 600 & \\
\hline 24 & 000100039001 & 3.7 & 14,8 & 0 & 150 & 536 & \\
\hline 25 & 000100040001 & 3.7 & 14,8 & 0 & 151 & 555 & \\
\hline 26 & 000100041001 & 3.7 & 14,8 & 0 & 152 & 617 & \\
\hline 27 & 000100042001 & 3.7 & 14,8 & 0 & 153 & 618 & \\
\hline 28 & 000100043001 & 3.7 & 14,8 & 0 & 154 & 565 & \\
\hline 29 & 000100044001 & 3.7 & 14,8 & 0 & 155 & 563 & \\
\hline 30 & 000100045001 & 3.7 & 14,8 & 0 & 156 & 616 & \\
\hline 31 & 000100061001 & 3.7 & 14,3 & 0 & 157 & 558 & \\
\hline 32 & 000100062001 & 3.7 & 14,3 & 0 & 158 & 582 & \\
\hline 33 & 000100063001 & 3.7 & 14,3 & 0 & 159 & 507 & \\
\hline 34 & 000100064001 & 3.7 & 14,3 & 0 & 160 & 536 & \\
\hline 35 & 000100065001 & 3.7 & 14,3 & 0 & 161 & 526 & \\
\hline 36 & 000100066001 & 3.7 & 14,3 & 0 & 162 & 577 & \\
\hline 37 & 000100067001 & 3.7 & 14,3 & 0 & 163 & 518 & \\
\hline 38 & 000100068001 & 3.7 & 14,3 & 0 & 164 & 597 & \\
\hline 39 & 000100069001 & 3.7 & 14,3 & 0 & 165 & 494 & \\
\hline 40 & 000100070001 & 3.7 & 14,3 & 0 & 166 & 560 & \\
\hline 41 & 000100071001 & 3.7 & 14,3 & 0 & 167 & 551 & \\
\hline 42 & 000100072001 & 3.7 & 14,3 & 0 & 168 & 604 & \\
\hline 43 & | 000100073001 & 3.7 & 14,3 & 0 & 169 & 505 & \\
\hline
\end{tabular}




\begin{tabular}{|c|c|c|c|c|c|c|c|}
\hline 44 & | 000100074001 & 3.7 & 14,3 & 0 & 170 & 517 & \\
\hline 45 & 000100075001 & 3.7 & 14,3 & 0 & 171 & 531 & \\
\hline 46 & 000100091001 & 3.7 & 13,8 & 0 & 172 & 451 & \\
\hline 47 & 000100092001 & 3.7 & 13,8 & 0 & 173 & 505 & \\
\hline 48 & 000100093001 & 3.7 & 13,8 & 0 & 174 & 544 & \\
\hline 49 & 000100094001 & 3.7 & 13,8 & 0 & 175 & 530 & \\
\hline 50 & 000100095001 & 3.7 & 13,8 & 0 & 176 & 529 & \\
\hline 51 & 000100096001 & 3.7 & 13,8 & 0 & 177 & 535 & \\
\hline 52 & 000100097001 & 3.7 & 13,8 & 0 & 178 & 553 & \\
\hline 53 & 000100098001 & 3.7 & 13,8 & 0 & 179 & 520 & \\
\hline 54 & 000100099001 & 3.7 & 13,8 & 0 & 180 & 526 & \\
\hline 55 & 000100100001 & 3.7 & 13,8 & 0 & 181 & 444 & \\
\hline 56 & 000100101001 & 3.7 & 13,8 & 0 & 182 & 496 & \\
\hline 57 & 000100102001 & 3.7 & 13,8 & 0 & 183 & 448 & \\
\hline 58 & 000100103001 & 3.7 & 13,8 & 0 & 184 & 535 & \\
\hline 59 & 000100104001 & 3.7 & 13,8 & 0 & 185 & 546 & \\
\hline 60 & 000100105001 & 3.7 & 13,8 & 0 & 186 & 488 & \\
\hline 61 & 000100121001 & 3.7 & 13,3 & 0 & 187 & 557 & \\
\hline 62 & 000100122001 & 3.7 & 13,3 & 0 & 188 & 493 & \\
\hline 63 & 000100123001 & 3.7 & 13,3 & 0 & 189 & 557 & \\
\hline 64 & 000100124001 & 3.7 & 13,3 & 0 & 190 & 496 & \\
\hline 65 & 000100125001 & 3.7 & 13,3 & 0 & 191 & 503 & \\
\hline 66 & 000100126001 & 3.7 & 13,3 & 0 & 222 & 448 & \\
\hline 67 & 000100127001 & 3.7 & 13,3 & 0 & 223 & 538 & \\
\hline 68 & 000100128001 & 3.7 & 13,3 & 0 & 224 & 528 & \\
\hline 69 & 000100129001 & 3.7 & 13,3 & 0 & 225 & 491 & \\
\hline 70 & 000100130001 & 3.7 & 13,3 & 0 & 226 & & falha \\
\hline 71 & 000100131001 & 3.7 & 13,3 & 0 & 227 & 530 & \\
\hline 72 & 000100132001 & 3.7 & 13,3 & 0 & 228 & 520 & \\
\hline 73 & 000100133001 & 3.7 & 13,3 & 0 & 229 & & falha \\
\hline 74 & 000100134001 & 3.7 & 13,3 & 0 & 230 & 480 & \\
\hline 75 & 000100135001 & 3.7 & 13,3 & 0 & 231 & 519 & \\
\hline 76 & 000100151001 & 3.7 & 15,8 & 0 & 232 & 572 & \\
\hline 77 & 000100152001 & 3.7 & 15,8 & 0 & 233 & 598 & \\
\hline 78 & 000100153001 & 3.7 & 15,8 & 0 & 234 & 649 & \\
\hline 79 & 000100154001 & 3.7 & 15,8 & 0 & 235 & 588 & \\
\hline 80 & 000100155001 & 3.7 & 15,8 & 0 & 236 & 596 & \\
\hline 81 & 000100156001 & 3.7 & 15,8 & 0 & 237 & 629 & \\
\hline 82 & 000100157001 & 3.7 & 15,8 & 0 & 238 & 628 & \\
\hline 83 & 000100158001 & 3.7 & 15,8 & 0 & 239 & 609 & \\
\hline 84 & 000100159001 & 3.7 & 15,8 & 0 & 240 & 575 & \\
\hline 85 & 000100160001 & 3.7 & 15,8 & 0 & 241 & 645 & \\
\hline 86 & 000100161001 & 3.7 & 15,8 & 0 & 242 & 573 & \\
\hline 87 & 000100162001 & 3.7 & 15,8 & 0 & 243 & 632 & \\
\hline 88 & 000100163001 & 3.7 & 15,8 & 0 & 244 & 565 & \\
\hline 89 & 000100164001 & 3.7 & 15,8 & 0 & 245 & 606 & \\
\hline 90 & 000100165001 & 3.7 & 15,8 & 0 & 246 & 572 & \\
\hline 91 & 000100181001 & 3.5 & 15,8 & 0 & 247 & 514 & \\
\hline 92 & 000100182001 & 3.5 & 15,8 & 0 & 248 & 558 & \\
\hline 93 & 000100183001 & 3.5 & 15,8 & 0 & 249 & 575 & \\
\hline 94 & 000100184001 & 3.5 & 15,8 & 0 & 250 & 582 & \\
\hline 95 & 000100185001 & 3.5 & 15,8 & 0 & 251 & 548 & \\
\hline 96 & 000100186001 & 3.5 & 15,8 & 0 & 252 & 554 & \\
\hline 97 & 000100187001 & 3.5 & 15,8 & 0 & 253 & 559 & \\
\hline
\end{tabular}




\begin{tabular}{|c|c|c|c|c|c|c|c|}
\hline 98 & $\mid 000100188001$ & 3.5 & 15,8 & 0 & 254 & 575 & \\
\hline 99 & 000100189001 & 3.5 & 15,8 & 0 & 255 & 567 & \\
\hline 100 & 000100190001 & 3.5 & 15,8 & 0 & 256 & 530 & \\
\hline 101 & 000100191001 & 3.5 & 15,8 & 0 & 272 & 601 & \\
\hline 102 & 000100192001 & 3.5 & 15,8 & 0 & 273 & 568 & \\
\hline 103 & 000100193001 & 3.5 & 15,8 & 0 & 274 & 543 & \\
\hline 104 & 000100194001 & 3.5 & 15,8 & 0 & 275 & 570 & \\
\hline 105 & 000100195001 & 3.5 & 15,8 & 0 & 276 & 534 & \\
\hline 106 & 000100211001 & 3.2 & 15,8 & 0 & 277 & 484 & \\
\hline 107 & 000100212001 & 3.2 & 15,8 & 0 & 278 & 479 & \\
\hline 108 & 000100213001 & 3.2 & 15,8 & 0 & 279 & 450 & \\
\hline 109 & 000100214001 & 3.2 & 15,8 & 0 & 280 & 493 & \\
\hline 110 & 000100215001 & 3.2 & 15,8 & 0 & 281 & 481 & \\
\hline 111 & 000100216001 & 3.2 & 15,8 & 0 & 282 & 453 & \\
\hline 112 & 000100217001 & 3.2 & 15,8 & 0 & 283 & 439 & \\
\hline 113 & 000100218001 & 3.2 & 15,8 & 0 & 284 & 458 & \\
\hline 114 & 000100219001 & 3.2 & 15,8 & 0 & 285 & 502 & \\
\hline 115 & 000100220001 & 3.2 & 15,8 & 0 & 286 & 456 & \\
\hline 116 & 000100221001 & 3.2 & 15,8 & 0 & 287 & 462 & \\
\hline 117 & 000100222001 & 3.2 & 15,8 & 0 & 288 & 495 & \\
\hline 118 & 000100223001 & 3.2 & 15,8 & 0 & 289 & 452 & \\
\hline 119 & 000100224001 & 3.2 & 15,8 & 0 & 290 & 485 & \\
\hline 120 & 000100225001 & 3.2 & 15,8 & 0 & 291 & 476 & \\
\hline 121 & 000100241001 & 2.8 & 15,8 & 0 & 292 & & falha \\
\hline 122 & 000100242001 & 2.8 & 15,8 & 0 & 293 & 383 & \\
\hline 123 & 000100243001 & 2.8 & 15,8 & 0 & 294 & 364 & \\
\hline 124 & 000100244001 & 2.8 & 15,8 & 0 & 295 & 338 & \\
\hline 125 & 000100245001 & 2.8 & 15,8 & 0 & 296 & 405 & \\
\hline 126 & 000100246001 & 2.8 & 15,8 & 0 & 297 & 367 & \\
\hline 127 & 000100247001 & 2.8 & 15,8 & 0 & 298 & 383 & \\
\hline 128 & 000100248001 & 2.8 & 15,8 & 0 & 299 & 340 & \\
\hline 129 & 000100249001 & 2.8 & 15,8 & 0 & 300 & 415 & \\
\hline 130 & 000100250001 & 2.8 & 15,8 & 0 & 301 & 364 & \\
\hline 131 & 000100251001 & 2.8 & 15,8 & 0 & 322 & 356 & \\
\hline 132 & 000100252001 & 2.8 & 15,8 & 0 & 323 & 347 & \\
\hline 133 & 000100253001 & 2.8 & 15,8 & 0 & 324 & 353 & \\
\hline 134 & 000100254001 & 2.8 & 15,8 & 0 & 325 & 355 & \\
\hline 135 & 000100255001 & 2.8 & 15,8 & 0 & 326 & 376 & \\
\hline 136 & 000100271001 & 2.4 & 15,8 & 0 & 327 & 226 & \\
\hline 137 & 000100272001 & 2.4 & 15,8 & 0 & 328 & 240 & \\
\hline 138 & 000100273001 & 2.4 & 15,8 & 0 & 329 & 302 & \\
\hline 139 & 000100274001 & 2.4 & 15,8 & 0 & 330 & 287 & \\
\hline 140 & 000100275001 & 2.4 & 15,8 & 0 & 331 & 268 & \\
\hline 141 & 000100276001 & 2.4 & 15,8 & 0 & 332 & 227 & \\
\hline 142 & 000100277001 & 2.4 & 15,8 & 0 & 333 & 284 & \\
\hline 143 & 000100278001 & 2.4 & 15,8 & 0 & 334 & 266 & \\
\hline 144 & 000100279001 & 2.4 & 15,8 & 0 & 335 & 211 & \\
\hline 145 & 000100280001 & 2.4 & 15,8 & 0 & 336 & 228 & \\
\hline 146 & 000100281001 & 2.4 & 15,8 & 0 & 337 & 225 & \\
\hline 147 & 000100282001 & 2.4 & 15,8 & 0 & 338 & 293 & \\
\hline 148 & 000100283001 & 2.4 & 15,8 & 0 & 339 & 250 & \\
\hline 149 & 000100284001 & 2.4 & 15,8 & 0 & 340 & 256 & \\
\hline 150 & 000100285001 & 2.4 & 15,8 & 0 & 341 & 235 & \\
\hline 151 & 000100301001 & 3.7 & 15,8 & 0 & 342 & 593 & \\
\hline
\end{tabular}




\begin{tabular}{|c|c|c|c|c|c|c|}
\hline 152 & 000100302001 & 3.7 & 15,8 & 0 & 343 & 568 \\
\hline 153 & 000100303001 & 3.7 & 15,8 & 0 & 344 & 548 \\
\hline 154 & 000100304001 & 3.7 & 15,8 & 0 & 345 & 613 \\
\hline 155 & 000100305001 & 3.7 & 15,8 & 0 & 346 & 618 \\
\hline 156 & 000100306001 & 3.7 & 15,8 & 0 & 347 & 566 \\
\hline 157 & 000100307001 & 3.7 & 15,8 & 0 & 348 & 576 \\
\hline 158 & 000100308001 & 3.7 & 15,8 & 0 & 349 & 641 \\
\hline 159 & 000100309001 & 3.7 & 15,8 & 0 & 350 & 602 \\
\hline 160 & 000100310001 & 3.7 & 15,8 & 0 & 351 & 562 \\
\hline 161 & 000100311001 & 3.7 & 15,8 & 0 & 352 & 574 \\
\hline 162 & 000100312001 & 3.7 & 15,8 & 0 & 353 & 591 \\
\hline 163 & 000100313001 & 3.7 & 15,8 & 0 & 354 & 576 \\
\hline 164 & 000100314001 & 3.7 & 15,8 & 0 & 355 & 604 \\
\hline 165 & 000100315001 & 3.7 & 15,8 & 0 & 356 & 616 \\
\hline 166 & 000100331001 & 3.7 & 15,8 & 1 & 357 & 580 \\
\hline 167 & 000100332001 & 3.7 & 15,8 & 1 & 358 & 465 \\
\hline 168 & 000100333001 & 3.7 & 15,8 & 1 & 359 & 502 \\
\hline 169 & 000100334001 & 3.7 & 15,8 & 1 & 360 & 526 \\
\hline 170 & 000100335001 & 3.7 & 15,8 & 1 & 361 & 536 \\
\hline 171 & 000100336001 & 3.7 & 15,8 & 1 & 362 & 591 \\
\hline 172 & 000100337001 & 3.7 & 15,8 & 1 & 363 & 575 \\
\hline 173 & 000100338001 & 3.7 & 15,8 & 1 & 364 & 539 \\
\hline 174 & 000100339001 & 3.7 & 15,8 & 1 & 365 & 502 \\
\hline 175 & 000100340001 & 3.7 & 15,8 & 1 & 366 & 565 \\
\hline 176 & 000100341001 & 3.7 & 15,8 & 1 & 367 & 465 \\
\hline 177 & 000100342001 & 3.7 & 15,8 & 1 & 368 & 496 \\
\hline 178 & 000100343001 & 3.7 & 15,8 & 1 & 369 & 461 \\
\hline 179 & 000100344001 & 3.7 & 15,8 & 1 & 370 & 458 \\
\hline 180 & 000100345001 & 3.7 & 15,8 & 1 & 371 & 427 \\
\hline 181 & 000100346001 & 3.7 & 15,8 & 1 & 372 & 455 \\
\hline 182 & 000100347001 & 3.7 & 15,8 & 1 & 373 & 431 \\
\hline 183 & 000100348001 & 3.7 & 15,8 & 1 & 374 & 439 \\
\hline 184 & 000100349001 & 3.7 & 15,8 & 1 & 375 & 405 \\
\hline 185 & 000100350001 & 3.7 & 13,8 & 1 & 376 & 420 \\
\hline
\end{tabular}


Tabela B.2 - Detalhamento dos Testes do Segundo Conjunto de Dados

\begin{tabular}{|c|c|c|c|c|c|c|c|}
\hline $\begin{array}{c}\begin{array}{c}\text { Número } \\
\text { do }\end{array} \\
\text { Teste }\end{array}$ & $\begin{array}{c}\begin{array}{c}\text { Nome } \\
\text { do }\end{array} \\
\text { Arquivo }\end{array}$ & $\begin{array}{c}\text { Corrente } \\
\text { usada } \\
{[\mathrm{kA}]}\end{array}$ & $\begin{array}{c}\text { Força } \\
\text { usada } \\
\text { (mm da } \\
\text { mola) }\end{array}$ & \begin{tabular}{|c|}
$\begin{array}{c}\text { Welding } \\
\text { Help }\end{array}$ \\
0=Sim/1=Não \\
\end{tabular} & \begin{tabular}{|c|} 
Uso \\
Eletrodo \\
(pontos) \\
\end{tabular} & \begin{tabular}{|c|} 
Força \\
Cisalham. \\
{$[\mathrm{N}]$} \\
\end{tabular} & Notas \\
\hline 1 & 00100002001 & 3,7 & 15,8 & 1 & 1 & 654 & \\
\hline 2 & 00100003001 & 3,7 & 15,8 & 1 & 2 & 711 & \\
\hline 3 & 00100004001 & 3,7 & 15,8 & 1 & 3 & 679 & \\
\hline 4 & 00100005001 & 3,7 & 15,8 & 1 & 4 & 589 & \\
\hline 5 & 00100006001 & 3,7 & 15,8 & 1 & 5 & 733 & \\
\hline 6 & 00100007001 & 3,7 & 15,8 & 1 & 6 & 665 & \\
\hline 7 & 00100008001 & 3,7 & 15,8 & 1 & 7 & 643 & \\
\hline 8 & 00100009001 & 3,7 & 15,8 & 1 & 8 & 664 & \\
\hline 9 & 00100010001 & 3,7 & 15,8 & 1 & 9 & 669 & \\
\hline 10 & 00100011001 & 3,7 & 15,8 & 1 & 10 & 693 & \\
\hline 11 & 00100012001 & 3,7 & 15,8 & 1 & 11 & 605 & \\
\hline 12 & 00100013001 & 3,7 & 15,8 & 1 & 12 & 615 & \\
\hline 13 & 00100014001 & 3,7 & 15,8 & 1 & 13 & 577 & \\
\hline 14 & 00100015001 & 3,7 & 15,8 & 1 & 14 & 728 & \\
\hline 15 & 00100016001 & 3,7 & 15,8 & 1 & 15 & 642 & \\
\hline 16 & 00100044001 & 3,7 & 14,8 & 1 & 43 & 624 & \\
\hline 17 & 00100045001 & 3,7 & 14,8 & 1 & 44 & 618 & \\
\hline 18 & 00100046001 & 3,7 & 14,8 & 1 & 45 & 514 & \\
\hline 19 & 00100047001 & 3,7 & 14,8 & 1 & 46 & 594 & \\
\hline 20 & 00100048001 & 3,7 & 14,8 & 1 & 47 & 652 & \\
\hline 21 & 00100049001 & 3,7 & 14,8 & 1 & 48 & 622 & \\
\hline 22 & 00100050001 & 3,7 & 14,8 & 1 & 49 & 555 & \\
\hline 23 & 00100051001 & 3,7 & 14,8 & 1 & 50 & 549 & \\
\hline 24 & 00100052001 & 3,7 & 14,8 & 1 & 51 & & falha \\
\hline 25 & 00100053001 & 3,7 & 14,8 & 1 & 52 & 571 & \\
\hline 26 & 00100054001 & 3,7 & 14,8 & 1 & 53 & 630 & \\
\hline 27 & 00100055001 & 3,7 & 14,8 & 1 & 54 & 529 & \\
\hline 28 & 00100056001 & 3,7 & 14,8 & 1 & 55 & 546 & \\
\hline 29 & 00100057001 & 3,7 & 14,8 & 1 & 56 & 617 & \\
\hline 30 & 00100058001 & 3,7 & 14,8 & 1 & 57 & 615 & \\
\hline 31 & 00100070001 & 3,7 & 14,3 & 1 & 69 & 475 & \\
\hline 32 & 00100071001 & 3,7 & 14,3 & 1 & 70 & 594 & \\
\hline 33 & 00100072001 & 3,7 & 14,3 & 1 & 71 & 574 & \\
\hline 34 & 00100073001 & 3,7 & 14,3 & 1 & 72 & 539 & \\
\hline 35 & 00100074001 & 3,7 & 14,3 & 1 & 73 & 533 & \\
\hline 36 & 00100075001 & 3,7 & 14,3 & 1 & 74 & 609 & \\
\hline 37 & 00100076001 & 3,7 & 14,3 & 1 & 75 & 584 & \\
\hline 38 & 00100077001 & 3,7 & 14,3 & 1 & 76 & 516 & \\
\hline 39 & 00100078001 & 3,7 & 14,3 & 1 & 77 & 463 & \\
\hline 40 & 00100079001 & 3,7 & 14,3 & 1 & 78 & 514 & \\
\hline 41 & 00100080001 & 3,7 & 14,3 & 1 & 79 & 615 & \\
\hline 42 & 00100081001 & 3,7 & 14,3 & 1 & 80 & 561 & \\
\hline 43 & 00100082001 & 3,7 & 14,3 & 1 & 81 & 542 & \\
\hline 44 & 00100083001 & 3,7 & 14,3 & 1 & 82 & 515 & \\
\hline 45 & 00100084001 & 3,7 & 14,3 & 1 & 83 & 622 & \\
\hline 46 & 00100096001 & 3,7 & 13,8 & 1 & 95 & 428 & \\
\hline
\end{tabular}




\begin{tabular}{|c|c|c|c|c|c|c|}
\hline 47 & 00100097001 & 3,7 & 13,8 & 1 & 96 & 513 \\
\hline 48 & 00100098001 & 3,7 & 13,8 & 1 & 97 & 524 \\
\hline 49 & 00100099001 & 3,7 & 13,8 & 1 & 98 & 542 \\
\hline 50 & 00100100001 & 3,7 & 13,8 & 1 & 99 & 509 \\
\hline 51 & 00100101001 & 3,7 & 13,8 & 1 & 100 & 443 \\
\hline 52 & 00100102001 & 3,7 & 13,8 & 1 & 101 & 543 \\
\hline 53 & 00100103001 & 3,7 & 13,8 & 1 & 102 & 583 \\
\hline 54 & 00100104001 & 3,7 & 13,8 & 1 & 103 & 530 \\
\hline 55 & 00100105001 & 3,7 & 13,8 & 1 & 104 & 482 \\
\hline 56 & 00100106001 & 3,7 & 13,8 & 1 & 105 & 462 \\
\hline 57 & 00100107001 & 3,7 & 13,8 & 1 & 106 & 517 \\
\hline 58 & 00100108001 & 3,7 & 13,8 & 1 & 107 & 539 \\
\hline 59 & 00100109001 & 3,7 & 13,8 & 1 & 108 & 555 \\
\hline 60 & 00100110001 & 3,7 & 13,8 & 1 & 109 & 486 \\
\hline 61 & 00100122001 & 3,7 & 13,3 & 1 & 121 & 498 \\
\hline 62 & 00100123001 & 3,7 & 13,3 & 1 & 122 & 482 \\
\hline 63 & 00100124001 & 3,7 & 13,3 & 1 & 123 & 431 \\
\hline 64 & 00100125001 & 3,7 & 13,3 & 1 & 124 & 488 \\
\hline 65 & 00100126001 & 3,7 & 13,3 & 1 & 125 & 518 \\
\hline 66 & 00100127001 & 3,7 & 13,3 & 1 & 126 & 508 \\
\hline 67 & 00100128001 & 3,7 & 13,3 & 1 & 127 & 492 \\
\hline 68 & 00100129001 & 3,7 & 13,3 & 1 & 128 & 411 \\
\hline 69 & 00100130001 & 3,7 & 13,3 & 1 & 129 & 521 \\
\hline 70 & 00100131001 & 3,7 & 13,3 & 1 & 130 & 554 \\
\hline 71 & 00100132001 & 3,7 & 13,3 & 1 & 131 & 496 \\
\hline 72 & 00100133001 & 3,7 & 13,3 & 1 & 132 & 492 \\
\hline 73 & 00100134001 & 3,7 & 13,3 & 1 & 133 & 456 \\
\hline 74 & 00100135001 & 3,7 & 13,3 & 1 & 134 & 508 \\
\hline 75 & 00100136001 & 3,7 & 13,3 & 1 & 135 & 514 \\
\hline 76 & 00100148001 & 3,7 & 16,8 & 1 & 147 & 669 \\
\hline 77 & 00100149001 & 3,7 & 16,8 & 1 & 148 & 688 \\
\hline 78 & 00100150001 & 3,7 & 16,8 & 1 & 149 & 658 \\
\hline 79 & 00100151001 & 3,7 & 16,8 & 1 & 150 & 648 \\
\hline 80 & 00100152001 & 3,7 & 16,8 & 1 & 151 & 640 \\
\hline 81 & 00100153001 & 3,7 & 16,8 & 1 & 152 & 653 \\
\hline 82 & 00100154001 & 3,7 & 16,8 & 1 & 153 & 624 \\
\hline 83 & 00100155001 & 3,7 & 16,8 & 1 & 154 & 698 \\
\hline 84 & 00100156001 & 3,7 & 16,8 & 1 & 155 & 615 \\
\hline 85 & 00100157001 & 3,7 & 16,8 & 1 & 156 & 666 \\
\hline 86 & 00100158001 & 3,7 & 16,8 & 1 & 157 & 679 \\
\hline 87 & 00100159001 & 3,7 & 16,8 & 1 & 158 & 643 \\
\hline 88 & 00100160001 & 3,7 & 16,8 & 1 & 159 & 643 \\
\hline 89 & 00100161001 & 3,7 & 16,8 & 1 & 160 & 657 \\
\hline 90 & 00100162001 & 3,7 & 16,8 & 1 & 161 & 653 \\
\hline 91 & 00100174001 & 3,7 & 15,8 & 1 & 173 & 543 \\
\hline 92 & 00100175001 & 3,7 & 15,8 & 1 & 174 & 582 \\
\hline 93 & 00100176001 & 3,7 & 15,8 & 1 & 175 & 645 \\
\hline 94 & 00100177001 & 3,7 & 15,8 & 1 & 176 & 602 \\
\hline 95 & 00100178001 & 3,7 & 15,8 & 1 & 177 & 643 \\
\hline 96 & 00100179001 & 3,7 & 15,8 & 1 & 178 & 575 \\
\hline 97 & 00100180001 & 3,7 & 15,8 & 1 & 179 & 638 \\
\hline 98 & 00100181001 & 3,7 & 15,8 & 1 & 180 & 667 \\
\hline 99 & 00100182001 & 3,7 & 15,8 & 1 & 181 & 633 \\
\hline 100 & 00100183001 & 3,7 & 15,8 & 1 & 182 & 615 \\
\hline
\end{tabular}




\begin{tabular}{|c|c|c|c|c|c|c|}
\hline 101 & 00100184001 & 3,7 & 15,8 & 1 & 183 & 583 \\
\hline 102 & 00100185001 & 3,7 & 15,8 & 1 & 184 & 607 \\
\hline 103 & 00100186001 & 3,7 & 15,8 & 1 & 185 & 633 \\
\hline 104 & 00100187001 & 3,7 & 15,8 & 1 & 186 & 639 \\
\hline 105 & 00100188001 & 3,7 & 15,8 & 1 & 187 & 571 \\
\hline 106 & 00100200001 & 3,5 & 15,8 & 1 & 199 & 571 \\
\hline 107 & 00100201001 & 3,5 & 15,8 & 1 & 200 & 570 \\
\hline 108 & 00100202001 & 3,5 & 15,8 & 1 & 201 & 538 \\
\hline 109 & 00100203001 & 3,5 & 15,8 & 1 & 202 & 500 \\
\hline 110 & 00100204001 & 3,5 & 15,8 & 1 & 203 & 585 \\
\hline 111 & 00100205001 & 3,5 & 15,8 & 1 & 204 & \\
\hline 112 & 00100206001 & 3,5 & 15,8 & 1 & 205 & 578 \\
\hline 113 & 00100207001 & 3,5 & 15,8 & 1 & 206 & 490 \\
\hline 114 & 00100208001 & 3,5 & 15,8 & 1 & 207 & 539 \\
\hline 115 & 00100209001 & 3,5 & 15,8 & 1 & 208 & 602 \\
\hline 116 & 00100210001 & 3,5 & 15,8 & 1 & 209 & 638 \\
\hline 117 & 00100211001 & 3,5 & 15,8 & 1 & 210 & 550 \\
\hline 118 & 00100212001 & 3,5 & 15,8 & 1 & 211 & 532 \\
\hline 119 & 00100213001 & 3,5 & 15,8 & 1 & 212 & 528 \\
\hline 120 & 00100214001 & 3,5 & 15,8 & 1 & 213 & 578 \\
\hline 121 & 00100226001 & 3,2 & 15,8 & 1 & 225 & 434 \\
\hline 122 & 00100227001 & 3,2 & 15,8 & 1 & 226 & 499 \\
\hline 123 & 00100228001 & 3,2 & 15,8 & 1 & 227 & 527 \\
\hline 124 & 00100229001 & 3,2 & 15,8 & 1 & 228 & 468 \\
\hline 125 & 00100230001 & 3,2 & 15,8 & 1 & 229 & 450 \\
\hline 126 & 00100231001 & 3,2 & 15,8 & 1 & 230 & 446 \\
\hline 127 & 00100232001 & 3,2 & 15,8 & 1 & 231 & 470 \\
\hline 128 & 00100233001 & 3,2 & 15,8 & 1 & 232 & 512 \\
\hline 129 & 00100234001 & 3,2 & 15,8 & 1 & 233 & 441 \\
\hline 130 & 00100235001 & 3,2 & 15,8 & 1 & 234 & 434 \\
\hline 131 & 00100236001 & 3,2 & 15,8 & 1 & 235 & 522 \\
\hline 132 & 00100237001 & 3,2 & 15,8 & 1 & 236 & 521 \\
\hline 133 & 00100238001 & 3,2 & 15,8 & 1 & 237 & 489 \\
\hline 134 & 00100239001 & 3,2 & 15,8 & 1 & 238 & 456 \\
\hline 135 & 00100240001 & 3,2 & 15,8 & 1 & 239 & 415 \\
\hline 136 & 00100252001 & 2,8 & 15,8 & 1 & 251 & 368 \\
\hline 137 & 00100253001 & 2,8 & 15,8 & 1 & 252 & 366 \\
\hline 138 & 00100254001 & 2,8 & 15,8 & 1 & 253 & 404 \\
\hline 139 & 00100255001 & 2,8 & 15,8 & 1 & 254 & 363 \\
\hline 140 & 00100256001 & 2,8 & 15,8 & 1 & 255 & 412 \\
\hline 141 & 00100257001 & 2,8 & 15,8 & 1 & 256 & 364 \\
\hline 142 & 00100258001 & 2,8 & 15,8 & 1 & 257 & 352 \\
\hline 143 & 00100259001 & 2,8 & 15,8 & 1 & 258 & 378 \\
\hline 144 & 00100260001 & 2,8 & 15,8 & 1 & 259 & 412 \\
\hline 145 & 00100261001 & 2,8 & 15,8 & 1 & 260 & 378 \\
\hline 146 & 00100262001 & 2,8 & 15,8 & 1 & 261 & 347 \\
\hline 147 & 00100263001 & 2,8 & 15,8 & 1 & 262 & 269 \\
\hline 148 & 00100264001 & 2,8 & 15,8 & 1 & 263 & 363 \\
\hline 149 & 00100265001 & 2,8 & 15,8 & 1 & 264 & 422 \\
\hline 150 & 00100266001 & 2,8 & 15,8 & 1 & 265 & 367 \\
\hline 151 & 00100278001 & 2,4 & 15,8 & 1 & 277 & 258 \\
\hline 152 & 00100279001 & 2,4 & 15,8 & 1 & 278 & 300 \\
\hline 153 & 00100280001 & 2,4 & 15,8 & 1 & 279 & 235 \\
\hline 154 & 00100281001 & 2,4 & 15,8 & 1 & 280 & 260 \\
\hline
\end{tabular}




\begin{tabular}{|c|c|c|c|c|c|c|c|}
\hline 155 & 00100282001 & 2,4 & 15,8 & 1 & 281 & 315 & \\
\hline 156 & 00100283001 & 2,4 & 15,8 & 1 & 282 & 303 & \\
\hline 157 & 00100284001 & 2,4 & 15,8 & 1 & 283 & 291 & \\
\hline 158 & 00100285001 & 2,4 & 15,8 & 1 & 284 & 260 & \\
\hline 159 & 00100286001 & 2,4 & 15,8 & 1 & 285 & 269 & \\
\hline 160 & 00100287001 & 2,4 & 15,8 & 1 & 286 & 266 & \\
\hline 161 & 00100288001 & 2,4 & 15,8 & 1 & 287 & 296 & \\
\hline 162 & 00100289001 & 2,4 & 15,8 & 1 & 288 & 222 & \\
\hline 163 & 00100290001 & 2,4 & 15,8 & 1 & 289 & 242 & \\
\hline 164 & 00100291001 & 2,4 & 15,8 & 1 & 290 & 269 & \\
\hline 165 & 00100292001 & 2,4 & 15,8 & 1 & 291 & 257 & \\
\hline 166 & 00100304001 & 4 & 15,8 & 1 & 303 & 661 & \\
\hline 167 & 00100305001 & 4 & 15,8 & 1 & 304 & 666 & \\
\hline 168 & 00100306001 & 4 & 15,8 & 1 & 305 & 761 & \\
\hline 169 & 00100307001 & 4 & 15,8 & 1 & 306 & 615 & \\
\hline 170 & 00100308001 & 4 & 15,8 & 1 & 307 & 603 & \\
\hline 171 & 00100309001 & 4 & 15,8 & 1 & 308 & 657 & \\
\hline 172 & 00100310001 & 4 & 15,8 & 1 & 309 & 689 & \\
\hline 173 & 00100311001 & 4 & 15,8 & 1 & 310 & 684 & \\
\hline 174 & 00100312001 & 4 & 15,8 & 1 & 311 & 610 & \\
\hline 175 & 00100313001 & 4 & 15,8 & 1 & 312 & 600 & \\
\hline 176 & 00100314001 & 4 & 15,8 & 1 & 313 & 683 & \\
\hline 177 & 00100315001 & 4 & 15,8 & 1 & 314 & 672 & \\
\hline 178 & 00100316001 & 4 & 15,8 & 1 & 315 & 603 & \\
\hline 179 & 00100317001 & 4 & 15,8 & 1 & 316 & 604 & \\
\hline 180 & 00100318001 & 4 & 15,8 & 1 & 317 & 615 & \\
\hline 181 & 00100330001 & 3,8 & 15,8 & 1 & 329 & 572 & \\
\hline 182 & 00100331001 & 3,8 & 15,8 & 1 & 330 & 565 & \\
\hline 183 & 00100332001 & 3,8 & 15,8 & 1 & 331 & 588 & \\
\hline 184 & 00100333001 & 3,8 & 15,8 & 1 & 332 & 593 & \\
\hline 185 & 00100334001 & 3,8 & 15,8 & 1 & 333 & 607 & \\
\hline 186 & 00100335001 & 3,8 & 15,8 & 1 & 334 & 547 & \\
\hline 187 & 00100336001 & 3,8 & 15,8 & 1 & 335 & 551 & \\
\hline 188 & 00100337001 & 3,8 & 15,8 & 1 & 336 & 615 & \\
\hline 189 & 00100338001 & 3,8 & 15,8 & 1 & 337 & 620 & \\
\hline 190 & 00100339001 & 3,8 & 15,8 & 1 & 338 & 594 & \\
\hline 191 & 00100340001 & 3,8 & 15,8 & 1 & 339 & 555 & \\
\hline 192 & 00100341001 & 3,8 & 15,8 & 1 & 340 & 594 & \\
\hline 193 & 00100342001 & 3,8 & 15,8 & 1 & 341 & 597 & \\
\hline 194 & 00100343001 & 3,8 & 15,8 & 1 & 342 & 637 & \\
\hline 195 & 00100344001 & 3,8 & 15,8 & 1 & 343 & 574 & \\
\hline 196 & 00100360001 & 3,8 & 15,8 & 0 & 359 & 599 & \\
\hline 197 & 00100361001 & 3,8 & 15,8 & 0 & 360 & 522 & \\
\hline 198 & 00100362001 & 3,8 & 15,8 & 0 & 361 & 586 & \\
\hline 199 & 00100363001 & 3,8 & 15,8 & 0 & 362 & 562 & \\
\hline 200 & 00100364001 & 3,8 & 15,8 & 0 & 363 & 481 & \\
\hline 201 & 00100365001 & 3,8 & 15,8 & 0 & 364 & 413 & \\
\hline 202 & 00100366001 & 3,8 & 15,8 & 0 & 365 & 533 & \\
\hline 203 & 00100367001 & 3,8 & 15,8 & 0 & 366 & & falha \\
\hline 204 & 00100368001 & 3,8 & 15,8 & 0 & 367 & 507 & \\
\hline 205 & 00100369001 & 3,8 & 15,8 & 0 & 368 & 601 & \\
\hline 206 & 00100370001 & 3,8 & 15,8 & 0 & 369 & 521 & \\
\hline 207 & 00100371001 & 3,8 & 15,8 & 0 & 370 & 578 & \\
\hline 208 & 00100372001 & 3,8 & 15,8 & 0 & 371 & 390 & \\
\hline
\end{tabular}




\begin{tabular}{|l|l|l|l|l|l|l|l|}
209 & 00100373001 & 3,8 & 15,8 & 0 & 372 & 529 & \\
210 & 00100374001 & 3,8 & 15,8 & 0 & 373 & 546 & \\
211 & 00100420001 & 3,8 & 15,8 & 1 & 419 & 533 & \\
212 & 00100421001 & 3,8 & 15,8 & 1 & 420 & 534 & \\
213 & 00100422001 & 3,8 & 15,8 & 1 & 421 & 562 & \\
214 & 00100423001 & 3,8 & 15,8 & 1 & 422 & 572 & \\
216 & 00100424001 & 3,8 & 15,8 & 1 & 423 & 552 & \\
217 & 00100425001 & 3,8 & 15,8 & 1 & 424 & 508 & \\
218 & 00100426001 & 3,8 & 15,8 & 1 & 425 & 520 & \\
219 & 00100427001 & 3,8 & 15,8 & 1 & 426 & 543 & falha \\
220 & 00100429001 & 3,8 & 15,8 & 1 & 427 & & falha \\
221 & 00100430001 & 3,8 & 15,8 & 1 & 428 & & falha \\
222 & 00100431001 & 3,8 & 15,8 & 15,8 & 1 & 429 & \\
223 & 00100432001 & 3,8 & 15,8 & 1 & 430 & 577 & \\
224 & 00100433001 & 3,8 & 15,8 & 1 & 432 & 590 & \\
225 & 00100434001 & 3,8 & 15,8 & 1 & 433 & 538 & \\
226 & 00102960001 & 3,8 & 15,8 & 1 & 2959 & 570 & \\
227 & 00102961001 & 3,8 & 15,8 & 1 & 2960 & 587 & \\
228 & 00102962001 & 3,8 & 15,8 & 1 & 2961 & 567 & \\
229 & 00102963001 & 3,8 & 15,8 & 1 & 2962 & 585 & \\
230 & 00102964001 & 3,8 & 15,8 & 1 & 2963 & 680 & \\
231 & 00102965001 & 3,8 & 15,8 & 1 & 2964 & 629 & \\
232 & 00102966001 & 3,8 & 15,8 & 1 & 2965 & 552 & \\
233 & 00102967001 & 3,8 & 15,8 & 1 & 2966 & 538 & \\
234 & 00102968001 & 3,8 & 15,8 & 1 & 2967 & 679 & \\
235 & 00102969001 & 3,8 & 15,8 & 1 & 2968 & 574 & \\
236 & 00102970001 & 3,8 & 15,8 & 1 & 2969 & 587 & \\
237 & 00102971001 & 3,8 & 15,8 & 1 & 2970 & 536 & \\
238 & 00102972001 & 3,8 & 15,8 & 1 & 2971 & 561 & \\
239 & 00102973001 & 3,8 & 15,8 & 1 & 2972 & 682 & \\
240 & 00102974001 & 3,8 & 15,8 & 1 & 2973 & 606 & \\
& & & 1 & & & \\
\end{tabular}

